\title{
The role of Hedgehog signalling in
}

\section{pituitary homeostasis in vitro and in vivo}

\author{
Dissertation \\ for the award of the degree \\ "Doctor rerum naturalium" \\ of the Georg-August-Universität Göttingen
}

within the doctoral programme Genes and Development

of the Georg-August University School of Science (GAUSS)

\author{
Submitted by \\ Dominik Simon Botermann \\ from Dormagen, Germany
}

Göttingen, 2020 



\section{Thesis advisory committee}

PD Dr. Anja Uhmann (advisor)

(University Medical Center Göttingen, Institute of Human Genetics)

Prof. Dr. Sigrid Hoyer-Fender

(University of Göttingen, Department of Developmental Biology)

Prof. Dr. Wolfgang Brück

(University Medical Center Göttingen, Institute of Neuropathology)

\section{Members of the examination board}

\section{Referee: PD Dr. Anja Uhmann}

(University Medical Center Göttingen, Institute of Human Genetics)

Co-referee: Prof. Dr. Hubertus Jarry

(University Medical Center Göttingen, Department of Clinical and Experimental Endocrinology)

\section{Other members of the examination board}

Prof. Dr. Sigrid Hoyer-Fender

(University of Göttingen, Department of Developmental Biology)

\section{Prof. Dr. Wolfgang Brück}

(University Medical Center Göttingen, Institute of Neuropathology)

\section{Prof. Dr. Peter Burfeind}

(University Medical Center Göttingen, Institute of Human Genetics)

\section{Dr. Nico Posnien}

(University of Göttingen, Department of Developmental Biology)

Day of the oral examination: 26.10 .2020 


\section{Affidavit}

Here I declare that my doctoral thesis entitled "The role of Hedgehog signalling in pituitary homeostasis in vitro and in vivo" has been written independently with no other sources and aids than quoted.

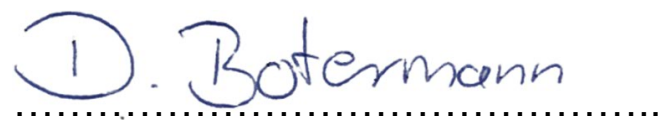

Dominik Simon Botermann

Göttingen, September 2020

Parts of this work have been submitted:

Botermann DS, Brandes N, Frommhold A, Heß I, Wolff A, Zibat A, Hahn H, Buslei R, Uhmann A. Hedgehog signaling in the regulation of pituitary hormone production. Journal of Endocrinology, 2020 (submitted) 


\section{Table of Content}

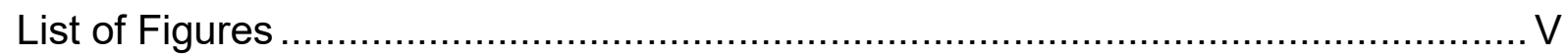

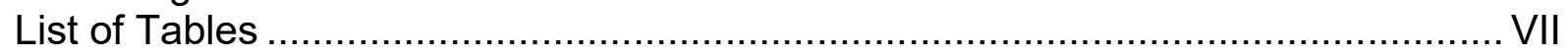

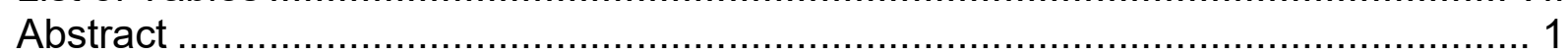

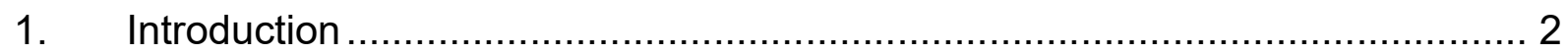

1.1. Structure, cell types and function of the pituitary gland ..............................

1.1.1. Hormone-producing cells of the adenohypophysis .................................. 3

1.1.2. Non-endocrine cells of the adenohypophysis ................................... 6

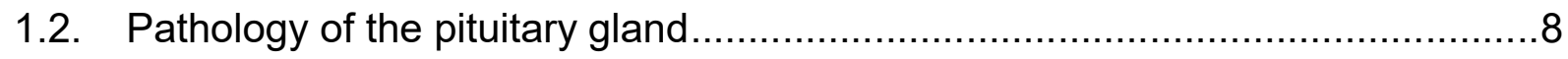

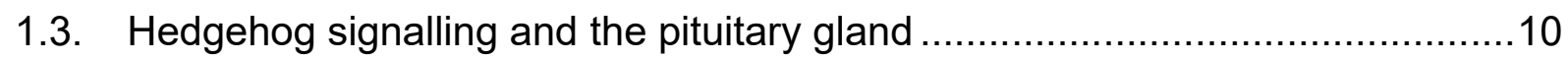

1.3.1. The Hedgehog signalling pathway.............................................. 10

1.3.2. Hh signalling in the developing and adult pituitary gland ....................... 13

1.3.3. Hh signalling and pituitary pathology ............................................ 15

1.4. In vitro and in vivo models to study pituitary tumorigenesis ........................17



3. Materials and Methods ...................................................................... 20

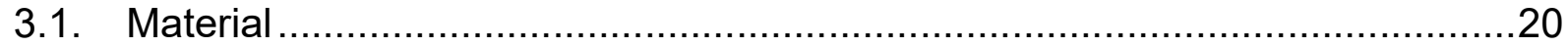

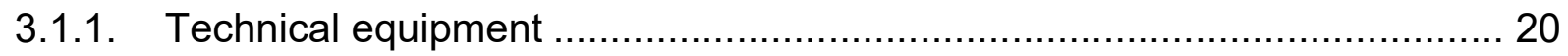

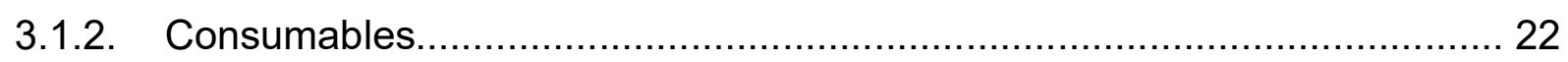

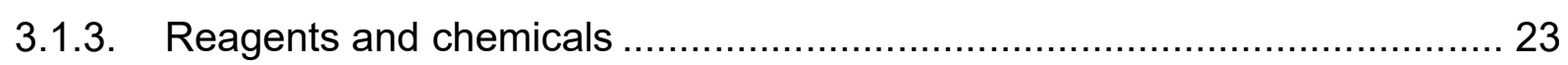

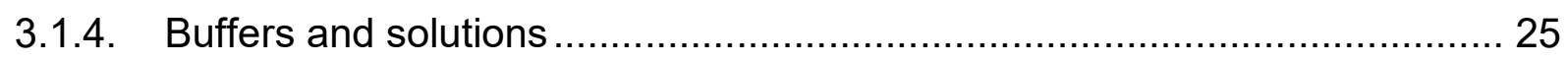

3.1.5. Kits and ready-to-use reaction systems ...................................... 27

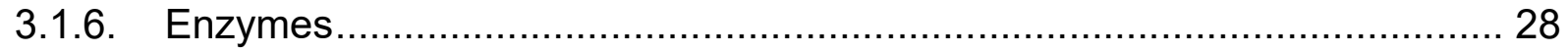

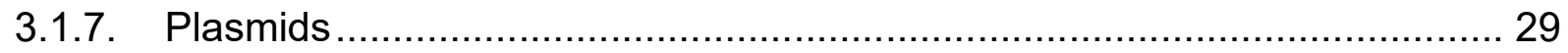



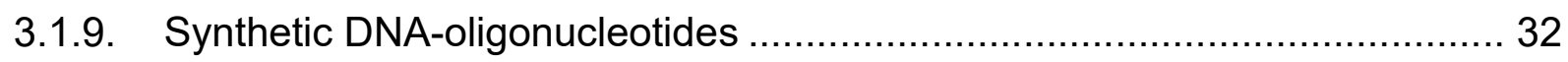

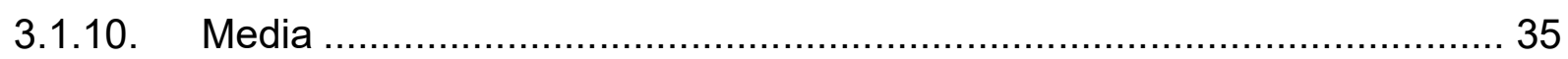



3.1.12. Software and digital resources ............................................. 38



3.2.1. Isolation and purification of nucleic acids ........................................... 39

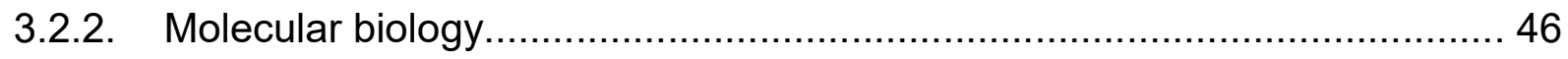

3.2.3. Molecular cloning of eukaryotic expression vectors............................. 47

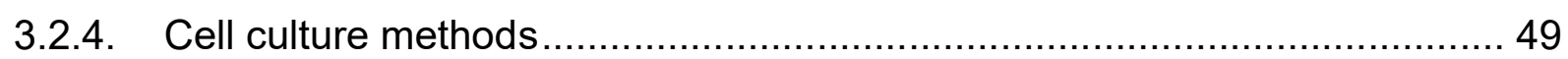

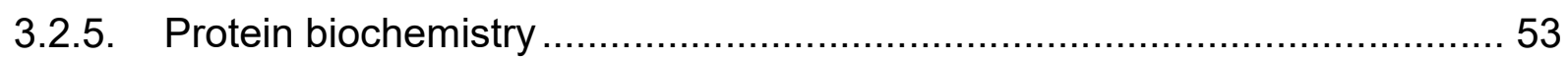




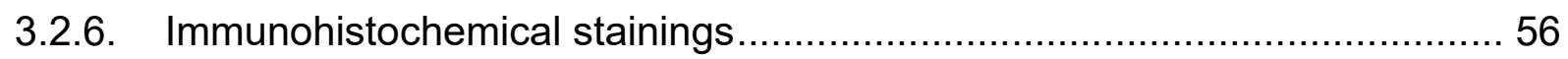

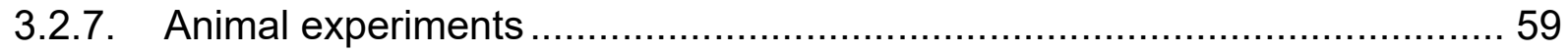

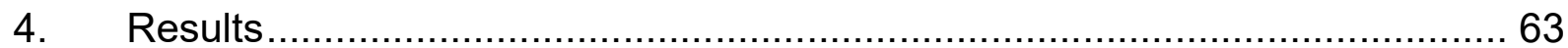

4.1. Deregulation of $\mathrm{Hh}$ signalling in corticotrophs of adult mice pituitary ..............63

4.1.1. The PomcCreERT2 deleter mouse strain expresses the CreERT2 cellspecific but its activity is moderately leaky in the pituitary gland............................ 63

4.1.2. In vivo activation/inactivation of Hh signalling in corticotrophs ..................66

4.1.3. Increasing the incidence of pituitary adenomas in a mouse model ............ 75

4.2. Fate mapping of Gli1-expressing cells in the adult pituitary gland ..................76

4.2.1. A subpopulation of $\mathrm{Gh}^{+}$and FSC descend from $\mathrm{Gli1}^{+}$cells in the adult

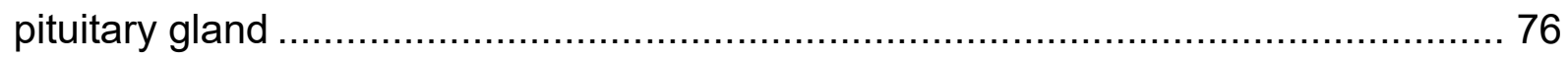

4.2.2. Gli1 transcripts in murine and human pituitary glands ............................ 81

4.3. The role of Hh signalling in somatotrophs and folliculostellate cells in the adult pituitary gland

4.3.1. Generation of a CreERT2 deleter mouse strain for targeting Gh-expressing cells of the adult pituitary gland

4.3.2. Increasing the incidence of pituitary adenomas in somatotrophs, thyrotrophs and lactotrophs

4.4. Evaluation of a model for $\mathrm{Hh}$ signalling deregulation in somatotrophs and folliculostellate cells in adult pituitary glands.



4.5.1. Identity and Hh signalling status of pituitary cell lines................................ 93

4.5.2. Stimulation of $\mathrm{Hh}$ signalling in pituitary cell lines .................................. 96

4.5.3. Conditioned medium of SAG-treated TtT/GF cells increases Gh secretion from $\mathrm{GH} 3$ cells

4.5.4. Transcriptome analyses of $\mathrm{Hh}$ signalling activated $\mathrm{FSC}$ cells 102

4.5.5. Vip can regulate hormone production and is secreted from SAG stimulated TtT/GF cells 104

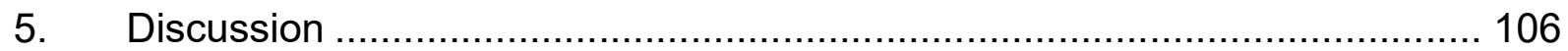

5.1. Cell-intrinsic $\mathrm{Hh}$ signalling does not play a role in corticotrophs of the adult pituitary gland

5.2. Cell-intrinsic $\mathrm{Hh}$ signalling in somatotrophs and FSC of the adult pituitary gland

5.2.1. Genetically engineered mouse lines to analyse the impact of $\mathrm{Hh}$ signalling in vivo or ex vivo cultured organs 
5.2.2. Hh signalling activity status and SAG-responsiveness of pituitary cell lines....

5.2.3. Activation of $\mathrm{Hh}$ signalling in TtT/GF cells induces the secretion of vasoactive intestinal polypeptide and stimulates $\mathrm{Gh}$ production from $\mathrm{GH} 3$ cells 116

5.3. The impact of the study in context of the pathology of the human pituitary ...118

5.4. Potential role of $\mathrm{Hh}$ signalling in the adult pituitary ..................................121



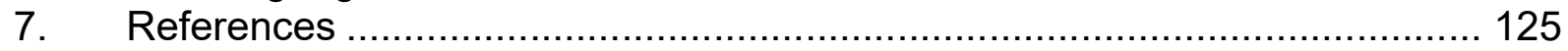

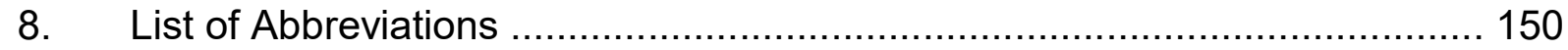




\section{List of Figures}

Figure 1 Target organs of hormones of the pituitary gland. 6

Figure 2 Schematic representation of a transverse section of an adult murine pituitary gland.......

Figure 3 Schematic representation of the Hh signalling pathway.

Figure 4 Schematic representation of the role of $\mathrm{Hh}$ signalling in the adult pituitary. 15

Figure 5 Schematic representation of the genomic tch $^{f}$ locus before and after Cremediated recombination.

Figure 6 Schematic representation of the medium transfer experiment.

Figure 7 Cell-type specific expression and inducibily of the CreERT2-recombinase of

PomcCreERT2 mice. 65

Figure 8 Mendelian ratios of the offspring of Pomc/Ptch ${ }^{f f f}$ and Pomc/Smo ${ }^{f f f}$ mice. ... 66

Figure 9 Body weight and blood glucose concentration of Pomc/Ptch ${ }^{f f}$ and

Pomc/Smo f/f mice. 68

Figure 10 Acth serum level and pituitary gland weight of $P o m c / P t c h h^{f / f}$ and

Pomc/Smo f/f mice.

Figure 11 Histological analysis of pituitary glands of tamoxifen-treated Pomc/Ptch ${ }^{f / f}$ and $\mathrm{Pomc} / \mathrm{Smo}^{\mathrm{fff}}$ mice.

Figure 12 Expression pattern of Acth and Pomc in Pomc/Ptch fff and Pomc/Smo ${ }^{f / f}$

pituitary glands.

Figure $13 \mathrm{Hh}$ signalling target gene expression in Pomc/Ptch fff and Pomc/Smo f/f pituitary glands.

Figure 14 Hormone gene expression in Pomc/Ptch ${ }^{f / f}$ and Pomc/Smo f/f pituitary glands.

Figure 15 Schematic representation of the $S m o^{f}$ locus before and after Cre-mediated recombination.

Figure 16 Cre-mediated recombination of the $\mathrm{Ptch}^{f}$ and Smo ${ }^{f}$ locus of Pomc/Ptch ${ }^{f / f}$ and $\mathrm{Pomc} / \mathrm{Smo}^{\mathrm{fff}}$ mice.

Figure 17 Characterization of AtT-20 cells and Western blot analysis for detection of cyclin E1 expression in AtT-20 cells. 75

Figure 18 Progeny of Gli1 expressing cells in ovary, testis, cerebellum and skin of adult Gli1/tdT mice.

Figure 19 Progeny of Gli1 expressing cells in adult Gli1/tdT pituitary glands. 78

Figure 20 Progeny of Gli1 expressing cells express Sox2, Ki-67 and take up the 
fluorescent dipeptide $\beta$-Ala-Lys-N( $\varepsilon$ )-AMCA.

Figure $21 \mathrm{EGFP}^{+}$pituitary cells of S100bEGFP mice express Sox2 and take up $\beta$ -

Ala-Lys-N( $(\varepsilon)$-AMCA. 80

Figure 22 Progeny of Gli1 expressing cells express the FSC marker S100b. 81

Figure 23 Gli1 transcript detection in Gli1/tdT and wild-type pituitary gland sections.

Figure 24 GL/1 transcript detection in sections of human pituitary glands. 82

Figure $25 \mathrm{GH} 3$ cells as a model for the expression of EGFP under the control of rat, murine or human Ghrhr promoter sequences. 85

Figure 26 In vitro recombination capacity of $h G H R H R C r e E R T 2$ constructs. 86

Figure 27 Genotyping of founder mice for genomic integration of the $h G H R H R(-310$,-

19)CreERT2 transgene. 87

Figure 28 Characterization of the $\alpha$ GSU.PTTG plasmid. 89

Figure 29 Lineage tracing of the Aldh1/1CreERT2 transgene in Aldh1/1/tdT and

Aldh1/1/tdT/S100bEGFP pituitaries.

Figure 30 Genomic recombination of the $\operatorname{Ptch}^{f}$ and $S m o^{f}$ locus of $A / d h 1 / 1 / S m o^{f f f}$,

Gli1/Ptch fff and Gli1/Smo ${ }^{f f f}$ mice.

Figure 31 Expression analyses of FSC specific marker genes in TtT/GF and NIH/3T3 cells. 94

Figure $32 \mathrm{Hh}$ signalling status of TtT/GF, AtT-20 and GH3 cells. 96

Figure $33 \mathrm{Hh}$ signalling activation in TtT/GF cells in standard and starvation medium.

Figure $34 \mathrm{Hh}$ signalling activation in AtT-20 and GH3 cells with SAG. 99

Figure $35 \mathrm{CM}$ generation from TtT/GF cells and its effect on AtT-20 cells. 101

Figure $36 \mathrm{CM}$ generation from SAG-treated TtT/GF cells and its effect on $\mathrm{GH} 3$ cells.

Figure 37 Transcriptome analysis of SAG- and DMSO-treated TtT/GF cells. 103

Figure 38 Vip expression and Vip signalling components in pituitary cell lines. 105

Figure 39 Schematic representation of the expected and resulting phenotype of Pomc/Ptch ${ }^{f / f}$ or Pomc/Smo ${ }^{f / f}$ pituitaries.

Figure 40 Proposed model for the role of $\mathrm{Hh}$ signalling in the adult pituitary gland in vivo. 


\section{List of Tables}

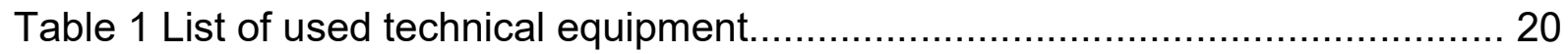

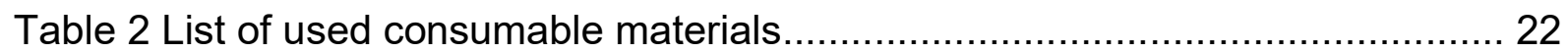

Table 3 List of used reagents and chemicals................................................... 23

Table 4 Utilized buffers and solutions and their composition ................................. 25

Table 5 List of kits and ready-to-use reaction systems ...................................... 27

Table 6 List of used restriction enzymes ..................................................... 28

Table 7 List of enzymes............................................................................... 28

Table 8 Used and generated plasmids ……………................................... 29

Table 9 List of primary antibodies used for this work ......................................... 30

Table 10 List of used secondary antibodies...................................................... 31

Table 11 DNA-oligonucleotides used for PCR-based genotyping, for recombination assay and the generation of expression plasmids ....................................... 32

Table 12 DNA-oligonucleotides used for qRT-PCR approaches ........................... 34

Table 13 List of DNA-oligonucleotides used for Sanger sequencing ....................... 35

Table 14 Media and reagents used for culture of eukaryotic cells .......................... 35

Table 15 Composition of media used for cultivation of prokaryotic cells.................. 36

Table 16 Used eukaryotic cell lines and their respective supplier........................... 36

Table 17 List of utilized genetically modified mouse lines.................................... 37

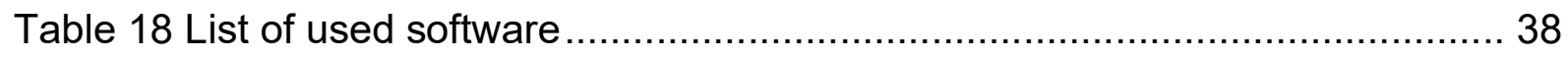

Table 19 Cycling conditions used for quantitative real-time PCR analyses............. 44

Table 20 Conditions for amplification of DNA for sequencing analyses................... 45

Table 21 Growth media and composition for cultivation of cell lines....................... 49

Table 22 Seeded cell numbers for culture in different cultivation vessels................ 50

Table 23 Specifications for electroporation of eukaryotic cells .............................. 51

Table 24 Composition of starvation medium of pituitary cell lines ......................... 51

Table 25 Medium for cultivation of ex vivo pituitary glands..................................... 53

Table 26 RNAscope ${ }^{\circledR}$ specific probes used for detection of transcripts ................... 59

Table 27 PCR thermocycler settings for genotyping of mice form the indicated stains. 


\section{Abstract}

The pivotal role of the Hedgehog $(\mathrm{Hh})$ signalling pathway during embryonal development of the pituitary gland is well established. However, the knowledge about its function in the adult pituitary is still sparse. Our group recently showed that excessive $\mathrm{Hh}$ signalling in murine pituitary explants (e.g. by inducible global homozygous Ptch depletion) leads to enhanced growth hormone (Gh), prolactin (Prl), and adrenocorticotropic hormone (Acth) production and enhanced proliferation of Sox $2^{+} /$Sox $9^{+}$pituitary cells, which are assumed to be involved in pituitary homeostasis. Moreover, these studies also revealed that Sox $2^{+}$cells of the anterior pituitary express Gli1, a surrogate marker for active Hh signalling. This demonstrated that the $\mathrm{Hh}$ signalling pathway plays a role in the homeostasis and hormone production/release of the adult pituitary gland. Moreover, since active Hh signalling is known to be involved in formation/maintenance of a variety of tumour entities the fact that also ACTH-, PRL-, and GH-producing pituitary adenoma show high $\mathrm{Hh}$ signalling activity indicated a role of this pathway in pituitary tumorigenesis. However, the pituitary cell type/s which depend on Hh signalling and the regulatory mechanisms were unknown. Thus, in this thesis the effect of a deregulated Hh signalling in Acth-expressing cells of the adult gland was investigated by in vivo approaches. For this purpose, the $\mathrm{Hh}$ signalling pathway was activated or inactivated in pro-opiomelanocortin (Pomc)-expressing cells of adult murine pituitary glands by homozygous Ptch or Smo depletion using cellspecific inducible Cre/loxP system. These analyses revealed that neither activation nor inhibition of the $\mathrm{Hh}$ signalling pathway impact the function of $\mathrm{Pomc}^{+}$cells during the development nor in the adult gland. Indeed, tissue expression analyses and in vivo lineage tracing approaches verified that Pomc ${ }^{+}$cells never express Gli1 or descent from Gli ${ }^{+}$cells whereas subpopulations of $\mathrm{Gh}^{+}$cells and folliculostellate cells (FSC) do. To analyse the role of $\mathrm{Hh}$ signalling in Gh-producing cells in more detail a new deleter mouse strain was generated. Additionally, in vitro media transfer experiments and transcriptome analyses were conducted to investigate the role of $\mathrm{Hh}$ signalling in FSC, which are known to regulate the activity of endocrine pituitary cells, express Sox2 and harbour stem cell-like characteristics. These approaches revealed that $\mathrm{Hh}$ signalling activation in FSC leads to the secretion of vasoactive intestinal peptide from FSC and $\mathrm{Gh}$ release from GH3 cells indicating that Hh signalling in FSC regulates hormone secretion of endocrine cells in a paracrine manner. 


\section{Introduction}

\subsection{Structure, cell types and function of the pituitary gland}

The pituitary gland is a hormonal gland with a superordinate role in the regulation of most of the body's function via acting as a mediator between the hypothalamus and peripheral organs and thereby forming a hypothalamus-pituitary-peripheral organ axis (Figure 1). The pituitary gland is located in a bony cavity (sella turgica) in the skull at the base of the brain. It is covered by meninges and in close proximity of the hypothalamus and the optical chiasm (crossing point of optic nerves) ${ }^{1}$. Anatomically and functionally, the gland consists of two distinct parts: (1) the adenohypophysis, including the anterior lobe (AL) and the intermediate lobe (IL) and (2) the neurohypophysis or posterior lobe (PL) (Figure 1). Both the adeno- and the neurohypophysis consist of different hormone-producing (endocrine) cell types and of pituitary-specific non-endocrine cells (Figure 2).

The endocrine cells of the $A L$ are corticotrophs, that secrete the adrenocorticotropic hormone (Acth), lactotrophs, that secrete prolactin ( $\mathrm{Prl}$ ), somatotrophs, that secrete growth hormone (Gh), thyrotrophs, that secrete thyroid-stimulating hormone (Tsh) and gonadotrophs, that secrete luteinizing hormone (Lh) and follicle-stimulating hormone (Fsh) (Figure 2). Acth, a derivative of pro-opiomelanocortin (Pomc), mainly regulates glucocorticoid synthesis in the adrenal gland; Prl is responsible for milk synthesis in females; Gh regulates metabolism and linear growth; Tsh regulates growth and iodine uptake of the thyroid gland and Lh and Fsh control the function of gonads by initiating maturation and maintaining reproductive function (Figure 1). The specific binding and activation of the different hormones to their respective receptor in its target tissue is assured by the structure of the hormones. However, in this context it is noteworthy that the hormones Lh, Tsh and Fsh possess the same alpha subunit (glycoprotein hormones, alpha polypeptide; $\alpha \mathrm{GSU}$ ) but their biological activity depends on the beta subunit (e.g. $\operatorname{Lh} \beta, \operatorname{Tsh} \beta, F \operatorname{sh} \beta$ ) that is unique for each hormone. Beside the endocrine cells, the gland also consists of non-endocrine cells. These cells have a supportive function in the gland and are characterized by their agranular appearance ${ }^{2}$.

In the IL alpha melanocyte stimulating hormone ( $\alpha$ Msh), also a derivative of Pomc, is produced that binds to melanocytes in the skin and initiates melanogenesis and increases melanocyte proliferation (Figure 1) ) $^{3,4}$. 
In the PL oxytocin (Oxt), that is involved in parturition and recovery of the uterus, and antidiuretic hormone (vasopressin; Adh), which controls arterial blood pressure are produced (Figure 1) $)^{5-9}$.

The secretion of the hormones from the secretory vesicles of endocrine cells is mainly regulated by cyclic adenosine monophosphate (cAMP) signalling. Thus, after receiving a distinct signal from another cell, intracellular CAMP concentration of the endocrine cell increases and an influx of extracellular $\mathrm{Ca}^{2+}$ leads to exocytosis of the hormonecontaining vesicles and the release of the hormone into the blood stream ${ }^{10}$.

\subsubsection{Hormone-producing cells of the adenohypophysis}

\subsubsection{Pro-opiomelanocortin and its bioactive peptide hormones}

In the adenohypophysis, Pomc is expressed in both the $\mathrm{AL}$ and the IL (Figure 2). However, apart from the pituitary, also several other tissues express Pomc [e.g. arcuate nucleus of the hypothalamus (ANH), skin and placenta] ${ }^{11}$. The Pomc protein resembles a precursor polypeptide, which is differentially cleaved into bioactive peptide hormones Acth, $\alpha$ Msh, $\beta$-endorphin and/or $\beta$-lipoprotein depending on the tissue and the cell-type ${ }^{12}$. In the $\mathrm{ANH}$, mainly $\alpha \mathrm{Msh}$ and $\beta$-endorphin are produced from Pomc. The neurons that secrete $\alpha M s h$ and $\beta$-endorphin are responsive to leptin and insulin and are involved in regulation of energy balance and food intake ${ }^{13}$. In the AL Pomc is cleaved to Acth, which then is secreted from corticotrophs after stimulation with the corticotroph releasing factor/hormone (Crf/Crh) that originates from the hypothalamus ${ }^{14}$. Acth exits the gland via the hypophyseal vein and activates cells of the adrenal cortex provoking the production of glucocorticoids. Thus, Acth is the key player in the hypothalamus-pituitary-adrenal gland axis (Figure 1). Free glucocorticoids inhibit the release of Acth by blocking the hypothalamic neurons as well as the corticotrophs and thereby acting as a negative feedback loop. Glucocorticoids are a subgroup of steroid hormones and are involved in many metabolic processes. They control gluconeogenesis in the liver ${ }^{15}$, protein consumption in the muscles ${ }^{16}$, blood pressure ${ }^{17,18}$, they increase the amount of fatty acids in the circulation ${ }^{19}$ and increase the expression of fatty acid synthase ${ }^{20,21}$. One of the main representatives of the glucocorticoid group is cortisol, also called the "stress hormone" that is mainly produced during stress situation. However, blood serum concentration of Acth and 
cortisol vary during the day depending on the level of activity in a species ${ }^{22}$.

\subsubsection{Prolactin and its effects on metabolism}

$\mathrm{Prl}$ - secreted by lactotrophs - promotes milk synthesis and preservation of lactation postnatally ${ }^{23}$ (Figure 1). Thus, the amount of Prl secreting cells in the pituitary varies depending on the female lactation cycle. Beyond that, $\mathrm{Prl}$ also increases glucose homeostasis by increasing the mass of beta cells of the pancreas. Hence, pathologically enhanced Prl levels can lead to insulin resistance ${ }^{24,25}$. Prl was also shown to increase dihydroepiandrosterone ${ }^{23}$, cortisol and aldosterone secretion from the adrenal cortex ${ }^{26}$. Moreover, it plays a role in immune responses ${ }^{27}$, is involved in osmoregulation $^{28}$ and can stimulate proliferation, differentiation and migration of neuronal stem cells ${ }^{29}$.

The secretion of $\mathrm{Prl}$ is mainly regulated by endocrine neurons of the hypothalamus via the dopaminergic system. Thereby the neurotransmitter dopamine inhibits Prl release from the pituitary gland. Furthermore, Prl secretion is stimulated by Trh, Oxt, neurotensin ${ }^{30}$, angiotensin II and acetylcholine (ACh) ${ }^{31}$ and inhibited by somatostatin, $\mathrm{Y}$ amino butyric acid (GABA) $)^{30}$, arginine-vasopressin peptide ${ }^{32}$ and neuropeptide $\mathrm{Y}^{31}$.

\subsubsection{Growth hormone and its biological role}

The main regulatory molecules for $\mathrm{G}$ secretion from the $\mathrm{AL}$ are hypothalamic growth hormone releasing hormone (Ghrh) and somatostatin ${ }^{33}$. Thereby Ghrh binds to the Ghrh receptor (Ghrhr) on somatotrophs, which leads to an upregulation of $G$ and Ghrhr transcription and $\mathrm{G}$ release. Gh is liberated into the blood stream and regulates the expression of insulin-like growth factor 1 (Igf-1) from the liver. High blood serum levels of Gh and Igf-1 in turn lead to a decreased Ghrh release and an enhanced somatostatin secretion from the hypothalamus which then blocks $\mathrm{Gh}$ secretion from the pituitary.

The main function of $\mathrm{Gh}$ is the regulation of longitudinal growth after birth (Figure 1). Nevertheless, it also regulates lipolysis in adipocytes and decreases body fat, it maintains muscle mass and strength ${ }^{33,34}$. It furthermore stimulates $B$ and $T$ cell 
proliferation, immunoglobulin synthesis ${ }^{35}$, growth of the heart ${ }^{36}$ and axon growth of developing nervous tissue $\mathrm{e}^{34,37,38}$. However, $\mathrm{G}$ is not exclusively expressed in the $\mathrm{AL}$ of the pituitary since it can also be found in e.g. reproductive, respiratory and skeletal tissue $^{39-41}$ where it is involved in oocyte maturation ${ }^{42}$, lung development ${ }^{43}$ and regulation of cartilage growth ${ }^{44}$.

\subsubsection{Thyrotrophic hormone and its function}

Tsh, the main regulator of thyroid gland's function, is released from the pituitary in response to the hypothalamic thyroid-releasing hormone (Trh). In the thyroid gland, Tsh stimulates the release of triiodothyronine (T3) and thyroxine (T4) from follicular cells (Figure 1). High T3/T4 blood serum levels reduce Tsh secretion from the pituitary resulting in a negative feedback loop for Tsh production. T3/T4 act on nearly all organs but generally their stimulation leads to increased metabolic rate and thermogenesis ${ }^{45,46}$.

\subsubsection{Gonadotrophic hormones and their role in reproduction}

Gonadotrophs produce the two gonadotrophic hormones Lh and Fsh. Both hormones act in a synergistic manner to stimulate follicular growth and ovulation in females $^{47}$ (Figure 1). Lh regulates the order of the menstrual cycle and is pivotal for ovulation and implantation of an egg in the uterus via increasing the level of oestrogen and estradiol ${ }^{48}$. However, in males $\mathrm{Lh}$ is involved in the release of testosterone from Leydig cells of the testes ${ }^{49}$ (Figure 1). Fsh is involved in folliculogenesis, oocyte selection and synthesis of sex steroid hormones in females ${ }^{50}$. In males, it regulates testicular development and spermatogenesis ${ }^{51}$. Both Lh and Fsh are released after stimulation with the gonadotropin-releasing hormone (Gnrh) from the hypothalamus ${ }^{52}$. Increased levels of testosterone and oestrogen lead to inhibition of $L$ h and Fsh release in a negative feedback mechanism ${ }^{53}$. 


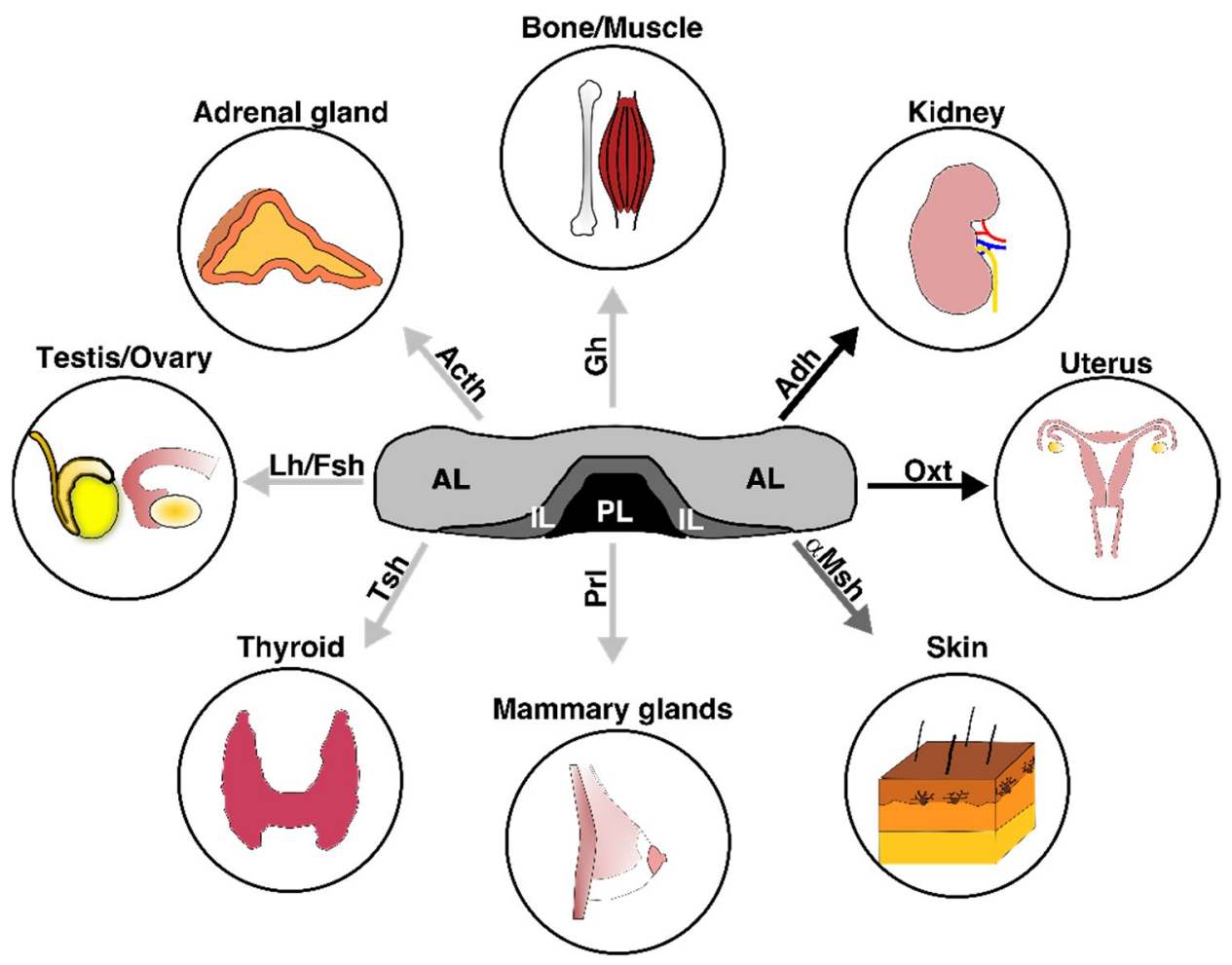

Figure 1 Target organs of hormones of the pituitary gland. The murine pituitary gland (center) is subdivided into the anterior lobe (AL, grey), the intermediate lobe (IL, dark grey) and the posterior lobe (PL, black). Growth hormone (Gh), adrenocorticotropic hormone (Acth), luteinizing hormone (Lh), follicle-stimulating hormone (Fsh), thyroid-stimulating hormone (Tsh) and prolactin ( $\mathrm{Prl})$ are produced in the AL. Alpha melanocyte-stimulating hormone $(\alpha \mathrm{Msh})$ is produced in the IL. Oxytocin (Oxt) and antidiuretic hormone (Adh) are produced in the PL.

\subsubsection{Non-endocrine cells of the adenohypophysis}

The major role of the pituitary gland is the release of hormones that regulate most of the body's function. It receives signals from the hypothalamus and controls itself via negative feedback inhibition. However, beside the 5 endocrine cell types the adult adenohypophysis also harbours non-endocrine cell types.

As described for other adult organs (e.g. brain, trachea, hair follicle) also the adult pituitary harbours Sox2- [SRY (sex determining region Y)-box 2] expressing stem cells ${ }^{54-58}$. In the pituitary Sox $2^{+}$cells are mainly located in a specific compartment called marginal zone (MZ) (Figure 2). The $M Z$ is a thin cellular layer at the border of the $A L$ to the IL. Besides the MZ Sox2 ${ }^{+}$are occasionally found also in the $\mathrm{AL}^{54,59}$. The Sox2 ${ }^{+}$ cells in the pituitary are able to recreate all endocrine cell types of the gland ${ }^{54}$. However, a major depletion of these cells does not affect the homeostasis or remodelling of the gland and therefore the final role of these cells is not fully elucidated ${ }^{60}$. 
Besides these putative stem cells, the adult pituitary also contains a non-endocrine cell type which was first discovered in $1953^{2}$. These cells were encountered throughout the complete adenohypophysis and were named folliculostellate cells (FSC) in regard to their star-like processes and their follicles (Figure 2). FSC form a meshwork, that comprise about $10 \%$ of the cells of the adenohypophysis and in which they are connected via gap junctions and signal via calcium waves ${ }^{61-64}$. In addition, they stain positive for the calcium-sensing protein $\mathrm{S} 100^{63,64}$. Therefore, it has been assumed that FSC display a local communication network in the pituitary. Moreover, due to their morphology, their S100 expression and their ability to perform phagocytosis it was furthermore suggested that FSC might represent immune cells of the adenohypophysis ${ }^{65-68}$. However, FSC produce a plethora of different signalling molecules including annexin $\mathrm{A} 1$ (Anxa1) ${ }^{69}$, follistatin (Fst) ${ }^{70,71}$, basic fibroblast growth factor $(\mathrm{bFgf})^{72}$, vascular endothelial growth factor $(\text { Vegf })^{73-75}$, pituitary adenylate cyclase-activating peptide (Pacap) ${ }^{76}$, transforming growth factor $\beta 1$ (Tgf $\left.\beta 1\right)$ and leptin $^{77}$ as well as receptors for Pacap ${ }^{78,79}$, glucocorticoids ${ }^{80}$, leptin ${ }^{77}$, Vegf ${ }^{81}$, platelet derived growth factor (Pdgfr) ${ }^{82}$, norepinephrine ${ }^{83}$, vasoactive intestinal peptide (Vip $)^{79}$, angiotensin $^{84}$ and Tsh ${ }^{85}$. Thus, FSC obviously are capable to respond to certain signalling pathways and send signals to neighbouring cells. However, their distinct role in the homeostasis of the adenohypophysis remains unclear and is under constant discussion 86,87 .

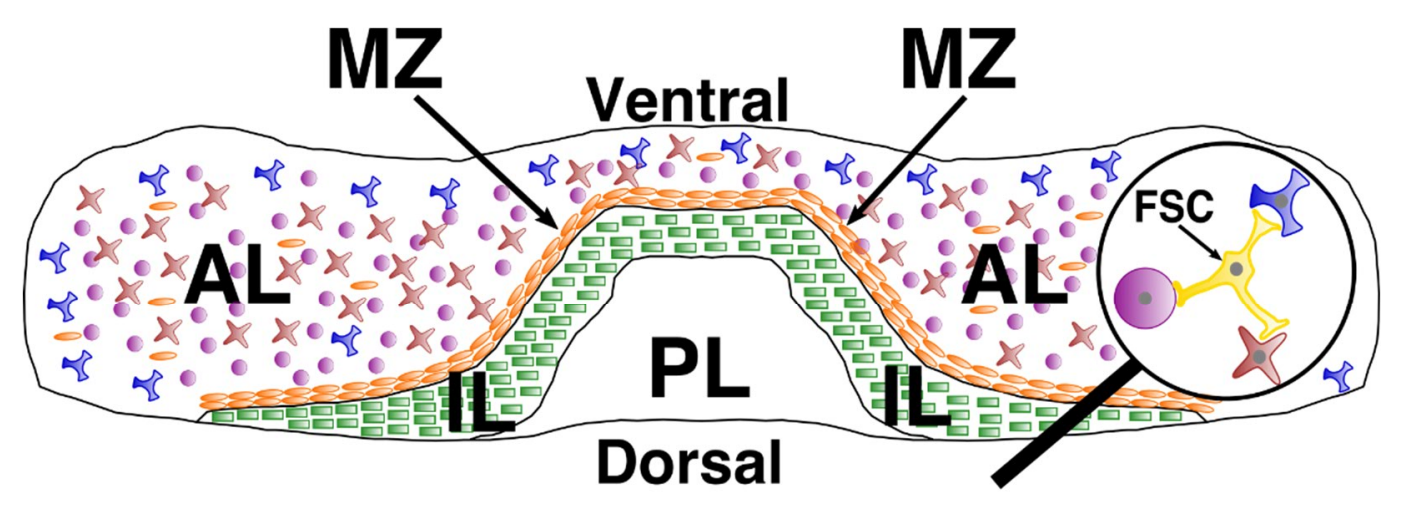

Æcth $\times$ Prl $\odot$ Gh $\boxminus \alpha M s h-$ Sox2

Figure 2 Schematic representation of a transverse section of an adult murine pituitary gland. The pituitary gland is subdivided in 3 parts (anterior lobe, $A L$; intermediate lobe, IL; posterior lobe, $P L$ ), whereas the $A L$ and the IL together comprise the adenohypophysis and the $\mathrm{PL}$ represents the neurohypophysis. In the $\mathrm{AL}$ adrenocorticotropic hormone- (Acth), prolactin- (Prl) and growth hormone- (Gh) secreting cells are located, whereas $\mathrm{Acth}^{+}$cells are found rather at the border. In the IL alpha melanocyte stimulating hormone ( $\alpha$ Msh) secreting cells are observed. SRY (sex determining region Y)-box 2 (Sox2) expressing cells are located in the marginal zone (MZ), a thin layer at the margin of the $\mathrm{AL}$, as well as scattered throughout the $\mathrm{AL}$. In a closer magnification of the $\mathrm{AL}$ (magnifying glass) a folliculostellate cell (FSC) is shown with its characteristic morphology and the connection to the endocrine cells. For convenience Tsh, Lh, Fsh, Oxt and Adh secreting cells are not shown. 


\subsection{Pathology of the pituitary gland}

The most common disease of the pituitary gland is the pituitary adenoma (PA), a tumour that represent $10-15 \%$ of all intracranial tumours. The prevalence of a pituitary tumour is approximately $17 \%^{88-91}$. In general (>95\%) PA develop from a sporadic neoplasms and are not associated to a hereditary syndrome ${ }^{92}$. However, $5-7 \%$ of patients with PA have a familial isolated pituitary adenoma (FIPA) or suffer from the multiple endocrine neoplasia type 1 (MEN1) syndrome ${ }^{93,94}$. PA occur predominantly in adulthood and are localised in the adenohypophysis. They are identified by histology, immunohistochemistry, ultrastructural analysis, biochemical findings, imaging and the intraoperative impression. 3 groups of tumours are distinguished based on the biological behaviour of the tumour: (1) benign PA, (2) invasive PA and (3) pituitary carcinomas ${ }^{95-97}$. The largest group comprises the benign adenomas that account for approximately $65 \%$ of all pituitary neoplasm, $35 \%$ belong to the invasive PA that could infiltrate the dura mater, cranial bone or the sphenoid sinus but less than $0.2 \%$ are carcinomas that could metastasize ${ }^{98-102}$. Clinically PA are characterised by considerable hormonal dysfunctions and/or symptoms deriving from a neoplastic expansion that damage neighbouring structures and lead to visual field deficits and headache ${ }^{103}$. In general PA grow slowly and are often incidentally diagnosed by magnetic resonance imaging conducted for an unconnected reason ${ }^{104}$.

Based on the hormone production of the PA they are classified as lactotrophinomas (PRL-secreting, $50 \%$ of all adenomas), gonadotrophinomas (FSH- or $\mathrm{LH}$-secreting, $\sim 30 \%$ of all adenomas), somatotrophinomas (GH-secreting, $\sim 15-20 \%$ of all adenomas), corticotrophinomas (ACTH-secreting, $\sim 5-10 \%$ of all adenomas) and thyrotrophinomas (TSH-secreting, $<1 \%$ of all adenomas). However, PA can secrete more than one hormone ${ }^{99,105}$. Since distinct hormones affect different cell types and tissues, the symptoms of a PA are abundant. For example, corticotrophinomas can result in development of Cushing's disease (Morbus Cushing) that is accompanied by weight gain, growth of fad pads in the face and fatigue ${ }^{106}$ whereas somatotrophinomas can lead to a clinical manifestation of acromegaly that is characterized by excessive skeletal growth and soft tissue enlargement ${ }^{107}$.

In accordance with the fact that PA go along with many different and partly severe symptoms, PA are usually surgically removed (resection) and/or treated by radiation and/or therapeutic therapy ${ }^{108}$. However, promising pharmacological therapeutic 
approaches are currently only available for lactotrophinomas (dopamine agonists) and the somatotrophinomas (somatostatin analogues) ${ }^{109-111}$ whereas so far no adequate pharmacotherapy has been established for the treatment of clinically inactive adenomas PA (PA without detectable hormones production). Thus, resection is the treatment of election ${ }^{112,113}$. In addition, for patients suffering from adenomas with a high recurrence rate $(7-12 \%)$ that require repeated surgical and/or radiotherapeutic, only experimental therapeutic approaches are currently available intervention 114-121. Moreover, such problematic courses can only be described very insufficiently by the actual established criteria from diagnostics (determination of hormone secretion, determination of proliferation tendency and size of the adenoma) and thus target molecules for pharmacotherapeutic intervention are actually unknown ${ }^{122-124}$. Altogether the molecular pathogenesis of PA and possible differences between different adenoma subtypes, are still largely unclear which impedes the development of new pharmacotherapeutic treatment options ${ }^{125}$. 


\subsection{Hedgehog signalling and the pituitary gland}

\subsubsection{The Hedgehog signalling pathway}

The Hedgehog $(H h)$ gene was firstly described in 1980 by Nüsslein-Volhard \& Wieschaus which observed that $H h$ depletion leads to a spike-like ("Hedgehog"-like) phenotype in Drosophila melanogaster larvae ${ }^{126}$. In vertebrates the $3 \mathrm{Hh}$ homologs Sonic $\mathrm{Hh}(\mathrm{Shh})$, Desert $\mathrm{Hh}(\mathrm{Dhh})$ and Indian $\mathrm{Hh}(\mathrm{Ihh})$ were identified, all acting as ligands for activation of the Hh signalling pathway. Shh - the best characterized vertebrate $\mathrm{Hh}$ - is widely expressed in mammalian tissues especially in the limb buds, neural tube and liver during early embryonic development ${ }^{127-130}$. Hh proteins act in a paracrine and autocrine manner and thereby affecting neighbouring cells and the secreting cells. The bioactive form of Shh requires post-translational modifications of the protein. Thus, newly synthesized Shh preproprotein is autoprocessed into an Nterminal signalling domain (Shh-N) and a C-terminal catalytic domain (Shh-C). During this process, a cholesterol molecule is added to the C-terminus and a palmitate molecule to the $\mathrm{N}$-terminus of Shh-N ${ }^{131-133}$. Afterwards the bioactive Shh-N protein is released by sequestering cells via the transmembrane protein Dispatched1 (Disp1) ${ }^{134-}$ 136 .

Besides the Hh gene Nüsslein-Volhard \& Wieschaus also discovered the Patched (Ptc) gene which encodes for the Hh ligand receptor ${ }^{126,137,138}$. In vertebrates two Ptc homologs - Patched1 (Ptch) and Patched2 (Ptch2) - exist ${ }^{130,139,140 .}$. The 12transmembrane Ptch protein function as a negative regulator of $\mathrm{Hh}$ signal transduction since without $\mathrm{Hh}$ binding it suppresses the activity of the transmembrane protein Smoothened $(\mathrm{Smo})$ and thereby the whole $\mathrm{Hh}$ signalling pathway ${ }^{137,138}$. Upon $\mathrm{Hh}$ binding to its receptor, Ptch-meditated inhibition of the Smo protein is released which results in the processing of transcription factors of the Glioma-associated oncogene (Gli) family and target gene expression (Figure 3$)^{141}$.

However, the functionality of the Hh signalling pathway is closely linked to the existence of primary cilia on a certain cell type. A primary cilium is a slender protrusion of nearly all vertebrate cells. It functions as an antenna and is involved in the transduction of external signals into cellular responses ${ }^{142}$. In case of $\mathrm{Hh}$ signalling the primary cilium acts as an antenna for Hh ligands since its receptor Ptch is located at the ciliary membrane whereas Smo is enclosed in vesicles in the cytoplasm (Figure 3). 
Binding of $\mathrm{Hh}$ to Ptch leads to degradation of the ligand/receptor-complex from the cilium and to the translocation of Smo to the ciliary membrane (Figure 3). Thus, Smo signal transduction is activated which results in activation of Gli transcription factors (Figure 3). In vertebrates, the Gli family comprises 3 members (Gli1, Gli2 and Gli3) that can act as activators or repressors of transcription. Only Gli1 exists in a full-length transcriptional activator (Gli1A) form, whereas Gli2 and Gli3 can act as both activator (Gli2A/Gli3A) and repressor (Gli2R/Gli3R) depending on post-transcriptional and posttranslational modifications. In the absence of $\mathrm{Hh}$ ligands $\mathrm{Gli}$ proteins are phosphorylated and converted into the respective repressor form or are degraded whereas in the presence of $\mathrm{Hh}$ ligands Gli proteins are processed into their full-length activator forms and are translocated into the nucleus to activate target gene expression ${ }^{143}$. Target genes of the active pathway include $\mathrm{Hh}$ signalling activators (e.g. Gli1) as well as repressors [e.g. Ptch and Hhip ( $\mathrm{Hh}$ interacting protein)]. Thus, $\mathrm{Hh}$ signalling activation leads to a signal amplification and negative feedback regulation simultaneously (Figure 3).

Depending on (1) the amount of Hh ligands, (2) the cell-type of the receiving cell and (3) the time point during the cell is exposed to $\mathrm{Hh}$ ligands the target genes of $\mathrm{Hh}$ signalling range from growth [insulin-like growth factor 2 (Igf2) ${ }^{144}$ and Pdgfr] to vascularization (Vegf) ${ }^{145}$, stemness [nanog homeobox (Nanog), Sox2] and epithelialto-mesenchymal transition (EMT) [matrix metalloproteinase (Mmp)9, Snain] ${ }^{127,128,141,146-}$ 152. Although there are plenty of genes transcribed after activation of Hh signalling Gli1 expression is considered to be the most reliable read-out for detection of active $\mathrm{Hh}$ signalling ${ }^{153-155}$. 

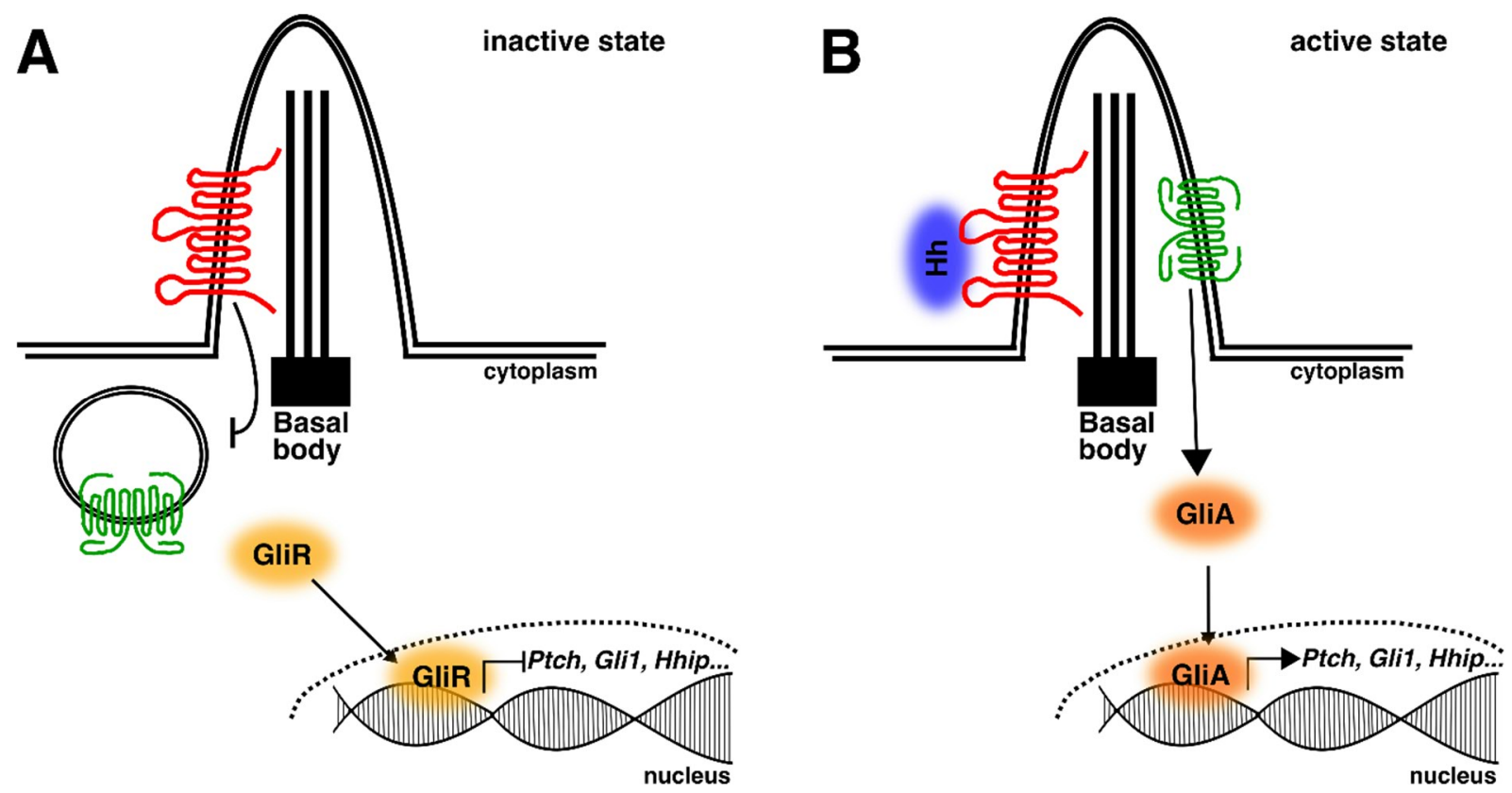

Figure 3 Schematic representation of the Hh signalling pathway. In the inactive state of the pathway, the $\mathrm{Hh}$ receptor Ptch (red) is located at membrane of the primary cilium whereas the Smo protein (green) is localized in intracellular vesicles. This leads to the processing of the Gli transcription factors to their repressor forms (GliR, yellow) that translocate into the nucleus and prevent target gene transcription (A). Binding of one of the Hh ligands (blue) to the receptor Ptch results in Smo translocation into the primary cilium and induces the generation of Gli activator forms (GliA, orange). GliA translocate in the nucleus and act as transcriptional activators for Hh-specific gene transcription (B). Modified from Jiang et al. $2008^{156}$.

Ptch and Smo are the key player of Hh signalling. Therefore, depletion of one of these genes is an effective tool to modulate Hh signalling adequately. Genetically modified mice harbouring floxed alleles of Ptch (Ptch $f$, Figure 5$)^{157}$ or Smo $\left(S^{2} o^{f} \text {, Figure } 15\right)^{158}$ permit a Cre-recombinase-mediated depletion of the respective gene resulting in constitutive activation (Ptch $\left.{ }^{d e l}\right)$ or inactivation $\left(S m o^{d e l}\right)$ of the pathway, respectively. Thereby, cell-specific expression of the Cre-recombinase as well as application of a Cre-recombinase activator (e.g. tamoxifen for CreERT2-recombinases) determine the recombination of the floxed alleles and thus enable the analysis of a cell-specific deregulated $\mathrm{Hh}$ signalling in vivo (for further details about the used genetically engineered mouse lines see Table 17). 


\subsubsection{Hh signalling in the developing and adult pituitary gland}

The Hh signalling pathway is essential for the development of organs, tissues and cell structures ${ }^{159}$. It plays an important role during the formation of limbs and digits ${ }^{160}$, is required for the development of the neural tube ${ }^{161,162}$ and the mammary gland epithelium ${ }^{163}$. Additionally, the development of the pituitary gland is closely linked to the regulation of the Hh signalling cascade ${ }^{164}$.

The pituitary gland of vertebrates originates from two different ectodermal structures: the oral ectoderm, which gives rise to the adenohypophysis and neural ectoderm that develops into the neurohypophysis ${ }^{165-168}$. During embryogenesis the oral ectoderm invaginates and comes into close contact to a part of the neural ectoderm (ventral diencephalon) to form Rathke's pouch that resembles the primordium of the pituitary gland ${ }^{169,170}$. The ventral diencephalon evaginates ventrally and forms the infundibulum that develops into the PL and the pituitary stalk (connection between the pituitary gland and the brain $)^{171}$. The pouch separates completely from the oral ectoderm and the lumen perseveres as pituitary cleft, separating the $A L$ and $\mathrm{IL}$ in the mature organ. Differentiation of the gland occurs via a ventrally relocation of the cells. Proliferative progenitors are located in a perilumenal area that is still present in the adult ${ }^{54}$. Glycoprotein hormones alpha subunit ( $\mathrm{Cga}$ ) encoding for $\alpha \mathrm{GSU}$ is the first differential marker that is expressed in the developing gland. Cells expressing this marker also express the transcription factor Islet-1 (Is/1), indicating that they are determined to become thyrotrophs. Cga is expressed by gonadotrophs and thyrotrophs of the mature gland. Next, corticotrophs start to differentiate based on their expression of Pomc. Afterwards explicit thyrotrophs are detected characterised by their expression of Tshb. The somatotroph and lactotroph lineage develops nearly at the same time and are marked by $\mathrm{Gh}$ and Prl expression. The last developing endocrine cell-type are the gonadotrophs that express $L h b$ and $F s h b^{172-175}$.

During early pituitary development Shh expression is detected in the oral ectoderm but not in Rathke's pouch itself ${ }^{164,170}$. However, Ptch is highly expressed in Rathke's pouch and Gli proteins are expressed in the ventral diencephalon and in Rathke's pouch indicating that the developing pituitary gland is capable to respond and react to $\mathrm{Hh}$ signalling ${ }^{164,176}$. Complete depletion of Shh leads to the loss of midline structures of the brain and cyclopia and thereby even no pituitary gland precursor is formed. Therefore, loss of function studies of proteins implicated in $\mathrm{Hh}$ signalling during pituitary 
gland development are hardly to assess ${ }^{177}$. Nevertheless, ectopically expression of the $\mathrm{Hh}$ antagonist Hhip in the oral ectoderm and in Rathke's pouch leads to arrested pouch development. Moreover, overexpression of Shh in early developing $\alpha \mathrm{GSU}^{+}$cells results in up-regulation of the bone morphogenic protein 2 (Bmp2) that is physiologically expressed in Rathke's pouch, and thereby to enhanced proliferation of thyrotroph and gonadotroph cell-types ${ }^{164,170}$. Besides aberrations in the Hh ligand also the deletion of Gli1 or Gli2 leads to variable lack or the complete lack of the pituitary, 5,178 . Moreover, in humans inactivating mutations in GLI2 are associated with hypopituitarism ${ }^{179}$, malformation of the pituitary gland ${ }^{180}$ and aplasia ${ }^{181}$ of the adenohypophysis. These results indicate that $\mathrm{Hh}$ signalling plays a pivotal role in both development as well as differentiation of the pituitary gland. Moreover, the expression of Gli1 and/or Gli2 rather seems to be a necessary factor/s for proliferation than for differentiation of the gland.

Besides its crucial role in the vertebrate development $\mathrm{Hh}$ signalling is also implicated in cell differentiation, stem cell maintenance, tissue homeostasis and repair of adult organs ${ }^{128,182}$. However, the knowledge about the role of the pathway in the adult pituitary is sparse although several lines of evidence point towards an implication of $\mathrm{Hh}$ signalling in the maintenance and function of the adult gland. Thus, immunohistological stainings of adult human pituitaries showed a PTCH expression in gonadotrophs and thyrotrophs, a PTCH2 expression in somatotrophs and in a subpopulation of lactotrophs and GLI1 and SHH expression in corticotrophs. Due to these results, an active $\mathrm{HH}$ signalling in gonadotrophs, thyrotrophs, somatotrophs, lactotrophs and corticotrophs was assumed ${ }^{183}$. In vitro studies furthermore revealed that Shh stimulation leads to increased Pomc transcription, elevated Acth secretion and inhibition of cell growth of the murine corticotroph cell line AtT-20 and to increased $\mathrm{Gh}$ and $\mathrm{Prl}$ secretion of the rat somatotroph cell line $\mathrm{GH} 3^{183,184}$. These results suggested that activation of $\mathrm{Hh}$ signalling in pituitary endocrine cells triggers hormone secretion and inhibits their proliferation.

However, our group demonstrated that Gli1 - the most reliable read-out for active $\mathrm{Hh}$ signalling - is expressed in Sox $2^{+}$(stem) cells of the $A L$ in murine adult pituitaries (Figure 4). Moreover, activation of $\mathrm{Hh}$ signalling via homozygous Ptch depletion in every cell of murine pituitary explants lead to a significant increased transcription of Pomc, Gh and Prl and an elevated Acth release (Figure 4). Beyond 
that, Ptch depletion also results in an increased proliferation of Sox $2^{+}$and Sox $9^{+}$(SRYbox9) pituitary cells. These results indicated that active Hh signalling indeed affects hormone production of corticotrophs, somatotrophs and lactotrophs but also has a proliferative effect on Sox $2^{+}$and Sox9 ${ }^{+}$non-endocrine pituitary cells in the adult adenohypophysis ${ }^{185}$. Furthermore, Ptch and Smo were detected in a subset of pituitary stem cells ${ }^{186,187}$. Additionally, Gli1 and Gli2 are increased in these stem cells after injury of the pituitary gland ${ }^{188-190}$.

\section{wild-type}

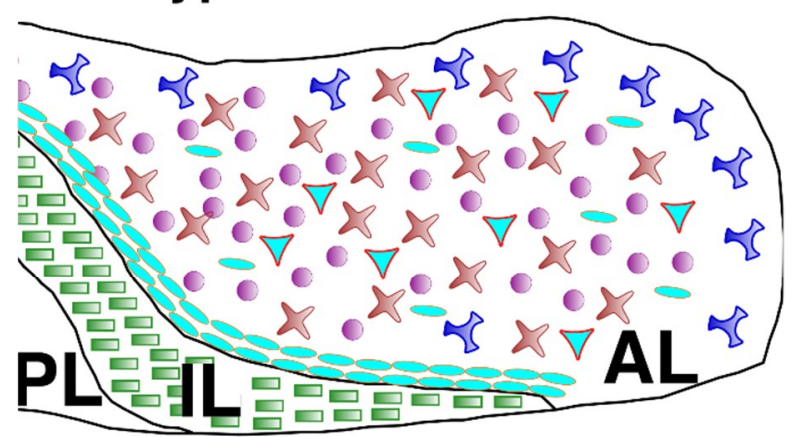

ubiquitous Ptch depletion



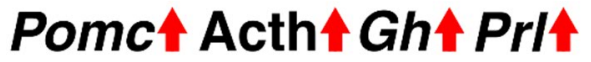



Figure 4 Schematic representation of the role of $\mathrm{Hh}$ signalling in the adult pituitary. In adult wild-type pituitary glands (left) two Gli1 ${ }^{+}$cell populations are detected: (1) Sox $2^{+} / \mathrm{Gli} 1^{+}$double positive cells and Sox ${ }^{\text {neg }} / \mathrm{Gli} 1^{+}$cells that are located in the anterior lobe $(\mathrm{AL})$. A homozygous ubiquitous Ptch depletion in adult murine pituitaries (right) leads to enhanced proliferation of Sox $2^{+}$cells and increased transcription of Pomc, Gh and Prl. Furthermore, the glands secrete increased levels of Acth. IL: intermediate lobe; PL: posterior lobe.

\subsubsection{Hh signalling and pituitary pathology}

Well restricted and regulated $\mathrm{Hh}$ signalling is essential for proper development and maintenance of adult organs, tissues and cell structures. Changes in the activity pattern of the pathway play a not negligible role in the development of diseases. In particular, pathological $\mathrm{Hh}$ signalling activation, e.g. due to inactivating mutations of Ptch or activating mutations of Smo, can cause developmental defects and/or tumour development ${ }^{156}$. Thus, Gorlin-Goltz-syndrome (nevoid basal cell carcinoma syndrome) patients with a heterozygous germline PTCH mutation suffer from developmental defects, are predisposed for the development of basal cell carcinoma (BCC) and have a higher risk for medulloblastoma, glioma and meningioma formation ${ }^{191-195}$. Beyond that also somatic mutations that lead to a pathologically activated Hh signalling 
pathway (e.g. inactivating mutations of Ptch, activating mutations of Smo, amplifications of $H H$ or $G L I$ ) can lead to tumour development e.g. of the skin (BCC $)^{196-}$ ${ }^{200}$, the gastrointestinal system ${ }^{201}$, the pancreas ${ }^{202}$ or the lung ${ }^{203}$.

The role of $\mathrm{HH}$ signalling in the pathology of the adult pituitary is sparse although Gorlin-Goltz-patients occasionally show characteristics of acromegaly and inactivating mutations of GL/2 correlate with holoprosencephaly and lack of the adenohypophysis ${ }^{179,181,204-206}$. Because Hh signalling plays a significant role during pituitary development and $\mathrm{HH}$ signalling proteins are expressed in healthy adult pituitary glands it can be assumed that $\mathrm{HH}$ signalling may be also implicated the pathogenesis of the gland.

However, early immunohistological studies on human PA detected $\mathrm{SHH}$ expression only in exceptional cases whereas $\mathrm{PTCH}$ and $\mathrm{PTCH} 2$ were expressed in a moderate level in the investigated samples. Therefore, the authors concluded that $\mathrm{HH}$ signalling is rather downregulated than overactivated in $\mathrm{PA}^{183}$. Since this observation stands in clear contrast to the well-accepted role of $\mathrm{Hh}$ signalling in tumour formation, our group also analysed the expression pattern of the $\mathrm{Hh}$ signalling activator $\mathrm{SHH}$ and its downstream target GL/1 in approximately 100 human PA samples. Remarkably, this approach revealed that the $\mathrm{HH}$ signalling pathway is overactivated in $\mathrm{ACTH}-\mathrm{GH}$ - and PRL-expressing $P A^{185}$. Together with the fact that $\mathrm{Hh}$ signalling activation in murine pituitaries increased the proliferation of $\mathrm{Sox}^{+}$cells these data suggest that a deregulation of the Hh signalling pathway might play a crucial role in the development of pituitary neoplasia and thus might be a potential new therapeutic target for treatment of $\mathrm{PA}^{185}$. 


\subsection{In vitro and in vivo models to study pituitary tumorigenesis}

Investigations on pituitary tumorigenesis and tumour progression is ideally based on model systems that reflect the characteristics of a pituitary tumour in an adequate manner. Thus, the pituitary pathogenesis can be either investigated by analysing tumour-derived cell lines or primary culture of PA-derived material or by in vitro or in vivo studies of animal models that develop a pituitary tumour to certain frequency. In the last decades plenty of pituitary cell lines were established that derive mainly from rodents and belong either to a PA (including expression a specific hormone) or a carcinoma. The most frequent used pituitary cell lines are GH3, AtT-20 and TtT/GF 207. $\mathrm{GH} 3$ cells derive from a Gh secreting rat pituitary adenoma and were established $1968^{208}$. They secrete $\mathrm{G}$ as well as $\mathrm{Prl}$ and express different receptors including oestrogen receptor ${ }^{209}$, thyroid hormone receptor ${ }^{210}$ and somatostatin receptor ${ }^{211}$. AtT20 cells were established 1966 from a murine Acth secreting PA ${ }^{212}$. In 1992, Inoue and colleagues established the murine FSC cell line - TtT/GF - that derived from a thyrotrophic pituitary tumour ${ }^{213}$. TtT/GF cells resemble morphological features and expression of $\mathrm{S} 100$ of FSC and were used for cell migration and invasion studies ${ }^{76,213-}$ 219

Beyond that, also primary pituitary cell culture from human ${ }^{220}$, rat ${ }^{221}$ and murine ${ }^{222}$ PA has been used to investigate pituitary tumour behaviour. In fact, these cells more precisely reflect the physiological status of a PA than immortalized cell lines. Additionally, primary tumours can be used for xenotransplantation. For this purpose the tumour cells are dissociated and afterwards transplanted in the brain or under the skin of immunosuppressed mice ${ }^{223-226}$. With this approach, the proliferation and the invasiveness of the tumour can be investigated in more detail and pharmacotherapeutics can be applied in a physiological-like setting. However, prolonged cultivation of primary cultured cells is often impossible and collection of source material, especially if human samples are requested, is difficult.

Unfortunately, cell lines and primary cultures mostly are restricted to one cell type of a full-blown pituitary tumour. Additionally, immortalized cell lines often encountered genetic changes, i.e. gene mutations or chromosome aberrations ${ }^{227,228}$. Therefore, this system is not necessarily suitable to investigate early tumorigenesis. Moreover, hypothalamic signals and feedback loops from peripheral organs cannot be recreated appropriately in in vitro approaches. Thus, an in vivo model system is more convenient 
to address these obstructions.

There are over 30 animal (predominantly mice) models available to investigate pituitary tumorigenesis. They were generated based on activation of an oncogene or inactivation of a tumour suppressor gene. The targeted genes include both genes that are known to be implicated in the development and progression of human pituitary tumours and genes that are not directly associated to the development of pituitary

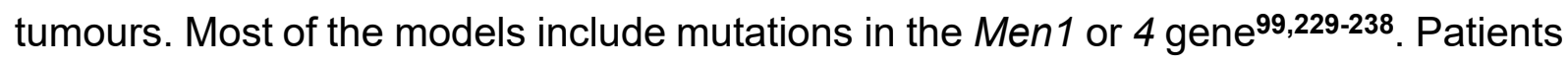
carrying mutations in this gene suffer from different tumours affecting the parathyroid, pancreas and pituitary 239-243. Heterozygous deletion of Men1 in mice results in PA formation with an incidence of $26-45 \%$ whereas homozygous deletion is embryonic lethal ${ }^{99,229,230,233-235,244,245}$. Nevertheless, also mutations in genes that are implicated in regulation of the cell cycle can result in PA or pituitary carcinoma formation [e.g. retinoblastoma $(R b)$, cyclin-dependent kinase inhibitor $2 B(C d k n 2 b)]$. Thus, heterozygous depletion of $R b$ leads to pituitary carcinoma ${ }^{246-248}$ and homozygous $C d k n 2 b$ knockout leads to PA formation ${ }^{249}$. Not only inactivation or loss of specific genes results in PA or carcinoma development but also the overexpression of certain proteins. For example, human pituitary tumours overexpress the pituitary tumour transforming gene (PTTG) which is involved in genome stability ${ }^{250}$. Overexpression of PTTG in murine $\alpha \mathrm{GSU}^{+}$cells causes focal pituitary hyperplasia ${ }^{251}$ whereas inactivation is associated with pituitary hypoplasia ${ }^{252}$. Moreover, cyclin E1 expression in Pomc ${ }^{+}$ cells drives PA growth and increases PA incidence and frequency in mice ${ }^{253}$.

Thus, PA animal models are advantageous to understand tumour formation in this complex organ and they provide a crucial support for the development of novel therapies. However, available animal models have only a prevalence of PA formation of maximum $45 \%$. Therefore, it is essential to develop also new model systems to understand PA formation and maintenance in an improved way. 


\section{Aim of the thesis}

The pituitary gland is the master gland of the body. It regulates a vast majority of body functions and works as a link between the brain and peripheral organs. Although the regulation of hormone release from the gland is strictly regulated, the pituitary has a high incidence to develop tumours that can alter the hormone regulation and thereby can have devastating consequences for the patient. Previous data from our lab showed that the Hh signalling pathway, which plays an important role in adult tissue maintenance and tumour development, is also implicated in pituitary homeostasis and pathology. However, the Hh-regulated cell type and the mechanism of Hh-mediated hormone release in normal and diseased pituitaries was not identified so far.

Thus, the main focus of this thesis was to determine the impact of Hh signalling in the adult pituitary on cellular level and to evaluate if active $\mathrm{Hh}$ signalling might be a potential driver for PA formation.

For this purpose, first tamoxifen-inducible conditional mouse models for activation (Ptch depletion) or inactivation (Smo depletion) of Hh signalling in corticotrophs of the adult pituitary were established. Afterwards it was analysed if the deregulation of the pathway in corticotrophs results in symptoms of hypo- or hypercorticolism and/or PA development.

Secondly, an in vivo Gli1-lineage tracing approach was used to identify the pituitary cell type/s, which descend from Gli1 ${ }^{+}$cells in the normal adult gland. Since Gli1 is the most reliable marker for active Hh signalling the lineage tracing results should be used to determine the cellular population/s that show active $\mathrm{Hh}$ signalling in the adult pituitary. Following, combined RNAScope/immunohistological stainings were used to verify the expression of Gli1 in subpopulations of somatotrophs and FSC of normal adult murine and human pituitaries.

In a third approach, the effect of activated Hh signalling in the murine FSC cell line TtT/GF was investigated. Thereby, transcriptome analyses and medium transfer experiments were applied to determine candidate molecules that might regulate hormone production from endocrine cells in response to Hh signalling activated FSC. 


\section{Materials and Methods}

\subsection{Material}

\subsubsection{Technical equipment}

Table 1 List of used technical equipment

\begin{tabular}{|c|c|}
\hline Technical Equipment & Supplier \\
\hline 3500xL Genetic Analyzer & $\begin{array}{l}\text { Thermo Fisher Scientific Inc., Waltham, MA, } \\
\text { USA }\end{array}$ \\
\hline 7900 HT Fast Real-Time PCR System & Applied Biosystems, Waltham, MA, USA \\
\hline Agarose gel electrophoresis chamber & $\begin{array}{l}\text { Peqlab Biotechnology GmbH, Erlangen, } \\
\text { Germany }\end{array}$ \\
\hline Autoclave (9216E) & Fedegari Autoclavi SpA, Albuzzano, Italy \\
\hline Autoclave (Systec DX-150) & Systec GmbH \& Co. KG, Linden, Germany \\
\hline $\begin{array}{l}\text { Blood Glucose Measurement Device } \\
\text { (Contour XT) }\end{array}$ & Bayer AG, Leverkusen, Germany \\
\hline Centrifuge $(1-15 K)$ & $\begin{array}{l}\text { Sigma Laborzentrifugen } \mathrm{GmbH} \text {, Osterode, } \\
\text { Germany }\end{array}$ \\
\hline Centrifuge (5427 R) & Eppendorf AG, Hamburg, Germany \\
\hline $\begin{array}{l}\text { Centrifuges (Biofuge pico, fresco, primo, } \\
\text { Multifuge 3LR) }\end{array}$ & Heraeus Holding GmbH, Hanau, Germany \\
\hline $\mathrm{CO}_{2}$-Incubator $(6000, \mathrm{BBD}, 6220)$ & $\begin{array}{l}\text { Thermo Fisher Scientific Inc., Waltham, MA, } \\
\text { USA }\end{array}$ \\
\hline $\mathrm{CO}_{2}$-Incubator (CB220-230V-G) & Binder $\mathrm{GmbH}$, Tuttlingen, Germany \\
\hline Cooling plate (EG1150 C) & $\begin{array}{l}\text { Leica Microsystems GmbH, Wetzlar, } \\
\text { Germany }\end{array}$ \\
\hline Cryostat (CM 1900-1-1) & $\begin{array}{l}\text { Leica Microsystems GmbH, Wetzlar, } \\
\text { Germany }\end{array}$ \\
\hline $\begin{array}{l}\text { Digital monochrome thermal video printer } \\
\text { (P91D) }\end{array}$ & Mitsubishi Electric Co., Tokyo, Japan \\
\hline Dispersing tool for homogenizer (DS-8/P) & Miccra GmBH, Heitersheim, Germany \\
\hline Dissection tools & $\begin{array}{l}\text { Karl Hammacher GmbH, Solingen, } \\
\text { Germany }\end{array}$ \\
\hline Fragment Analyzer, & $\begin{array}{l}\text { Agilent Technologies, Santa Clara, CA, } \\
\text { USA }\end{array}$ \\
\hline Freezer $\left(-20^{\circ} \mathrm{C}\right)$ & Liebherr GmbH, Bulle, Switzerland \\
\hline Freezer $\left(-80^{\circ} \mathrm{C}\right)$ & Sanyo Electric Co., Ltd., Osaka, Japan \\
\hline Freezing container (Mr. Frosty ${ }^{\mathrm{TM}}$ ) & $\begin{array}{l}\text { Thermo Fisher Scientific Inc., Waltham, MA, } \\
\text { USA }\end{array}$ \\
\hline Fridge $\left(4^{\circ} \mathrm{C}\right)$ & Robert Bosch GmbH, Stuttgart, Germany \\
\hline Gas burner & Campingaz, Hattersheim, Germany \\
\hline Heating block shaker (ThermoMixer@) & Eppendorf AG, Hamburg, Germany \\
\hline $\begin{array}{l}\text { High-precision scales (Sartorius Basic plus } \\
\text { 2100) }\end{array}$ & Sartorius AG, Göttingen, Germany \\
\hline HiSeq4000 & Illumina, San Diego, CA, USA \\
\hline Homogenizer (Miccra D-1) & Miccra GmBH, Heitersheim, Germany \\
\hline Hybridization oven (HB-1000 Hybridizer) & Analytik Jena US, Upland, CA, USA \\
\hline $\begin{array}{l}\text { Inverted fluorescence microscope (Axiovert } \\
\text { 25) }\end{array}$ & Carl Zeiss GmbH, Jena, Germany \\
\hline Inverted research microscope (IX71) & Olympus Optical Co., Ltd., Tokyo, Japan \\
\hline Liquid nitrogen tank & L'air liquid S.A., Paris, France \\
\hline Magnetic stirrer (MR3000/3001) & $\begin{array}{l}\text { Heidolph Instruments GmbH \& Co. KG, } \\
\text { Schwabach, Germany }\end{array}$ \\
\hline
\end{tabular}




\begin{tabular}{|c|c|}
\hline Technical Equipment & Supplier \\
\hline Microplate reader (SynergyMx) & $\begin{array}{l}\text { BioTek Instruments GmbH, Bad } \\
\text { Friedrichshall, Germany }\end{array}$ \\
\hline Microscope (FV3000) & Olympus Optical Co., Ltd., Tokyo, Japan \\
\hline Microscope (Olympus BX 60) & Olympus Optical Co., Ltd., Tokyo, Japan \\
\hline Microtome (HN 40) & $\begin{array}{l}\text { Leica Microsystems GmbH, Wetzlar, } \\
\text { Germany }\end{array}$ \\
\hline Microwave oven (Dimension 4) & Panasonic Corp., Kadoma, Japan \\
\hline Neon ${ }^{\mathrm{TM}}$ Transfection system & $\begin{array}{l}\text { Thermo Fisher Scientific Inc., Waltham, MA, } \\
\text { USA }\end{array}$ \\
\hline Neubauer counting chamber & Brand GmbH \& Co KG, Wertheim, Germany \\
\hline Paraffin dispenser (PAG12) & $\begin{array}{l}\text { Medite Medizintechnik GmbH, Burgdorf, } \\
\text { Germany }\end{array}$ \\
\hline Paraffin tissue floating bath & $\begin{array}{l}\text { Medax GmbH \& Co. KG, Rendburg, } \\
\text { Germany }\end{array}$ \\
\hline $\begin{array}{l}\text { PCR Thermocycler (Labcycler Basic, } \\
\text { Labcycler Gradient) }\end{array}$ & SensoQuest GmbH, Göttingen, Germany \\
\hline PCR Thermocycler (Mastercycler $\AA)$ & Eppendorf AG, Hamburg, Germany \\
\hline $\begin{array}{l}\text { pH-meter (inoLab, pH Level 1) and } \\
\text { electrode (SenTix 91) }\end{array}$ & WTW, Weilheim, Germany \\
\hline Pipette controller (accu-jet@ pro) & $\begin{array}{l}\text { Brand GmbH \& Co. KG, Wertheim, } \\
\text { Germany }\end{array}$ \\
\hline Pipettes (Multi- and single-channel pipettes) & Eppendorf AG, Hamburg, Germany \\
\hline Platform shaker (Unimax1010) & $\begin{array}{l}\text { Heidolph Instruments GmbH \& Co. KG, } \\
\text { Schwabach, Germany }\end{array}$ \\
\hline $\begin{array}{l}\text { Power supply for agarose gel } \\
\text { electrophoresis }\end{array}$ & $\begin{array}{l}\text { Peqlab Biotechnology GmbH, Erlangen, } \\
\text { Germany }\end{array}$ \\
\hline Power supply for western blot transfer & $\begin{array}{l}\text { Cleaver Scientific Itd., Rugby, United } \\
\text { Kingdom }\end{array}$ \\
\hline Precision weighing balance (ALC-210.4) & Sartorius AG, Göttingen, Germany \\
\hline Spectrophotometer (NanoDrop 8000) & $\begin{array}{l}\text { Thermo Fisher Scientific Inc., Waltham, MA, } \\
\text { USA }\end{array}$ \\
\hline Stereo microscope (Stemi 2000) & Carl Zeiss GmbH, Jena, Germany \\
\hline Sterile workbench (Euroflow EF/A 5) & Clean Air Techniek, Woerden, Netherlands \\
\hline Table centrifuge (Micro Centrifuge SD) & $\begin{array}{l}\text { Carl Roth GmbH \& Co. KG, Karlsruhe, } \\
\text { Germany }\end{array}$ \\
\hline $\begin{array}{l}\text { Tissue embedding and dehydrating } \\
\text { machine (TP 1020) }\end{array}$ & $\begin{array}{l}\text { Leica Microsystems GmbH, Wetzlar, } \\
\text { Germany }\end{array}$ \\
\hline Tissue processor (TP1020) & $\begin{array}{l}\text { Leica Microsystems GmbH, Wetzlar, } \\
\text { Germany }\end{array}$ \\
\hline TruSeq® RNA Sample Preparation v2; & Illumina, San Diego, CA, USA \\
\hline Ultraviolet (UV) light -Transilluminator & $\begin{array}{l}\text { INTAS Science Imaging Instruments } \mathrm{GmbH} \text {, } \\
\text { Göttingen, Germany }\end{array}$ \\
\hline Vacuum pump (EcoVac) & Schuett-biotec GmbH, Göttingen, Germany \\
\hline Vibratome VT1000S & Leica Biosystems, Nußloch, Germany \\
\hline Vortex mixer (Vortex-Genie2®) & Scientific Industries Inc, Bohemia, NY, USA \\
\hline Water bath (1083) & GFL mbH, Burgwedel, Germany \\
\hline Water purification system (Arium® $611 \mathrm{VF}$ ) & Sartorius AG, Göttingen, Germany \\
\hline Western Blot imaging system (Azure c300) & Azure Biosystem, Dublin, CA, USA \\
\hline $\begin{array}{l}\text { Western Blot imaging system } \\
\text { (FluorChem }{ }^{\mathrm{TM}} \mathrm{Q} \text { ) }\end{array}$ & Bio-Techne Corp., Minneapolis, MN, USA \\
\hline $\begin{array}{l}\text { Western Blot transfer system (Trans-Blot }{ }^{\circledR} \\
\text { SD semi-dry electroblotting system) }\end{array}$ & $\begin{array}{l}\text { Bio-Rad Laboratories GmbH, Munich, } \\
\text { Germany }\end{array}$ \\
\hline
\end{tabular}




\subsubsection{Consumables}

Table 2 List of used consumable materials

\begin{tabular}{|c|c|}
\hline Consumable & Supplier \\
\hline 24-well cell culture plate & $\begin{array}{l}\text { Corning Incorporated, New York City, NY, } \\
\text { USA }\end{array}$ \\
\hline 384-well plate black \& adhesive seal sheet & 4titude $®$ Ltd., Surrey, UK \\
\hline 6-well cell culture plate & Sarstedt AG \& Co., Nürnberg, Germany \\
\hline Cell scraper & Sarstedt AG \& Co., Nürnberg, Germany \\
\hline Centrifuge tubes (15 ml, $50 \mathrm{ml}$ ) & $\begin{array}{l}\text { Greiner Bio-One International GmbH, } \\
\text { Kremsmünster, Austria }\end{array}$ \\
\hline $\begin{array}{l}\text { Combitips advanced } 囚(0.2 \mathrm{ml}, 0.5 \mathrm{ml}, 2.5 \\
\mathrm{ml}, 5 \mathrm{ml}, 10 \mathrm{ml})\end{array}$ & Eppendorf AG, Hamburg, Germany \\
\hline Coverslips & $\begin{array}{l}\text { Thermo Fisher Scientific Inc., Waltham, MA, } \\
\text { USA }\end{array}$ \\
\hline Coverslips (round)for cultivation & $\begin{array}{l}\text { TH. Geyer GmbH \& Co. KG, Renningen, } \\
\text { Germany }\end{array}$ \\
\hline CryoPure tubes & Sarstedt AG \& Co., Nürnberg, Germany \\
\hline Delicate task wipes & Kimberly-Clark Europe Ltd., Surrey, UK \\
\hline Disposable cups $(100 \mathrm{ml})$ & Sarstedt AG \& Co., Nürnberg, Germany \\
\hline $\begin{array}{l}\text { Disposable needles (Sterican } \varnothing 0.45 \mathrm{x} \\
12 \mathrm{~mm} \text { or } \varnothing 0.30 \times 12 \mathrm{~mm} \text { ) }\end{array}$ & B.Braun AG, Melsungen, Germany \\
\hline $\begin{array}{l}\text { Disposable syringes (BD DiscarditTM II } 1, \\
2,10,20,50 \mathrm{ml} \text { ) }\end{array}$ & BD Biosciences, San Jose, CA, USA \\
\hline $\begin{array}{l}\text { Filter tips (Biosphere }{ }^{8} 20 \mu \mathrm{l}, 100 \mu \mathrm{l}, 200 \mu \mathrm{l} \text {, } \\
1000 \mu \mathrm{l})\end{array}$ & Sarstedt AG \& Co., Nürnberg, Germany \\
\hline Fluted filters & Sartorius AG, Göttingen, Germany \\
\hline Glass Petri dishes & $\begin{array}{l}\text { TH. Geyer GmbH \& Co. KG, Renningen, } \\
\text { Germany }\end{array}$ \\
\hline Glassware & Schott AG, Mainz, Germany \\
\hline Histoacryl® & B.Braun AG, Melsungen, Germany \\
\hline $\begin{array}{l}\text { Microscope slides \& Superfrost } ® \text { plus } \\
\text { microscope slides }\end{array}$ & $\begin{array}{l}\text { Thermo Fisher Scientific Inc., Waltham, MA, } \\
\text { USA }\end{array}$ \\
\hline $\begin{array}{l}\text { Nitrocellulose membrane (Hybond ECL), } \\
0.2 \mu \mathrm{M} \text { pore size }\end{array}$ & $\begin{array}{l}\text { GE Healthcare Europe GmbH, Freiburg, } \\
\text { Germany }\end{array}$ \\
\hline $\begin{array}{l}\text { Nunclon }^{\mathrm{TM}} \text { disposables for cell culture (10 } \\
\mathrm{cm} \text { cell culture dish, 96-well plate) }\end{array}$ & $\begin{array}{l}\text { Thermo Fisher Scientific Inc., Waltham, MA, } \\
\text { USA }\end{array}$ \\
\hline NuPAGE Novex 4-12 \% Bis-Tris Gel & Invitrogen, Carlsbad, CA, USA \\
\hline Parafilm $®$ laboratory film & Bemis Company, Inc., Neenah, WI, USA \\
\hline Pasteur pipettes & $\begin{array}{l}\text { TH. Geyer GmbH \& Co. KG, Renningen, } \\
\text { Germany }\end{array}$ \\
\hline PCR tear-a-way plates \& cap strips & 4titude $®$ Ltd., Surrey, UK \\
\hline Petri dishes & Ochs $\mathrm{GmbH}$, Bovenden/Lenglern, Germany \\
\hline Pipette tips $(20 \mu \mathrm{l}, 200 \mu \mathrm{l}, 1000 \mu \mathrm{l})$ & Sarstedt AG \& Co., Nürnberg, Germany \\
\hline Reaction tubes $(1.5 \mathrm{ml}, 2 \mathrm{ml}, 5 \mathrm{ml})$ & Sarstedt AG \& Co., Nürnberg, Germany \\
\hline Safeseal microtubes (1.5 ml, $2 \mathrm{ml})$ & Sarstedt AG \& Co., Nürnberg, Germany \\
\hline $\begin{array}{l}\text { Serological pipettes }(2 \mathrm{ml}, 5 \mathrm{ml}, 10 \mathrm{ml} \text {, } \\
25 \mathrm{ml})\end{array}$ & Sarstedt AG \& Co., Nürnberg, Germany \\
\hline Shi-fix ${ }^{\mathrm{TM}}$ coverslips & Everest Biotech, Oxfordshire, UK \\
\hline Softa-Man $®$ hand disinfectant & B.Braun AG, Melsungen, Germany \\
\hline Steel Base Molds & Ted Pella, Inc, Redding, CA, USA \\
\hline Sterile filters $(0.2 \mu \mathrm{m})$ & Sartorius AG, Göttingen, Germany \\
\hline Surgical blades & Aesculap AG, Tuttlingen, Germany \\
\hline Vibratome Blades & Tondeo, Solingen, Germany \\
\hline
\end{tabular}




\begin{tabular}{l|l} 
Consumable & Supplier \\
\hline Weighing paper & $\begin{array}{l}\text { Macherey-Nagel GmbH \& Co. KG, Düren, } \\
\text { Germany }\end{array}$ \\
\hline Whatman® Blotting paper (GB 33 B003) & $\begin{array}{l}\text { Heinemann Labortechnik GmbH, } \\
\text { Duderstadt, Germany }\end{array}$ \\
\hline
\end{tabular}

\subsubsection{Reagents and chemicals}

Table 3 List of used reagents and chemicals

\begin{tabular}{|c|c|}
\hline Reagent or chemical & Supplier \\
\hline 1,4-diazabicyclo[2.2.2]octane & Sigma-Aldrich Co., St. Louis, MO, USA \\
\hline 3-Amino-9-ethylcarbazole (AEC) & Sigma-Aldrich Co., St. Louis, MO, USA \\
\hline $\begin{array}{l}\text { 4-(2-hydroxyethyl)-1- } \\
\text { piperazineethanesulfonic acid (HEPES) }\end{array}$ & Sigma-Aldrich Co., St. Louis, MO, USA \\
\hline Acetic acid & $\begin{array}{l}\text { Carl Roth GmbH \& Co. KG, Karlsruhe, } \\
\text { Germany }\end{array}$ \\
\hline Agarose & $\begin{array}{l}\text { WWR International GmbH, Erlangen, } \\
\text { Germany }\end{array}$ \\
\hline Agarose, low melting & $\begin{array}{l}\text { Carl Roth GmbH \& Co. KG, Karlsruhe, } \\
\text { Germany }\end{array}$ \\
\hline Amphotericin B & Biochrom, Berlin, Germany \\
\hline Ampicillin sodium salt & $\begin{array}{l}\text { Carl Roth GmbH \& Co. KG, Karlsruhe, } \\
\text { Germany }\end{array}$ \\
\hline Ampuwa $\mathrm{H}_{2} \mathrm{O}$ & $\begin{array}{l}\text { Fresenius Kabi Deutschland GmbH, } \\
\text { Germany }\end{array}$ \\
\hline Boric acid & $\begin{array}{l}\text { Carl Roth GmbH \& Co. KG, Karlsruhe, } \\
\text { Germany }\end{array}$ \\
\hline $\begin{array}{l}\text { Bovine serum albumin fraction V (BSA), } \\
\text { protease free }\end{array}$ & $\begin{array}{l}\text { Carl Roth GmbH \& Co. KG, Karlsruhe, } \\
\text { Germany }\end{array}$ \\
\hline Chloroform & $\begin{array}{l}\text { Carl Roth GmbH \& Co. KG, Karlsruhe, } \\
\text { Germany }\end{array}$ \\
\hline Citric acid monohydrate & $\begin{array}{l}\text { Carl Roth GmbH \& Co. KG, Karlsruhe, } \\
\text { Germany }\end{array}$ \\
\hline Cresol red, sodium salt & $\begin{array}{l}\text { Aldrich Chemical Company Inc., Milwaukee, } \\
\text { WI, USA }\end{array}$ \\
\hline Cryoblock embedding medium & $\begin{array}{l}\text { Medite Medizintechnik GmbH, Burgdorf, } \\
\text { Germany }\end{array}$ \\
\hline Deoxyribonucleotide triphosphates (dNTPs) & $\begin{array}{l}\text { Roche Diagnostics GmbH, Mannheim, } \\
\text { Germany }\end{array}$ \\
\hline Dimethylformamide (DMF) & Sigma-Aldrich Co., St. Louis, MO, USA \\
\hline Dimethylsulfoxide (DMSO) & $\begin{array}{l}\text { Thermo Fisher Scientific Inc., Waltham, MA, } \\
\text { USA }\end{array}$ \\
\hline Dithiothreitol (DTT) & $\begin{array}{l}\text { Thermo Fisher Scientific Inc., Waltham, MA, } \\
\text { USA }\end{array}$ \\
\hline RNase-free $\mathrm{H}_{2} \mathrm{O}$ & Invitrogen, Carlsbad, CA, USA \\
\hline Eosin $Y$ & Merck KGaA, Darmstadt, Germany \\
\hline Ethanol $(\mathrm{EtOH}) 99 \%$, denatured & $\begin{array}{l}\text { TH. Geyer GmbH \& Co. KG, Renningen, } \\
\text { Germany }\end{array}$ \\
\hline Ethidium bromide (EtBr) $0.07 \%$ & $\begin{array}{l}\text { Inno-Train Diagnostik GmbH, Kronberg im } \\
\text { Taunus, Germany }\end{array}$ \\
\hline $\begin{array}{l}\text { Ethylenediamine tetraacetic acid (EDTA) } \\
\text { disodium salt dihydrate }\end{array}$ & $\begin{array}{l}\text { Carl Roth GmbH \& Co. KG, Karlsruhe, } \\
\text { Germany }\end{array}$ \\
\hline
\end{tabular}




\begin{tabular}{|c|c|}
\hline Reagent or chemical & Supplier \\
\hline $\begin{array}{l}\text { GeneRuler DNA ladder ( } 50 \text { base pairs (bp), } \\
100 \text { bp plus, } 1 \text { kilobase }(k b))\end{array}$ & $\begin{array}{l}\text { Thermo Fisher Scientific Inc., Waltham, MA, } \\
\text { USA }\end{array}$ \\
\hline Glutaraldehyde & Sigma-Aldrich Co., St. Louis, MO, USA \\
\hline Glycergel mounting medium & $\begin{array}{l}\text { Dako North America Inc., Carpinteria, CA, } \\
\text { USA }\end{array}$ \\
\hline Haematoxylin crystalline, Mayer's & Merck KGaA, Darmstadt, Germany \\
\hline Hydrochloric acid (37 \%) & $\begin{array}{l}\text { Carl Roth GmbH \& Co. KG, Karlsruhe, } \\
\text { Germany }\end{array}$ \\
\hline Hydrogen peroxide $\left(\mathrm{H}_{2} \mathrm{O}_{2}\right)(35 \%)$ & $\begin{array}{l}\text { Carl Roth GmbH \& Co. KG, Karlsruhe, } \\
\text { Germany }\end{array}$ \\
\hline $\begin{array}{l}\text { Immersion oil for microscopy (Immersion }{ }^{\mathrm{TM}} \\
518 \mathrm{~N} \text { ) }\end{array}$ & Carl Zeiss GmbH, Jena, Germany \\
\hline Isoflurane (FORENE) & $\begin{array}{l}\text { Abbott Laboratories Inc, Santa Clara, CA, } \\
\text { USA }\end{array}$ \\
\hline Isopropanol & $\begin{array}{l}\text { Carl Roth GmbH \& Co. KG, Karlsruhe, } \\
\text { Germany }\end{array}$ \\
\hline Kanamycin A & Sigma-Aldrich Co., St. Louis, MO, USA \\
\hline Liquid barrier marker & $\begin{array}{l}\text { Carl Roth GmbH \& Co. KG, Karlsruhe, } \\
\text { Germany }\end{array}$ \\
\hline Loading dye solution for DNA (6 x) & $\begin{array}{l}\text { Thermo Fisher Scientific Inc., Waltham, MA, } \\
\text { USA }\end{array}$ \\
\hline Methanol (MeOH) & $\begin{array}{l}\text { Carl Roth GmbH \& Co. KG, Karlsruhe, } \\
\text { Germany }\end{array}$ \\
\hline Mowiol 4-88 & Sigma-Aldrich Co., St. Louis, MO, USA \\
\hline NuPAGE MES SDS running buffer, $20 \mathrm{x}$ & Invitrogen, Carlsbad, CA, USA \\
\hline Paraformaldehyde (PFA) & $\begin{array}{l}\text { Carl Roth GmbH \& Co. KG, Karlsruhe, } \\
\text { Germany }\end{array}$ \\
\hline Pertex mounting medium & $\begin{array}{l}\text { Medite Medizintechnik GmbH, Burgdorf, } \\
\text { Germany }\end{array}$ \\
\hline $\begin{array}{l}\text { Phosphatase inhibitor cocktail Tab.ts } \\
\text { (PhosSTOP) }\end{array}$ & $\begin{array}{l}\text { Roche Diagnostics GmbH, Mannheim, } \\
\text { Germany }\end{array}$ \\
\hline Phosphate buffered saline (PBS) Tab.ts & Invitrogen, Carlsbad, CA, USA \\
\hline $\begin{array}{l}\text { Poly-L-Lysine hydrobromide (MW 30,000 - } \\
70,000) \text { (PLL) }\end{array}$ & Sigma-Aldrich Co., St. Louis, MO, USA \\
\hline Powdered milk & $\begin{array}{l}\text { Carl Roth GmbH \& Co. KG, Karlsruhe, } \\
\text { Germany }\end{array}$ \\
\hline $\begin{array}{l}\text { Primer "random" } \mathrm{p}(\mathrm{dN}) 6 \text { Hexamer- } \\
\text { oligonucleotides }\end{array}$ & $\begin{array}{l}\text { Roche Diagnostics GmbH, Mannheim, } \\
\text { Germany }\end{array}$ \\
\hline $\begin{array}{l}\text { ProLong Gold antifade mountant with 4',6- } \\
\text { diamidino-2-phenylindole (DAPI) }\end{array}$ & $\begin{array}{l}\text { Thermo Fisher Scientific Inc., Waltham, MA, } \\
\text { USA }\end{array}$ \\
\hline Protease inhibitor cocktail (cOmplete Mini) & $\begin{array}{l}\text { Roche Diagnostics GmbH, Mannheim, } \\
\text { Germany }\end{array}$ \\
\hline RNA-pure EtOH $99 \%$ & J.T. Baker B.V., Deventer, Netherlands \\
\hline RNaseZAP & Sigma-Aldrich Co., St. Louis, MO, USA \\
\hline $\begin{array}{l}\text { S.O.C. (Super optimal broth with catabolite } \\
\text { repression) medium }\end{array}$ & Invitrogen, Carlsbad, CA, USA \\
\hline $\begin{array}{l}\text { SeeBlue Plus2 Pre-Stained Protein } \\
\text { Standard }\end{array}$ & Invitrogen, Carlsbad, CA, USA \\
\hline Smoothened Agonist (SAG) & Cayman Chemical, Ann Arbour, MI, USA \\
\hline Sodium chloride & AppliChem GmbH, Darmstadt, Germany \\
\hline Sodium hydroxide & $\begin{array}{l}\text { Carl Roth GmbH \& Co. KG, Karlsruhe, } \\
\text { Germany }\end{array}$ \\
\hline Sodiumdodecylsulfate (SDS) & AppliChem GmbH, Darmstadt, Germany \\
\hline Tamoxifen & Sigma-Aldrich Co., St. Louis, MO, USA \\
\hline
\end{tabular}




\begin{tabular}{|c|c|}
\hline Reagent or chemical & Supplier \\
\hline $\begin{array}{l}\text { Tris(hydroxymethyl)aminomethane (TRIS) } \\
\text { base }\end{array}$ & AppliChem GmbH, Darmstadt, Germany \\
\hline Triton $^{\mathrm{TM}} \mathrm{X}-100$ & Sigma-Aldrich Co., St. Louis, MO, USA \\
\hline Tropix® I-BLOCK ${ }^{\mathrm{TM}}$ & Applied Biosystems, Waltham, MA, USA \\
\hline Tryptone (peptone ex casein) & $\begin{array}{l}\text { Carl Roth GmbH \& Co. KG, Karlsruhe, } \\
\text { Germany }\end{array}$ \\
\hline TWEEN® 20 & Sigma-Aldrich Co., St. Louis, MO, USA \\
\hline Vismodegib (GDC-0449) & Selleckchem, Munich, Germany \\
\hline $\begin{array}{l}\text { X-Gal (5-bromo-4-chloro-3-indolyl- } \beta-D- \\
\text { galactopyranoside) }\end{array}$ & $\begin{array}{l}\text { Carl Roth GmbH \& Co. KG, Karlsruhe, } \\
\text { Germany }\end{array}$ \\
\hline Xylene & J.T. Baker B.V., Deventer, Netherlands \\
\hline Yeast extract & $\begin{array}{l}\text { Carl Roth GmbH \& Co. KG, Karlsruhe, } \\
\text { Germany }\end{array}$ \\
\hline $\begin{array}{l}\beta \text {-Ala-Lys-Ne-amino-4-methylcoumarin-3- } \\
\text { acetic acid ( } \beta \text {-Ala-Lys- } N(\varepsilon) \text {-AMCA) }\end{array}$ & Carbosynth, Berkshire, UK \\
\hline
\end{tabular}

\subsubsection{Buffers and solutions}

Table 4 Utilized buffers and solutions and their composition

\begin{tabular}{|c|c|}
\hline Buffer/Solution & Composition \\
\hline $6 \times$ SDS loading buffer & $\begin{array}{l}375 \mathrm{mM} \text { Tris, } \mathrm{pH} 6.8 \\
12 \%(\mathrm{w} / \mathrm{v}) \text { SDS } \\
60 \%(\mathrm{v} / \mathrm{v}) \text { Glycerol } \\
0.6 \mathrm{M} \mathrm{DTT} \\
0.01 \%(\mathrm{w} / \mathrm{v}) \text { Bromophenol blue }\end{array}$ \\
\hline $\begin{array}{l}10 \times \text { PBS } \\
\mathrm{pH} 7.4\end{array}$ & $\begin{array}{l}1.4 \mathrm{M} \mathrm{NaCl} \\
65 \mathrm{mM} \mathrm{Na}_{2} \mathrm{HPO}_{4} \\
27 \mathrm{mM} \mathrm{KCl} \\
15 \mathrm{mM} \mathrm{KH}_{2} \mathrm{PO}_{4}\end{array}$ \\
\hline $\begin{array}{l}10 \times \text { Tris-boric acid-EDTA solution (TBE) } \\
\text { pH } 8.0\end{array}$ & $\begin{array}{l}890 \mathrm{mM} \text { Tris/ } \mathrm{HCl}, \mathrm{pH} 8.0 \\
730 \mathrm{mM} \text { boric acid } \\
12.5 \mathrm{mM} \text { EDTA }\end{array}$ \\
\hline $\begin{array}{l}10 \times \text { Tris-buffered saline (TBS) } \\
\mathrm{pH} 7.4\end{array}$ & $\begin{array}{l}150 \mathrm{mM} \mathrm{NaCl} \\
10 \mathrm{mM} \text { Tris/HCl, } \mathrm{pH} 8.0\end{array}$ \\
\hline $\begin{array}{l}\text { AEC chromogen } \\
\text { pH } 5.2\end{array}$ & $\begin{array}{l}70 \mathrm{mM} \text { Sodium acetate trihydrate } \\
30 \mathrm{mM} \text { Acetic acid } \\
16 \mathrm{mM} \text { 3-Amino-9 Ethylcarbazole } \\
\text { Dissolved in DMF }\end{array}$ \\
\hline blocking buffer & $\begin{array}{l}5 \% \text { milk powder } \\
\text { Dissolved in } 1 \times \text { TBS-Tween }\end{array}$ \\
\hline Blotting buffer for semi-dry blotting & $\begin{array}{l}50 \mathrm{mM} \text { Tris } \\
40 \mathrm{mM} \text { Glycine } \\
20 \%(\mathrm{v} / \mathrm{v}) \text { Methanol } \\
0.0325 \%(\mathrm{w} / \mathrm{v}) \text { SDS }\end{array}$ \\
\hline BSA-azide & $\begin{array}{l}3 \mathrm{mM} \text { Sodium azide } \\
2 \%(\mathrm{w} / \mathrm{v}) \mathrm{BSA} \\
\text { Dissolved in PBST }\end{array}$ \\
\hline IHC-Block & $\begin{array}{l}0.2 \%(w / v) \text { I-Block } \\
\text { Dissolved in } 1 \times \text { TBS }\end{array}$ \\
\hline $\begin{array}{l}\text { Citric acid buffer } \\
\mathrm{pH} 3.0 \text { or } \mathrm{pH} 6.0\end{array}$ & 10 mM Sodium Citrate \\
\hline
\end{tabular}




\begin{tabular}{|c|c|}
\hline Buffer/Solution & Composition \\
\hline Cresol & $\begin{array}{l}0.1 \%(\mathrm{w} / \mathrm{v}) \text { Cresol red } \\
\text { Dissolved in saturated sucrose-solution }\end{array}$ \\
\hline dNTP-Mix & $\begin{array}{l}10 \mathrm{mM} \text { dATP } \\
10 \mathrm{mM} \text { dCTP } \\
10 \mathrm{mM} \text { dGTP } \\
10 \mathrm{mM} \text { dTTP } \\
\end{array}$ \\
\hline Eosin solution & $\begin{array}{l}80 \%(v / v) \text { EtOH } \\
1 \%(w / v) \text { Eosin y (water soluble) }\end{array}$ \\
\hline Haematoxylin solution, Mayer's & $\begin{array}{l}300 \mathrm{mM} \text { Trichloro acetaldehyde hydrate } \\
100 \mathrm{mM} \text { Potassium aluminum sulfate } \\
50 \mathrm{mM} \text { Citric acid } \\
35 \mathrm{mM} \text { Haematoxylin } \\
75 \mathrm{nM} \text { Sodium iodate }\end{array}$ \\
\hline $\begin{array}{l}\text { Lysis buffer } \\
\mathrm{pH} 8.8\end{array}$ & $\begin{array}{l}150 \mathrm{mM} \mathrm{NaCl} \\
30 \mathrm{mM} \text { Tris/HCl, } \mathrm{pH} 7.5 \\
10 \%(\mathrm{v} / \mathrm{v}) \mathrm{Glycerol} \\
1 \%(\mathrm{v} / \mathrm{v}) \text { Triton } \mathrm{X}-100 \\
1 \mathrm{Tab} . \mathrm{t} / 10 \mathrm{ml} \text { phosphatase inhibitor and } \\
\text { protease inhibitor } \\
\text { added before use: } 2 \mathrm{mM} \text { DTT, } \\
500 \mu \mathrm{M} \text { Phenylmethanesulfonylfluoride }\end{array}$ \\
\hline $\begin{array}{l}\text { Modified radioimmunoprecipitation assay } \\
\text { buffer (RIPA) }\end{array}$ & $\begin{array}{l}50 \mathrm{nM} \text { Tris/HCl, } \mathrm{pH} 7.4 \\
1 \%(\mathrm{v} / \mathrm{v}) \mathrm{NP}-40 \\
0.25 \%(\mathrm{v} / \mathrm{v}) \mathrm{Na}-\mathrm{Deoxycholat} \\
150 \mathrm{mM} \mathrm{NaCl} \\
1 \mathrm{mM} \text { EDTA } \\
1 \mathrm{Tab} . \mathrm{t} / 10 \mathrm{ml} \text { phosphatase inhibitor and } \\
\text { protease inhibitor }\end{array}$ \\
\hline Mowiol Mounting Medium & $\begin{array}{l}\text { 4,3 mM Mowiol 4-88 } \\
\text { 3016,24 mM Glycerol } \\
\text { 18502,811 } \mathrm{mM} \mathrm{H}_{2} \mathrm{O} \\
133 \mathrm{mM} \text { Tris pH } 8.5 \\
\text { 34,05 mM 1,4-diazabicyclo[2.2.2]octane }\end{array}$ \\
\hline Paraformaldehyde $4 \%$ & $\begin{array}{l}4 \%(w / v) \text { Paraformaldehyde } \\
\text { Dissolved in PBS }\end{array}$ \\
\hline PBS-Tween 20 (PBS-T) & $\begin{array}{l}0.1 \%(v / v) \text { Tween-20 } \\
\text { Dissolved in PBS }\end{array}$ \\
\hline $\begin{array}{l}\text { Proteinase K } \\
\mathrm{pH} 8.0\end{array}$ & $\begin{array}{l}50 \mathrm{mM} \text { Tris/ } \mathrm{HCl} \\
5 \mathrm{mM} \text { EDTA } \\
10 \mathrm{mg} / \mathrm{ml} \text { Proteinase } \mathrm{K}\end{array}$ \\
\hline Sodium Chloride-Tris-EDTA (STE) buffer & $\begin{array}{l}100 \mathrm{mM} \mathrm{NaCl} \\
50 \mathrm{mM} \mathrm{Tris} / \mathrm{HCl} \\
1 \mathrm{mM} \text { EDTA } \\
1 \%(\mathrm{w} / \mathrm{v}) \mathrm{SDS} \\
\end{array}$ \\
\hline TBS-Triton X-100 & $\begin{array}{l}0.1 \%(\mathrm{v} / \mathrm{v}) \text { Triton } \mathrm{X}-100 \\
\text { Dissolved in TBS }\end{array}$ \\
\hline TBS-Tween 20 (TBS-T) & $\begin{array}{l}0.5 \%(v / v) \text { Tween-20 } \\
\text { Dissolved in TBS }\end{array}$ \\
\hline $\begin{array}{l}\text { Tris-EDTA (TE) buffer } \\
\mathrm{pH} 8.0\end{array}$ & $\begin{array}{l}10 \mathrm{mM} \text { Tris } \\
1 \mathrm{mM} \text { EDTA }\end{array}$ \\
\hline $\begin{array}{l}\text { Tris-EDTA (TE) buffer for mouse oocytes } \\
\text { pH } 7.4\end{array}$ & $\begin{array}{l}5 \mathrm{mM} \text { Tris } \\
0.1 \mathrm{mM} \text { EDTA } \\
\text { steril-filtrated }\end{array}$ \\
\hline
\end{tabular}




\begin{tabular}{|c|c|}
\hline Buffer/Solution & Composition \\
\hline X-Gal stock solution & $\begin{array}{l}4 \%(w / v) X-G a l \\
\text { Dissolved in DMF }\end{array}$ \\
\hline $\begin{array}{l}\text { Hank's Balanced Salt Solution (HBSS) } \\
\mathrm{pH} 7.4\end{array}$ & $\begin{array}{l}0,952 \mathrm{mM} \mathrm{CaCl}_{2} \bullet 2 \mathrm{H}_{2} \mathrm{O} \\
5,36 \mathrm{mM} \mathrm{KCl} \\
0,411 \mathrm{mM} \mathrm{KH}_{2} \mathrm{PO}_{4} \\
0,812 \mathrm{mM} \mathrm{MgSO}_{4} \bullet 7 \mathrm{H}_{2} \mathrm{O} \\
136,7 \mathrm{mM} \mathrm{NaCl} \\
0,385 \mathrm{mM} \mathrm{Na}_{2} \mathrm{HPO}_{4} \\
25 \mathrm{mM} \mathrm{D-Glucose} \bullet \mathrm{H}_{2} \mathrm{O} \\
10 \mathrm{mM} \mathrm{HEPES}\end{array}$ \\
\hline $\begin{array}{l}\text { HEPES Dissociation buffer (HDB) } \\
\text { pH } 7.3\end{array}$ & $\begin{array}{l}25 \mathrm{mM} \mathrm{HEPES} \\
137 \mathrm{mM} \mathrm{NaCl} \\
5 \mathrm{mM} \mathrm{KCl} \\
0.7 \mathrm{mM} \mathrm{Na}_{2} \mathrm{HPO}_{4} \\
10 \mathrm{mM} \mathrm{Glucose} \\
1250 \mu \mathrm{g} / \mathrm{l} \text { Amphotericin B } \\
10^{5} \text { units/l Penicillin/Streptomycin }\end{array}$ \\
\hline
\end{tabular}

\subsubsection{Kits and ready-to-use reaction systems}

Table 5 List of kits and ready-to-use reaction systems

\begin{tabular}{|c|c|}
\hline Reaction system & Supplier \\
\hline $\begin{array}{l}\text { Amersham enhanced chemiluminescence } \\
(E C L) \text { western blotting detection reagents }\end{array}$ & $\begin{array}{l}\text { GE Healthcare Europe GmbH, Freiburg, } \\
\text { Germany }\end{array}$ \\
\hline $\begin{array}{l}\text { BigDyeTM Terminator v3.1 Cycle } \\
\text { Sequencing Kit }\end{array}$ & $\begin{array}{l}\text { Thermo Fisher Scientific Inc., Waltham, MA, } \\
\text { USA }\end{array}$ \\
\hline $\begin{array}{l}\text { Dako REAL }{ }^{\mathrm{TM}} \text { EnVision }{ }^{\mathrm{TM}} \text { detection system, } \\
\text { Rabbit/Mouse }\end{array}$ & $\begin{array}{l}\text { Dako North America Inc., Carpinteria, CA, } \\
\text { USA }\end{array}$ \\
\hline Dual-Luciferase ${ }^{\circledR}$ Reporter assay system & Promega $\mathrm{GmbH}$, Mannheim, Germany \\
\hline NEON Transfection kit & $\begin{array}{l}\text { Thermo Fisher Scientific Inc., Waltham, MA, } \\
\text { USA }\end{array}$ \\
\hline PCR clean-up Gel extraction Kit & Macherey-Nagel, Düren, Germany \\
\hline Pierce BCA Protein assay kit & $\begin{array}{l}\text { Thermo Fisher Scientific Inc., Waltham, MA, } \\
\text { USA }\end{array}$ \\
\hline $\begin{array}{l}\text { Platinum }^{\mathrm{TM}} \text { SYBR }{ }^{\mathrm{TM}} \text { Green } \mathrm{qPCR} \\
\text { SuperMix-UDG w/ROX }\end{array}$ & Invitrogen, Carlsbad, CA, USA \\
\hline PureLink®HiPure Plasmid Midiprep Kit & Invitrogen, Carlsbad, CA, USA \\
\hline QIAamp DNA FFPE Tissue Kit & Qiagen $\mathrm{GmbH}$, Hilden, Germany \\
\hline QuantiTect SYBR® Green RT-PCR Kit & Qiagen $\mathrm{GmbH}$, Hilden, Germany \\
\hline $\begin{array}{l}\text { RevertAid }{ }^{\mathrm{M}} \mathrm{H} \text { Minus First Strand cDNA } \\
\text { Synthesis Kit }\end{array}$ & $\begin{array}{l}\text { Thermo Fisher Scientific Inc., Waltham, MA, } \\
\text { USA }\end{array}$ \\
\hline TRIzol@ Reagent & Life Technologies Co., Camarillo, CA, USA \\
\hline $\begin{array}{l}\text { Mouse Adrenocorticottropic Hormone (Acth) } \\
\text { ELISA Kit }\end{array}$ & $\begin{array}{l}\text { Biomatik Corporation, Cambridge, Ontario, } \\
\text { Canada }\end{array}$ \\
\hline RNAscope 2.5 HD Assay & $\begin{array}{l}\text { Advanced Cell Diagnostics, Newark, CA, } \\
\text { USA }\end{array}$ \\
\hline $\begin{array}{l}\text { Vip Chemiluminescent enzyme } \\
\text { immunoassay Kit }\end{array}$ & $\begin{array}{l}\text { Phoenix Pharmaceuticals, Inc, Burlingame, } \\
\text { CA, USA }\end{array}$ \\
\hline
\end{tabular}




\subsubsection{Enzymes}

Table 6 List of used restriction enzymes

\begin{tabular}{l|l} 
Restriction enzyme & Supplier \\
\hline Apal & New England Biolabs, Ipswich, MA, USA \\
\hline BamHl & New England Biolabs, Ipswich, MA, USA \\
\hline Bpml & New England Biolabs, Ipswich, MA, USA \\
\hline Eagl & New England Biolabs, Ipswich, MA, USA \\
\hline EcoRI & New England Biolabs, Ipswich, MA, USA \\
\hline EcoRV & New England Biolabs, Ipswich, MA, USA \\
\hline HindlII & New England Biolabs, Ipswich, MA, USA \\
\hline$H p a l$ & New England Biolabs, Ipswich, MA, USA \\
\hline Kpnl & New England Biolabs, Ipswich, MA, USA \\
\hline$M f e l$ & New England Biolabs, Ipswich, MA, USA \\
\hline Ncol & New England Biolabs, Ipswich, MA, USA \\
\hline Nhel & New England Biolabs, Ipswich, MA, USA \\
\hline Notl & New England Biolabs, Ipswich, MA, USA \\
\hline Psil & New England Biolabs, Ipswich, MA, USA \\
\hline PspOMl & New England Biolabs, Ipswich, MA, USA \\
\hline Sacl & New England Biolabs, Ipswich, MA, USA \\
\hline Sall & New England Biolabs, Ipswich, MA, USA \\
\hline Sspl & New England Biolabs, Ipswich, MA, USA \\
\hline &
\end{tabular}

Table 7 List of enzymes

\begin{tabular}{l|l} 
Enzyme & Supplier \\
\hline Proteinase K & $\begin{array}{l}\text { Carl Roth GmbH \& Co. KG, Karlsruhe, } \\
\text { Germany }\end{array}$ \\
\hline Q5 DNA Polymerase & New England Biolabs, Ipswich, MA, USA \\
\hline RNase A & $\begin{array}{l}\text { Carl Roth GmbH \& Co. KG, Karlsruhe, } \\
\text { Germany }\end{array}$ \\
\hline SuperScript ${ }^{\text {TM }}$ II Reverse Transcriptase & $\begin{array}{l}\text { Thermo Fisher Scientific Inc., Waltham, MA, } \\
\text { USA }\end{array}$ \\
\hline T4 DNA ligase & New England Biolabs, Ipswich, MA, USA \\
\hline Thermus aquaticus-Polymerase (MolTaq) & $\begin{array}{l}\text { Molzym GmbH \& Co. KG, Bremen, } \\
\text { Germany }\end{array}$ \\
\hline
\end{tabular}




\subsubsection{Plasmids}

Table 8 Used and generated plasmids

\begin{tabular}{|c|c|c|c|}
\hline Plasmid & Description & $\begin{array}{l}\text { Selection } \\
\text { Antibiotic }\end{array}$ & $\begin{array}{l}\text { Supplier or } \\
\text { Reference }\end{array}$ \\
\hline$\alpha G S U . P T T G$ & $\begin{array}{l}\text { Expression of cDNA of human } \\
\text { PTTG under the control of the } \\
\alpha G S U \text { promoter }\end{array}$ & Kanamycin & 251 \\
\hline pBluescript II SK (+) & $\begin{array}{l}\text { High copy plasmid, that enables } \\
\text { blue/white screening of bacterial } \\
\text { colonies }\end{array}$ & Ampicillin & \begin{tabular}{|l} 
Stratagene, \\
San Diego, \\
CA, USA \\
\end{tabular} \\
\hline $\begin{array}{l}\text { pBluescript_hGHRHR(- } \\
\text { 2207,-19)_CreERT2 }\end{array}$ & $\begin{array}{l}\text { Expression of a tamoxifen } \\
\text { inducible Cre-recombinase } \\
\text { (CreERT2) under the control of } \\
2188 \text { bp of the human Growth } \\
\text { hormone realising hormone } \\
\text { receptor (hGHRHR) promoter }\end{array}$ & Ampicillin & $\begin{array}{l}\text { Generated } \\
\text { in this work }\end{array}$ \\
\hline $\begin{array}{l}\text { pBluescript_hGHRHR(- } \\
\text { 2207,-19)_CreERT2 } \\
\text { _IRES_EGFP }\end{array}$ & $\begin{array}{l}\text { Expression of a CreERT2 and } \\
\text { enhanced green fluorescent } \\
\text { protein (EGFP) under the control } \\
\text { of } 2188 \text { bp of the } h G H R H R \\
\text { promoter }\end{array}$ & Ampicillin & $\begin{array}{l}\text { Generated } \\
\text { in this work }\end{array}$ \\
\hline $\begin{array}{l}\text { pBluescript_hGHRHR(- } \\
2207,-19) \_E G F P\end{array}$ & $\begin{array}{l}\text { Expression of EGFP under the } \\
\text { control of } 2188 \text { bp of the } \\
h G H R H R \text { promoter }\end{array}$ & Ampicillin & $\begin{array}{l}\text { Generated } \\
\text { in this work }\end{array}$ \\
\hline $\begin{array}{l}\text { pBluescript_hGHRHR(- } \\
\text { 310,-19)_CreERT2 }\end{array}$ & $\begin{array}{l}\text { Expression of a CreERT2 under } \\
\text { the control of } 291 \mathrm{bp} \text { of the } \\
\text { hGHRHR promoter }\end{array}$ & Ampicillin & $\begin{array}{l}\text { Generated } \\
\text { in this work }\end{array}$ \\
\hline $\begin{array}{l}\text { pBluescript_hGHRHR(- } \\
\text { 310,-19)_CreERT2 } \\
\text { IRES_EGFP }\end{array}$ & $\begin{array}{l}\text { Expression of a CreERT2 and } \\
\text { EGFP under the control of } 291 \mathrm{bp} \\
\text { of the } h G H R H R \text { promoter }\end{array}$ & Ampicillin & $\begin{array}{l}\text { Generated } \\
\text { in this work }\end{array}$ \\
\hline $\begin{array}{l}\text { pBluescript_hGHRHR(- } \\
\text { 310,-19)_EGFP }\end{array}$ & $\begin{array}{l}\text { Expression of EGFP under the } \\
\text { control of } 291 \text { bp of the } h G H R H R \\
\text { promoter }\end{array}$ & Ampicillin & $\begin{array}{l}\text { Generated } \\
\text { in this work }\end{array}$ \\
\hline $\begin{array}{l}\text { pBluescript_mGhrhr_Cre } \\
\text { ERT2 }\end{array}$ & $\begin{array}{l}\text { Expression of a CreERT2 under } \\
\text { the control of the murine Growth } \\
\text { hormone realising hormone } \\
\text { receptor ( } m G h r h r) \text { promoter }\end{array}$ & Ampicillin & $\begin{array}{l}\text { Generated } \\
\text { in this work }\end{array}$ \\
\hline $\begin{array}{l}\text { pBluescript_mGhrhr_EG } \\
\text { FP }\end{array}$ & $\begin{array}{l}\text { Expression of EGFP under the } \\
\text { control of the } m G h r h r \text { promoter }\end{array}$ & Ampicillin & \begin{tabular}{|l|} 
Generated \\
in this work \\
\end{tabular} \\
\hline pBluescript_mT_mG & $\begin{array}{l}\text { Expression of floxed membrane } \\
\text { tagged tdTomato (mT) and } \\
\text { membrane tagged EGFP (mG) } \\
\text { under the control of a } \\
\text { cytomegalovirus early enhancer } \\
\text { element, first exon and intron of } \\
\text { chicken beta-actin gene, splice } \\
\text { acceptor of rabbit beta-globin } \\
\text { gene (CAG) promoter }\end{array}$ & Ampicillin & $\begin{array}{l}\text { Generated } \\
\text { in this work }\end{array}$ \\
\hline $\begin{array}{l}\text { pBluescript_rGhrhr_CreE } \\
\text { RT2 }\end{array}$ & $\begin{array}{l}\text { Expression of a CreERT2 under } \\
\text { the control of the rat Growth } \\
\text { hormone realising hormone } \\
\text { receptor ( } r \text { Ghrhr) promoter }\end{array}$ & Ampicillin & $\begin{array}{l}\text { Generated } \\
\text { in this work }\end{array}$ \\
\hline
\end{tabular}




\begin{tabular}{|c|c|c|c|}
\hline Plasmid & Description & $\begin{array}{l}\text { Selection } \\
\text { Antibiotic }\end{array}$ & $\begin{array}{l}\text { Supplier or } \\
\text { Reference }\end{array}$ \\
\hline $\begin{array}{l}\text { pBluescript_rGhrhr_EGF } \\
P\end{array}$ & $\begin{array}{l}\text { Expression of EGFP under the } \\
\text { control of the } r G h r h r \text { promoter }\end{array}$ & Ampicillin & $\begin{array}{l}\text { Generated } \\
\text { in this work }\end{array}$ \\
\hline $\begin{array}{l}\text { pCAG_CreERT2_IRES_ } \\
E G F P\end{array}$ & $\begin{array}{l}\text { Expression of a CreERT2 and the } \\
\text { EGFP gene under the control of a } \\
\text { CAG promoter }\end{array}$ & Kanamycin & $\begin{array}{l}\text { Generated } \\
\text { in this work }\end{array}$ \\
\hline$p E G F P-N 1$ & $\begin{array}{l}\text { Expression of EGFP under the } \\
\text { control of a CAG promoter }\end{array}$ & Kanamycin & $\begin{array}{l}\text { BD } \\
\text { Bioscience } \\
\text { Clontech, } \\
\text { Heidelberg, } \\
\text { Germany }\end{array}$ \\
\hline pIRES_EGFP & $\begin{array}{l}\text { Harbours an internal ribosomal } \\
\text { entry side (IRES) and an EGFP } \\
\text { gene under the control of a CAG } \\
\text { promoter }\end{array}$ & Kanamycin & $\begin{array}{l}\text { Clontech, } \\
\text { Mountain } \\
\text { View, CA, } \\
\text { USA }\end{array}$ \\
\hline pMC Cre & $\begin{array}{l}\text { Expression vector for a Cre- } \\
\text { recombinase under the control of } \\
\text { a thymidine kinase }(T K) \text { promoter }\end{array}$ & Ampicillin & 254 \\
\hline pmGli1_IRES_EGFP & $\begin{array}{l}\text { Expression of murine Gli1 and } \\
\text { EGFP under the control of a CAG } \\
\text { promoter }\end{array}$ & Kanamycin & $\begin{array}{l}\text { Generated } \\
\text { in this work }\end{array}$ \\
\hline $\operatorname{Ptch}^{f}$ & $\begin{array}{l}\text { Encoding parts of the murine Ptch } \\
\text { gene with loxP sites flanking } \\
\text { exon } 8 \text { and } 9\end{array}$ & Ampicillin & 157 \\
\hline Rosa26 mT_mG & $\begin{array}{l}\text { Reporter expression plasmid } \\
\text { harbouring floxed } m T \text { and } m G \\
\text { genes with homologous sequence } \\
\text { of the murine ROSA26 locus }\end{array}$ & Kanamycin & 255 \\
\hline Tg.PCE & $\begin{array}{l}\text { Expression of cyclin E1 under the } \\
\text { control of the Pomc promoter }\end{array}$ & Ampicillin & 253 \\
\hline
\end{tabular}

\subsubsection{Antibodies}

\subsubsection{Primary Antibodies}

Table 9 List of primary antibodies used for this work

\begin{tabular}{l|l|l|l} 
Antigen & Company & $\begin{array}{l}\text { Host } \\
\text { species }\end{array}$ & $\begin{array}{l}\text { Method } \\
\text { (conc.) }\end{array}$ \\
\hline Acetylated tubulin & Sigma-Aldrich Co., St. Louis, MO, USA & Mouse & $\begin{array}{l}\text { ICC }(1: 100) \\
\text { IHC }(1: 100)\end{array}$ \\
\hline Acth & $\begin{array}{l}\text { National Hormone \& Pituitary Program, } \\
\text { Torrance, CA, USA }\end{array}$ & Rabbit & $\begin{array}{l}\text { ICC }(1: 1000) \\
\text { IHC }(1: 1000) \\
\text { WB }(1: 5000)\end{array}$ \\
\hline Alpha tubulin & Dianova, Hamburg, Germany & Mouse & WB (1:10000) \\
\hline Cre-recombinase & Covance, Princeton, NJ, USA & Rabbit & WB (1:1000) \\
\hline Cyclin E1 & Dianova, Hamburg, Germany & Rabbit & WB (1:500) \\
\hline GFAP & Abcam, Cambrige, UK & Rabbit & IHC $(1: 500)$ \\
\hline GFP & NovusBio, Littleton, CO, USA & Goat & IHC (1:1000) \\
\hline GFP & $\begin{array}{l}\text { Rockland Immunochemicals Inc, } \\
\text { Gilbertsville, PA, USA }\end{array}$ & Rabbit & $\begin{array}{l}\text { IHC }(1: 500) \\
\text { WB }(1: 5000)\end{array}$ \\
\hline
\end{tabular}




\begin{tabular}{|c|c|c|c|}
\hline Antigen & Company & $\begin{array}{l}\text { Host } \\
\text { species }\end{array}$ & $\begin{array}{l}\text { Method } \\
\text { (conc.) }\end{array}$ \\
\hline Gh & $\begin{array}{l}\text { National Hormone \& Pituitary Program, } \\
\text { Torrance, CA, USA }\end{array}$ & Rabbit & $\begin{array}{l}\text { IHC }(1: 500) \\
\text { ICC }(1: 500) \\
\text { WB }(1: 5000)\end{array}$ \\
\hline Ghrhr & Antibodies online, Aachen, Germany & Rabbit & $\begin{array}{l}\text { ICC }(1: 500) \\
\text { WB }(1: 5000)\end{array}$ \\
\hline HSC-70 & Santa Cruz, Dallas, TX, USA & Mouse & WB $(1: 10000)$ \\
\hline Ki-67 & BD Pharmigen, Heidelberg, Germany & Mouse & $\begin{array}{l}\mathrm{IHC}(1: 50) \\
\mathrm{ICC}(1: 50)\end{array}$ \\
\hline Pomc & NovusBio, Littleton, CO, USA & Goat & $\mathrm{IHC}(1: 200)$ \\
\hline Pomc & NovusBio, Littleton, CO, USA & Rabbit & $\begin{array}{l}\text { IHC }(1: 1000) \\
\text { ICC }(1: 1000) \\
\text { WB }(1: 2000)\end{array}$ \\
\hline Prl & $\begin{array}{l}\text { National Hormone \& Pituitary Program, } \\
\text { Torrance, CA, USA }\end{array}$ & Rabbit & $\operatorname{IHC}(1: 1000)$ \\
\hline PTTG & $\begin{array}{l}\text { Thermo Fisher Scientific Inc., } \\
\text { Waltham, MA, USA }\end{array}$ & Rabbit & $\begin{array}{l}\text { ICC (1:500) } \\
\text { WB }(1: 500)\end{array}$ \\
\hline RFP & MyBioSource, San Diego, CA, USA & Goat & $\mathrm{IHC}(1: 500)$ \\
\hline S100 & $\begin{array}{l}\text { Dako North America Inc., Carpinteria, } \\
\text { CA, USA }\end{array}$ & Rabbit & $\begin{array}{l}\mathrm{IHC} \\
\text { (undiluted) }\end{array}$ \\
\hline Smoothened & Abcam, Cambrige, UK & Rabbit & $\begin{array}{l}\text { IHC }(1: 1000) \\
\text { ICC }(1: 1000)\end{array}$ \\
\hline Sox2 & eBioscience, San Diego, CA, USA & Rat & $\begin{array}{l}\text { IHC }(1: 100) \\
\text { ICC }(1: 100)\end{array}$ \\
\hline
\end{tabular}

IHC: immunohistochemistry; ICC: Immunocytochemistry; WB: Western blot

\subsubsection{Secondary Antibodies}

Table 10 List of used secondary antibodies

\begin{tabular}{l|l|l|l} 
Name & Company & Host Species & Method (conc.) \\
\hline Anti-rabbit-Cy3 & Dianova, Hamburg, Germany & Donkey & $\begin{array}{l}\text { IHC }(1: 200) \\
\text { ICC }(1: 200)\end{array}$ \\
\hline Anti-mouse-TRITC & Dianova, Hamburg, Germany & Donkey & $\begin{array}{l}\text { IHC }(1: 200) \\
\text { ICC }(1: 200)\end{array}$ \\
\hline Anti-rat-Cy3 & Dianova, Hamburg, Germany & Donkey & $\begin{array}{l}\text { IHC }(1: 200) \\
\text { ICC }(1: 200)\end{array}$ \\
\hline Anti-goat-Alexa488 & Dianova, Hamburg, Germany & Bovine & $\begin{array}{l}\text { IHC }(1: 200) \\
\text { ICC }(1: 200)\end{array}$ \\
\hline Anti-rabbit-Alexa488 & Dianova, Hamburg, Germany & Donkey & $\begin{array}{l}\text { IHC }(1: 200) \\
\text { ICC }(1: 200)\end{array}$ \\
\hline Anti-mouse-HRP & Dianova, Hamburg, Germany & Rabbit & WB (1:10000) \\
\hline Anti-rabbit-HRP & Dianova, Hamburg, Germany & Goat & WB (1:10000) \\
\hline $\begin{array}{l}\text { EnVision TM Anti- } \\
\text { mouse/rabbit-HRP }\end{array}$ & $\begin{array}{l}\text { Dako North America Inc., } \\
\text { Carpinteria, CA, USA }\end{array}$ & Goat & IHC (undiluted) \\
\hline
\end{tabular}

IHC: immunohistochemistry; ICC: Immunocytochemistry; WB: Western blot; HRP: horseradish peroxidase; Cy3: Cyanine Dye 3; TRITC: tetramethylrhodamine 


\subsubsection{Synthetic DNA-oligonucleotides}

\subsubsection{DNA-oligonucleotides for PCR-based genotyping recombination} assays and generation of expression plasmids

Table 11 DNA-oligonucleotides used for PCR-based genotyping, for recombination assay and the generation of expression plasmids

\begin{tabular}{|c|c|c|c|}
\hline Oligonucleotide name & $\begin{array}{l}\text { DNA-oligonucleotide sequence } \\
\left(5^{\prime} \rightarrow 3^{\prime} \text { orientation) }\right.\end{array}$ & $\begin{array}{l}\text { Amplicon } \\
\text { size }\end{array}$ & $\begin{array}{l}\text { Refer } \\
\text { ence }\end{array}$ \\
\hline \multicolumn{4}{|c|}{ DNA-oligonucleotides for genotyping } \\
\hline $\begin{array}{l}\text { Aldh1/1-CreERT2_for } \\
\text { Aldh1/1-CreERT2_rev }\end{array}$ & $\begin{array}{l}\text { CAACTCAGTCACCCTGTGCTC } \\
\text { TTCTTGCGAACCTCATCACTCG }\end{array}$ & $590 \mathrm{bp}$ & 256 \\
\hline $\begin{array}{l}\text { GFP-F } \\
\text { GFP-R }\end{array}$ & $\begin{array}{l}\text { AAGTTCATCTGCACCACCG } \\
\text { TCCTTGAAGAAGATGGTGCG }\end{array}$ & 173 bp & 257 \\
\hline $\begin{array}{l}\text { Gli1-CreERT2-F } \\
\text { Gli1-CreERT2-R }\end{array}$ & $\begin{array}{l}\text { GCGGTCTGGCAGTAAAAACTATC } \\
\text { GTGAAACAGCATTGCTGTCACTT }\end{array}$ & 102 bp & 258 \\
\hline $\begin{array}{l}\text { Gli1-wt-F } \\
\text { Gli1-wt-R }\end{array}$ & $\begin{array}{l}\text { GGGATCTGTGCCTGAAACTG } \\
\text { CTTGTGGTGGAGTCATTGGA }\end{array}$ & $74 \mathrm{bp}$ & 258 \\
\hline $\begin{array}{l}\text { hGHRHR_CreERT2_fo } \\
\text { rward } \\
\text { hGHRHR_CreERT2_re } \\
\text { verse }\end{array}$ & $\begin{array}{l}\text { GTCCCACCTCAGGGTCAATG } \\
\text { ACATCTTCAGGTTCTGCGGG }\end{array}$ & $459 \mathrm{bp}$ & \\
\hline $\begin{array}{l}m P t c N x F \\
m P t c N x R \\
m P t c w t R\end{array}$ & $\begin{array}{l}\text { TGGTAATTCTGGGCTCCCGT } \\
\text { CCGGTAGAATTAGCTTGAAGTTCCT } \\
\text { TCAAGGAGCAGAGGCCCAA }\end{array}$ & $\begin{array}{l}150 \mathrm{bp} \text { (mut) } \\
445 \mathrm{bp} \text { (wt) }\end{array}$ & 259 \\
\hline $\begin{array}{l}\text { PomcCreER-F } \\
\text { PomcCreER-R } \\
\text { CreER }\end{array}$ & $\begin{array}{l}\text { GGAAACAGAGAGGGAAACTGCC } \\
\text { CTCTTCCCTTTGCTCTGTAC } \\
\text { GCTCTACTTCATCGCATTCCTTG }\end{array}$ & $\begin{array}{l}500 \text { bp (wt) } \\
400 \text { bp (mut) }\end{array}$ & 260 \\
\hline $\begin{array}{l}\text { RosaTomato mut-F } \\
\text { RosaTomato mut-R }\end{array}$ & $\begin{array}{l}\text { GGCATTAAAGCAGCGTATCC } \\
\text { CTGTTCCTGTACGGCATGG }\end{array}$ & 196 bp & 261 \\
\hline $\begin{array}{l}\text { RosaTomato wt- } F \\
\text { RosaTomato wt-R }\end{array}$ & $\begin{array}{l}\text { AAGGGAGCTGCAGTGGAGTA } \\
\text { CCGAAAATCTGTGGGAAGTC }\end{array}$ & 297 bp & 261 \\
\hline $\begin{array}{l}\text { Smo wt-F } \\
\text { Smo wt-R }\end{array}$ & $\begin{array}{l}\text { CCACTGCGAGCCTTTGCGCTAC } \\
\text { CCCATCACCTCCGCGTCGCA }\end{array}$ & $130 \mathrm{bp}$ & 158 \\
\hline $\begin{array}{l}\text { Smoflox- } F \\
\text { Smoflox-R }\end{array}$ & $\begin{array}{l}\text { CTTGGGTGGAGAGGCTATTC } \\
\text { AGGTGAGATGACAGGAGATC }\end{array}$ & $215 b p$ & 158 \\
\hline $\begin{array}{l}\text { Sox } 2 \text { CreERT2 mut-F } \\
\text { Sox } 2 \text { CreERT2 mut-R }\end{array}$ & $\begin{array}{l}\text { GCGGTCTGGCAGTAAAAACTATC } \\
\text { GTGAAACAGCATTGCTGTCACTT }\end{array}$ & $100 \mathrm{bp}$ & 262 \\
\hline $\begin{array}{l}\text { Sox2CreERT2 wt-F } \\
\text { Sox2CreERT2 wt-R }\end{array}$ & $\begin{array}{l}\text { ACCAGCTCGCAGACCTACAT } \\
\text { CGGGGAGGTACATGCTGAT }\end{array}$ & $208 \mathrm{bp}$ & 262 \\
\hline \multicolumn{4}{|c|}{ DNA-oligonucleotides for recombination assays } \\
\hline $\begin{array}{l}\text { Exon 7-F } \\
\text { neoR }\end{array}$ & $\begin{array}{l}\text { AGGAAGTATATGCATTGGCAGGAG } \\
\text { GCATCAGAGCAGCCGATTGTCTG }\end{array}$ & $\begin{array}{l}2700 \mathrm{bp} \\
\text { (before } \\
\text { recombinatio } \\
\text { n) } \\
950 \text { bp (after } \\
\text { recombinatio } \\
\text { n) }\end{array}$ & 259 \\
\hline
\end{tabular}




\begin{tabular}{|c|c|c|c|}
\hline Oligonucleotide name & $\begin{array}{l}\text { DNA-oligonucleotide sequence } \\
\left(5^{\prime} \rightarrow 3^{\prime} \text { orientation) }\right.\end{array}$ & $\begin{array}{l}\text { Amplicon } \\
\text { size }\end{array}$ & $\begin{array}{l}\text { Refer } \\
\text { ence }\end{array}$ \\
\hline Smo5'_long_forward & $\begin{array}{l}\text { GGGTTCCCAGGGTTGAAGACAGCTT } \\
\text { CGATCTCCAG }\end{array}$ & $590 \mathrm{bp}$ & \\
\hline Smo_del_WT_rev & GTAGCGCAAAGGCTCGCAGTGG & & \\
\hline Smo5'_long_forward & $\begin{array}{l}\text { GGGTTCCCAGGGTTGAAGACAGCTT } \\
\text { CGATCTCCAG }\end{array}$ & $400 \mathrm{bp}$ & \\
\hline Smoflox_recombi_rev & CCTGGTCTTGCAGGGTGTAGT & & \\
\hline \multicolumn{4}{|c|}{ DNA-oligonucleotides for the generation of expression plasmids } \\
\hline $\begin{array}{l}\text { CreERT2_forward } \\
\text { CreERT2_reverse }\end{array}$ & $\begin{array}{l}\text { ATGTCCAATTTACTGACCGTACACC } \\
\text { AAAAT } \\
\text { TCAAGCTGTGGCAGGGAAACC }\end{array}$ & $1997 \mathrm{bp}$ & \\
\hline $\begin{array}{l}\text { hGHRHR_1_for } \\
\text { hGHRHR_HindIII_rev }\end{array}$ & $\begin{array}{l}\text { ATTGCCCACTGGATCTAGGC } \\
\text { GGGAAGCTTCCCTCCACCAGCCTCA } \\
\text { GTAAGCCTT }\end{array}$ & $2620 \mathrm{bp}$ & 263 \\
\hline $\begin{array}{l}\text { Eagl rGhrhrProm-F } \\
\text { Mfel rGhrhrProm-R }\end{array}$ & $\begin{array}{l}\text { GTACGGCCGCCATGGCCTCTGCAT } \\
\text { CAACTTCTGCTTCCAGG } \\
\text { CAAGTTAACCCATGGCAGTGGTGCC } \\
\text { TGTAGTCCGCCCCA }\end{array}$ & $1973 \mathrm{bp}$ & \\
\hline $\begin{array}{l}\text { mGhrhr_1.5kb_UTR_Cl } \\
\text { al_f } \\
\text { mGGhrhr_1.5kb_UTR_N } \\
\text { col_r }\end{array}$ & $\begin{array}{l}\text { GTCCCCAAGGAGAGCCAAAT } \\
\text { GTAGCCCACATCAGGCCA }\end{array}$ & $1560 \mathrm{bp}$ & \\
\hline
\end{tabular}




\subsubsection{DNA-oligonucleotides for quantitative real time PCR and Sanger} sequencing

Table 12 DNA-oligonucleotides used for qRT-PCR approaches

\begin{tabular}{|c|c|c|c|c|}
\hline $\begin{array}{l}\text { Transcri } \\
\text { pt }\end{array}$ & $\begin{array}{l}\text { DNA- } \\
\text { oligonucleotide } \\
\text { name }\end{array}$ & $\begin{array}{l}\text { DNA-oligonuceotide sequence } \\
\left(5^{\prime} \rightarrow 3^{\prime} \text { orientation }\right)\end{array}$ & $\begin{array}{l}\text { DNA- } \\
\text { oligonu } \\
\text { cleotide } \\
\text { location }\end{array}$ & $\begin{array}{l}\text { Amplic } \\
\text { on size }\end{array}$ \\
\hline \multicolumn{5}{|c|}{ DNA-oligonucleotide for murine and rat sequences } \\
\hline $18 S$ & $\begin{array}{l}\text { 18S-fwd } \\
18 S-r e v 2\end{array}$ & $\begin{array}{l}\text { CGCAAATTACCCACTCCCG } \\
\text { TTCCAATTACAGGGCCTCGAA }\end{array}$ & $\begin{array}{l}\text { Exon } 1 \\
\text { Exon } 1\end{array}$ & $81 \mathrm{bp}$ \\
\hline Cga & $\begin{array}{l}\text { Cga- } 11 \\
\text { Cga-R1 }\end{array}$ & $\begin{array}{l}\text { GTCATTCTGGTCATGCTGTCCAT } \\
\text { G } \\
\text { GATATGCCCTGGAGAAGCAACA } \\
\text { GC }\end{array}$ & $\begin{array}{l}\text { Exon } 2 \\
\text { Exon } 3\end{array}$ & $169 \mathrm{bp}$ \\
\hline Fn1 & $\begin{array}{l}\text { mFn1_for } \\
\text { mFn1_rev }\end{array}$ & $\begin{array}{l}\text { TTCAAGTGTGATCCCCATGAAG } \\
\text { CAGGTCTACGGCAGTTGTCA }\end{array}$ & $\begin{array}{l}\text { Exon } 43 \\
\text { Exon } 45\end{array}$ & $154 \mathrm{bp}$ \\
\hline Fst & $\begin{array}{l}\text { mFst_for } \\
\text { mFst_rev }\end{array}$ & $\begin{array}{l}\text { TGCTGCTACTCTGCCAGTTC } \\
\text { GTGCTGCAACACTCTTCCTTG }\end{array}$ & $\begin{array}{l}\text { Exon } 1 \\
\text { Exon } 2\end{array}$ & $130 \mathrm{bp}$ \\
\hline Gapdh & $\begin{array}{l}\text { Gapdh-F } \\
\text { Gapdh-R }\end{array}$ & $\begin{array}{l}\text { ATCTTCTTGTGCAGTGCCAG } \\
\text { ATGGCATGGACTGTGGTCAT }\end{array}$ & $\begin{array}{l}\text { Exon } 1 \\
\text { Exon } 5 \\
\end{array}$ & 574 bp \\
\hline Gh & $\begin{array}{l}\text { Gh-F } \\
\text { Gh-R }\end{array}$ & $\begin{array}{l}\text { AAGAGGGCATCCAGGCTCT } \\
\text { CGTCGTCGCTGCGCATGTT }\end{array}$ & $\begin{array}{l}\text { Exon } 4 \\
\text { Exon } 5 \\
\end{array}$ & $111 \mathrm{bp}$ \\
\hline Gli1 & $\begin{array}{l}m \text { Gli1-tq-F } \\
m \text { Gli1-tq-R }\end{array}$ & $\begin{array}{l}\text { TACATGCTGGTGGTGCACATG } \\
\text { ACCGAAGGTGCGTCTTGAGG }\end{array}$ & $\begin{array}{l}\text { Exon } 9 \\
\text { Exon } 10\end{array}$ & $115 \mathrm{bp}$ \\
\hline Gli2 & $\begin{array}{l}\text { Gli2-RT-PCR-F } \\
\text { Gli2-RT-PCR-R }\end{array}$ & $\begin{array}{l}\text { GGTCATCTACGAGACCAACTGC } \\
\text { GTGTCTTCAGGTTCTCCAGGC }\end{array}$ & $\begin{array}{l}\text { Exon } 8 \\
\text { Exon } 9\end{array}$ & $272 \mathrm{bp}$ \\
\hline Hhip & $\begin{array}{l}\text { mHhipF.1 } \\
\text { mHhipR.2 }\end{array}$ & $\begin{array}{l}\text { GGAGCCTTACTTGGACATTCAC } \\
\text { AA } \\
\text { ACCGTTCCTGGTTGGTGGTATA } \\
\text { A }\end{array}$ & $\begin{array}{l}\text { Exon } 4 \\
\text { Exon } 5\end{array}$ & 143 bp \\
\hline Nos1 & $\begin{array}{l}\text { mNos1_for } \\
\text { mNos1_rev }\end{array}$ & $\begin{array}{l}\text { CTGGTGAAGGAACGGGTCAG } \\
\text { CCGATCATTGACGGCGAGAAT }\end{array}$ & $\begin{array}{l}\text { Exon } 2 \\
\text { Exon 2 } \\
\end{array}$ & $120 \mathrm{bp}$ \\
\hline Pomc & $\begin{array}{l}\text { Pomc-F1 } \\
\text { Pomc-R1 }\end{array}$ & $\begin{array}{l}\text { CAGACCTCCATAGATGTGTGGA } \\
\text { G } \\
\text { GCGGAAGTGACCCATGACGTAC }\end{array}$ & $\begin{array}{l}\text { Exon } 3 \\
\text { Exon } 4\end{array}$ & 111 bp \\
\hline Prl & $\begin{array}{l}\text { Prl-F1 } \\
\text { Prl-R1 }\end{array}$ & $\begin{array}{l}\text { GAGAGCTGTTTGACCGTGTGG } \\
\text { GATGACCTTGACCATAAACTCA } \\
\text { C }\end{array}$ & $\begin{array}{l}\text { Exon } 2 \\
\text { Exon } 3\end{array}$ & 196 bp \\
\hline Ptch & $\begin{array}{l}m P t c 10 \\
m P t c 11 R\end{array}$ & $\begin{array}{l}\text { TACAGTCCGGGACAGCATACC } \\
\text { GTACCCATGGCCAACTTCGGCT } \\
\text { TT }\end{array}$ & $\begin{array}{l}\text { Exon } 5 \\
\text { Exon } 6\end{array}$ & 152 bp \\
\hline S100a4 & $\begin{array}{l}\text { mS100a4_2_tq_for } \\
\text { mS100a4_2_tq_rev }\end{array}$ & $\begin{array}{l}\text { TCAGGCAAAGAGGGTGACAA } \\
\text { TCССTGTTGCTGTCCAAGTT }\end{array}$ & $\begin{array}{l}\text { Exon } 2 \\
\text { Exon } 3\end{array}$ & $143 \mathrm{bp}$ \\
\hline S100b & $\begin{array}{l}\text { mS100b_3_tq_for } \\
\text { mS100b_3_tq_rev }\end{array}$ & $\begin{array}{l}\text { AACAACGAGCTCTCTCACTTCC } \\
\text { CTGGAAGTCACACTCCССАTC } \\
\end{array}$ & $\begin{array}{l}\text { Exon } 2 \\
\text { Exon 3 } \\
\end{array}$ & $105 \mathrm{bp}$ \\
\hline Vip & $\begin{array}{l}\text { mVip_2_for } \\
\text { mVip_2_rev }\end{array}$ & $\begin{array}{l}\text { AGCAGAAAATGGCACACCCTA } \\
\text { AAGTCTGCTGTAATCGCTGGT }\end{array}$ & $\begin{array}{l}\text { Exon } 2 \\
\text { Exon } 3 \\
\end{array}$ & $85 \mathrm{bp}$ \\
\hline \multicolumn{5}{|c|}{ DNA-oligonucleotides for murine sequences } \\
\hline Mif & $\begin{array}{l}\text { mMif_for } \\
\text { mMif_rev }\end{array}$ & $\begin{array}{l}\text { GCCAGAGGGGTTTCTGTCG } \\
\text { GTTCGTGCCGCTAAAAGTCA }\end{array}$ & $\begin{array}{l}\text { Exon } 1 \\
\text { Exon } 2\end{array}$ & 118 bp \\
\hline
\end{tabular}




\begin{tabular}{|c|c|c|c|c|}
\hline $\begin{array}{l}\text { Transcri } \\
\text { pt }\end{array}$ & $\begin{array}{l}\text { DNA- } \\
\text { oligonucleotide } \\
\text { name }\end{array}$ & $\begin{array}{l}\text { DNA-oligonuceotide sequence } \\
\left(5^{\prime} \rightarrow 3^{\prime} \text { orientation) }\right.\end{array}$ & $\begin{array}{l}\text { DNA- } \\
\text { oligonu } \\
\text { cleotide } \\
\text { location }\end{array}$ & $\begin{array}{l}\text { Amplic } \\
\text { on size }\end{array}$ \\
\hline Vegfa & $\begin{array}{l}\text { mVegfa_qRT_ } \\
\text { forward } \\
\text { mVegfa_qRT_rever } \\
\text { se }\end{array}$ & $\begin{array}{l}\text { CCCACGACAGAAGGAGAGCAG } \\
\text { AAGT } \\
\text { CATCAGCGGCACACAGGACGG }\end{array}$ & $\begin{array}{l}\text { Exon } 2 \\
\text { Exon } 3\end{array}$ & 159 bp \\
\hline \multicolumn{5}{|c|}{ DNA-oligonucleotide for rat sequences } \\
\hline PacR & $\begin{array}{l}\text { rPac1_1_for } \\
\text { rPac1_1_rev }\end{array}$ & $\begin{array}{l}\text { AGAGGATCCAGAGGGCCAAC } \\
\text { TCAGGGCAGCTTACAAGGAC }\end{array}$ & $\begin{array}{l}\text { Exon } 3 \\
\text { Exon } 4 \\
\end{array}$ & 130 bp \\
\hline VipR1 & $\begin{array}{l}\text { rVipr1_1_for } \\
\text { rVipr1_1_rev }\end{array}$ & $\begin{array}{l}\text { TGAGATACAGCGTCAGCAGTG } \\
\text { AGGTTGTCCCACATCTTGCT }\end{array}$ & $\begin{array}{l}\text { Exon } 2 \\
\text { Exon } 3 \\
\end{array}$ & $81 \mathrm{bp}$ \\
\hline VipR2 & $\begin{array}{l}\text { rVipr2_2_for } \\
\text { rVipr2_2_rev }\end{array}$ & $\begin{array}{l}\text { TACAACGACCCCGAGGATGA } \\
\text { TCAGAGAAACACTGTAGCCCA }\end{array}$ & $\begin{array}{l}\text { Exon } 4 \\
\text { Exon } 5\end{array}$ & 85 bp \\
\hline
\end{tabular}

Table 13 List of DNA-oligonucleotides used for Sanger sequencing

\begin{tabular}{l|l} 
DNA-Oligonucleotide & Sequence $\left(\mathbf{5}^{\prime} \rightarrow \mathbf{3}\right.$ ' orientation) \\
\hline$T 3$ & GCAATTACCCTCACTAAAGG \\
\hline$T 7$ & TAATACGACTCACTATAGGG \\
\hline CreERT2_forward & ATGTCCAATTTACTGACCGTACACCAAAAT \\
\hline CreERT2_Seq\#2_for & TTCGAACGCACTGATTTCGACCAG \\
\hline CreERT2_Seq\#3_for & CGATTGATTTACGGCGCTAAG \\
\hline CreERT2_Seq\#4_for & GATCCTACCAGACCCTTCAGTG \\
\hline CreERT2_Seq\#5_for & AGCACCCTGAAGTCTCTGGAAG \\
\hline NeoResist_2_for & CGACCACCAAGCGAAACATC \\
\hline Smoflox_Recombi_loxP_rev & CAAAGCGCCATTCGCCATTC \\
\hline Smoflox-F & CTTGGGTGGAGAGGCTATTC \\
\hline Smoflox-R & AGGTGAGATGACAGGAGATC \\
\hline Smowt-F & CCACTGCGAGCCTTTGCGCTAC \\
\hline LacZ-F1 & TGGAGTGCGATCTTCCTGAGG \\
\hline LacZ-R1 & CACCGCACGATAGAGATTCGG \\
\hline
\end{tabular}

\subsubsection{Media}

\subsubsection{Media and reagents for cultivation of eukaryotic cells}

Table 14 Media and reagents used for culture of eukaryotic cells

\begin{tabular}{l|l} 
Medium or reagent & Supplier \\
\hline $\begin{array}{l}\text { Dulbecco's Modified Eagle Medium } \\
\text { supplemented with 4.5 g/L Glucose, L- } \\
\text { Glutamine, Sodium Pyruvate (DMEM+++) }\end{array}$ & Invitrogen, Carlsbad, CA, USA \\
\hline $\begin{array}{l}\text { Dulbecco's Modified Eagle Medium } \\
\text { supplemented with 4.5 g/L Glucose, L- } \\
\text { Glutamine (DMEM++-) }\end{array}$ & Invitrogen, Carlsbad, CA, USA \\
\hline $\begin{array}{l}\text { Dulbecco's Modified Eagle Medium/Nutrient } \\
\text { Mixture F-12 (DMEM/F12) }\end{array}$ & Invitrogen, Carlsbad, CA, USA \\
\hline Fetal bovine serum (FBS) & Invitrogen, Carlsbad, CA, USA \\
\hline Ham's F-12K (Kaighn's)-Medium & Invitrogen, Carlsbad, CA, USA \\
\hline Horse Serum (HS) & Invitrogen, Carlsbad, CA, USA \\
\hline $\begin{array}{l}\text { PBS Tab.ts for cell culture (1 Tab.t dissolved } \\
\text { in 500 ml ddH20, autoclaved before use) }\end{array}$ & Invitrogen, Carlsbad, CA, USA \\
\hline
\end{tabular}




\begin{tabular}{l|l} 
Medium or reagent & Supplier \\
\hline TrypLE Express & Invitrogen, Carlsbad, CA, USA \\
\hline $\begin{array}{l}\text { Penicillin }(10.000 \mathrm{U} / \mathrm{ml}) \text { and Streptomycin } \\
(10 \mathrm{mg} / \mathrm{ml})(\mathrm{Pen} / \mathrm{Strep})\end{array}$ & PAN Biotech GmbH, Aidenbach, Germany \\
\hline L-Glutamine & Invitrogen, Carlsbad, CA, USA \\
\hline MEM non-essential amino acids & Invitrogen, Carlsbad, CA, USA \\
\hline Insulin & Sigma-Aldrich Co., St. Louis, MO, USA \\
\hline Apo-transferrin & Sigma-Aldrich Co., St. Louis, MO, USA \\
\hline 3,3'-5 Triiodo-L-thyroinine sodium salt (T3) & Sigma-Aldrich Co., St. Louis, MO, USA \\
\hline Sodium selenite & Sigma-Aldrich Co., St. Louis, MO, USA \\
\hline
\end{tabular}

\subsubsection{Media for cultivation of prokaryotic cells}

Table 15 Composition of media used for cultivation of prokaryotic cells

\begin{tabular}{l|l} 
Medium & Composition \\
\hline \multirow{2}{*}{ Lysogeny broth medium (LB medium) } & $1 \%(\mathrm{w} / \mathrm{v})$ Bacto-tryptone \\
& $1 \%(\mathrm{w} / \mathrm{v}) \mathrm{NaCl}(\mathrm{pH} 7.0)$ \\
\hline \multirow{2}{*}{ Lysogeny broth agar (LB agar) } & $0.5 \%(\mathrm{w} / \mathrm{v})$ Yeast extract \\
\hline
\end{tabular}

Selection for antibiotic resistance was performed via addition of the respective selection antibiotic (Ampicilin $100 \mu \mathrm{g} / \mathrm{ml}$ or Kanamycin $50 \mu \mathrm{g} / \mathrm{ml}$ ) directly to the medium or the agar. The corresponding antibiotic is given in Table 8.

\subsubsection{Biological material}

\subsubsection{Bacterial strains}

To ensure proper propagation of plasmid DNA DH5 $\alpha$ Escherichia coli (E.coli) with the genotype $\mathrm{F}^{-}$Ф80lacZ $\Delta \mathrm{M} 15 \Delta$ (lacZYA-arg F) U169 recA1 endA1 $h s d \mathrm{R} 17\left(\mathrm{rk}^{-}, \mathrm{m}_{\mathrm{k}}{ }^{+}\right)$phoA supE44 thi-1 gyrA96 relA1 $\lambda^{-}$obtained from Invitrogen, Carlsbad, CA, USA were used.

\subsubsection{Eukaryotic cell lines}

Table 16 Used eukaryotic cell lines and their respective supplier.

\begin{tabular}{l|l|l} 
Cell Line & General information & Depositor \\
\hline AtT-20 & $\begin{array}{l}\text { Murine pituitary tumor derived, Acth } \\
\text { secreting cell line }\end{array}$ & ATCC, Manassas, VA, USA \\
\hline B9 & Adult murine fibroblast cell line & 264 \\
\hline GH3 & $\begin{array}{l}\text { Rat pituitary tumor derived Growth } \\
\text { hormone secreting cell line }\end{array}$ & $\begin{array}{l}\text { Gift from Dr. Ulrich Renner, } \\
\text { Munich, Germany }\end{array}$ \\
\hline
\end{tabular}




\begin{tabular}{l|l|l} 
Cell Line & General information & Depositor \\
\hline MCF-7 & Human breast cancer derived cell line & ATCC, Manassas, VA, USA \\
\hline NIH/3T3 & Adult murine fibroblast cell line & ATCC, Manassas, VA, USA \\
\hline TtT/GF & Murine FSC cell line & RIKEN Cell Bank, Ibaraki, Japan \\
\hline
\end{tabular}

\subsubsection{Genetically modified mouse lines}

Aldh1/1CreERT2, PomcCreERT2, Ptch f/f, R26-tdTomato, S100bEGFP, Sox2GFP and Sox2CreERT2 mice were maintained on C57BL6/N and Gli1CreERT2 and Smo ${ }^{f / f}$ mice were maintained on 129Sv background.

Table 17 List of utilized genetically modified mouse lines

\begin{tabular}{|c|c|c|c|c|}
\hline Strain & $\begin{array}{l}\text { Genetically } \\
\text { background }\end{array}$ & Nomenclature & Specification & Reference \\
\hline Aldh1/1CreERT2 & C57BL6/N & $\begin{array}{l}\text { Tg(Aldh1l1- } \\
\text { cre/ERT2)02K } \\
\text { an }\end{array}$ & $\begin{array}{l}\text { Gene encoding for a } \\
\text { tamoxifen inducible } \\
\text { CreERT2 fusion protein in } \\
\text { intron } 1 / \text { exon } 2 \text { of aldehyde } \\
\text { dehydrogenase } 1 \text { family, } \\
\text { member } L 1 \text { (Aldh1/1) gene }\end{array}$ & 256 \\
\hline Gli1CreERT2 & $129 S v$ & $\mathrm{Gli}^{\mathrm{tm} 3(\mathrm{cre} / \mathrm{ERT} \text { )Alj }}$ & $\begin{array}{l}\text { Gene encoding for a } \\
\text { tamoxifen inducible } \\
\text { CreERT2 fusion protein } \\
\text { under the control of } \\
\text { endogenous Gli1 } \\
\text { promoter/enhancer element }\end{array}$ & 265 \\
\hline PomcCreERT2 & C57BL6/N & $\begin{array}{l}\text { Tg(Pomc- } \\
\text { cre/ERT2)\#Jke }\end{array}$ & $\begin{array}{l}\text { Gene encoding for a } \\
\text { tamoxifen inducible } \\
\text { CreERT2 fusion protein } \\
\text { under the control of Pomc } \\
\text { regulatory elements }\end{array}$ & 260 \\
\hline $\operatorname{Ptch}^{f / f}$ & C57BL6/N & Ptch $1^{\text {tm1Hahn }}$ & $\begin{array}{l}\text { loxP sites flanking exon } 8 \\
\text { and } 9 \text { of the endogenous } \\
\text { Ptch gene }\end{array}$ & 157 \\
\hline R26-tdTomato & C57BL6/N & $\begin{array}{l}\text { Gt(ROSA)26S } \\
\text { ortm9(CAG- }_{\text {tdtomato)Hze }}\end{array}$ & $\begin{array}{l}\text { A loxP flanked STOP } \\
\text { cassette followed by the } \\
t d T o m a t o \text { gene and } \\
\text { polyadenylation sequence } \\
\text { integrated into the } \\
\text { endogenous ROSA } 26 \text { locus }\end{array}$ & 261 \\
\hline S100bEGFP & C57BL6/N & $\begin{array}{l}\text { Tg(S100b- } \\
\text { EGFP)11Lgrv }\end{array}$ & $\begin{array}{l}\text { EGFP expression under the } \\
\text { control of the endogenous } \\
\text { S100b promoter/enhancer } \\
\text { element }\end{array}$ & 266 \\
\hline $\mathrm{Smo}^{\mathrm{f} / \mathrm{f}}$ & $129 S v$ & $S m o^{\operatorname{tm} 2 A m c}$ & $\begin{array}{l}\text { loxP sites flanking exon } 1 \text { of } \\
\text { Smo gene }\end{array}$ & 158 \\
\hline
\end{tabular}




\begin{tabular}{|c|c|c|c|c|}
\hline Strain & $\begin{array}{l}\text { Genetically } \\
\text { background }\end{array}$ & Nomenclature & Specification & Reference \\
\hline Sox2GFP & $129 S v$ & Sox $2^{\text {tm2Hoch }}$ & $\begin{array}{l}\text { EGFP expression under the } \\
\text { control of endogenous Sox } 2 \\
\text { promoter/enhancer element }\end{array}$ & 262 \\
\hline Sox 2 CreERT2 & C57BL6/N & $\begin{array}{l}\text { Sox } 2^{\operatorname{tm} 1(\text { cre/ERT2) }} \\
\text { Hoch }\end{array}$ & $\begin{array}{l}\text { Gene encoding for a } \\
\text { tamoxifen inducible } \\
\text { CreERT2 fusion protein } \\
\text { under the control of } \\
\text { endogenous Sox2 } \\
\text { promoter/enhancer element }\end{array}$ & 262 \\
\hline
\end{tabular}

\subsubsection{Software and digital resources}

Table 18 List of used software

\begin{tabular}{l|l} 
Software & Developer \\
\hline 4D & 4D Deutschland GmbH, Eching, Germany \\
\hline Adobe Photoshop CS5 & Adobe Systems Incorporated, San Jose, USA \\
\hline AlphaView Q SA 3.2.2 & Cell Bioscience, Santa Clara, CA, USA \\
\hline CellSens Dimension & Olympus Optical Co., Ltd., Tokyo, Japan \\
\hline Endnote X5 & Thomson ISI ResearchSoft, Carlsbad, CA, USA \\
\hline Fiji & Schindelin et al. ${ }^{267}$ \\
\hline FluoView FV 1000 & Olympus Optical Co., Ltd., Tokyo, Japan \\
\hline Freehand MX & Adobe Systems Incorporated, San Jose, USA \\
\hline Gen5 & BioTek Instruments GmbH, Bad Friedrichshall, \\
\hline GraphPad Prism 6 & Germany \\
\hline Inkscape & GraphPad Software, Inc., La Jolla, CA, USA \\
\hline Microsoft Office & Inkscape Community \\
\hline NanoDrop 800 V2.3 & Microsoft Co., Redmond, WA, USA \\
\hline SDS 2.2 & Thermo Fisher Scientific Inc., Waltham, MA, USA \\
\hline SnapGene Viewer & Applied Biosystems, Waltham, MA, USA \\
\hline Tick@Lab & GSL Biotech LLC, San Diego, CA, USA \\
\hline RStudio & a-tune Software AG, Darmstadt, Germany \\
\hline & RStudio, Inc., USA \\
\hline
\end{tabular}




\subsection{Methods}

\subsubsection{Isolation and purification of nucleic acids}

3.2.1.1. Isolation of genomic DNA from eukaryotic cell lines and tissue samples

Pelleted eukaryotic cells or freshly isolated or frozen tissue or were incubated with $500 \mu \mathrm{l} \mathrm{STE} \mathrm{buffer} \mathrm{containing} 250 \mu \mathrm{g}$ proteinase $\mathrm{K}$ at $55^{\circ} \mathrm{C}$ over night. Afterwards the samples were centrifuged for $10 \mathrm{~min}$ at $13,000 \mathrm{rpm}$ at room temperature and $300 \mu \mathrm{l}$ from the supernatant was transferred into a new tube containing $1 \mathrm{ml} 99 \% \mathrm{EtOH}$. The samples were centrifuged for $30 \mathrm{~min}$ at $13,000 \mathrm{rpm}$ at $4{ }^{\circ} \mathrm{C}$ and the supernatant was discarded. Next, $200 \mu \mathrm{l} 70 \% \mathrm{EtOH}$ was added and the samples were again centrifuged for $10 \mathrm{~min}$ at $13,000 \mathrm{rpm}$ at $4{ }^{\circ} \mathrm{C}$. Afterwards the supernatant was discarded, the DNA-pellet was dried at $55^{\circ} \mathrm{C}$ for $10 \mathrm{~min}$ and finally solved in $70-130 \mu \mathrm{l}$ Ampuwa $\mathrm{H}_{2} \mathrm{O}$. The DNA-containing solution was stored at $4{ }^{\circ} \mathrm{C}$ until further analysis.

\subsubsection{Isolation of low amounts of plasmid DNA}

For the isolation of low amounts of plasmid DNA the reagents of the PureLink®HiPure Plasmid Midiprep Kit from Invitrogen were used. First, a $2 \mathrm{ml}$ bacteria overnight culture was centrifuged at $13,000 \mathrm{rpm}$ for $20 \mathrm{sec}$. The supernatant was discarded and the pellet was dissolved in $200 \mu \mathrm{l}$ resuspension buffer. $200 \mu \mathrm{l}$ lysis buffer were added and stored for $2 \mathrm{~min}$ at room temperature. The reaction was stopped by addition of $200 \mu \mathrm{l}$ of precipitation buffer. Afterwards, the sample was centrifuged for $10 \mathrm{~min}$ at $13,000 \mathrm{rpm}$ and at $4{ }^{\circ} \mathrm{C}$ and the clear supernatant was transferred into a new tube containing $700 \mu \mathrm{l} 99 \% \mathrm{EtOH}$. Subsequently the DNA was precipitated by incubation of the sample at $-80{ }^{\circ} \mathrm{C}$ for $20 \mathrm{~min}$ and centrifugation for $30 \mathrm{~min}$ at $13,000 \mathrm{rpm}$ and $4{ }^{\circ} \mathrm{C}$. The supernatant was discarded and the DNA-pellet was washed in $70 \% \mathrm{EtOH}$ and centrifuged for $10 \mathrm{~min}$ at $13,000 \mathrm{rpm}$ and $4{ }^{\circ} \mathrm{C}$. This step was repeated and then the DNA was dried at $55^{\circ} \mathrm{C}$ for $10 \mathrm{~min}$. The pellet was solved in $20 \mu \mathrm{Ampuwa} \mathrm{H}_{2} \mathrm{O}$ and $1 \mu \mathrm{l}$ of the solved DNA was used for further restriction hydrolysis. For long-time storage, isolated DNA was stored at $-20^{\circ} \mathrm{C}$ until use. 


\subsubsection{Isolation of high amounts of plasmid DNA}

High amounts of plasmid DNA were isolated with the PureLink $\otimes H i P u r e$ Plasmid Midiprep Kit from Invitrogen. The procedure was done according to manufacturer's instructions. After elution, the eluate was divided into 5 tubes à $2 \mathrm{ml}$ containing $1 \mathrm{ml}$ $99 \%$ isopropanol each. Subsequently the samples were incubated at $-80^{\circ} \mathrm{C}$ for $20 \mathrm{~min}$ and followed by centrifugation for $30 \mathrm{~min}$ at $13,000 \mathrm{rpm}$ and $4{ }^{\circ} \mathrm{C}$. The supernatants were discarded and the pellets were washed in $70 \% \mathrm{EtOH}$ and again centrifuged for $10 \mathrm{~min}$ at $13,000 \mathrm{rpm}$ and $4{ }^{\circ} \mathrm{C}$. This step was repeated and then the DNA was dried at $55{ }^{\circ} \mathrm{C}$ for $10 \mathrm{~min}$. Each pellet was solved in $20 \mu \mathrm{l}$ Ampuwa $\mathrm{H}_{2} \mathrm{O}$ and reunited to obtain $100 \mu \mathrm{l}$ of DNA solution. The DNA-concentration of the solution was measured using a NanoDrop. The DNA was stored at $-20^{\circ} \mathrm{C}$ until further use.

\subsubsection{Polymerase chain reaction (PCR)}

The amplification of DNA (e.g. form plasmid DNA, cDNA or genomic DNA) was performed in reaction volumes of $10 \mu \mathrm{l}, 20 \mu \mathrm{l}, 30 \mu \mathrm{l}$ or $50 \mu \mathrm{l}$ per run with the following reagents and final concentrations: 10-100 ng matrix DNA, 0.5 $\mu \mathrm{M}$ sequence-specific forward DNA-oligonucleotide, $0.5 \mu \mathrm{M}$ sequence-specific reverse DNA-oligonucleotide, $0.2 \mathrm{mM}$ dNTP mix, $0.3 \mathrm{mM} \mathrm{MgCl} 2,10 \%(\mathrm{v} / \mathrm{v})$ cresol, 1 x polymerase buffer and $0.1 \mathrm{U}$ polymerase.

The PCR conditions were adapted to the used matrix DNA, DNA-oligonucleotides and DNA polymerases. The first denaturation step at $95^{\circ} \mathrm{C}$ was performed for $5 \mathrm{~min}$ followed by 25 to 35 cycles of one denaturation step each $\left(95^{\circ} \mathrm{C}\right.$ for 30 to $\left.60 \mathrm{sec}\right)$, one DNA-oligonucleotide annealing step at 50 to $68^{\circ} \mathrm{C}(30 \mathrm{sec}$ to $2 \mathrm{~min})$ and one elongation step at $72^{\circ} \mathrm{C}$ (30 sec to $3 \mathrm{~min}$ ). At the end of the program an elongation step of $5 \mathrm{~min}$ length $\left(72^{\circ} \mathrm{C}\right)$ was added. Depending on the further use of the PCR product, either the entire reaction or only an aliquot was examined by agarose gel electrophoresis. A list of cycling conditions for genotyping is given in Table 27. All used DNA-oligonucleotides and fragment sizes of PCR amplicons are listed in Table 11. 


\subsubsection{Detection of recombination of the murine Ptch locus $^{f}$}

Cre-mediated recombination of the Ptch flocus was verified by PCR using DNA isolated from $4 \times 10^{5}$ transfected eukaryotic cells or genomic DNA isolated from murine tissue and the DNA-oligonucleotide pair Exon-7F/NeoR. Amplification of the $\mathrm{Ptch}^{f}$ allele using these DNA-oligonucleotides results in a 2700 bp fragment whereas a 950 bp fragment is amplified from the recombined Ptch $^{f}$ allele (Ptch $\left.{ }^{\text {del}}\right)$ (Figure 5).
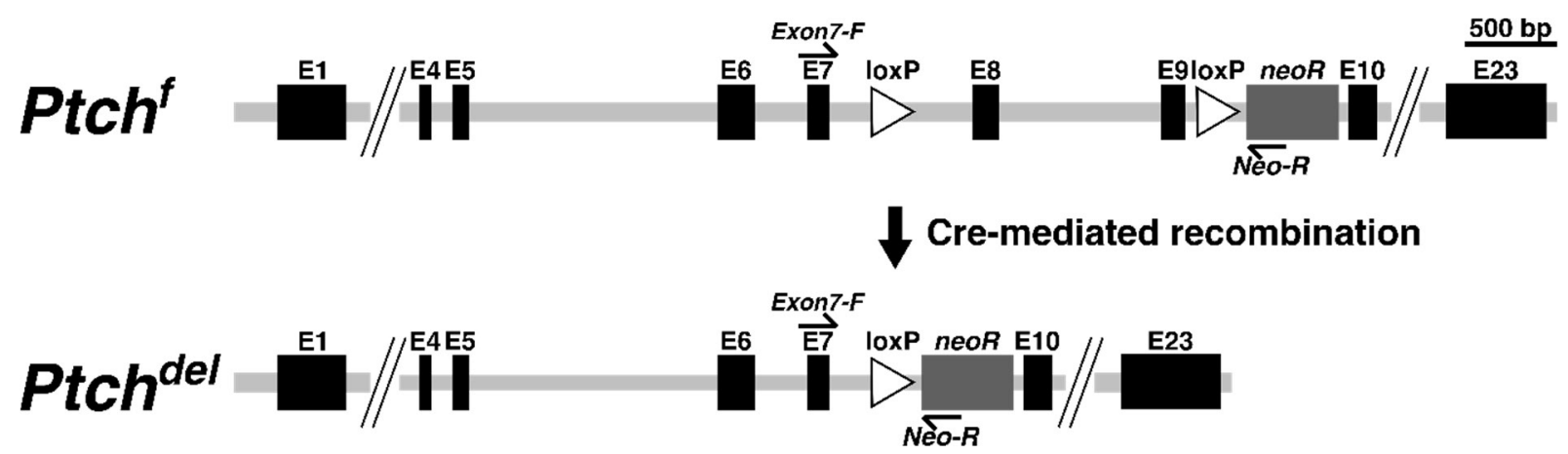

Figure 5 Schematic representation of the genomic Ptch $^{f}$ locus before and after Cre-mediated

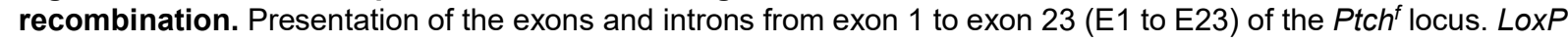
sites are located between E7 and E8 and between E9 and E10 (white rectangles). After Cre-recombinase-mediated recombination $\mathrm{E} 8$ and $\mathrm{E} 9$ are deleted $\left(P t c h^{d e l}\right)$. Verification of Cre-mediated recombination was performed with the DNA-oligonucleotide pair Exon7-F/Neo-R. Amplicon size for Ptch $^{f}$ is $2700 \mathrm{bp}$ and for Ptch ${ }^{\text {del }} 950 \mathrm{bp}$. neoR: Neomycin resistance cassette.

\subsubsection{Agarose gel electrophoresis with ethidium bromide}

DNA fragments of different fragment sizes were separated by agarose gel electrophoresis. Before loading, the samples were mixed with $6 \times$ loading buffer. Depending on the DNA-fragment sizes to be analysed the agarose content of the gels ranging from $0.8-2 \%(\mathrm{w} / \mathrm{v})$ in $1 \times$ TBE. A few drops of ethidium bromide $(0.07 \%)$ added to the liquid gel served for visualization of DNA when illuminated with UV light. DNA-separation was performed in a gel electrophoresis apparatus filled with $1 \times$ TBE and with a constant voltage at $100 \mathrm{~V}$. A DNA ladder was loaded as marker to examine DNA fragment sizes. Documentation was performed using a UV transilluminator and INTAS GDS 3.39 software.

\subsubsection{Agarose gel electrophoresis without ethidium bromide}

For the generation of transgenic mice, the preparation of linearized plasmid DNA without containing minimum amounts of ethidium bromide was required. Therefore, an $1 \%(\mathrm{w} / \mathrm{v})$ agarose gel in $1 \times \mathrm{TBE}$ was prepared as described in section 3.2.1.6 but 
without the addition of ethidium bromide. After finished agarose gel electrophoresis for $4 \mathrm{hrs}$ at $100 \mathrm{~V}$ the right and left flanking sites of the gel were cut and stained individually with ethidium bromide-containing 1 x TBE buffer for 10 min under constant agitation. Afterwards the remaining unstained gel was placed together with the ethidium bromide-stained gel parts and imaged on an UV transilluminator. The position of the desired DNA-fragment was estimated by the ethidium bromide-stained parts and was cut out. Extraction of the DNA-fragment from the gel was performed as described in section 3.2.2.3.

\subsubsection{Ribonucleic acid (RNA) isolation from eukaryotic cells and tissues}

Total RNA was isolated from cultured eukaryotic cells and tissue samples. For RNA isolation from cultured eukaryotic cells, the medium of adherent cells was aspired, $1 \mathrm{ml}$ TriZol reagent per well of a 6-well plate was added and the cells were detached by pipetting the solution up and down. The mixture was then transferred into a $2 \mathrm{ml}$ tube. Non-adherent cells were pelleted ( $300 \mathrm{rpm}$ for $5 \mathrm{~min}$ at $4{ }^{\circ} \mathrm{C}$ ) and dissolved in $1 \mathrm{ml}$ TriZol reagent. For RNA isolation from tissue, the samples were fragmented in $1 \mathrm{ml}$ TriZol reagent by using a tissue processor. Next, the samples were vortexed for $2 \mathrm{~min}$ and incubated for $5 \mathrm{~min}$ at room temperature. $200 \mu \mathrm{l}$ of chloroform were added and vortexed for $15 \mathrm{sec}$. Subsequently, the mixture was incubated for $5 \mathrm{~min}$ at room temperature and centrifuged for $10 \mathrm{~min}$ at $12,000 \mathrm{rpm}$ at $4{ }^{\circ} \mathrm{C}$. The clear upper phase was transferred into a new tube containing $700 \mu \mathrm{l}$ ice-cold $99 \%$ RNA-pure EtOH. Afterwards, the solution was stored for $24-72 \mathrm{hrs}$ at $-20^{\circ} \mathrm{C}$. The RNA was precipitated by centrifugation at $12,000 \mathrm{rpm}$ at $4{ }^{\circ} \mathrm{C}$ for $1 \mathrm{hr}$. The supernatant was discarded and the pellet was washed two times with $700 \mu \mathrm{l}$ ice-cold $70 \%$ RNA-pure EtOH followed by a centrifugation step at $12,000 \mathrm{rpm}$ at $4{ }^{\circ} \mathrm{C}$ for $30 \mathrm{~min}$ after each washing. Next, the RNA-pellet was dried on air for approximately $1 \mathrm{hr}$. Completely dried pellets were reconstituted with RNase-free $\mathrm{H}_{2} \mathrm{O}$. Dissolved RNA was stored at $-80^{\circ} \mathrm{C}$ until further use. 


\subsubsection{Photometric quantification of nucleic acids}

Nucleic acids were quantified by using a NanoDrop spectrophotometer by measuring the absorption of the sample at $260 \mathrm{~nm}$. The purity of the sample was determined by calculation of the absorption quotient measured at $260 \mathrm{~nm} / 280 \mathrm{~nm}$ and $260 \mathrm{~nm} / 230 \mathrm{~nm}$. RNA or DNA samples with absorption ratios at $260 \mathrm{~nm} / 230 \mathrm{~nm}$ of 2.0 or at $280 \mathrm{~nm} / 260 \mathrm{~nm}$ of 1.8 were assumed to be contamination-free.

\subsubsection{Reverse transcription of isolated RNA}

RNA was reverse transcribed with the Invitrogen SuperScript II reverse transcriptase kit. 1 or $2 \mu \mathrm{g}$ of total RNA were diluted in RNase-free $\mathrm{H}_{2} \mathrm{O}$ in a final volume of $7 \mu \mathrm{l}$ and mixed with $5 \mu \mathrm{l}(250 \mathrm{ng})$ random hexamer-oligonucleotides. The mixture was heated for $10 \mathrm{~min}$ at $70^{\circ} \mathrm{C}$ and afterwards cooled down at room temperature for $10 \mathrm{~min}$. Next, $4 \mu \mathrm{l}$ first-strand buffer, $2 \mu \mathrm{l}(10 \mathrm{mM})$ DTT and $1 \mu \mathrm{l}(0.5 \mathrm{mM})$ oligo dNTP's were added and the mixture was incubated for $2 \mathrm{~min}$ at $42^{\circ} \mathrm{C}$. Then $1 \mu \mathrm{l}$ SuperScript II $(200 \mathrm{U} / \mu \mathrm{l})$ was pipetted directly to the mixture and the reaction was incubated for $1 \mathrm{hr}$ at $42^{\circ} \mathrm{C}$. Subsequently, the reaction was stopped by incubation at $70^{\circ} \mathrm{C}$ for further $10 \mathrm{~min}$. Finally, $20 \mu \mathrm{l}$ RNase-free $\mathrm{H}_{2} \mathrm{O}$ was added to the solution to obtain the final stock of the cDNA solution. cDNA was stored at $-20^{\circ} \mathrm{C}$ until further use. Based on the assumption that cDNA synthesis has an approximately $50 \%$ efficiency an amount of $1 \mu \mathrm{g} \mathrm{cDNA}$ transcribed from of $2 \mu \mathrm{g}$ RNA was assumed. Thus, at the final reaction volume of $20 \mu \mathrm{l}$ contained $50 \mathrm{ng} / \mu \mathrm{l}$ cDNA.

\subsubsection{Quantitative real time PCR}

The comparison of different expression levels of a gene in different samples was performed by the relative quantification method of quantitative real time PCR-analyses. For this purpose, sequence-specific DNA-oligonucleotides (Table 12) and the Platinum SYBR Green qPCR Super Mix (Invitrogen) or QuantiTect SYBR Green PCR (Qiagen) were used to amplify cDNA target sequences. Per reaction $5 \mu \mathrm{l}$ SYBR Green (Invitrogen or Qiagen), $0.4 \mu \mathrm{l}$ forward DNA-oligonucleotide $(0.5 \mu \mathrm{M}), 0.4 \mu \mathrm{l}$ reverse DNA-oligonucleotide $(0.5 \mu \mathrm{M}), 2.2 \mu \mathrm{R}$ Rase-free $\mathrm{H}_{2} \mathrm{O}$ and $2 \mu \mathrm{cDNA}$ were mixed and pipetted into 1 well of a black 384-well plate. Each sample was measured in technical triplicates. Depending on the used SYBR Green the amplification protocols given in 
Table 19 were used.

In order to compare the expression level of different cDNA samples, a standard curve was generated from a sample with high and constant expression of the gene of interest (GOI). The assumed concentrations of the standard were plotted against the corresponding measured cycle threshold (CT) and an exponential regression line was defined. The slope of the line was determined and based on this the concentrations of the investigated samples were calculated. To normalize the expression of the target gene, the expression of the endogenous control gene 18S rRNA was measured. If applicable, the data were furthermore normalised to experimental controls, i.e. solvent controls.

The statistical evaluation of at least 3 test series was carried out by using the GraphPad Prism 6 software. The significance of differences and equality of the individual groups was assessed by unpaired t-tests testing for independent groups. $P$ values of $P<0.05$ were considered to be significant, and $P$ values of $P>0.05$ were considered as nonsignificant.

Table 19 Cycling conditions used for quantitative real-time PCR analyses.

\begin{tabular}{l|l|l}
\multicolumn{2}{|c}{$\begin{array}{r}\text { Platinum SYBR Green } \\
\text { qPCR Super Mix } \\
\text { (Invitrogen) }\end{array}$} \\
\hline Temp. & Duration & Cycles \\
\hline $50^{\circ} \mathrm{C}$ & $2 \mathrm{~min}$ & \\
\hline $95^{\circ} \mathrm{C}$ & $2 \mathrm{~min}$ & \\
\hline $95^{\circ} \mathrm{C}$ & $30 \mathrm{sec}$ & \multirow{2}{*}{$40 \mathrm{x}$} \\
\hline $60^{\circ} \mathrm{C}$ & $1 \mathrm{~min}$ & \\
\hline
\end{tabular}

Dissociation stage

\begin{tabular}{|c|c|c|}
\hline \multicolumn{3}{|c|}{$\begin{array}{c}\text { QuantiTect SYBR Green } \\
\text { PCR (Qiagen) }\end{array}$} \\
\hline Temp. & Duration & Cycles \\
\hline $50^{\circ} \mathrm{C}$ & $2 \mathrm{~min}$ & \\
\hline $95^{\circ} \mathrm{C}$ & $15 \min$ & \\
\hline $95^{\circ} \mathrm{C}$ & $15 \mathrm{sec}$ & \multirow{3}{*}{$40 x$} \\
\hline $60^{\circ} \mathrm{C}$ & $30 \mathrm{sec}$ & \\
\hline $72{ }^{\circ} \mathrm{C}$ & $30 \mathrm{sec}$ & \\
\hline
\end{tabular}

Dissociation stage

$\left(95^{\circ} \mathrm{C}: 15 \mathrm{sec}, 60^{\circ} \mathrm{C}: 15 \mathrm{sec}\right.$, $\left.95^{\circ} \mathrm{C}: 15 \mathrm{sec}\right)$ $\left(95^{\circ} \mathrm{C}: 15 \mathrm{sec}, 60^{\circ} \mathrm{C}: 15 \mathrm{sec}\right.$, $\left.95^{\circ} \mathrm{C}: 15 \mathrm{sec}\right)$

\subsubsection{Sanger sequencing of plasmid DNA or PCR products}

Sanger sequencing was performed by using the BigDye ${ }^{\mathrm{TM}}$ Terminator v3.1 cycle sequencing kit. Per reaction $500 \mathrm{ng}$ plasmid DNA or up to $5 \mu \mathrm{l}$ of gel extracted PCR products were mixed with $1 \mu \mathrm{l}$ BigDye ${ }^{\mathrm{TM}}$ reagent, $2 \mu \mathrm{l} 5 \mathrm{x}$ buffer, $1 \mu \mathrm{l}$ sequence specific DNA-oligonucleotide $(0.5 \mu \mathrm{M})$ and filled to up to $10 \mu \mathrm{l}$ with Ampuwa $\mathrm{H}_{2} \mathrm{O}$. Afterwards the mixture was incubated as shown in Table 20. Subsequently $10 \mu \mathrm{Ampuwa} \mathrm{H}_{2} \mathrm{O}$ 
was added and sequencing was performed on a $3500 \times \mathrm{L}$ Genetic Analyzer at the molecular diagnostics lab of the Institute of Human Genetics, Göttingen. Used DNAoligonucleotides and their respective sequences are given in Table 13. The obtained DNA sequences were analysed with SnapGene Viewer and Micosoft Word 2016 software. DNA sequences were assembled by hand and aligned to reference sequences (if applicable) with the use of the nucleotide BLAST tool from NCBI (https://blast.ncbi.nlm.nih.gov/Blast.cgi?PROGRAM=blastn\&PAGE_TYPE=BlastSear ch\&LINK_LOC=blasthome).

Table 20 Conditions for amplification of DNA for sequencing analyses.

\begin{tabular}{l}
\multicolumn{3}{c}{ Sequence amplification } \\
\begin{tabular}{l|l|l} 
Temp. & Duration & Cycles \\
\hline $95^{\circ} \mathrm{C}$ & $1 \mathrm{~min}$ & \\
\hline $95^{\circ} \mathrm{C}$ & $30 \mathrm{seC}$ & \multirow{2}{*}{$30 \mathrm{x}$} \\
\hline $60^{\circ} \mathrm{C}$ & $2 \mathrm{~min} 30 \mathrm{sec}$ & \\
\hline $60^{\circ} \mathrm{C}$ & $5 \mathrm{~min}$ & \\
\hline
\end{tabular}
\end{tabular}

\subsubsection{RNA sequencing}

Total RNA was extracted from TtT/GF cells and dissolved in RNase-free $\mathrm{H}_{2} \mathrm{O}$ (3.2.1.8). RNA quality control, cDNA library preparation and RNA sequencing were performed at the NGS Service Facility for Integrative Genomics (NIG), Institute of Human Genetics, Göttingen. All fastq files are single end reads with 51 basepair readlength. They were aligned against the reference of mus musculus (Mus_musculus.GRCh38 Ensembl 96) genome with the RNA-Seq splice aware aligner STAR version 2.7.0f268. Afterwards, aligned reads were counted towards their features (genes) with rsem calculate expression (RSEM v1.1.1), not only utilizing unique matched reads, but multi matched reads as well, allowing for the most comprehensive usage of the input read data ${ }^{269}$. The resulting expected counts were the baseline input for further analysis in the programming language $R$ (3.6.1) using the limma + voom (limma version 3.40.6) package for differential gene expression analysis ${ }^{270}$. Following GSEA utilising the clusterProfiler v3.12 package in $\mathrm{R}^{271}$. For quality control during the analysis pipeline multiQC version 1.8, evaluating the output of fastqc (https://www.bioinformatics.babraham.ac.uk/projects/fastqc/) and the log files of STAR, was used ${ }^{272}$. Final data visualization was performed with RStudio and GraphPadPrism 6. 


\subsubsection{Molecular biology}

\subsubsection{Plasmid cloning}

Restriction hydrolysis of DNA was performed in a total volume of $10 \mu \mathrm{l}$, in the optimal restriction buffer (supplied by the manufacturer) at the optimal temperature of the restriction enzyme for $1 \mathrm{hr}$. Per $1 \mu \mathrm{g}$ of DNA 2-3 $U$ of restriction enzyme were used. The reaction was terminated with a heat-inactivation step at $65^{\circ} \mathrm{C}$ for $15 \mathrm{~min}$.

\subsubsection{Ligation of DNA with T4 DNA ligase}

DNA fragments were ligated with a T4 DNA ligase. 50 - $200 \mathrm{ng}$ of DNA were mixed with $400 \mathrm{U}$ T4 DNA ligase and $1 \mu \mathrm{l}$ of $10 \mathrm{x}$ ligation buffer in a total volume of $10 \mu \mathrm{l}$. Ligation was performed at $16 \mathrm{C}$ over night and the reaction was used for further propagation in bacteria (3.2.2.6).

\subsubsection{Isolation of DNA fragments from agarose gels}

Isolation of DNA fragments from agarose gels was performed with PCR clean-up Gel extraction Kit from Macherey-Nagel. The respective fragment was cut out from agarose gel using a sterile scalpel and UV light illumination. DNA isolation was performed according to manufacturer's instructions. The concentration of the isolated fragment was determined with a Nanodrop.

\subsubsection{Isolation of DNA fragments for the generation of transgenic mice}

Generation of transgenic mice required ultra-pure, linearized DNA for the injection in male pronucleus of fertilized mouse oocytes. Thus $300 \mu \mathrm{g}$ of the $h G H R H R(-310,-$ 19)CreERT2 plasmid was hydrolysed with $K p n l$ and Spel restriction endonucleases and the respective DNA fragment was isolated with the PCR clean-up Gel extraction Kit from Macherey-Nagel from an ethidiumbromide free agarose gel (3.2.1.7). The DNA was eluted in a minimum of $130 \mu \mathrm{lTE}$ buffer for mouse oocytes injection (3.1.4). The DNA-concentration measured by using a NanoDrop was set to $30 \mathrm{ng} / \mathrm{\mu l}$ and directly centrifuged for $10 \mathrm{~min}$ at $13,000 \mathrm{rpm}$ at room temperature. Afterwards $80 \%$ of the supernatant (minimum $100 \mu$ ) was transferred into a new tube and the correct size of the DNA-fragment was verified by agarose gel electrophoresis. The linearized 
plasmid DNA was afterwards injected into fertilized mouse oocytes at the Max-PlanckInstitute for experimental Medicine, Göttingen.

\subsubsection{Molecular Cloning of PCR fragments}

PCR based amplicons were isolated from agarose gels and directly subcloned into the pBluescript $S K(+)$ vector via blunt-end cloning (3.2.2.2).

\subsubsection{Transformation of bacteria}

$50 \mu$ l of competent DH5 $\alpha$ E.coli cells were thawed on ice for 20 min and either $100 \mathrm{ng}$ of plasmid DNA or $5 \mu$ of a ligation reaction were added and incubated on ice for further $20 \mathrm{~min}$. Transformation of DNA was performed by a heat-shock at $42^{\circ} \mathrm{C}$ for $30 \mathrm{sec}$. After 1 min on ice, the mixture was filled with $450 \mu$ S.O.C. medium and incubated for 50 min at $37^{\circ} \mathrm{C}$ with $400 \mathrm{rpm}$. Afterwards $100-150 \mu \mathrm{l}$ of the transformation mix was plated on agarose plates supplemented with the appropriate selection antibiotic (Table 8). The plates were incubated at $37^{\circ} \mathrm{C}$ over night.

\subsubsection{Molecular cloning of eukaryotic expression vectors}

\subsubsection{Generation of Ghrhr promoter sequence containing plasmids}

In order to analyse the efficient transcription from the Ghrhr promoter different lengths of the promoter from different species (rat, mouse and human) were cloned into the pBluescript $S K(+)$ vector. Therefore, DNA-oligonucleotides for PCR-based amplification of the promoter sequences listed in Table 11 were used to amplify the respective sequences from genomic DNA of rat, mouse and human. Afterwards the respective amplicons were analysed by agarose gel electrophoresis and ligated via blunt-end cloning into the EcoRV-opened pBluescript $S K(+)$ vector to obtain the plasmids pBluescript_rGhrhr(-1964,+9) and the pBluescript_mGhrhr(-1538,-1). The generation of the plasmids pBluescript_hGHRHR(-2207,-19) and the pBluescript_hGHRHR(-310,-19) was performed as described by Iguchi et al. ${ }^{263}$. The numbers refer to the base position in the sequence assuming the adenine of the start codon (ATG) was declared as +1 . 
To generate EGFP expression analyses plasmids the EGFP-gene from $p E G F P-N 1$ plasmid was isolated by EcoRI/Sspl restriction hydrolysis. Afterwards the $1036 \mathrm{bp}$ DNA-fragment was ligated downstream of the promoter sequences of the Mfel/Smal opened pBluescript_rGhrhr(-1964,+9), Ncol/Smal opened pBluescript_mGhrhr(1538,-1), EcoRI/Smal opened pBluescript_hGHRHR(-2207,-19) or EcoRI/Smal opened pBluescript_hGHRHR(-310,-19) plasmids.

For generation of the hGHRHRCreERT2-containing expression plasmid the CreERT2 gene was amplified from genomic DNA of the murine B9 fibroblast cell line that descend from Ptch ${ }^{f f} R 26 C r e E R T 2$ transgenic mice ${ }^{157,264}$. The used DNAoligonucleotides are listed in Table 11. The $1997 \mathrm{bp}$ amplicon was ligated into the EcoRV-opened pBluescript $S K(+)$ vector to obtain the pBluescript_CreERT2 plasmid. The CreERT2 gene from the pBluescript_CreERT2 plasmid was isolated by Sall/Smal restriction hydrolysis. Afterwards the $2024 \mathrm{bp}$ DNA-fragment was ligated in the Sall/Smal-opened pIRES_EGFP plasmid generating a CreERT2 expression under the control of a CAG promoter (pCAGCreERT2_IRES_EGFP). Then the $3616 \mathrm{bp}$ CreERT2_IRES_EGFP fragment was isolated by restriction hydrolysis with EcoRI/SspI and ligated into EcoRI/Smal-opened pBluescript_hGHRHR(-2207,-19) and pBluescript_hGHRHR(-310,-19) plasmids, respectively. Afterwards Smal/Hpal restriction hydrolysis was performed for removal of the IRES_EGFP fragment. The resulting plasmids were named pBluescript_hGHRHR(-2207,-19)CreERT2 and pBluescript_hGHRHR(-310,-19)CreERT2. To exclude mutations, the whole inserted DNA-fragments (hGHRHR(-2207,-19)CreERT2 and hGHRHR(-310,-19)CreERT2) were sequenced (3.2.1.12). Used sequencing DNA-oligonucleotides are given is in Table 13.

The insertion of the respective promoter and gene sequences was approved by restriction hydrolysis of all generated plasmids using appropriate DNA-endonucleases. 


\subsubsection{Cell culture methods}

\subsubsection{Cultivation of eukaryotic cell lines}

The used eukaryotic cell lines and their specific growth media are summarized in Table 21. Some experiments required divergent serum concentrations. These alterations can be found in Table 24 and in the respective experimental section. Cells were cultured in $\varnothing 10 \mathrm{~cm}$ cell culture dishes in an atmosphere of $37^{\circ} \mathrm{C}, 5 \% \mathrm{CO}_{2}$ with $95 \%$ humidity. The medium was changed 3 times a week and cultures were split when they reached $>90 \%$ confluency. Passaging of cells was performed by medium removal and addition of $2 \mathrm{ml}$ TrypLE Express. The cells were incubated at $37^{\circ} \mathrm{C}, 5 \% \mathrm{CO}_{2}$ and $95 \%$ humidity for 5 min or until all cells were detached. Afterwards the cells were resuspended in $3 \mathrm{ml}$ of the respective cell culture medium and centrifuged at $300 \mathrm{rpm}$ for $5 \mathrm{~min}$ at $4{ }^{\circ} \mathrm{C}$. The supernatant was aspired and the cell pellet was resuspended in $5 \mathrm{ml}$ cell culture medium. The cells were split 1:5 - 1:50 into new cell culture dishes with fresh medium.

Table 21 Growth media and composition for cultivation of cell lines

\begin{tabular}{l|l|l} 
Cell Line & Medium & Supplements \\
\hline AtT-20 & Ham's F12-K & $\begin{array}{l}15 \% \text { Horse serum } \\
2.5 \% \mathrm{FBS}\end{array}$ \\
\hline B9 & DMEM+++ & $10 \% \mathrm{FBS}$ \\
\hline GH3 & Ham's F12-K & $\begin{array}{l}15 \% \text { Horse serum } \\
2.5 \% \mathrm{FBS}\left[\text { heat inactivated }\left(56^{\circ} \mathrm{C} \text { for }\right.\right. \\
30 \mathrm{~min})]\end{array}$ \\
\hline MCF-7 & DMEM+++ & $10 \% \mathrm{FBS}$ \\
\hline NIH/3T3 & DMEM+++ & $10 \% \mathrm{FBS}$ \\
\hline TtT/GF & DMEM/HamF12 & $\begin{array}{l}10 \% \mathrm{Horse} \text { serum } \\
2.5 \% \mathrm{FBS}\end{array}$ \\
\hline
\end{tabular}

\subsubsection{Cryoconservation of cells}

Long-time preservation of cell lines was ensured by cryoconservation of the cells in liquid nitrogen. Thus, the cells were detached with TrypLE Express and centrifuged as described in chapter 3.2.4.1. After centrifugation, the supernatant was aspired and the pellet of $3 \varnothing 10 \mathrm{~cm}$ cell culture dishes was resuspended in $1 \mathrm{ml}$ cell line specific medium supplemented with $10 \%$ DMSO (v/v). The suspension was transferred into a fresh cryo vial and immediately frozen at $-80^{\circ} \mathrm{C}$ in a Mr. Frosty ${ }^{\mathrm{TM}}$ freezing container equipped with $99 \%$ isopropanol. After $24 \mathrm{hrs}$ the cells were transferred in liquid nitrogen tanks until use. 


\subsubsection{Counting of cells}

To guarantee the same cell amount in each experiment the cells were counted with a Neubauer counting chamber. Therefore, the cells were detached and centrifuged as described in section 3.2.4.1. The pellet was resuspended in $5 \mathrm{ml}$ of cell culture medium and $10 \mu \mathrm{l}$ from this suspension were transferred onto a Neubauer counting chamber. All 4 big quadrants were counted and the cell number $/ \mathrm{ml}$ was calculated with following formula:

$$
\frac{\text { Cells }}{\mathrm{ml}}=\frac{\text { Counted cells }}{\text { Number of counted big quadrants }} \times 10^{4}
$$

Afterwards the cells were seeded in an adequate amount according to the cell numbers in Table 22.

Table 22 Seeded cell numbers for culture in different cultivation vessels

\begin{tabular}{l|l|l|c}
\multirow{2}{*}{ Cell line } & \multicolumn{2}{|c|}{ 6-well plate } & \multirow{2}{*}{ 24-well plate } \\
\cline { 2 - 3 } & $\begin{array}{l}\text { Seeding } \\
\text { density }\end{array}$ & $\begin{array}{l}\text { Medium } \\
\text { volume/well }\end{array}$ & \\
\hline AtT-20 & $1 \times 10^{5} /$ well & 1 or $2 \mathrm{ml}$ & $1 \times 10^{5} /$ well in $500 \mu l / w e l l$ \\
\hline GH3 & $4 \times 10^{5} /$ well & 1 or $2 \mathrm{ml}$ & $1 \times 10^{5} /$ well in $500 \mu l / w e l l$ \\
\hline $\mathrm{NIH} / 3 T 3$ & $1 \times 10^{5} /$ well & $2 \mathrm{ml}$ & - \\
\hline TtT/GF & $5 \times 10^{4} /$ well & $2 \mathrm{ml}$ & $1 \times 10^{4} /$ well in $500 \mu \mathrm{l} /$ well \\
\hline
\end{tabular}

\subsubsection{Attachment of suspension cells on cover slips}

Staining of suspension cells (e.g. AtT-20) required the attachment of these cells to specialized coverslips. Therefore, Shi-fix ${ }^{\mathrm{TM}}$ coverslips were used. AtT-20 cells were aspired and transferred into a tube. The cells were centrifuged at $300 \mathrm{rpm}$ for $5 \mathrm{~min}$ at $4{ }^{\circ} \mathrm{C}$ and afterwards the supernatant was removed. The pellet was resuspended in $5 \mathrm{ml} \mathrm{PBS}$ and the cells were counted. Subsequently, $1 \times 10^{5}$ cells in $100 \mu \mathrm{l} \mathrm{PBS}$ were placed on a Shi-fix ${ }^{\mathrm{TM}}$ coverslip. The cells were incubated for $30 \mathrm{~min}$ at room temperature. Afterwards the cells were washed $1 \times$ with $500 \mu \mathrm{l} 1 \times$ PBS and then incubated with $500 \mu \mathrm{l} 4 \%$ PFA for $10 \mathrm{~min}$. After 3 more washing steps with $1 \times$ PBS the cells were used for immunocytochemistry (3.2.6.4). 


\subsubsection{Electroporation of cells}

Transfection of eukaryotic cells was performed with the neon transfection system from Invitrogen. The procedure was done according to manufacturer's instructions. Table 23 shows the used conditions for the different cell lines.

Table 23 Specifications for electroporation of eukaryotic cells

\begin{tabular}{l|l|l|l} 
Cell line & Voltage (V) & Pulse length (ms) & Pulse width \\
\hline AtT-20 & 1200 & 30 & 2 \\
\hline GH3 & 1350 & 30 & 1 \\
\hline NIH/3T3 & 1350 & 20 & 2 \\
\hline
\end{tabular}

\subsubsection{SAG and vismodegib stimulation of TtT/GF, GH3 and AtT-20 cells}

For SAG and vismodegib stimulation, the appropriate cell number of the respective cell lines (e.g. TtT/GF; GH3; AtT-20) was seeded on a 6-well plate (Table 22) in $2 \mathrm{ml}$ of their respective growth medium per well. $24 \mathrm{hrs}$ post seeding the cells were starved for $24 \mathrm{hrs}$ in $2 \mathrm{ml}$ of their respective starvation medium (Table 24) per well. Cells were stimulated with $100 \mathrm{nM}$ SAG, $1 \mu \mathrm{M}$ vismodegib or as a solvent control with the respective amount of DMSO for $48 \mathrm{hrs}$ in $2 \mathrm{ml}$ of their respective starvation medium per well. Total RNA of the cells was isolated as described in 3.2.1.8.

Table 24 Composition of starvation medium of pituitary cell lines

\begin{tabular}{l|l|l} 
Cell Line & Medium & Supplements for starvation medium \\
\hline AtT-20 & Ham's F12-K & $\begin{array}{l}0.5 \% \text { Horse Serum } \\
0.125 \% \text { FBS }\end{array}$ \\
\hline \multirow{2}{*}{ GH3 } & Ham's F12-K & $\begin{array}{l}0.5 \% \text { Horse Serum } \\
\left.0.125 \% \text { FBS [heat inactivated }\left(56^{\circ} \mathrm{C} \text { for } 30 \mathrm{~min}\right)\right]\end{array}$ \\
\hline \multirow{2}{*}{ TtT/GF } & DMEM/HamF12 & $\begin{array}{l}0.5 \% \text { Horse Serum } \\
0.125 \% \text { FBS }\end{array}$ \\
\hline
\end{tabular}

\subsubsection{Generation of conditioned medium}

$5 \times 10^{4}$ TtT/GF cells per well were seeded on a 6 -well plate in $2 \mathrm{ml}$ of their growth medium (Table 21). 24 hrs post seeding the cells were incubated in starvation medium of either GH3 or AtT-20 cells (Table 24) for $24 \mathrm{hrs}$. Afterwards the cells were treated with SAG or solvent (DMSO) in starvation medium of GH3 or AtT-20 cells, respectively. $48 \mathrm{hrs}$ after stimulation the supernatant was harvested and filtered through a $0.2 \mu \mathrm{m}$ filter. $200 \mu \mathrm{l}$ of the filtrate was directly frozen at $-80^{\circ} \mathrm{C}$ until further analysis. The 
remaining conditioned medium was stored for maximum two weeks at $4{ }^{\circ} \mathrm{C}$.

\subsubsection{Incubation with conditioned medium}

Endocrine cells (GH3 or AtT-20) were seeded and starved as described in section 3.2.4.6. After the starvation period, the cells were incubated for $48 \mathrm{hrs}$ with conditioned medium (3.2.4.7) for $48 \mathrm{hrs}$. Subsequently the supernatant was harvested and stored at $-80^{\circ} \mathrm{C}$. Total RNA was extracted from the cells (3.2.1.8).

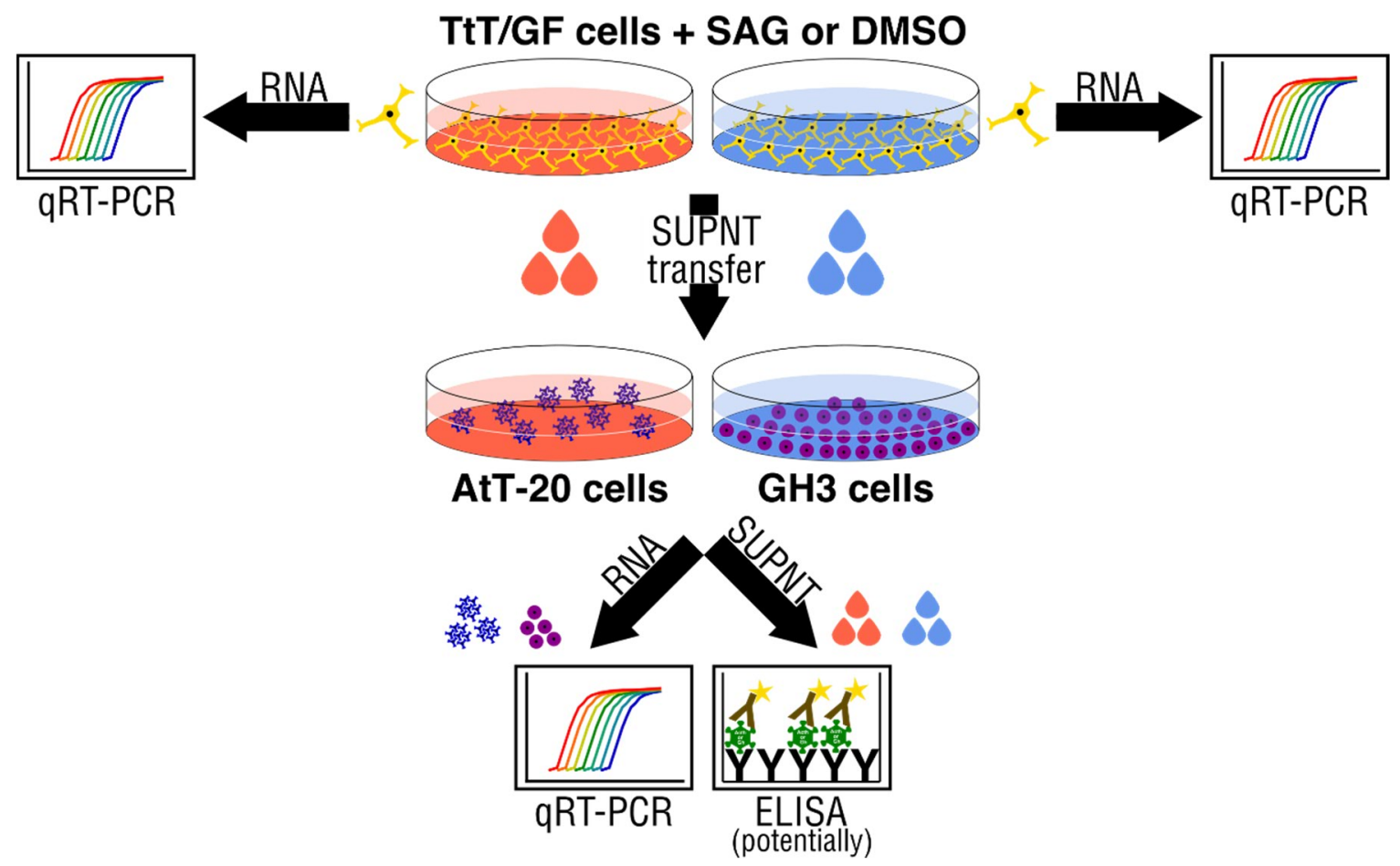

Figure 6 Schematic representation of the medium transfer experiment. TtT/GF cells were cultured either in AtT-20 (red) or GH3 (blue) medium and treated with SAG or DMSO, respectively. RNA was isolated from the treated TtT/GF cells and analysed for differential gene expression with the use of qRT-PCR (upper row). In parallel, the supernatant (SUPNT) from treated TtT/GF cells was incubated with AtT-20 or GH3 cells, respectively (middle row). Afterwrads RNA was isolated from treated AtT-20 and GH3 cells and gene expression levels were analysed via qRT-PCR. Furthermore, the supernatants from treated AtT-20 and GH3 cells were analysed via an ELISA if necessary (lower row).

\subsubsection{Ex vivo cultivation of murine pituitary glands}

Freshly isolated murine pituitary glands were washed in HDB and separately cultured in one well of a 24-well plate containing pituitary cultivation medium (Table 25) for 5 days at $37{ }^{\circ} \mathrm{C}, 5 \% \mathrm{CO}_{2}$ and $95 \%$ humidity. The medium was changed once a week. Recombination of cultivated pituitary glands was achieved by incubation of the pituitaries with $10 \mu \mathrm{M}$ tamoxifen or the respective amount of the solvent (DMSO) for 
5 consecutive days. During the incubation period, the medium was renewed once by fresh tamoxifen- or DMSO-containing medium, respectively.

Table 25 Medium for cultivation of ex vivo pituitary glands

\begin{tabular}{l|l} 
Medium & Supplements \\
\hline & $10 \%$ FBS [heat inactivated $\left(56^{\circ} \mathrm{C}\right.$ for $\left.\left.30 \mathrm{~min}\right)\right]$ \\
& $1 \times$ L-Glutamine \\
& $1 \%$ Pen/Strep \\
& $1250 \mu \mathrm{g}$ Amphotericin B \\
& $1 \times \mathrm{MEM}$ non-essential amino acids \\
& $5 \mu \mathrm{g} / \mathrm{ml}$ Insulin \\
& $5 \mu \mathrm{g} / \mathrm{ml}$ Apo-transferrin \\
& $60 \mathrm{pmol}$ T3 \\
& $20 \mathrm{pg} / \mathrm{ml}$ Sodium selenite \\
\hline
\end{tabular}

\subsubsection{0. $\quad \beta$-Ala-Lys-N( $(\varepsilon)$-AMCA staining of pituitary acute slices}

Freshly isolated murine pituitary glands (see section 3.2.7.6) were washed in HDB and placed in HBSS on ice. $2 \%$ (w/v) low melting agarose was dissolved in HBSS and heated at $65^{\circ} \mathrm{C}$ for $10 \mathrm{~min}$. Subsequently the agarose was cooled down for $10-15 \mathrm{~min}$ to $37^{\circ} \mathrm{C}$ and poured carefully into a metal mold. One pituitary gland was placed into the agarose and cooled on ice until the agarose solidified. The embedded gland was placed in cooled HBSS and $200 \mu \mathrm{m}$ thick slices were cut on a Leica VT1000S vibratome with a frequency of $60 \mathrm{~Hz}$. The slices were stored in cooled HBSS until further use. According to Bonnefont et.al. ${ }^{273}$ the slices were assumed to be viable for up to $10 \mathrm{hrs}$. Afterwards the slices were incubated for $3 \mathrm{hrs}$ in $50 \mu \mathrm{M} \beta$-Ala-Lys-N $(\varepsilon)$ AMCA diluted in $\mathrm{HBSS}$ at $37{ }^{\circ} \mathrm{C}$ with $5 \% \mathrm{CO}_{2}$ in the dark. Then, they were placed on microscope slides and dried for $5 \mathrm{~min}$ at $37 \mathrm{C}$. The slices were mounted with mowiol mounting medium and imaged on a confocal laser scanning microscope (Olympus Fluoview FV1000) (3.2.6.6).

\subsubsection{Protein biochemistry}

\subsubsection{Protein isolation from cultured eukaryotic cells and murine tissue}

To isolate proteins from cultured eukaryotic cells the cells were cultivated on $\varnothing 10 \mathrm{~cm}$ cell culture dishes until they reached $>90 \%$ confluency. Electroporated cells were harvested 48 hours post electroporation. For protein isolation the cells were washed two times with ice-cooled $1 \times$ PBS. Then $500 \mu \mathrm{l}$ fresh 1 x PBS were added, and the cells were scraped from the dish with a cell scraper. The cell suspension was 
centrifuged at 2,000 rpm for $5 \mathrm{~min}$ at $4{ }^{\circ} \mathrm{C}$ and the pellet was snap freezed in liquid nitrogen and thawed on ice. The pellet was resuspended in 30-100 $\mu \mathrm{l}$ lysis buffer (Table 4) and incubated for $45 \mathrm{~min}$ on ice with short vortexing every $15 \mathrm{~min}$. Afterwards, the sample was centrifuged for $25 \mathrm{~min}$ at $13,000 \mathrm{rpm}$ and $4{ }^{\circ} \mathrm{C}$ and the protein lysate containing supernatant was transferred into a new tube. Protein lysates were stored at $-80 \mathrm{C}$ until further use.

Total protein from murine tissue was isolated from $30-100 \mathrm{mg}$ of fresh or frozen tissue. The samples were placed in $300 \mu \mathrm{l}$ (for pituitary: $180 \mu \mathrm{l}$ ) modified RIPA buffer (Table 4) and homogenized for $1 \mathrm{~min}$ on ice with a tissue processor. The samples were shock freezed in liquid nitrogen and afterwards thawed on ice. At last, the sample was centrifuged at $10,000 \mathrm{rpm}$ for $10 \mathrm{~min}$ at $4{ }^{\circ} \mathrm{C}$ and the protein-containing supernatant was transferred in a new tube.

\subsubsection{Quantification of isolated protein samples}

Protein quantification of total protein lysates from cell culture or from tissues samples was performed by using the Pierce ${ }^{\mathrm{TM}}$ BCA Protein Assay Kit. The supplied BSA standard was diluted according to manufacturer's instructions. Pierce ${ }^{\mathrm{TM}}$ BCA Protein Assay Kit solution A was diluted 1:50 in the provided Pierce ${ }^{\mathrm{TM}}$ BCA Protein Assay Kit solution B and $200 \mu \mathrm{l}$ of this solution was added in one well of a 96-well plate. $10 \mu \mathrm{l}$ of the prepared standard or $1 \mu \mathrm{l}$ of the respective protein sample were added to the detection reagent and the mixture was incubated at $37^{\circ} \mathrm{C}$ for $30 \mathrm{~min}$. The absorption of the sample was measured in technical triplicates at $562 \mathrm{~nm}$ with a plate reader. The absorption values of the standard curve were plotted and a linear regression line was fitted to the data points. The slope of this regression line was used to calculate the protein concentration of the samples with the use of Microsoft Excel 2016 software.

\subsubsection{SDS-polyacrylamide gel electrophoresis (PAGE) and Western blotting}

Proteins were separated by their size by SDS-PAGE. Therefore $20 \mu \mathrm{g}$ of total protein were mixed with $6 \times$ SDS loading buffer in a total volume of $20 \mu \mathrm{l}$ and the solution was heated up for $5 \mathrm{~min}$ at $95^{\circ} \mathrm{C}$ with shaking at $450 \mathrm{rpm}$. Afterwards, the mixture was loaded onto a $4-12 \%$ Bis Tris Midi gel in ice cooled running buffer. Proteins were 
separated for $30 \mathrm{~min}$ at $100 \mathrm{~V}$ and afterwards for $120 \mathrm{~min}$ at $120 \mathrm{~V}$. A pre-stained marker was loaded as a protein standard. The protein gel was then blotted on a nitrocellulose membrane with a semidry blotting system. Activation of the membrane was performed with $\mathrm{dd}_{2} \mathrm{O}$. Whatman filter paper were wetted in transfer buffer. The gel was placed on the membrane and the blot was assembled in the blot apparatus. Blotting was performed for $85 \mathrm{~min}$ at $20 \mathrm{~V}$.

After blotting the membrane was transferred in a vessel and blocked in blocking buffer for $1 \mathrm{hr}$ at room temperature under continuous agitation. After $3 \times 5$ min washing with TBS-Tween the membrane was placed in a $50 \mathrm{ml}$ Falcon tube and incubated with the primary antibody (diluted in BSA-Azid) over night at $4{ }^{\circ} \mathrm{C}$ under continuous rotation. Afterwards, the membrane was washed for $3 \times 5$ min with TBS-Tween at room temperature and stained with HRP-labelled secondary antibody in blocking buffer for $1 \mathrm{hr}$ at room temperature under continuous rotation. Subsequently the membrane was washed for $3 \times 5$ min with TBS-Tween and the detection was performed by incubation the membrane with the ECL substrate solution according to manufacturer's recommendations. Documentation was performed either on the FluorChem ${ }^{\mathrm{TM}} \mathrm{Q}$ or the Azure c300 imaging system. Used primary and secondary antibodies as well as the used antibody dilutions are given in Table 9 and Table 10.

\subsubsection{Hormone concentration determination via an enzyme linked immunosorbent assay (ELISA)}

For measurement of Acth serum concentration the Acth specific ELISA kit from Biomatik was used according to manufacturer's instructions. The determination of $\mathrm{Gh}$ concentration in supernatants of $\mathrm{GH} 3$ cells was performed with the Gh specific ELISA kit from Biomatik according to manufacturer's instructions. For data analysis, the logarithmized standard concentration and the corresponding absorption values were plotted. Then a logarithmic regression line was fitted to the data points and the slope was used to calculate the Acth or Gh concentration in the samples, respectively. Data analysis was performed using Microsoft EXCEL 2016 software. 


\subsubsection{Vasoactive intestinal peptide (Vip) concentration determination with a chemiluminescent enzyme immunoassay (EIA)}

For measurement of Vip concentrations in supernatants of TtT/GF cells the Vip specific EIA kit from Phoenix Pharmaceuticals was used according to manufacturer's instructions. For data analysis the logarithmized standard concentrations and the corresponding relative luminescence values were plotted. Next, a reverse sigmoidal regression line was fitted to the data points and the slope was used to calculate the Vip concentration in the samples. Data analysis was performed using Microsoft EXCEL 2016 software and GraphPad Prism 6 software.

\subsubsection{Immunohistochemical stainings}

\subsubsection{Paraffin-embedding of murine tissue samples}

Organs to be analysed were fixed in $4 \% \mathrm{PFA}$ at $4^{\circ} \mathrm{C}$ for at least 2 days and afterwards transferred in $1 \times$ PBS and stored at $4{ }^{\circ} \mathrm{C}$ until further proceeding. PFA-fixed tissue samples were dehydrated with an ascending alcohol series $(70 \%, 80 \%, 90 \%, 96 \%$, $99 \%$ and xylene) and embedded in paraffin with an embedding machine. Afterwards paraffin embedded tissues were cut into $5 \mu \mathrm{m}$ thick sections with a microtome.

\subsubsection{Haematoxylin and eosin staining}

For haematoxylin and eosin (HE) staining, microtome-sectioned paraffin-embedded tissue samples were de-paraffinized by incubation in xylene for $2 \times 10 \mathrm{~min}$. The sections were rehydrated by a descending EtOH series $(2 \times 99 \%, 1 \times 96 \%, 1 \times 80 \%$ and $1 \times 70 \%$ ) and washed under running $\mathrm{ddH}_{2} \mathrm{O}$. Then the slides were incubated in hematoxylin solution for $20 \mathrm{~min}$ at room temperature. Afterwards, the slides were washed under running warm tap water until excessive hematoxylin was completely dissolved from the slides. Next, the slides were stained with $1 \%$ eosin solution for $20 \mathrm{sec}$ and shortly washed in $\mathrm{ddH}_{2} \mathrm{O}$. Directly after washing, the samples were dehydrated with an ascending EtOH series (1 x $70 \%, 1 \times 80 \%, 1 \times 96 \%, 1 \times 99 \%)$ and dipped $2 x$ in fresh xylene. Finally, the sections were mounted with Pertex and imaged on an Olympus microscope. 


\subsubsection{Immunohistological staining}

For immunhistological antibody stainings microtome-sectioned paraffin-embedded tissue samples were de-paraffinized by incubation in xylene for $2 \times 10 \mathrm{~min}$. Afterwards the sections were rehydrated in descending alcohol series $(100 \%, 96 \%, 70 \%)$ for $10 \mathrm{sec}$ each and washed in $\mathrm{dd}_{2} \mathrm{O}$. For antigen retrieval the sections were heated $1 \times 4 \mathrm{~min}$ and $3 \times 3 \mathrm{~min}$ in citrate buffer $\mathrm{pH} 6$ in a microwave at $600 \mathrm{~W}$. Evaporated buffer was refilled by $d_{d H_{2}} \mathrm{O}$. The cooled sections were washed with $1 \times$ TBS and afterwards incubated with $3 \% \mathrm{H}_{2} \mathrm{O}_{2}$ for 20 min to block endogenous peroxidases if the staining was visualized with HRP-labeled secondary antibodies or EnVision ${ }^{\mathrm{TM}}$ system and the AEC chromogen. After a second washing step the samples were incubated with IHC-Block for 20 min to reduce unspecific binding of the primary antibody. The primary antibody was diluted in $1 \times$ TBS and incubated on the sections over night at $4{ }^{\circ} \mathrm{C}$. On the next day, the slides were washed 3 times in $1 \times$ TBS and incubated with enzyme- or fluorescent-labeled secondary antibodies or with undiluted HRP $\mathrm{rb} / \mathrm{m}$ solution of the DAKO EnVision ${ }^{\mathrm{TM}}$ Kit for $1 \mathrm{hr}$ or $30 \mathrm{~min}$ at room temperature, respectively. Immunofluorescence stainings were mounted with DAPI mounting medium and kept in the dark at $4^{\circ} \mathrm{C}$ or $-20^{\circ} \mathrm{C}$ until images were taken. Visualization of sections stained with HRP-labeled secondary antibodies or the HRP $\mathrm{rb} / \mathrm{m}$ solution (DAKO EnVision ${ }^{\mathrm{TM}} \mathrm{Kit}$ ) was performed with AEC chromogen. For this purpose, the slides were incubated with freshly prepared AEC solution for up to $30 \mathrm{~min}$. Enzymatic reaction was stopped by placing the slides in $\mathrm{ddH}_{2} \mathrm{O}$. Afterwards the sections were counterstained with haematoxylin and mounted with Glycergel. Used primary and secondary antibodies and their used dilutions are summarized in Table 9 and Table 10.

\subsubsection{Immunocytochemistry}

For immunocytochemistry, eukaryotic cells were seeded in 24-well plates containing PLL-coated round cover slips $(0.1 \mathrm{mg} / \mathrm{ml}$ PLL for $30 \mathrm{~min})$ or were spotted onto Shifix $^{\mathrm{TM}}$ coverslips (see section 3.2.4.4). For fixation of the cells, the medium was aspired and $500 \mu \mathrm{l} 4 \%$ PFA was applied to the cells for $10 \mathrm{~min}$ at room temperature. Afterwards, cells were washed 3 times with $1 \times$ PBS and incubated with $1 \times$ PBS containing $0.5 \%$ Triton $\mathrm{X}-100$ for 30 min at room temperature. After 3 times washing with $1 \times$ PBS the unspecific antigens were blocked with $500 \mu \mathrm{IHC}$-Block for $30 \mathrm{~min}$ at room temperature. Next cells were incubated with the primary antibody in $1 \times$ PBS for 
$1 \mathrm{~h}$ at room temperature. Subsequently, the cells were washed for 3 times with $1 \mathrm{x}$ PBS and incubated with fluorescent-labeled secondary antibody in $1 \times$ PBS for $45 \mathrm{~min}$ at room temperature in the dark. Afterwards, the cells were washed once with $1 \times$ PBS and the coverslips were mounted with DAPI mounting media upside down on microscope slides. Used primary and secondary antibodies and their used dilutions are summarized in Table 9 and Table 10.

\subsubsection{Detection of murine Gli1/GLI1 transcripts in histological sections using RNAscope technique}

Detection of gene transcripts in paraffin-embedded, microtome-sectioned tissue samples was performed by using the RNAscope $2.5 \mathrm{HD}$ assay kit. Paraffin sections were cut one day before staining and dried over night at $37^{\circ} \mathrm{C}$. On the next day, the slides were incubated for $1 \mathrm{hr}$ at $60^{\circ} \mathrm{C}$ and afterwards de-paraffinized for $2 \times 5 \mathrm{~min}$ in xylene and rehydrated $2 \times 1$ min in $99 \%$ RNA-pure EtOH. After air drying of the slides for 10 min they were incubated for 20 min with RNAscope $\mathrm{H}_{2} \mathrm{O}_{2}$ at room temperature. Subsequently the slides were washed for a few seconds in autoclaved $\mathrm{ddH}_{2} \mathrm{O}$ and target retrieval was performed by incubation of the slides in preheated RNAscope Target Retrieval Reagent at $135 \mathrm{~W}$ for $10 \mathrm{~min}$ and for $180 \mathrm{~W}$ for $6 \mathrm{~min}$ in the microwave. The slides were immediately transferred in prewarmed autoclaved $\mathrm{dd}_{2} \mathrm{O}$ and washed first for a few seconds with autoclaved $\mathrm{ddH}_{2} \mathrm{O}$ and then with $99 \%$ RNApure $\mathrm{EtOH}$ for $30 \mathrm{sec}$. The sections were completely dried in a wet chamber over night at room temperature. On the next day, the sections were incubated for $30 \mathrm{~min}$ with RNAscope Protease Plus at $40^{\circ} \mathrm{C}$ in a wet chamber. Following a short washing step in autoclaved $\mathrm{ddH}_{2} \mathrm{O}$ the samples were hybridized by an incubation with two drops of the respective probe for $2 \mathrm{hrs}$ at $40^{\circ} \mathrm{C}$ in a wet chamber (Table 26). The slides were washed for $4 \mathrm{~min}$ in $1 \mathrm{x}$ RNAscope Wash Buffer under constant agitation. Afterwards the sections were incubated with two drops of AMP1 (30 min), AMP2 (15 min), AMP3 (30 min), AMP4 (15 min), AMP5 (1 hr) and AMP6 (15 min), respectively at $40{ }^{\circ} \mathrm{C}$ in a wet chamber. Between each incubation with one of the AMP probes the slides were washed for 4 min in $1 \times$ RNAscope Wash Buffer under constant agitation. After AMP6-incubation the slides were washed two times with $1 \times$ RNAscope Wash Buffer under constant agitation for $4 \mathrm{~min}$. Signal detection was performed with the FastRED reagent. For this purpose, Fast RED-B was diluted 1:60 in Fast-RED-A and the mixture was applied on the slides and incubated for $10 \mathrm{~min}$ at room temperature in a 
wet chamber. Antibody staining was performed directly after the signal detection with Fast RED. Therefore, the slides were washed with $1 \times$ TBS and blocked for 20 min in IHC-Block at room temperature. The following steps were identical with standard antibody staining (3.2.6.3).

Table 26 RNAscope ${ }^{\circledR}$ specific probes used for detection of transcripts

\begin{tabular}{|c|c|c|}
\hline Target transcript & Probe name & Order number \\
\hline$P P I B$ & RNAscope ${ }^{\circledR}$ PositiveControlProbe -Hs-PPIB & 313901 \\
\hline Ppib & RNAscope®PositiveControlProbe -Mm-Ppib & 313911 \\
\hline GLI1 & RNAscope®Probe -Hs-GLI1 & 310991 \\
\hline Gli1 & RNAscope $\circledast$ Probe -Mm-Gli1 & 311001 \\
\hline Negative control & 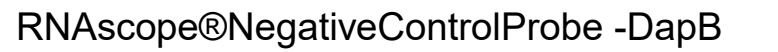 & 310043 \\
\hline
\end{tabular}

\subsubsection{Analysis of immunohistological stainings}

All fluorescent stainings were imaged with a confocal laser scanning microscope (Olympus Fluoview FV1000) equipped with the Fluoview FV10-ASW 4.2 software. Afterwards the pseudo-coloured images were edited with the Fluoview FV10-ASW Viewer software by changing the colours with the use of a Look Up Table (LUT). Immunohistological stainings were imaged with a light microscope (Olympus BX60) equipped with CellSens software. Scale bars were added to the pictures with the use of Fiji.

\subsubsection{Animal experiments}

\subsubsection{Ethical statements and animal housing}

All experiments using animals were performed in compliance with all German legal and ethical requirements and have been approved by the Lower Saxony State Office for Consumer Protection and Food Safety (file number 33.9-42502-04-15/1787 and 33.942502-04-17/2538). The responsible Institutional Animal Care and Use Committee (Lower Saxony, Germany) approved all animal experiments. All animals were kept under SPF conditions with a $12 \mathrm{hr}$ dark/light cycle and with food and water ad libitum. Used mouse lines are summarized in Table 17.

Human material was obtained from Prof. Rolf Buslei (Institute of Pathology, Sozialstiftung Bamberg, Germany). All experiments using human material were performed in compliance with the Ethical Committee of the University of Erlangen- 
Nürnberg (file number 3598 awarded to Prof. Rolf Buslei). Written informed consent from all patients were acquired.

\subsubsection{Genotyping of mice}

In order to ensure the desired genotype of the mice, all animals were biopsied at an age of 3 to 4 weeks. Either tissue from the tail tip or from an ear punch was used. From these tissue samples genomic DNA was isolated (3.2.1.1) and used for a PCR-based genotyping. All PCR reactions included $1 \mu \mathrm{l} 10$ x PCR buffer, $1 \mu \mathrm{l}$ Cresol, $0.2 \mu \mathrm{l} 10 \mathrm{mM}$ dNTPs, $0.6 \mu \mathrm{C} \mathrm{CaCl}_{2}, 0.5 \mu \mathrm{l}$ forward DNA-oligonucleotide $(0.5 \mu \mathrm{M}), 0.5 \mu \mathrm{l}$ reverse DNAoligonucleotide $(0.5 \mu \mathrm{M}), 6.1 \mu \mathrm{l}$ Ampuwa $\mathrm{H}_{2} \mathrm{O}$ and $0.1 \mu \mathrm{l}$ MolTaq polymerase $(0.1 \mathrm{U})$. Used DNA-oligonucleotides and the expected amplicon sizes are given in Table 11. The reaction was performed in a PCR thermocycler with the settings listed in Table 27.

Table 27 PCR thermocycler settings for genotyping of mice form the indicated stains.

\begin{tabular}{|c|c|c|}
\hline \multicolumn{3}{|c|}{ Aldh1/1CreERT2 } \\
\hline Temp. & Duration & Cycles \\
\hline $94^{\circ} \mathrm{C}$ & $4 \min$ & $1 x$ \\
\hline $94^{\circ} \mathrm{C}$ & $20 \mathrm{sec}$ & \\
\hline $60{ }^{\circ} \mathrm{C}$ & $20 \mathrm{sec}$ & $40 x$ \\
\hline $72{ }^{\circ} \mathrm{C}$ & $45 \mathrm{sec}$ & \\
\hline $72{ }^{\circ} \mathrm{C}$ & $5 \min$ & $1 x$ \\
\hline
\end{tabular}

\begin{tabular}{|c|c|c|}
\hline \multicolumn{3}{|c|}{ Gli1CreERT2 } \\
\hline Temp. & Duration & Cycles \\
\hline $94{ }^{\circ} \mathrm{C}$ & $4 \mathrm{~min}$ & $1 x$ \\
\hline $94^{\circ} \mathrm{C}$ & $20 \mathrm{sec}$ & \\
\hline $60^{\circ} \mathrm{C}$ & $20 \mathrm{sec}$ & $33 x$ \\
\hline $72^{\circ} \mathrm{C}$ & $45 \mathrm{sec}$ & \\
\hline $72{ }^{\circ} \mathrm{C}$ & $5 \mathrm{~min}$ & $1 x$ \\
\hline
\end{tabular}

\begin{tabular}{l|l|l}
\multicolumn{3}{c}{ hGHRHRCreERT2 } \\
\cline { 1 - 2 } Temp. & Duration & Cycles \\
\hline $95{ }^{\circ} \mathrm{C}$ & $4 \mathrm{~min}$ & $1 \mathrm{x}$ \\
\hline $95^{\circ} \mathrm{C}$ & $45 \mathrm{sec}$ & \multirow{2}{*}{$35 \mathrm{x}$} \\
\hline $62{ }^{\circ} \mathrm{C}$ & $30 \mathrm{sec}$ & \\
\hline $72{ }^{\circ} \mathrm{C}$ & $45 \mathrm{sec}$ & \\
\hline $72{ }^{\circ} \mathrm{C}$ & $5 \mathrm{~min}$ & $1 \mathrm{x}$ \\
\hline
\end{tabular}

\begin{tabular}{l|l|l}
\multicolumn{3}{c}{ PomcCreERT2 } \\
\cline { 1 - 2 } Temp. & Duration & Cycles \\
\hline $94{ }^{\circ} \mathrm{C}$ & $3 \mathrm{~min}$ & $1 \mathrm{x}$ \\
\hline $94{ }^{\circ} \mathrm{C}$ & $30 \mathrm{sec}$ & \multirow{2}{*}{$29 \mathrm{x}$} \\
\hline $62{ }^{\circ} \mathrm{C}$ & $1 \mathrm{~min}$ & \\
\hline $72{ }^{\circ} \mathrm{C}$ & $50 \mathrm{sec}$ & \\
\hline $72{ }^{\circ} \mathrm{C}$ & $2 \mathrm{~min}$ & $1 \mathrm{x}$ \\
\hline
\end{tabular}

\begin{tabular}{l|l|l}
\multicolumn{3}{c}{ Ptchf; GFP; RosaTomato } \\
\hline Temp. & Duration & Cycles \\
\hline $94{ }^{\circ} \mathrm{C}$ & $4 \mathrm{~min}$ & $1 \mathrm{x}$ \\
\hline $94^{\circ} \mathrm{C}$ & $20 \mathrm{sec}$ & \multirow{2}{*}{$33 \mathrm{x}$} \\
\hline $60^{\circ} \mathrm{C}$ & $20 \mathrm{sec}$ & \\
\hline $72^{\circ} \mathrm{C}$ & $45 \mathrm{sec}$ & \\
\hline $72{ }^{\circ} \mathrm{C}$ & $5 \mathrm{~min}$ & $1 \mathrm{x}$ \\
\hline
\end{tabular}

\begin{tabular}{l|l|l}
\multicolumn{3}{c}{ Smo $^{f}$} \\
\hline Temp. & Duration & Cycles \\
\hline $94{ }^{\circ} \mathrm{C}$ & $3 \mathrm{~min}$ & $1 \mathrm{x}$ \\
\hline $94^{\circ} \mathrm{C}$ & $1 \mathrm{~min}$ & \multirow{2}{*}{$35 \mathrm{x}$} \\
\hline $65^{\circ} \mathrm{C}$ & $1 \mathrm{~min}$ & \\
\hline $72{ }^{\circ} \mathrm{C}$ & $1 \mathrm{~min}$ & \\
\hline $72{ }^{\circ} \mathrm{C}$ & $2 \min$ & $1 \mathrm{x}$ \\
\hline
\end{tabular}

\begin{tabular}{l|l|l}
\multicolumn{3}{c}{ Sox2CreERT2 } \\
\cline { 1 - 2 } Temp. & Duration & Cycles \\
\hline $95^{\circ} \mathrm{C}$ & $5 \mathrm{~min}$ & $1 \mathrm{x}$ \\
\hline $95^{\circ} \mathrm{C}$ & $15 \mathrm{sec}$ & \multirow{2}{*}{$35 \mathrm{x}$} \\
\hline $63^{\circ} \mathrm{C}$ & $15 \mathrm{sec}$ & \\
\hline $72^{\circ} \mathrm{C}$ & $30 \mathrm{sec}$ & \\
\hline $72^{\circ} \mathrm{C}$ & $2 \mathrm{~min}$ & $1 \mathrm{x}$ \\
\hline
\end{tabular}




\subsubsection{In vivo tamoxifen application}

Induction of CreERT2-mediated recombination of floxed loci in 4- and 8-week old transgenic mice was performed by intraperitoneally (i.p.) injection of $1 \mathrm{mg}$ tamoxifen in $100 \mu \mathrm{l}$ solvent for 5 consecutive days resulting in a total dose of $5 \mathrm{mg}$ tamoxifen per mouse. Tamoxifen solution for in vivo application was prepared by mixing $200 \mathrm{mg}$ tamoxifen with $800 \mu \mathrm{l} 99$ \% RNA-pure EtOH and $20 \mathrm{ml}$ sunflower seed oil. The solution without tamoxifen was used as solvent control. Ready-to-use syringes were stored at $-20^{\circ} \mathrm{C}$ until use, but maximum for 1 year.

\subsubsection{Blood serum isolation and glucose measurement from Pomc/Ptch Pff $^{\text {Plf }}$ and Pomc/Smo ${ }^{f / f}$ mice}

During the observation period of 250 days post tamoxifen application every two weeks approximately $150 \mu$ of blood was taken from the retro-orbital plexus of 8 weeks old Pomc/Ptch $^{f / f}$, Pomc/Smo ${ }^{f / f}$ and the respective control mice. The blood was collected in $1.5 \mathrm{ml}$ tubes and coagulated for $2 \mathrm{hrs}$ at $4{ }^{\circ} \mathrm{C}$. Afterwards the sample were centrifuged for $10 \mathrm{~min}$ at $3,000 \mathrm{rpm}$ and $4{ }^{\circ} \mathrm{C}$. The upper serum (approximately $80 \mu \mathrm{l}$ ) was transferred into a new tube and stored at $-80{ }^{\circ} \mathrm{C}$ until further use.

Simultaneously to blood collection one drop of blood was applied on test stripes of the Contour xt measurement device for measurement of blood glucose levels (mg/dl).

\subsubsection{Body weight analysis in Pomc/Ptch B $^{\mathrm{f} / \mathrm{f}}$ and $\mathrm{Pomc} / \mathrm{Smo}^{\mathrm{f} / \mathrm{f}} \mathrm{mice}$}

Once a week during the observation period of 250 days post tamoxifen application Pomc/Ptch fff, Pomc/Smo f/f and the respective control mice were weighed and the absolute body weight was plotted over time.

\subsubsection{Murine tissue isolation}

Mice were euthanized by cervical dislocation under deep $\mathrm{CO}_{2}$ anaesthesia. Next, the animal was fixed on the preparation table and fur was disinfected and wetted using $70 \% \mathrm{EtOH}$. After removing of the scalp, incisions were made from the foramen magnum towards the frontal bone along the parietal bone. The calotte was lifted 
rostrally. Subsequent the brain was removed by levering it caudally with a spatula, cut sagittal and the hemispheres were embedded together. Using a scalpel, the pituitary gland was separated from the left and right trigeminal nerve and taken out from the sella region. The organ was embedded in toto with its caudodorsal surface facing downwards. The abdomen of the mouse was opened along the linea alba and the respective organs were taken from the abdomen. For paraffin embedding the organs were placed in $4 \%$ PFA and processed as described in 3.2.6.1. For RNA or protein isolation, the organs were directly frozen at $-80^{\circ} \mathrm{C}$. 


\section{Results}

\subsection{Deregulation of Hh signalling in corticotrophs of adult mice pituitary}

Previously our lab showed that a ubiquitous overactivation of Hh signalling in ex vivo cultured adult pituitaries lead to increased Pomc, Gh and Prl transcription and stimulates the proliferation of Sox $2^{+}$cells in the $\mathrm{AL}^{185}$. However, the particular cell type/s which is/are responsive for Hh signalling activation and thus is/are responsible for the observed phenotype has/have not been determined so far although this information is of therapeutic interests, e. g. for ACTH-, GH- or PRL-expressing PA that show elevated $\mathrm{Hh}$ signalling activity ${ }^{185}$. However, ours ${ }^{185}$ and the data from other labs ${ }^{183,184}$ strongly pointed towards a direct impact of Hh signalling in Acth/Pomcexpressing cells in the adult pituitary gland. Thus, the cell-specific role of Hh signalling in Acth/Pomc-producing cells was investigated by using the conditional tamoxifeninducible in vivo gene knock out technique. For this purpose, the PomcCreERT2 deleter mouse strain that expresses a tamoxifen-inducible CreERT2-recombinase under the control of the Pomc promoter was chosen. However, neither inducibility, specificity nor efficiency of PomcCreERT2-mediated recombination in the adult pituitary was investigated so far. Thus, first PomcCreERT2/ROSA26tdTomato (Pomc/tdT) reporter mice were generated and inducibility, specificity and efficiency of the CreERT2-recombinase in the adult pituitary gland was analysed. Afterwards PomcCreERT2 mice were bred with Ptch $^{f / f}$ or Smo f/f mice, respectively, to investigate the effect of activated or inhibited $\mathrm{Hh}$ signalling in corticotrophs by homozygous depletion of Ptch and Smo, respectively, in PomcCreERT2-expressing cells in vivo.

\subsubsection{The PomcCreERT2 deleter mouse strain expresses the CreERT2 cell- specific but its activity is moderately leaky in the pituitary gland}

To study the inducibility, specificity and efficiency of the PomcCreERT2-recombinase PomcCreERT2 mice (Pomc) were bred with ROSA26-tdTomato reporter (tdT/tdT) mice that only express the red fluorescent protein tdTomato (tdT) after Cre-mediated recombination ${ }^{261}$. The resulting Pomc/tdT mice were injected with tamoxifen or solvent, respectively, at an age of 8 weeks and pituitaries were collected 7, 14, 50, 100, 150, 200 and 250 days post-injection. Afterwards the expression of tdT was analysed by 
anti-RFP antibody stainings of pituitary gland sections.

Pituitary glands of tamoxifen-treated Pomc/tdT showed strong tdT expression in the $\mathrm{AL}$ and in the IL (Figure 7 right, overview). The $\mathrm{td} \mathrm{T}^{+}$cells were located throughout the complete AL and all cells of the IL. At all investigated time points incl. up to 250 days post tamoxifen-treatment $\mathrm{tdT}^{+}$cells were detectable (Figure 7). However, mild or strong tdT expression was also observed in sections from solvent-treated Pomc/tdT pituitaries in the $\mathrm{AL}$ and the $\mathrm{IL}$, respectively (Figure 7, left, arrow heads). Double immunofluorescence staining furthermore showed a clear co-localization of tdT with Acth and Pomc but never with Gh or Prl (Figure 7) in tamoxifen- and solvent-treated pituitaries demonstrating the cell-specific expression of the CreERT2-recombinase in Pomc-/Acth-expressing cells. Comparison of age-matched tamoxifen- and solventinduced pituitaries furthermore revealed despite of the mild leakiness of the CreERT2recombinase in the $A L$ a strongly increased number of $\operatorname{tdT}^{+} A L$ cells in tamoxifentreated pituitaries (Figure 7, right). 


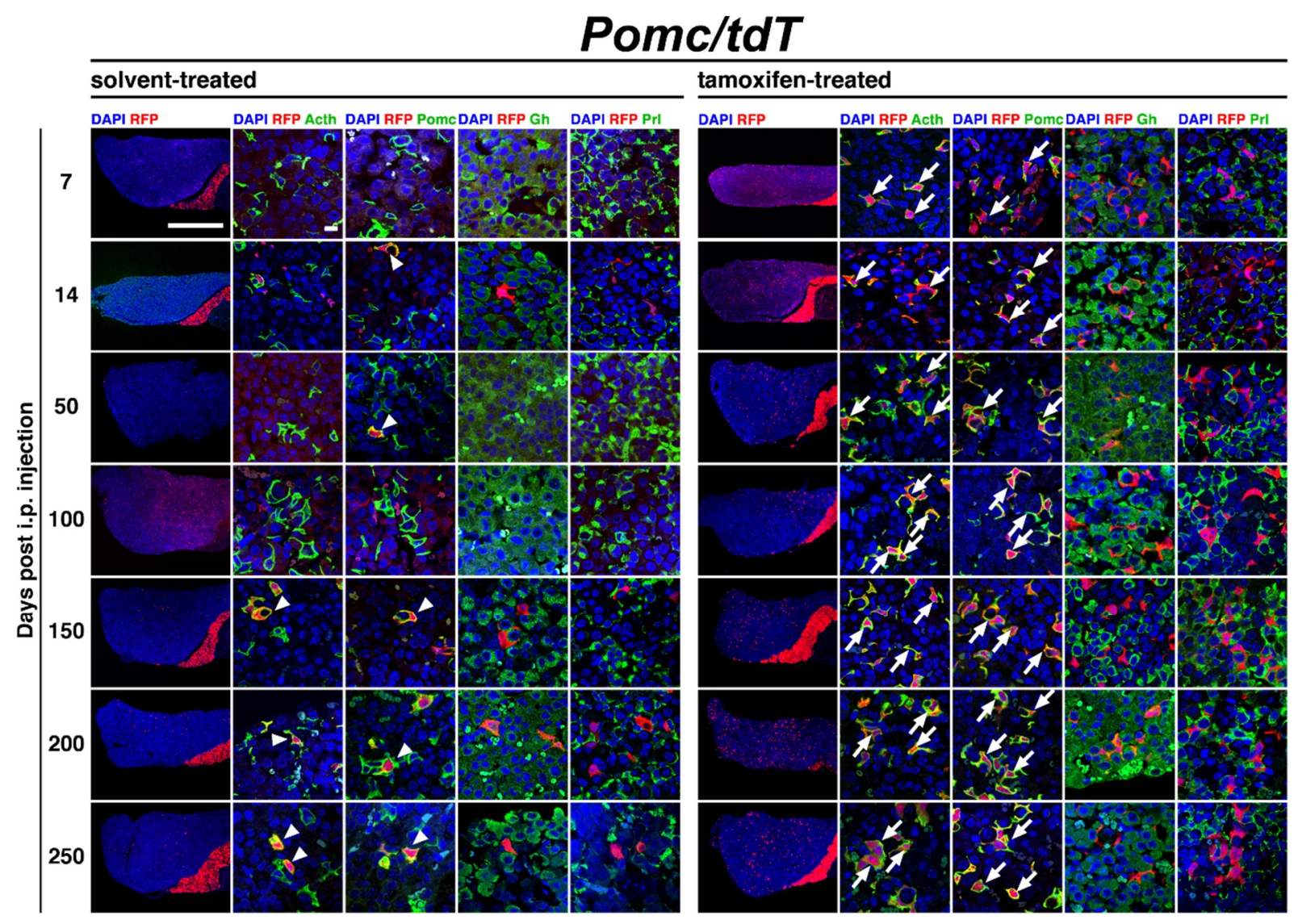

Figure 7 Cell-type specific expression and inducibily of the CreERT2-recombinase of PomcCreERT2 mice. tdT expression in pituitary glands of solvent- (left) and tamoxifen- (right) treated Pomc/tdT animals was examined with an anti-RFP (red) specific antibody. Overview pictures (first columns) show tdT expression in the AL and IL of tamoxifen and solvent-treated samples. Double immunofluorescence stainings with antibodies aginst Acth, Pomc, Gh and Prl revealed co-localization of tdT with Acth and Pomc in the tamoxifen-treated (arrows) and the solvent-treated animals (arrowheads). Scale bars represent $500 \mu \mathrm{m}$ for the overview pictures and $10 \mu \mathrm{m}$ for the magnified pictures.

These data demonstrate, that the CreERT2-recombinase of PomcCreERT2 mice is (1) cell-specifically expressed in Pomc-/Acth-expressing cells, (2) efficiently inducible in vivo in the pituitary gland by i.p. tamoxifen-application but (3) also mildly or strongly leaky without tamoxifen induction in the AL or IL, respectively. 


\subsubsection{In vivo activation/inactivation of Hh signalling in corticotrophs}

\subsubsection{Pomc/Ptch ${ }^{f / f}$ and Pomc/Smo ${ }^{f / f}$ mice are born in normal Mendelian ratio}

Ptch and Gli1 are expressed in the developing pituitary and are essential for the proliferation of the gland (see 1.3.2). Since Pomc is firstly expressed at E14 in rat pituitaries ${ }^{274}$ a depletion of Ptch or Smo in Pomc-expressing cells at this developmental stage could have been result in developmental abnormalities of the gland and/or Pomc-expressing cells. Since the mild leakiness of the PomcCreERT2 strain in adult pituitaries (Figure 7, left) hint towards also a leakiness during pituitary development, the birth ratio of the afterwards generated Pomc/Ptch ${ }^{f / f}$ and Pomc/Smo ${ }^{f / f}$ mice was analysed in comparison to Ptch/f and Smo ${ }^{f / f}$ littermates (Figure 8). Nonetheless, Pomc/Ptch $^{f / f}$ and Pomc/Smof/f mice were born in the suspected Mendelian ratios (Figure 8) and showed inconspicuous health status demonstrating that Hh signalling plays no role in Pomc-expressing cells during pituitary development. However, these results furthermore indicated that a deregulation of $\mathrm{Hh}$ signalling in some corticotrophs (due to the leakiness of the PomcCreERT2) might not affect the general health status of young mice.

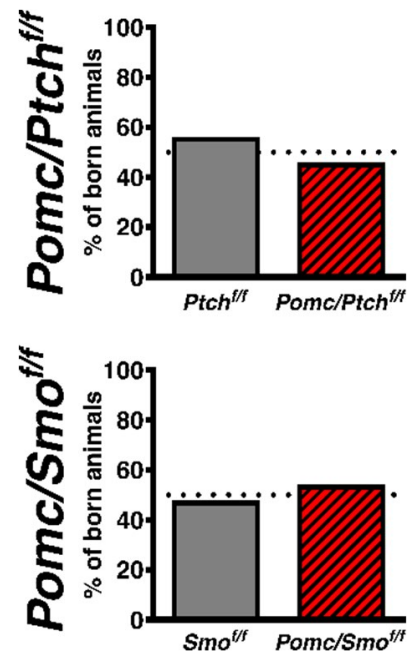

Figure 8 Mendelian ratios of the offspring of Pomc/Ptch f/f and Pomc/Smo ${ }^{f / f}$ mice. The offspring of Pomc/Ptch ${ }^{f / f}$ and $P o m c / S m o^{f / f}$ was counted manually and the percentage of born animals with the genotype Pomc/Ptch ${ }^{f / f}$ (red/black upper row) Ptch ${ }^{f / f}$ (grey, upper row), Pomc/Smo ${ }^{f / f}$ (red/black, lower row) and Pomc/Smo ${ }^{f / f}$ (grey, lower row) was calculated. 


\subsubsection{Body weight, blood glucose, serum Acth level and pituitary gland weight are not altered in tamoxifen-treated Pomc/Ptch ${ }^{f / f}$ and $\mathrm{Pomc}_{\mathrm{S}} \mathrm{mo} \mathrm{o}^{\mathrm{f} / \mathrm{f}}$ mice}

To analyse the effect of activated or inactivated Hh signalling in a large corticotroph population (compare solvent- and tamoxifen-treated Pomc/tdT pituitaries, Figure 7) in adult mice the CreERT2-recombinase of 4 and 8 weeks old Pomc/Ptch ${ }^{f / f}$ and $\mathrm{Pomc} / \mathrm{Smo}^{\mathrm{ff} / \mathrm{f}}$ mice was activated via i.p. tamoxifen-application. Solvent-treated Pomc/Ptch ${ }^{f / f}$ and Pomc/Smo fff and solvent- or tamoxifen-treated $\mathrm{Ptch}^{\mathrm{ff}}$ and $\mathrm{Smo} \mathrm{fth}^{\mathrm{ff}}$ mice served as controls.

Our previous results showed that ubiquitous activation of $\mathrm{Hh}$ signalling in the adult pituitary gland leads to increased Acth production ${ }^{184,185}$ pointing towards an cellintrinsic role of $\mathrm{Hh}$ signalling in Acth production from corticotrophs. Since furthermore Acth regulates the release of glucocorticoids from the adrenal gland which in turn control gluconeogenesis in the liver and de novo lipid production ${ }^{19}$ it was assumed that tamoxifen-induced Pomc/Ptch ${ }^{f f f}$ and Pomc/Smo ${ }^{f f f}$ mice may suffer from body weight, blood glucose level and/or Acth serum level variations. Thus, tamoxifen-induced $\mathrm{Pomc}_{\mathrm{Ptch}}{ }^{f f}$, Pomc/Smo fff as well as the respective control mice were monitored for 250 days post-injection and body weight, blood glucose levels as well as Acth serum levels were recorded at distinct time points during the observation period (see 3.2.7.4 and 3.2.7.5).

However, neither activation nor inactivation of Hh signalling in Pomc-/Acth-expressing cells resulted in significant changes in body weight (Figure 9A,C) or blood glucose concentration (Figure 9B,D) compared to the controls. Beyond that, neither Acth serum levels (Figure 10A,C) nor end-point measured pituitary weights (Figure 10B,D) differed in tamoxifen-treated Pomc/Ptch fff and Pomc/Smo ff/ mice compared to the respective controls.

These results demonstrate that neither the depletion of Ptch nor Smo in corticotrophs change the peripheral Acth serum concentration in vivo. Moreover, pathological health conditions that are caused by deregulated Acth levels (e.g. body weight or blood glucose) were also not observed. Thus, it has to be assumed that $\mathrm{Hh}$ signalling is not involved in Acth regulation in corticotrophs in vivo. 



\section{Blood Glucose}
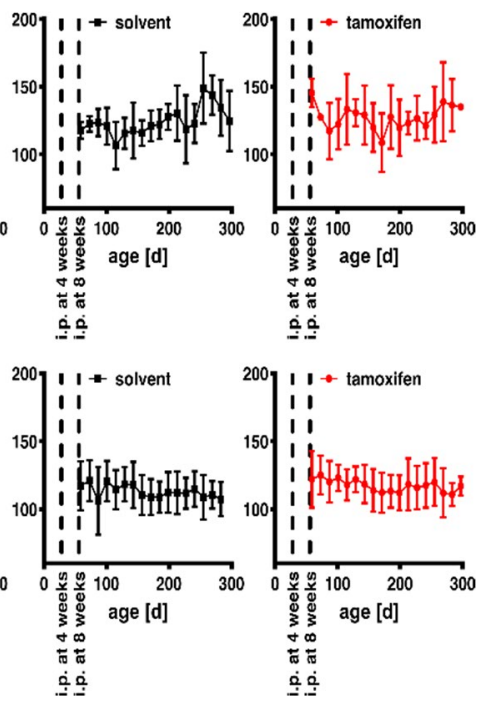

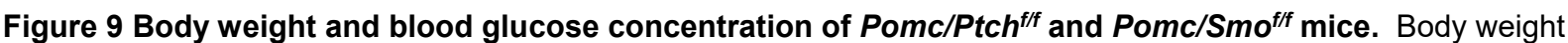
$(\mathbf{A}, \mathbf{C})$ and blood glucose level (B,D) of tamoxifen- (red) and solvent-treated (black) Pomc/Ptch ${ }^{\text {f/f }}(\mathbf{A}, \mathbf{B})$ or $\mathrm{Pomc}_{\mathrm{Smo}}^{\mathrm{fff}}(\mathbf{C}, \mathbf{D})$ and tamoxifen- and solvent-treated $\mathrm{Ptch}^{f / f}(\mathrm{~A}, \mathrm{~B})$ or $\mathrm{Smo}^{f / f}(\mathbf{C}, \mathrm{D})$ mice (grey). Body weight was measured weekly over 250 days post i.p. injection and blood glucose levels were determined every second week over 250 days post i.p. injection. Data represent mean \pm SD.
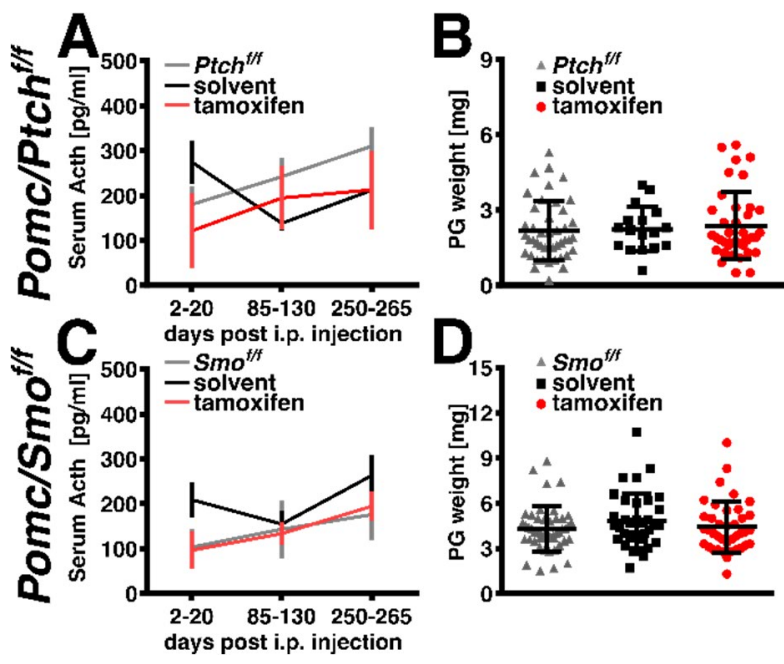

Figure 10 Acth serum level and pituitary gland weight of Pomc/Ptch ${ }^{f / f}$ and Pomc/Smo P $^{\mathrm{f} / f}$ mice. Acth serum concentration (A,C) and end-point pituitary gland (PG) weight (B,D) of tamoxifen- (red) and solvent-treated (black) $\operatorname{Pomc} \operatorname{Ptch}^{f / f}(\mathrm{~A}, \mathrm{~B})$ or Pomc/Smo ${ }^{f / f}(\mathbf{C}, \mathbf{D})$ and tamoxifen- or solvent-treated $\operatorname{Ptch}^{f / f}(\mathbf{A}, \mathbf{B})$ or Smo ${ }^{f / f}$ mice $(\mathbf{C}, \mathbf{D})(\mathrm{grey})$. Acth serum concentration was analyses at 3 different indicated time points $(\mathbf{A}, \mathbf{C})$. Data represent mean \pm SD. 


\subsubsection{The histology of tamoxifen-treated Pomc/Ptch/f and Pomc/Smo ${ }^{f / f}$ pituitary glands shows no alterations}

The depletion of Ptch or Smo did not resulted in obvious phenotypic alterations (Figure 8, Figure 9 Figure 10). To analyse potential morphological changes resulting from a deregulated $\mathrm{Hh}$ signalling in corticotrophs, the pituitaries of tamoxifen-treated Pomc/Ptch $^{f / f}$ and Pomc/Smo ${ }^{f / f}$ mice as well as of the controls were histologically and immunohistologically examined 250 days after tamoxifen/solvent application. H\&E stainings of the sectioned pituitaries revealed no morphological alterations (e.g. lesions, adenomas) in tamoxifen-treated Pomc/Ptch ${ }^{f / f}$ and Pomc/Smo ${ }^{f / f}$ mice compared to the respective controls. Beyond that, the pituitaries of tamoxifen-treated Pomc/Ptch f/f and $\mathrm{Pomc} / \mathrm{Smo}^{\mathrm{f} / \mathrm{f}}$ mice did not show alterations in the number of proliferative active cells (Figure 11) or in the Pomc or Acth expression pattern in comparison to the controls (Figure 12).

These data show that the depletion of Ptch or Smo in corticotrophs of the adult murine pituitary glands does not induce in morphological alterations of the gland (Figure 11), differential proliferation status of pituitary cells (Figure 11) or altered Pomc or Acth expression (Figure 12).



Figure 11 Histological analysis of pituitary glands of tamoxifen-treated Pomc/Ptch Pff $^{f}$ and Pomc/Smo Poff $^{\mathrm{f}}$ mice. H\&E (upper row) and anti-Ki-67 antibody stainings (lower row) of pituitary gland sections from tamoxifen- and

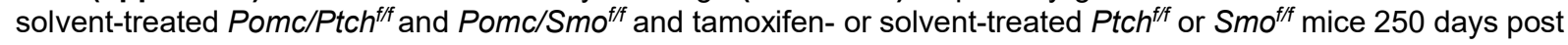
i.p. injection. Arrows indicated Ki-67 positive cells in the glands. Scale bars represent $50 \mu \mathrm{m}$. 


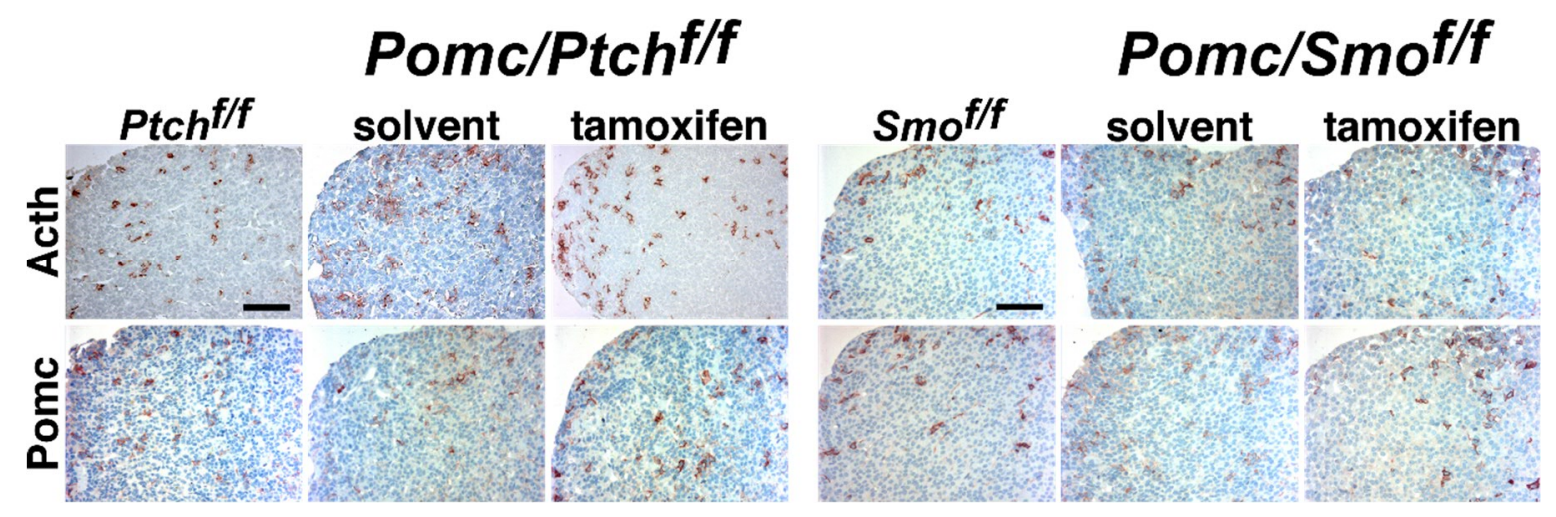

Figure 12 Expression pattern of Acth and Pomc in Pomc/Ptch ${ }^{f / f}$ and Pomc/Smo ${ }^{f / f}$ pituitary glands. Anti-Acth (upper row) and Pomc antibody stainings (lower row) of pituitary gland sections from tamoxifen- and solventtreated Pomc/Ptch ${ }^{f / f}$ and Pomc/Smo ${ }^{f / f}$ and tamoxifen- or solvent-treated Ptch ${ }^{f / f}$ or Smo ${ }^{f / f}$ mice 250 days post i.p. injection. Scale bars represent $50 \mu \mathrm{m}$.

\subsubsection{Tamoxifen-treated Pomc/Ptch ${ }^{f / f}$ and Pomc/Smo fff pituitary glands} show no explicit differences in gene expression analyses

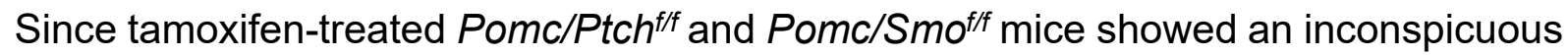
health status and no histological alterations of the pituitary next the Hh signalling activation status of the dissected pituitaries were examined. Therefore, the transcriptional level of the $\mathrm{Hh}$ target genes Gli1, Gli2 and Ptch and of the hormones Pomc, Gh and Prl were measured by qRT-PCR analyses.

These approaches revealed that neither the depletion of Ptch nor Smo in corticotrophs of adult murine pituitary glands resulted in changed Gli1, Gli2, Ptch (Figure 13), Gh or Prl transcript expression (Figure 14). However, depletion of Ptch in Pomc-expressing cells also did not alter the Pomc transcriptional level whereas Smo-depletion significantly reduced Pomc expression compared to the respective controls (Figure 14).

These results show that the homozygous depletion of Ptch or Smo in corticotrophs neither affect the $\mathrm{Hh}$ signalling activation status nor the expression level of $\mathrm{Gh}$ or Prl. However, since Pomc/Smo fff pituitaries showed decreased Pomc transcript levels an impact of Hh signalling inactivation of Pomc expression cannot completely ruled out although activation of the pathway had no effect on Pomc expression and "classical" Hh signalling target genes (e.g. Gli1, Gli2, Ptch) were not altered. 


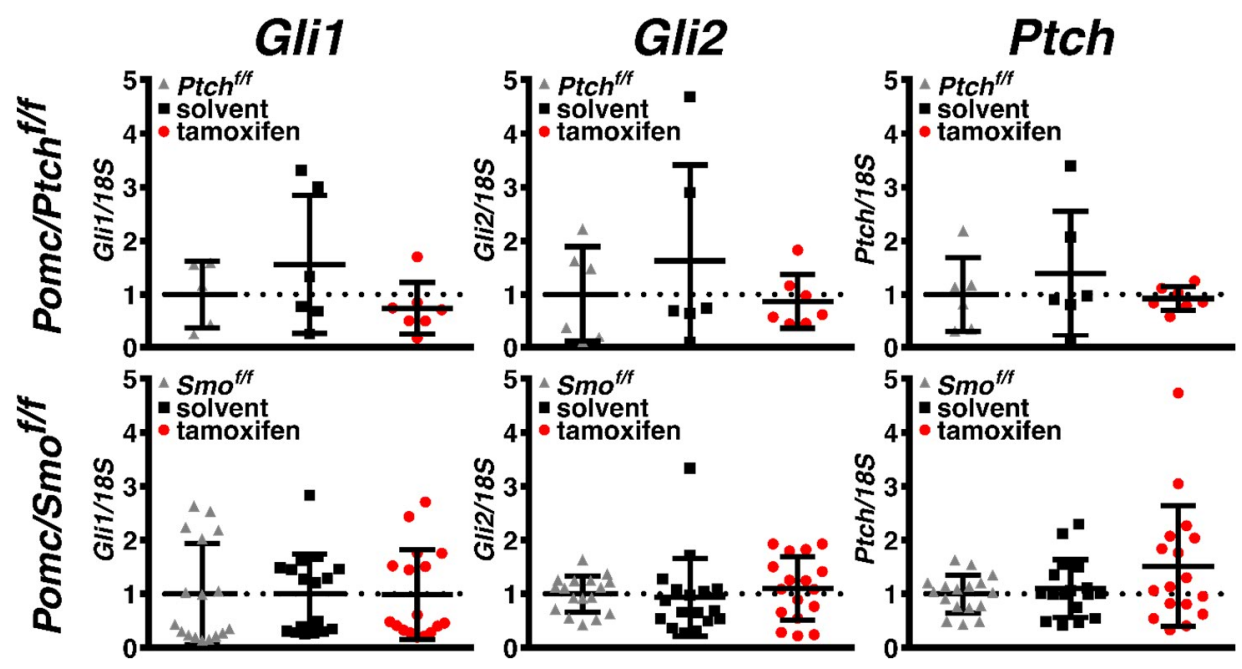

Figure $13 \mathrm{Hh}$ signalling target gene expression in Pomc/Ptch f/f and Pomc/Smo ${ }^{\mathrm{f} / \mathrm{f}}$ pituitary glands. RNA was isolated from tamoxifen-(red) or solvent-(black) treated Pomc/Ptch ${ }^{f / f}$ and $P o m c / S m o^{f / f}$ and tamoxifen- or solventtreated (grey) $\mathrm{Ptch}^{f / f}$, and $\mathrm{Smo}^{f / f}$ murine pituitary glands 250 days post i.p. application and the gene expression of the Hh target genes Gli1, Gli2 and Ptch were analysed via qRT-PCR. The data were normalized to 18S rRNA (18S) and are shown as fold expression in comparison to tamoxifen- or solvent-treated Ptch $^{f / f}$ (upper row) or Smo ${ }^{f / f}$ (lower row) mice pituitary glands set to 1 (dotted line). Each dot represents one pituitary gland measured in technical triplicates. The data is depicted as mean $\pm S D$.



Figure 14 Hormone gene expression in Pomc/Ptch f/f and Pomc/Smo Pff $^{f / t}$ pituitary glands. RNA was isolated from tamoxifen-(red) or solvent-(black) treated Pomc/Ptch ${ }^{f / f}$ and Pomc/Smo ${ }^{f / f}$ and tamoxifen- or solvent-treated (grey) $\mathrm{Ptch}^{f f f}$, and $S m o^{f / f}$ murine pituitary glands 250 days post i.p. application and the gene expression of the hormone genes Pomc, Gh and Prl were analysed via qRT-PCR. The data were normalized to 18S rRNA (18S) and are shown as fold expression in comparison to tamoxifen- or solvent-treated Ptch ${ }^{f / f}$ (upper row) or Smo ${ }^{f / f}$ mice (lower row) pituitary glands set to 1 (dotted line). Each dot represents one pituitary gland measured in technical triplicates. The data is depicted as mean \pm SD. For statistical analyses a two-tailed unpaired t-test was performed. * indicate significance compared to tamoxifen- or solvent-treated $P t c h{ }^{f / f}$ or $S m o^{f / f}$ or to solvent-treated mice. ${ }^{*} p<0.05$, ${ }^{* *} p<0.01$ 


\subsubsection{Depleted Ptch and Smo loci are detected in Pomc/Ptch ${ }^{\text {f/f }}$ and Pomc/Smo ${ }^{f / f}$ pituitary glands 250 days post tamoxifen-treatment}

The unaltered phenotype of tamoxifen-treated Pomc/Ptch ${ }^{f / f}$ and $\mathrm{Pomc} / \mathrm{Smo}^{\mathrm{f} / \mathrm{f}}$ mice as well as the fact that tamoxifen-treated $\mathrm{Pomc}_{\mathrm{Ptch}}^{\mathrm{fff}}$ and $\mathrm{Pomc} / \mathrm{Smo}^{\mathrm{f} / \mathrm{f}}$ pituitaries did not show any alterations in Hh signalling activity status hint towards the possibility that Ptch or Smo depleted cells were erased in pituitaries of these mice. To evaluate if tamoxifen-treated Pomc/Ptch ${ }^{f / f}$ and Pomc/Smo ${ }^{f / f}$ pituitaries still consists of Ptch or Smo depleted cells 250 days after CreERT2-induction PCR-based analyses for the detection of the recombined Ptch $^{f}$ and Smo ${ }^{f}$ loci in these pituitaries were assessed.

For the analysis of the recombined Ptch locus, which lacks exon 8 and 9 of the Ptch gene a previously described assay was used ${ }^{157}$. The principle of the assay is depicted in the corresponding method section (3.2.1.5). In short, the DNA-oligonucleotide Exon7-F binds in the coding region of exon 7 of the wild-type Ptch and the Ptch ${ }^{f}$ allele and the DNA-oligonucleotide Neo- $R$ binds in the neomycin resistance cassette that is located in the intron region between exon 9 and 10 of Ptch $^{f}$ allele. Thus, the resulting amplicon of this DNA-oligonucleotide pair on the Ptch locus has a size of approximately $2700 \mathrm{bp}$. After recombination of the Ptch ${ }^{f}$ allele, the amplicon of this DNA-oligonucleotide pair has a reduced size of $950 \mathrm{bp}$ and resembles the Ptchdel locus. An amplification of the wild-type Ptch allele does not occur.

The recombination of the $S m o^{f}$ locus, which leads to the depletion of exon 1 of the Smo gene and the expression of the beta-galactosidase gene $(L a c Z)^{158}$ was analysed by a newly established assay. Since more information about the exact Smof locus was not available the first $4300 \mathrm{bp}$ of the $S m o^{f}$ locus were sequenced to elucidate the unknown sequence. Afterwards specific DNA-oligonucleotides were generated to specifically amplify the $S m o^{f}$ as well as the recombined $S m o^{f}$ allele (Smodel) (Figure 15). Specific amplification of the $S m o^{f}$ allele by using DNA-oligonucleotides that bind in the 5' untranslated region (UTR) (Smo5' long forward) and in exon 1 (Smodel WT rev) results in a $590 \mathrm{bp}$ amplicon. The $S m o^{\text {del }}$ was detected by amplification of a $400 \mathrm{bp}$ amplicon by using Smo5' long forward and a DNA-oligonucleotide that binds downstream of the loxP sequence (Smoflox recombi rev) (Figure 15). 




Figure 15 Schematic representation of the $\mathrm{Smo}^{f}$ locus before and after Cre-mediated recombination. Presentation of exon 1 to 12 (E1 to E12) of the Smo locus. LoxP sites (white triangles) are located upstream of exon 1 and in intron 1 upstream of the beta-galactosidase gene (LacZ). In intron 1 a neomycin resistance gene (neoR) under the control of a phosphoglycerate kinase promoter (PGK Promoter) is located. After Cre-mediated recombination $\mathrm{E} 1$ as well as neoR and the PGK promoter are excised. The recombined Smo ${ }^{f}$ locus was named Smodel

Application of these recombination assays on genomic DNA of pituitaries from Pomc/Ptch fff or Pomc/Smofff mice 250 days post tamoxifen-injection revealed that Ptch $^{\text {del }}$ (Figure 16) or Smodel alleles (Figure 16) were efficiently amplifiable, respectively. Moreover, the assays furthermore substantiate the previously made observation that the PomcCreERT2 deleter strain expresses a slightly leaky CreERT2recombinase (Figure 7) since also in samples from solvent-treated Pomc/Ptch fff and Pomc/Smo fff mice the recombination-specific amplicons were detectable (Figure 16). However, the solvent-treated samples showed less intense band patterning in comparison to the tamoxifen-treated samples. Due to the assay design, also the detection of the unrecombined $\mathrm{Ptch}^{f}$ or $\mathrm{Smo}^{f}$ loci was possible. Thus, in tamoxifentreated $P t_{c h}^{f f f}$ or $S m o^{f f}$ samples exclusively the $\mathrm{Ptch}^{f}$ or $S m o^{f}$ amplicon was detected, respectively (Figure 16).

These results show that the cell-specific recombination of the $\operatorname{Ptch}^{f}$ or $S m o^{f}$ loci in Pomc/Ptch fff or Pomc/Smo fff pituitaries was successful and persists up to 250 days post induction. However, since Ptch or Smo depletion in Pomc-expressing cells of adult mice alters neither Hh signalling activity, hormone expression, proliferation in the pituitary gland nor health status of the mice it has to be assumed that Hh signalling does not play a role in corticotrophs of adult mice. 

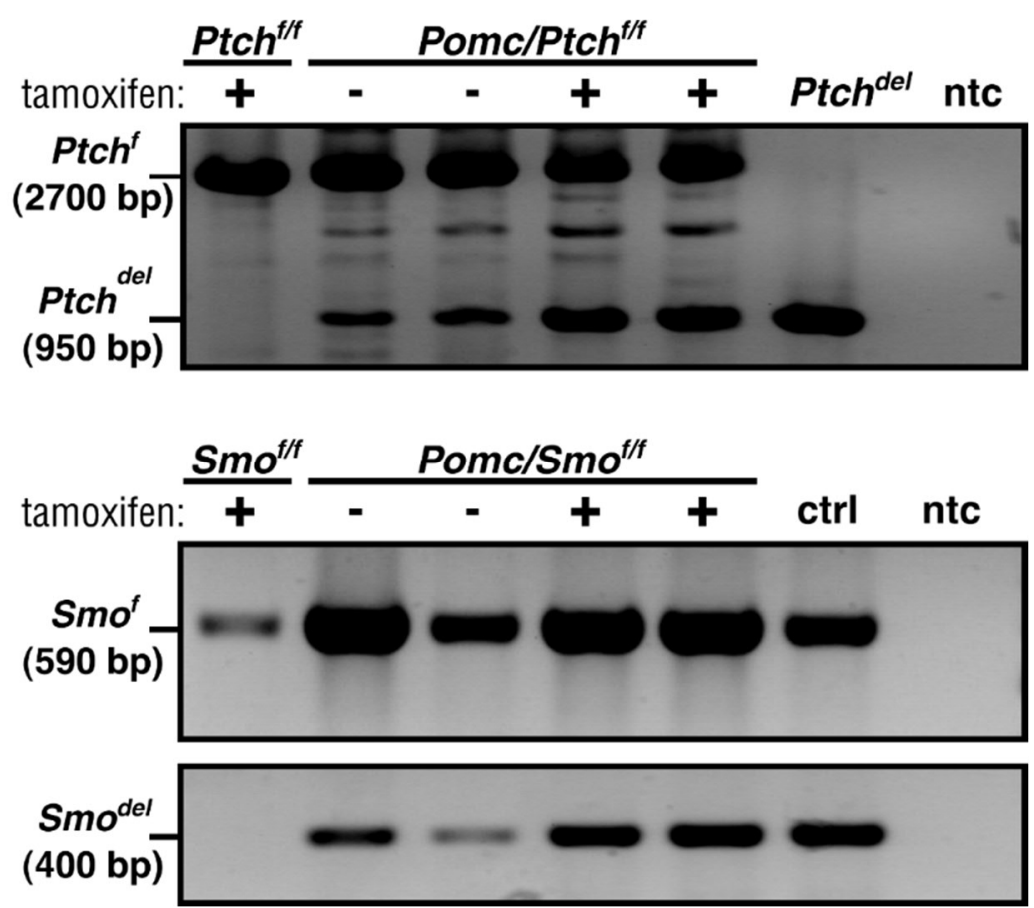

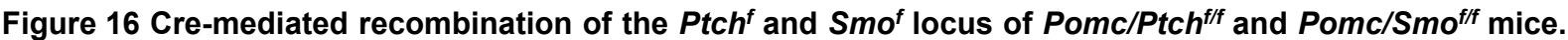
Pituitary glands of tamoxifen- or solvent-treated Pomc/Ptch ${ }^{f / f}, \mathrm{Ptch}^{f / f}, \mathrm{Pomc}_{\mathrm{Smo}} \mathrm{O}^{f / f}$ and $\mathrm{Smo} \mathrm{o}^{f / f}$ mice were collected 250 days after i.p. injection. The genomic DNA was isolated and the samples from Pomc/Ptch ${ }^{f / f}$ and $P_{t c h}^{f f f}$ were analysed with the DNA-oligonucleotide pair Exon7-F/NeoR via PCR (upper panel). The amplification of the Ptch ${ }^{f}$ locus results in an amplicon size of $2700 \mathrm{bp}$ whereas the $P t c h^{d e l}$ amplicon has a size of $950 \mathrm{bp}$. Genomic DNA of tamoxifen- and solvent-treated Pomc/Ptch ${ }^{f f f}$ pituitaries show both the amplicon of Ptch $^{f}$ and Ptch ${ }^{\text {del }}$. In addition band sizes between $\mathrm{Ptch}^{f}$ and $\mathrm{Ptch}^{\mathrm{del}}$ are detected, indicating partial amplifcation of side products. The amplification of the $S m o^{f}$ locus from genomic DNA from tamoxifen- and solvent-treated Pomc/Smo ${ }^{f / f}$ and tamoxifen $S m o^{f / f}$ pituitaries was mediated with the DNA-oligonucleotide pair Smo5' long forward/Smodel WT rev resulting in an band size of $590 \mathrm{bp}$. This band can be detected in all samples (middel panel). The amplification of the Smodel locus from genomic DNA from tamoxifen- and solvent-treated $\mathrm{Pomc} / \mathrm{Smo}^{f / f}$ and tamoxifen $\mathrm{Smo}^{\mathrm{f} / \mathrm{f}}$ pituitaries was mediated with the DNA-oligonucleotide pair Smo5' long forward/Smoflox recombi rev resulting in an band size of $400 \mathrm{bp}$. This band is only identified in tamoxifen- and solvent-treated Pomc/Smo ${ }^{f / f}$ pituitaries (lower panel). Ctrl: control; ntc: no template control. 


\subsubsection{Increasing the incidence of pituitary adenomas in a mouse model}

\subsubsection{Overexpression of cyclin E1 in AtT-20 cells was not achievable}

Acth-expressing human pituitary adenoma show high GLI1 expression levels indicating activated $\mathrm{Hh}$ signalling may also play a role in these tumours ${ }^{185}$. However, depletion of Ptch in Pomc-expressing cells in adult mice did not result in an increased Hh signalling activity, proliferation or hormone production compared to the controls. However, it is conceivable that besides a corticotroph-specific depletion of Ptch a second risk factor is necessary to develop alterations in pituitary homeostasis that might even lead to adenoma formation. So far, no mouse model that reliably develops PA is available (see 1.4). However, several risk factors are known to influence the occurrence of pituitary lesions, like the overexpression of cyclin E1 in Pomc-expressing (Tg-PCE) cells, which results in lesions of the gland and rarely in neoplasia formation ${ }^{253}$. Thus, a combination of modulated $\mathrm{Hh}$ signalling and overexpression of cyclin $\mathrm{E} 1$ was planned. Since $T g-P C E$ mice are not available anymore, the targeting DNA vector (Tg.PCE) that was used to generate the original mouse line was obtained to generate the $T g-P C E$ mice again. However, initial in vitro analyses revealed that transfection of the Pomcexpressing murine pituitary cell-line AtT-20 with the Tg.PCE plasmid did not result in an increased expression level of cyclin E1 compared to non-transfected cells (Figure 17).

This shows that the obtained targeting DNA vector is not suitable to increase cyclin E1 expression in AtT-20 cells and thus it is not advisable to use this vector to generate the mice again.

A

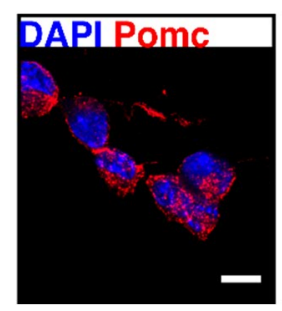

B

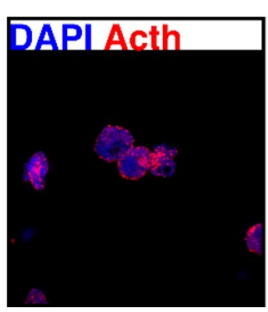

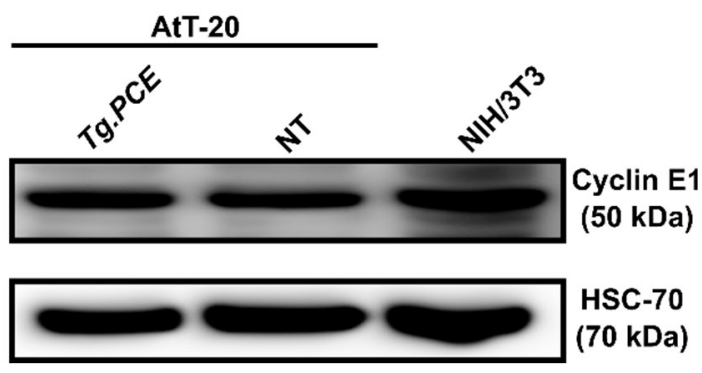

Figure 17 Characterization of AtT-20 cells and Western blot analysis for detection of cyclin E1 expression in AtT-20 cells. PFA-fixed and permeabiized AtT-20 cells were analysed for their expression of Pomc (red) and Acth (red) via immunofluorescence staining (A). Protein was isolated from AtT-20 cells, that have been transfected with $3 \mu \mathrm{g}$ of the cyclin E1 expression vector (Tg.PCE). $48 \mathrm{hrs}$ after transfection the cells were harvested and $20 \mu \mathrm{g}$ of total cell lysates were analysed via Western blot analyses for the detection cyclin E1 expression with a specific antibody. Non-transfected AtT-20 cells (NT) and NIH/3T3 served as controls. Detection of HSC-70 expression was used a loading control. Protein names and sizes in $\mathrm{kDa}$ are illustrated on the right side of the blot (B). Scale bar represents $10 \mu \mathrm{m}$. 


\subsection{Fate mapping of Gli1-expressing cells in the adult pituitary gland}

The corticotroph-specific depletion of neither Ptch nor Smo affected the homeostasis of adult pituitary glands. Contrarily, a ubiquitous Ptch depletion in adult pituitaries resulted in increased Acth, $\mathrm{Gh}$ and $\mathrm{Prl}$ expression and enhanced proliferation of Sox $2^{+}$ non-endocrine cells ${ }^{185}$. Since it has been furthermore shown that the AL of wild-type adult pituitary glands consists of Sox $2^{+} / \mathrm{Gli}^{+}{ }^{+}$and Sox $2^{\text {neg }} / \mathrm{Gli} 1^{+}$cells ${ }^{185}$ it was assumed that two different cell populations in the adult gland harbour an active $\mathrm{Hh}$ signalling cascade: (1) a Sox $2^{+}$stem cell/committed progenitor cell population and (2) a Sox $2^{\text {neg }}$ population that potentially represent a differentiated hormone producing cell type. In order to identify the cell type that expresses Gli1 and thereby most likely is dependent on active $\mathrm{Hh}$ signalling in vivo fate mapping experiments were performed. Fate mapping or lineage tracing experiments are useful tools that allow to mark a cell-type of interest (e.g. by the expression of a specific gene) and follow this cell and its progeny until the cell is degraded. In combination with the inducible (e.g. via tamoxifen) Cre/lox $P$ system, a cell can be traced at any desired time point. Here, specifically Gli $1^{+}$cells were labelled to characterise the cells that show/showed active Hh signalling in the adult pituitary gland.

\subsubsection{A subpopulation of $\mathrm{Gh}^{+}$and FSC descend from Gli1+ cells in the adult pituitary gland}

For lineage tracing of Gli1-expressing cells in the adult pituitary gland Gli1CreERT2 mice were used that express a tamoxifen-inducible CreERT2-recombinase under the control of the endogenous Gli1 promoter ${ }^{265}$. By breeding the Gli1CreERT2 to the ROSA26-tdTomato reporter strain (tdT/tdT) Gli1CreERT2/ROSA26-tdTomato mice (Gli1/tdT) were generated. Afterwards Gli1/tdT mice were i.p. injected with tamoxifen at an age of 8 weeks. To control a possible leakiness of the CreERT2-recombination a second cohort of Gli1/tdT mice was simultaneously treated with solvent only. The Gli1/tdT pituitary glands as well as ovary, testis, cerebellum and skin were collected 7 , 15 and 250 days post treatment and analysed for tdT expression by immunofluorescence stainings. 
First ovary, testis, cerebellum and skin were analysed for tdT expression since in these organs Gli1 lineage tracing has been already described and thus served as internal experimental controls. As expected, ovary, testis, cerebellum and skin sections from Gli1/tdT mice showed tdT ${ }^{+}$cells in mesenchymal cells around the primary follicle of the ovary $^{275}$, in Leydig cells of the testis ${ }^{276-278}$, in Purkinje cells of the cerebellum ${ }^{279}$ and in bulge cells of the hair follicle ${ }^{280}$ (Figure 18) indicating that the Gli1CreERT2recombinase specifically labels $\mathrm{Gli1}{ }^{+}$cells as well as their progeny in adult tissues.

\section{Gli1/tdT}

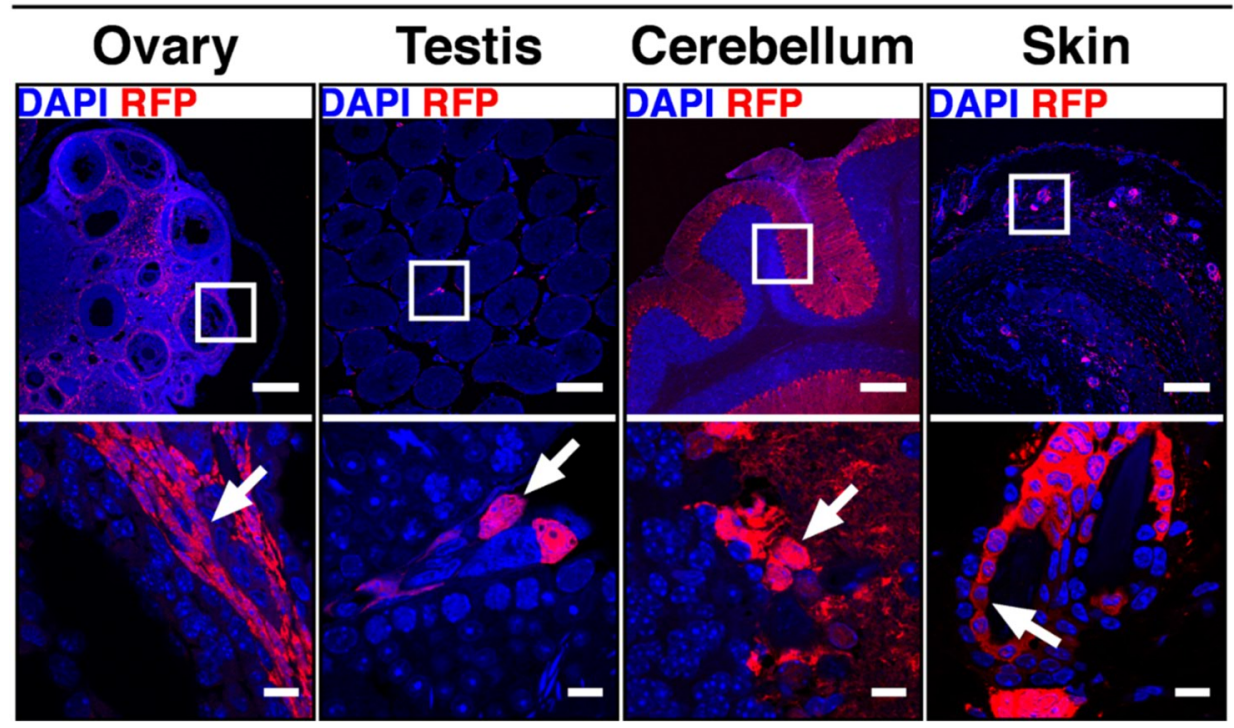

Figure 18 Progeny of Gli1 expressing cells in ovary, testis, cerebellum and skin of adult Gli1/tdT mice. 14 days post tamoxifen-treatment of 8 weeks old Gli1/tdT mice, ovary, testis, brain and skin were collected and analysed via immunofluorescence stainings. tdT expression (red) was detected with an anti-RFP antibody. White boxes in the overview pictures (upper row) represent the area that is magnified in the lower row. Arrows mark tdT ${ }^{+}$ cells in the respective tissue. Scale bars of the overview pictures represent $200 \mu \mathrm{m}$ and for the magnified pictures $10 \mu \mathrm{m}$.

The analyses of the lineage tracing experiments in pituitaries of tamoxifen-treated Gli1/tdT mice revealed that the offspring of Gli1-expressing cells also grow in the AL at all investigated time points. Only one $\mathrm{tdT}^{+}$cell was observed in pituitaries from solvent-treated controls (Figure 19). The number of $\mathrm{tdT}^{+}$cells in tamoxifen-treated Gli1/tdT pituitaries did not grossly differ between the different analysed time points and were mainly detected in the AL. Moreover, two morphologically different $\operatorname{tdT}^{+}$cell types were detected: (1) a flat, round cell type and (2) a stellar-shaped cell type with long processes. Double immunofluorescent stainings against tdT and Acth, Pomc, Gh or Prl furthermore revealed that the flat, round $\operatorname{tdT}^{+}$cell type always stained positive for Gh but never for Acth, Pomc or Prl (Figure 19). This demonstrated that the progeny of 
Gli1+ cells comprises a subpopulation of Gh-producing cells.

\section{Gli1/tdT}

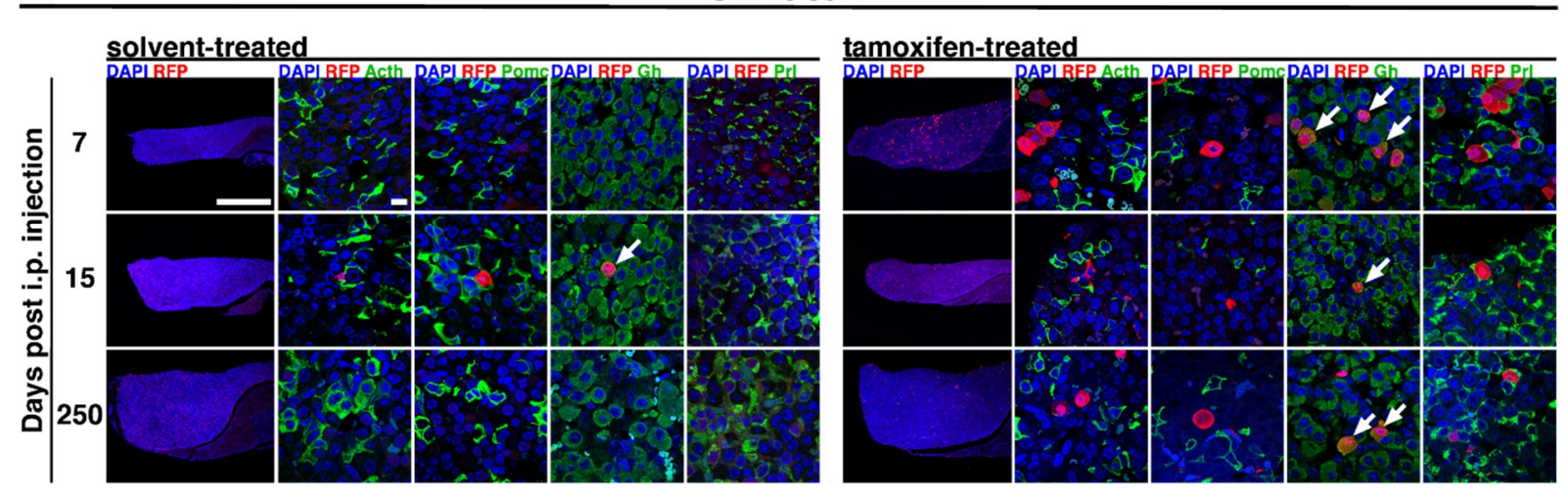

Figure 19 Progeny of Gli1 expressing cells in adult Gli1/tdT pituitary glands. Gli1/tdT mice were treated at an age of 8 weeks with solvent (left) or tamoxifen (right) and the pitutary glands from solvent- and tamoxifen-treated Gli1/tdT mice were collected 7, 15 or 250 days post i.p. application. Afterwards they were sectioned and stained against RFP (red) and the proteins Acth, Pomc, Gh and Prl (in each case green), respectively. Scale bars represent $500 \mu \mathrm{m}$ for the overview picture and $10 \mu \mathrm{m}$ for the magnified picture. Arrows indicate RFP/Gh double positive cells.

The second-mentioned stellar-shaped pituitary cell type that descent from Gli1expressing cells never stained positive for Acth, Pomc, Gh or Prl (Figure 19). However, these cells were positive for the stem cell marker Sox2 and the proliferation marker Ki-67 (Figure 20). Thus, based on their morphology, their non-endocrine characteristic and their Sox2 expression, it was assumed that these cells represent FSC. Since one major characteristic of FSC is that they are able to take up the fluorescent dipeptide $\beta$-Ala-Lys-N( $(\varepsilon)$-AMCA, vibratome sections of pituitaries from tamoxifen-treated Gli1/tdT mice were incubated with the dipeptide. Indeed, this approach revealed that the fluorescent signal of $\beta$-Ala-Lys-N( $(\varepsilon)$-AMCA co-localized with stellar-shaped $\mathrm{tdT}^{+}$ cells (Figure 20). 


\section{Gli1/tdT}

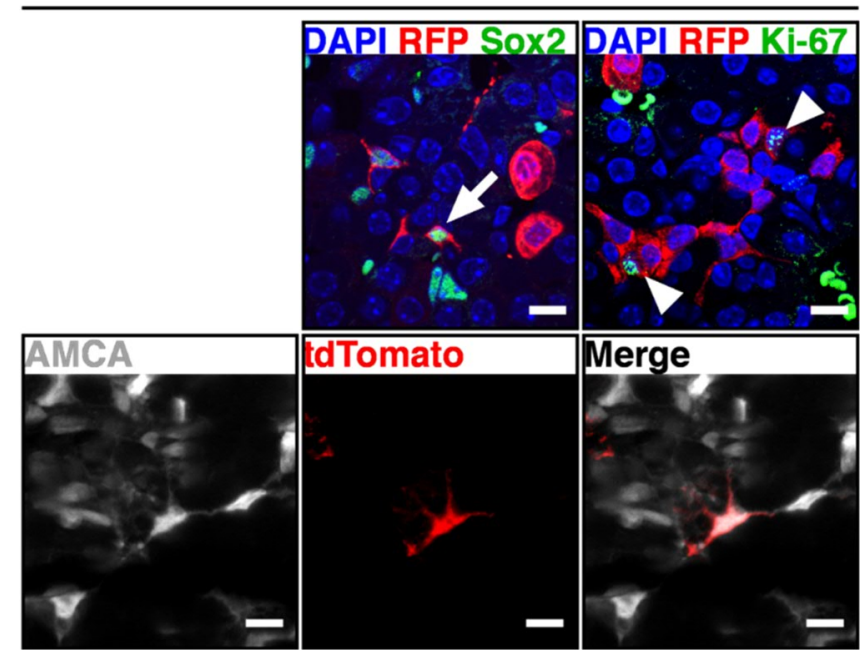

Figure 20 Progeny of Gli1 expressing cells express Sox2, Ki-67 and take up the fluorescent dipeptide $\beta$-AlaLys-N(ع)-AMCA. 14 days post tamoxifen-treatment pituitaries of Gli1/tdT were collected and stained against RFP (red) and Sox2 or Ki-67 (in each case green), respectively. Arrows indicated Sox2 and RFP co-localization and arrowheads represent Ki-67 and RFP co-localization (upper row). 14 days post tamoxifen-treatment of acute slices of pituitary glands from Gli1/tdT mice were prepared and incubated with $50 \mu \mathrm{M} \beta$-Ala-Lys-N( $\varepsilon$ )-AMCA (grey). $\beta$-Ala-Lys-N( $\varepsilon$ )-AMCA (grey) and tdTomato (red) douoble positve cells were observed (lower row). Scale bars represent $10 \mu \mathrm{m}$.

To further proof this assumption the expression of the FSC marker protein S100b in $\mathrm{tdT}^{+}$stellar-shaped pituitary cells was investigated ${ }^{64}$. First assessment of several available anti-S100b antibodies revealed that none of these resulted in FSC-specific staining in murine pituitaries (data not shown). Thus, secondly, Gli1/tdT mice were bred with S100bEGFP mice that express the EGFP gene under the control of the endogenous $5100 \mathrm{~b}$ promoter ${ }^{266}$. Simultaneously, S100bEGFP pituitary glands were analysed for specificity of the marker expression by staining against GFP and Acth, Pomc, Gh, Prl, Sox2 or Ki-67. Beyond that, also $\beta$-Ala-Lys-N( $(\varepsilon)-A M C A$ uptake of vibratome sections of $S 100 b E G F P$ pituitaries was analysed. These approaches revealed that $S 100 \mathrm{bEGFP}$ pituitaries contained $\mathrm{GFP}^{+}$cells with a stellate-shaped morphology and were predominantly located in the marginal zone but also in the AL of the pituitary. The EGFP signal neither co-localized with any of the investigated hormones nor with Ki-67, but with Sox2 (Figure 21). Additionally, the $\beta$-Ala-Lys- $N(\varepsilon)$ AMCA fluorescence signals co-localized with the EGFP expression (Figure 21) demonstrating that $S 100 b E G F P$ mice indeed were suitable to visualize $S 100 b^{+} \mathrm{FSC}$ in the adult pituitary. 


\section{S100bEGFP}

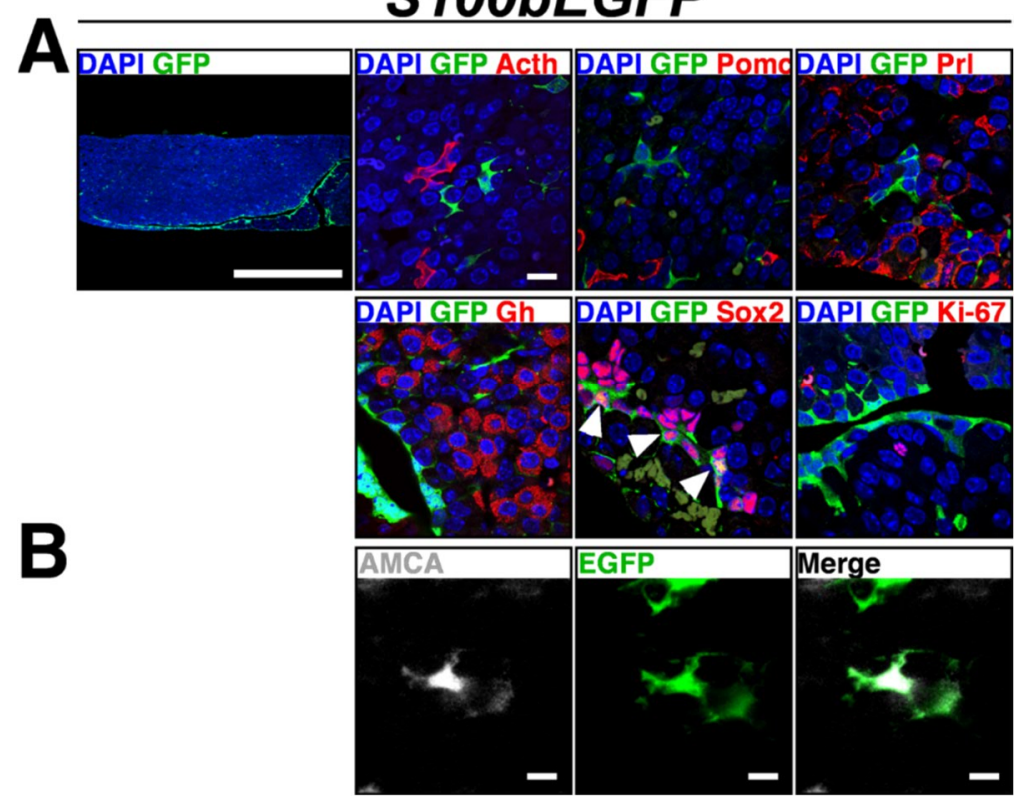

Figure 21 EGFP $^{+}$pituitary cells of S100bEGFP mice express Sox2 and take up $\beta$-Ala-Lys-N(ع)-AMCA. Pituitary glands from 8 week old S100bEGFP mice were collected and sections were analysed via immunofluorescence stainings. The sections were stained against GFP (green) and Acth, Pomc, Prl, Gh, Sox2 or Ki-67 (in each case red) (A). Arrowheads indicate Sox2/GFP double positive cells. Acute slices of pituitary glands from 8 week old S100bEGFP mice were prepared and incubated with $50 \mu \mathrm{M} \beta$-Ala-Lys-N(E)-AMCA (grey) (B). Colocalization of $\beta$-Ala-Lys-N $(\varepsilon)$-AMCA (grey) and EGFP (green) was observed. Scale bar of the overview picture represent $500 \mu \mathrm{m}$ and in the magnified pictures $10 \mu \mathrm{m}$.

Following, Gli1/tdT/S100bEGFP mice were i.p. injected with tamoxifen and the pituitaries were analysed for co-expression of EGFP and tdT. Indeed, this approach showed that stellar-shaped $\mathrm{tdT}^{+}$pituitary cells co-expressed EGFP (Figure 22) supporting the assumption that the progeny of Gli1 expressing cells in the adult pituitary represents a subpopulation of FSCs. 


\section{Gli1/tdT/S100bEGFP}

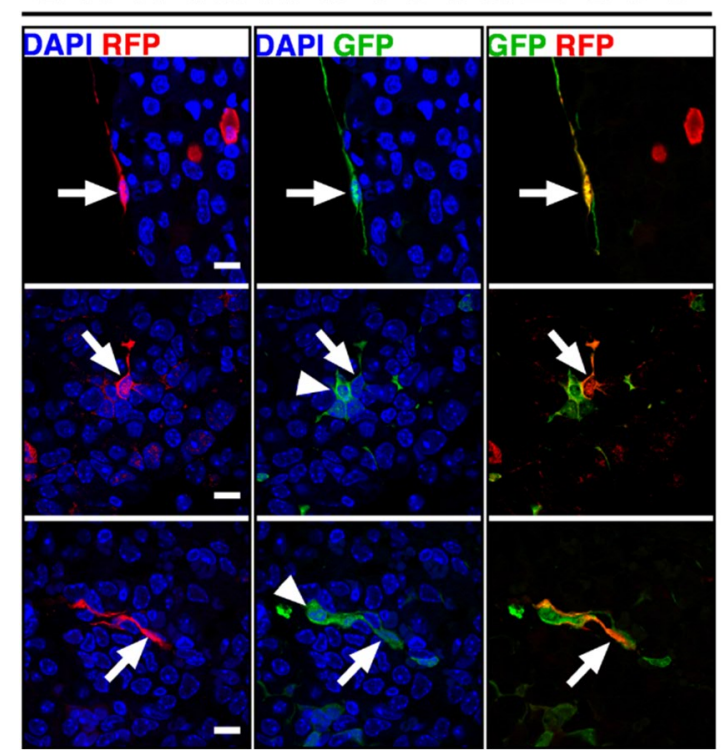

Figure 22 Progeny of Gli1 expressing cells express the FSC marker S100b. Pituitary glands from tamoxifentreated 8 week old Gli1/tdT/S100bEGFP mice were collected 14 days post i.p. application and sections were prepared. The sections were analysed via immunofluorescence stainings against GFP (green) and RFP (red). Arrows indicate GFP/RFP double positive cells. Arrowheads mark GFP single positive cells. Scale bars represent $10 \mu \mathrm{m}$.

\subsubsection{Gli1 transcripts in murine and human pituitary glands}

The results of the Gli1/tdT lineage tracing analyses showed that subpopulations of somatotrophs and FSC descent from Gli1-expressing cells. However, these analyses were not suitable to determine the parental Gli1-expressing cell/cell type since the reporter does not visualize the current Gli1 expression status of a particular cell. Thus, a combined RNAScope/immunofluorescent technique was used to simultaneously visualize Gli1 transcripts and the expression of tdT in pituitary cell of tamoxifen-treated Gli1/tdT mice. As shown in Figure 23, Gli1 transcript expression was detected in tdT $^{+}$ cells that either showed a round or a stellar-shaped morphology. Since this result indicated that both somatotrophs as well as FSC express Gli1, next sections of wildtype pituitaries were analysed for Gli1 transcript and Pomc, Gh or Prl expression. These analyses indeed revealed that Gli1 mRNA was detectable in a subpopulation of $\mathrm{Gh}^{+}$cells but never in corticotrophs or lactotrophs (Figure 23).

Moreover, similar analyses on sections of human pituitary gland from autopsies showed that both $\mathrm{S}_{100}{ }^{+}$and $\mathrm{GH}^{+}$but not $\mathrm{ACTH}^{+}$pituitary cells expressed $\mathrm{GLI}$ transcripts (Figure 24). 
Taken together these results demonstrate that Gli1 is expressed in a subpopulation of somatotrophs and FSC. Moreover, Gli ${ }^{+}$cells gave rise to either somatotrophs or FSC but never to corticotrophs or lactotrophs. Thus, active Hh signalling seemed to be relevant only in somatotrophs and FSC of the adult pituitary but not in any other pituitary cell type. This finding furthermore substantiates the observation that neither Ptch nor Smo depletion in corticotrophs resulted in a remarkable phenotype.

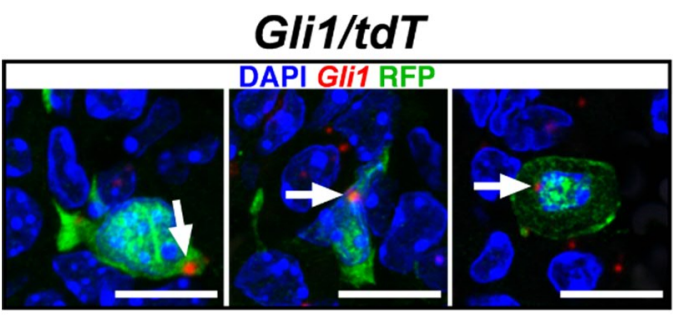

wild-type pituitary gland



Figure 23 Gli1 transcript detection in Gli1/tdT and wild-type pituitary gland sections. 7 days post tamoxifentreatment of Gli1/tdT mice, pituitary glands were collected and histological sections were prepared. RNAscope based dectection of Gli1 transcripts (red) and immunofluorescence staining against RFP (green) on these sections reveal Gli1 dectection in RFP ${ }^{+}$cells (upper row, arrows). Pituitary gland sections from wild-type mice were analysed for Gli1 transcripts (red) by RNAScope and co-stained with antibodies against Gh, Pomc or Prl (in each case green). Arrows indicate Gli1 single positive cells and arrowheads show Gli1/Gh double positive cells (lower row). Scale bars represent $10 \mu \mathrm{m}$.

\section{Human Pituitary Gland}

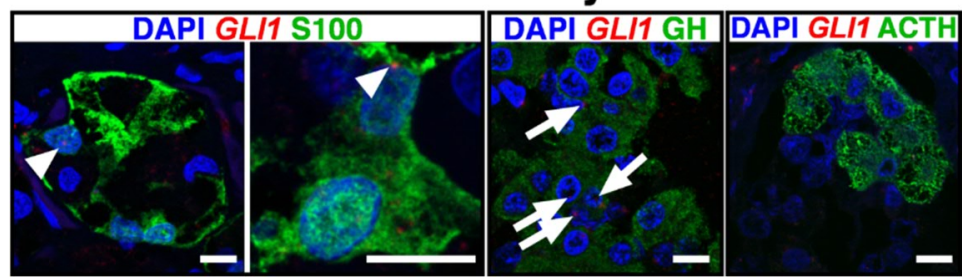

Figure 24 GLI1 transcript detection in sections of human pituitary glands. GL/1 transcripts (red) were detected in human pituitary gland sections from autopsies via RNAScope technology and simultaneously stained against $\mathrm{S} 100, \mathrm{GH}$ or ACTH (in each case green). Arrowheads mark cells with GL/1/S100 double positive cells. Arrows indicate GL/1/GH double positive cells. Scale bars represent $10 \mu \mathrm{m}$. 
4.3. The role of Hh signalling in somatotrophs and folliculostellate cells in the adult pituitary gland

\subsubsection{Generation of a CreERT2 deleter mouse strain for targeting Gh-expressing cells of the adult pituitary gland}

Lineage tracing of Gli1+ cells in adult pituitaries revealed that a subpopulation of $\mathrm{Gh}^{+}$ cells expresses Gli1 transcripts and/or descent from Gli1+ cells. Since furthermore ubiquitous Ptch depletion in the adult pituitary results in enhanced transcription of $G h^{185}$ a direct impact of $\mathrm{Hh}$ signalling on Gh production and/or release seemed to be conceivable. However, to determine the exact role of $\mathrm{Hh}$ signalling in $\mathrm{Gh}^{+}$cells an in vivo tool to analyse the effect of a deregulated $\mathrm{Hh}$ signalling specifically in $\mathrm{Gh}^{+}$cells of adult pituitaries would be advantageous. One possibility would be a Cre/loxPmediated activation/inactivation of $\mathrm{Hh}$ signalling in somatotrophs, which however requires a Cre deleter mouse strain for a somatotroph-specific expression of a CreERT2-recombinase. So far, there are different commercially available Cre deleter mouse strains that expresses a Cre-recombinase in Gh-producing cells or even in the Pou1f1, POU domain, class 1, transcription factor 1 (Pit-1) lineage targeting somatotrophs, lactotrophs and thyrotrophs simultaneously ${ }^{281-283}$. However, all these strains express a constitutive active Cre-recombinase, which most likely would interfere with the analysis of a deregulated $\mathrm{Hh}$ signalling in the pituitary gland of adult animals. Thus, a new mouse line that expresses a tamoxifen-inducible CreERT2recombinase in $\mathrm{Gh}^{+}$cells was established.

Given the fact, that ubiquitous depletion of Ptch in the pituitary leads to increased expression of $\mathrm{Gh}$ but also of $\mathrm{Pr}{ }^{185}$, it was suggested that a targeting of somatotrophs and lactotrophs simultaneously by the new deleter strain might advantageous. Thus, the Ghrhr promoter region that has been described to effectively drive Crerecombinase expression in both cell types ${ }^{281}$ was chosen as the promoter for the new transgene. Endogenously Ghrhr is mainly expressed in the pituitary but also in the renal medulla ${ }^{284}$, the hypothalamus ${ }^{285}$ and the testis ${ }^{286}$. However, a Cre-recombinase transgene driven by the rat Ghrhr ( $r G h r h r)$ promoter was shown to be specifically expressed in murine somatotrophs, lactotrophs and thyrotrophs. Besides a minor expression of the rGhrhr-Cre transgene was reported in the vibrissae and in hair follicles of the proximal limb during embryogenesis ${ }^{281}$. However, it was assumed that the Ghrhr promoter is very well suited as a driver for a somatotroph-, lactotroph- and/or 
thyrotroph-specific expression of a CreERT2-recombinase. Thus, various lengths of the Ghrhr promoter sequences from 3 different species (rat, mouse and human) were cloned upstream of the EGFP gene (Ghrhr_EGFP) to analyse the somatotroph-specific expression of the promoter region in vitro.

\subsubsection{In vitro expression analysis of the rat, mouse and human Ghrhr/GHRHR promoter sequences}

To study the expression of the Ghrhr_EGFP reporter plasmids in vitro the rat somatotroph cell line $\mathrm{GH} 3$ was chosen and initially tested for their Gh and Ghrhr expression via immunofluorescence staining and Western blot analysis. The results revealed that $\mathrm{GH} 3$ cells endogenously express $\mathrm{Gh}$ and the $\mathrm{Ghrhr}$ proteins (Figure 25A,B). Thus, the 4 different reporter plasmids [rGhrhr(-1964,+9)_EGFP, $m G h r h r(-1538,-1) \_E G F P, \quad h G H R H R(-2207,-19) \_E G F P$ and $h G H R H R(-310,-$ 19)_EGFP] were transfected in $\mathrm{GH} 3$ cells and the EGFP reporter expression was analysed. Whereas no EGFP expression was observed in $\mathrm{GH} 3$ cells transfected with the $r$ Ghrhr(-1964, +9)_EGFP plasmid (Figure 25C) GH3 cells transfected with $m$ Ghrhr(1538,-1)_EGFP, hGHRHR(-2207,-19)_EGFP or $h$ GHRHR(-310,-19)_EGFP showed a robust EGFP expression (Figure 25C). 


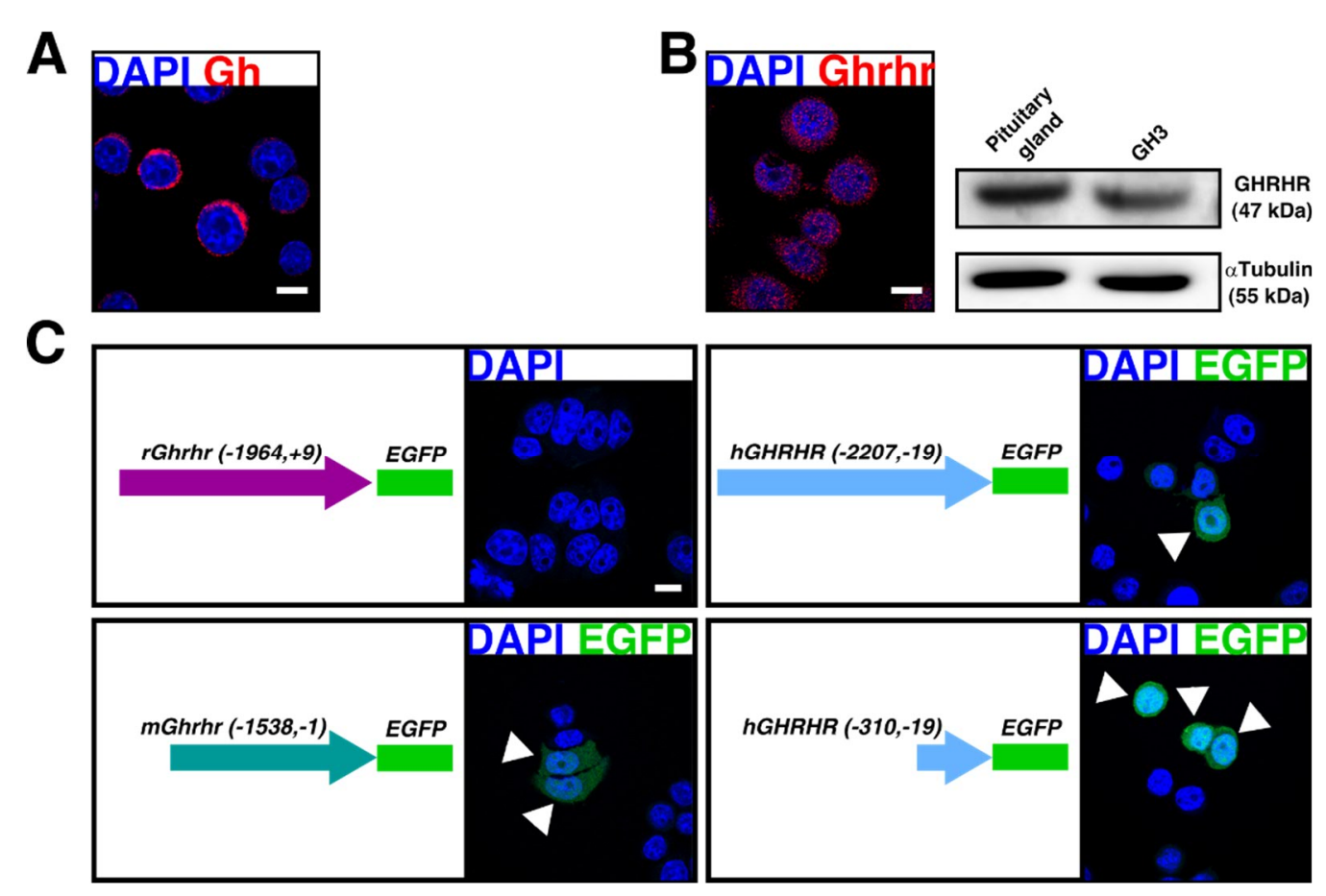

Figure $25 \mathrm{GH} 3$ cells as a model for the expression of EGFP under the control of rat, murine or human Ghrhr promoter sequences. PFA-fixed and permeabilized $\mathrm{GH} 3$ cells were immunofluorescent stained against $\mathrm{Gh}$ (red) (A) or Ghrhr (red) (B). Total protein from a wild-type murine pituitary gland and GH3 cells was isolated and analysed via Western blot for the detection of Ghrhr with a specific antibody (B). Detection of atubulin expression was used a loading control. Protein names and sizes in $\mathrm{kDa}$ are illustrated on the right side of the blot. Schematic representation of the reporter construct for visualization of the expression of Ghrhr promoter sequences from rat (rGhrhr), mouse (mGhrhr) or human ( $h G h r h r)$ and immunofluorescence analyses of GH3 cells 48 hrs post transfection with $2 \mu \mathrm{g}$ of plasmids containing an EGFP-gene under the control of rGhrhr, mGhrhr or hGHRHR promoter sequences (C). Arrowheads indicate EGFP expressing cells. Scale bars represent $10 \mu \mathrm{m}$.

Since the strongest EGFP expression was observed in $\mathrm{GH} 3$ cells transfected with the plasmids containing human GHRHR promoter sequences next the EGFP gene was exchanged to a CreERT2-encoding gene (tamoxifen-inducible Cre-recombinase) or a CreERT2-encoding gene followed by an internal ribosomal entry site (IRES) and a EGFP-gene (Figure 26A). The resulting hGHRHRCreERT2- and hGHRHRCreERT2IRES-EGFP-expression plasmids were tested for CreERT2-recombinase expression as well as for tamoxifen-inducibility and recombination efficacy of the encoded CreERT2-recombinase. Therefore, the plasmid for generation of Ptch ${ }^{f / f}$ mice $\left(P t c h{ }^{f}\right.$ plasmid, see Figure 5) was co-transfected with either one of the hGHRHRCreERT2expression plasmids into GH3 cells. Transfection of a constitutively active Crerecombinase under a thymidine kinase (TK) promoter (pMCCre) served as control for the recombination of the Ptch ${ }^{f}$ plasmid. Transfected cells were treated with tamoxifen or DMSO as solvent control. Afterwards the recombination of the Ptch plasmid was assessed by a PCR-based recombination assay for the Ptch locus described in 
chapter 3.2.1.5 (Figure 5) on genomic DNA isolated from the transfected GH3 cells. As shown in Figure 26B only the co-transfection of the $h \operatorname{GHRHR}(-310,-19) \_C r e E R T 2$ plasmid resulted in robust recombination of the Ptch plasmid upon tamoxifentreatment whereas similar results were not observed upon transfection of the other hGHRHRCreERT2-expression plasmids (Figure 26) or after solvent-treatment of transfected $\mathrm{GH} 3$ cells.

These data revealed that a) GH3 cells are a suitable model system to test Ghrhrpromoter driven expression of plasmid-encoded genes in vitro, b) the murine and the human Ghrhr/GHRHR promoter sequences are capable to drive an EGFP reporter in GH3 cells and c) a robust expression and tamoxifen-inducibility of a CreERT2recombinase resulting in an efficient Ptch $^{f}$-recombination was only achieved by using the $h \operatorname{GHRHR}(-310,-19) \_C r e E R T 2$ plasmid.
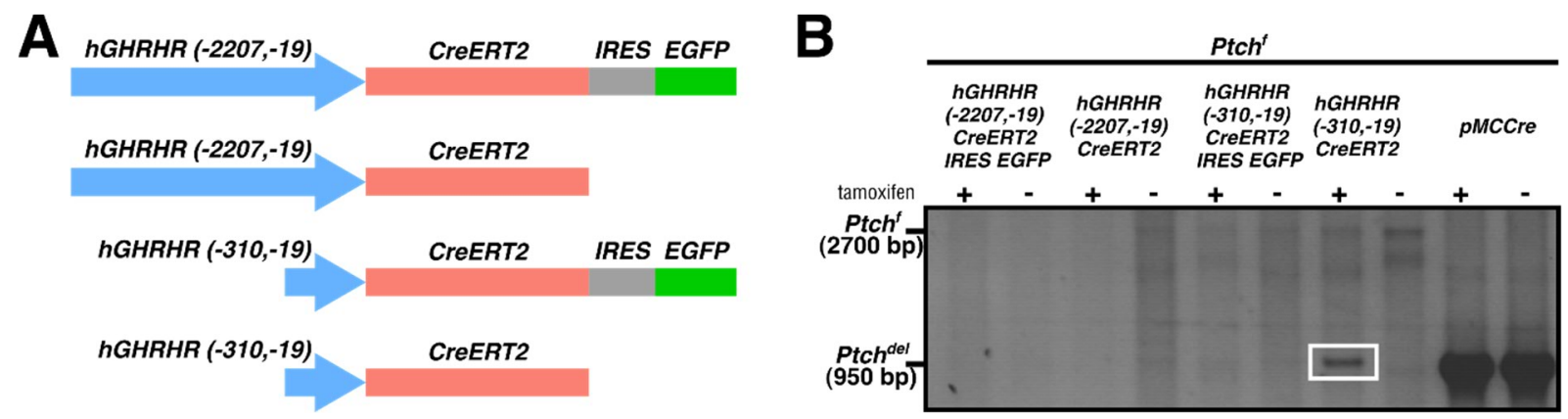

Figure 26 In vitro recombination capacity of $h$ GHRHRCreERT2 constructs. Schematic representation of hGHRHRCreERT2 constructs that were co-transfected with the Ptch ${ }^{f}$ plasmid in GH3 cells (A). 24 hrs post transfection $\mathrm{GH} 3$ cells were incubated with $10 \mu \mathrm{M}$ tamoxifen or DMSO for $48 \mathrm{hrs}$. Afterwards the genomic DNA was isolated and the samples were analysed with the DNA-oligonucleotide pair Exon7-F/NeoR via PCR. The amplification of the Ptch targeting vector results in an amplicon size of $2700 \mathrm{bp}$ whereas the Ptch ${ }^{\text {del }}$ amplicon has a size of $950 \mathrm{bp}$. Recombination of Ptch $^{f}$ targeting vector was observed with $h$ GHRHR(-310,-19)CreERT2 in combination with tamoxifen-treatment (white box) (B). Transfection with a constitutively active Crerecombinase ( $p M C C r e)$ served as control. IRES: internal ribosomal entry site 


\subsubsection{Generation of $h G H R H R C r e E R T 2$ founder mice}

After successful in vitro evaluation of the expression and tamoxifen-inducibility of the CreERT2-recombinase encoded by the $h G H R H R(-310,-19)$ CreERT2 plasmid, the construct was used to generate transgenic mice. For this purpose, the $h G H R H R(-310$,19)_CreERT2 plasmid DNA was linearized and delivered into the pronuclei of fertilized mouse embryos via microinjection (performed at the Max-Planck-Institute for experimental medicine, Göttingen). 3 (2 male, 1 female) out of 17 born pups were positively genotyped for genomic insertion of the $h G H R H R(-310,-19) C r e E R T 2$ transgene (Figure 27). The 3 founders were then used for establishing founder mouse lines by breeding to wild-type C57BL6/N mice.

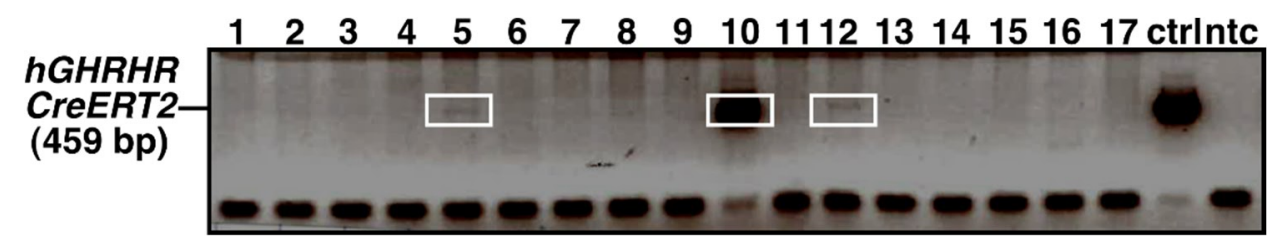

Figure 27 Genotyping of founder mice for genomic integration of the $h$ GHRHR(-310,-19)CreERT2 transgene. Genomic DNA was isolated from tailtips of 17 founder animals obtained from $h G H R H R(-310,-19) C r e E R T 2$ plasmid microinjection and analysed with the DNA-oligonucleotide pair hGHRHR_CreERT2_forwardl hGHRHR_CreERT2_reverse via PCR. The resulting amplicon has a size of $459 \mathrm{bp} .3$ mice were genotyped positively (white boxes). ctrl: control; ntc: no template control. 


\subsubsection{Increasing the incidence of pituitary adenomas in somatotrophs, thyrotrophs and lactotrophs}

\subsubsection{Sequence discrepancies in the $\alpha$ GSU.PTTG expression plasmid}

Overexpression of the human pituitary transforming gene (hPTTG) under control of the $\alpha G S U$ promoter ( $\alpha$ GSU.PTTG) results in small pituitary lesions from gonadotrophs and somatotrophs ${ }^{251}$. To test whether an additional $\mathrm{Hh}$ signalling deregulation in $\alpha$ GSU.PTTG mice can lead to a pituitary adenoma future plans were to breed $\alpha G S U . P T T G$ mice to $h$ GHRHR(-310,-19)CreERT2/Ptch/f mice. However, the $\alpha$ GSU.PTTG mouse model was no longer available and thus had to be generated again by using the original plasmid ${ }^{251}$. Beforehand the $\alpha$ GSU.PTTG plasmid was evaluated for its correctness.

Originally the $\alpha$ GSU.PTTG plasmid is described to contain an EGFP gene (Figure 28A $)^{251}$. Thus, initially the existence of this EGFP gene in the $\alpha$ GSU.PTTG plasmid was tested by using the $\alpha$ GSU.PTTG plasmid as a template to amplify an EGFP fragment with the EGFP-specific DNA-oligonucleotide pair GFP-F/GFP-R. As a positive control, the pIRES_EGFP plasmid was used as a template. Although the $173 \mathrm{bp}$ EGFP fragment was efficiently amplified from the positive control template unfortunately, no EGFP amplicon could be detected when using the $\alpha$ GSU.PTTG plasmid as a template (Figure 28B). However, also the expression of the PTTG gene from the $\alpha$ GSU.PTTG plasmid was tested in vitro. Therefore, first the endogenous expression of the Cga gene encoding for $\alpha \mathrm{GSU}$ in $\mathrm{GH} 3$ cells was tested. For this purpose, total RNA from GH3 cells, NIH/3T3 cells and wild-type pituitary glands was isolated and cDNA was prepared. Afterwards Cga was amplified with the DNAoligonucleotide pair Cga-F1/Cga-R1. The amplification of the glycerinaldehyd-3phosphat-dehydrogenase (Gapdh) gene served as control. As shown in Figure 28C, low and high Cga transcript levels were detected in cDNA from GH3 cells and pituitary glands, respectively, whereas NIH/3T3 cells do not express Cga. Thus, it was concluded that $\mathrm{GH} 3$ cells might be suitable to express genes under the control of the $\alpha G S U$-promoter. Hence, subsequently PTTG expression levels of $\mathrm{GH} 3$ cells transfected with the $\alpha$ GSU.PTTG plasmid were measured via Western blot analysis. Therefore, $3 \mu \mathrm{g}$ of $\alpha$ GSU.PTTG plasmid were transfected in GH3 cells and $48 \mathrm{hrs}$ post transfection total protein was isolated and analysed for PTTG expression. Non- 
transfected and NIH/3T3 cells served as controls. Indeed, this approach showed that $\alpha$ GSU.PTTG-transfected GH3 cells express increased levels of PTTG in comparison to non-transfected cells (Figure 28D). Thus, although the sequence of the $\alpha$ GSU.PTTG plasmid is not identical to the published sequence, the $\alpha$ GSU.PTTG plasmid seems to encode for PTTG and therefore can be used to regenerate the $\alpha$ GSU.PTTG mouse line.

A

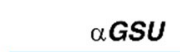
aGSU hPTTG IRES EGFP



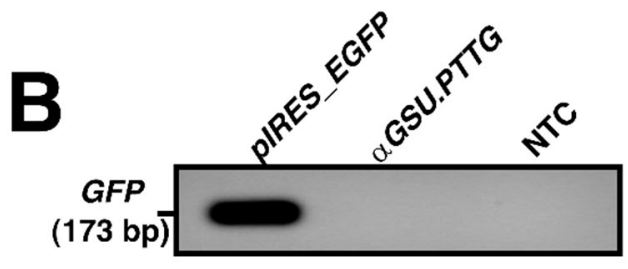

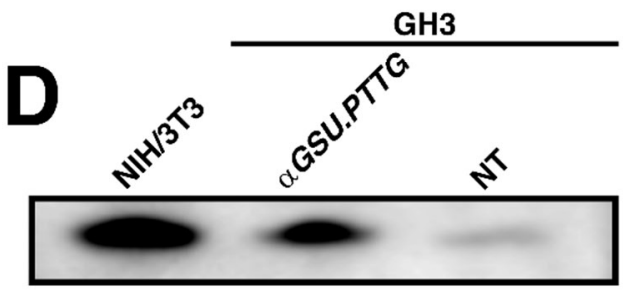

PTTG (23 kDa)

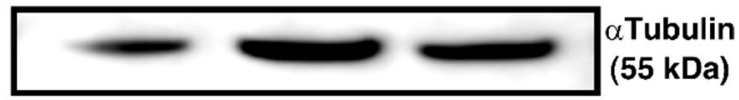

Figure 28 Characterization of the $\alpha$ GSU.PTTG plasmid. Schematic representation of the linearized $\alpha$ GSU.PTTG plasmid adopted from Abbud et al., $2005^{251}$ (A). PCR-based amplification of the EGFP gene with the DNAoligonucleotide pair GFP-F/GFP-R and the $\alpha$ GSU.PTTG plasmid as a template. Amplification from the pIRES_EGFP plasmid was used as a positive control template. The amplicon size from the respective DNAoligonucleotide pair is $173 \mathrm{bp}(\mathrm{B})$. RNA from NIH/3T3 cells, GH3 cells and a wild-type pituitary gland was isolated and analysed via RT-PCR for the expression of Cga. Gapdh expression was used as a loading control (C). Protein was isolated from GH3 cells that have been transfected with $3 \mu \mathrm{g}$ of the PTTG expression vector $(\alpha G S U . P T T G)$. $48 \mathrm{hrs}$ after transfection the cells were harvested and $20 \mu \mathrm{g}$ of total cell lysates were analysed via Western blot analyses for the detection PTTG expression with a specific antibody. Non-transfected GH3 cells (NT) and NIH/3T3 served as controls. Detection of $\alpha$ Tubulin expression was used a loading control. Protein names and sizes in $\mathrm{kDa}$ are illustrated on the right side of the blot (D) IRES: intra ribosomal entry site; NTC: no template control. 
4.4. Evaluation of a model for Hh signalling deregulation in somatotrophs and folliculostellate cells in adult pituitary glands

The results of this thesis so far strongly indicated that $\mathrm{Hh}$ signalling plays a significant role in somatotrophs and FSC in the adult pituitary. For a more detailed analysis of the impact of $\mathrm{Hh}$ signalling in these both cell types a mouse model for targeting somatotrophs and FSC simultaneously should be established. However, so far neither a somatotroph- nor an FSC-specific CreERT2-deleter mouse strain is available.

By extensively literature search the Aldh1/1CreERT2 (Aldh1/1) mouse strain that expresses a CreERT2-recombinase under the control of aldehyde dehydrogenase 1 family, member $L 1$ promoter which has been described for being expressed in S100b positive cells in the brain came into the focus ${ }^{256}$. Although it was not known which pituitary cell type expresses the Aldh1/1CreERT2-recombinase it was postulated that also $S 100 b^{+}$FSC of the pituitary might be targeted by this deleter mouse strain. To test this hypothesis Aldh1/1 mice were bred to $t d T$ reporter mice and additionally for some experiments to S100bEGFP mice. Afterwards, 8 weeks old Aldh1/1/tdT and Aldh1/1/tdT/S100bEGFP mice were injected with tamoxifen and 14 days post-injection the pituitaries were dissected. Subsequent immunofluorescence analyses showed that a subpopulation of Gh-expressing cells expressed tdT (Figure 29) whereas corticotrophs and lactotrophs never stained positive for tdT (Figure 29). Moreover, also GFP/tdT double positive cells were observed (Figure 29) indicating that also a subpopulation of FSC expressed the Aldh1/1CreERT2 transgene. 


\section{Aldh1/1/tdT}

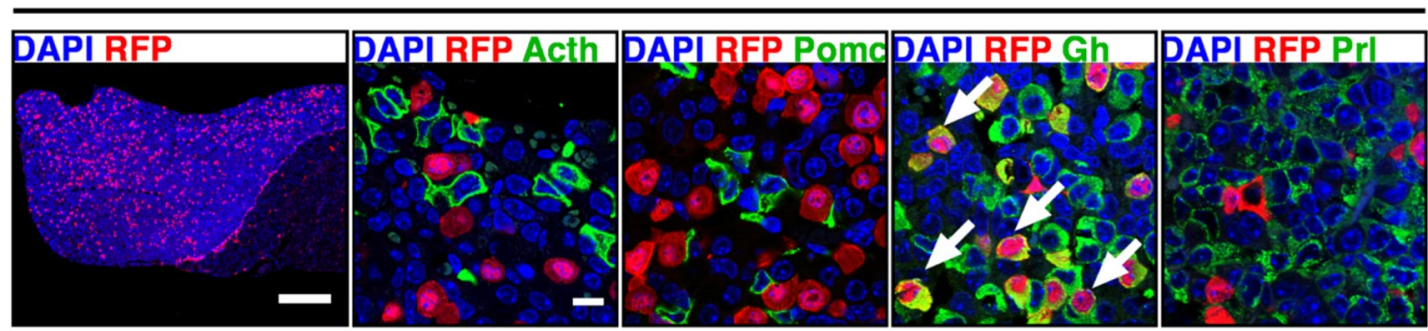

\section{Aldh1/1/tdT/S100bEGFP}



Figure 29 Lineage tracing of the Aldh1/1CreERT2 transgene in Aldh1/1/tdT and Aldh1/1/tdT/S100bEGFP pituitaries. Aldh1/1/tdT (upper row) and Aldh1/1/tdT/S100bEGFP (lower row) mice were treated with tamoxifen at an age of 8 weeks and the pituitaries were collected 14 days post treatment. Afterwards the pituitaries were sectioned and analysed via immunofluorescence stainings. They were stained with antibodies against RFP (red) and Acth, Pomc, Gh or Prl (upper row, each time green) or against RFP (red) and GFP (lower row, green). Arrows indicate Gh and RFP double positive cells. Arrowheads show RFP and GFP double positive cells. Scale bars in the overview picture represent $500 \mu \mathrm{m}$ and in the magnified pictures $10 \mu \mathrm{m}$.

Since these results indicated that Aldh1/1CreERT2 mice are suitable for targeting somatotrophs and FSC in the adult pituitary next the deleter strain was bred to Ptch f/f and $\mathrm{Smo}^{\mathrm{f} / \mathrm{f}}$ mice to generate Aldh1/1/Ptch/f and Aldh1/1/Smo $\mathrm{P}^{\mathrm{f} / \mathrm{f}}$ mice. Unfortunately, breeding of Aldh1/1/Ptch ${ }^{f / f}$ mice was not accomplished within this thesis. As a control and due to the fact that the Gli1CreERT2-deleter strain also targets somatotrophs and FSC additionally Gli1/Ptch/f and Gli1/Smo f/f mice were generated.

Both deleter mouse lines (Aldh1/1CreERT2 and Gli1CreERT2) express the CreERT2recombinase not exclusively in the adult pituitary but also in the brain (Aldh1/1CreERT2 ${ }^{256}$, Gli1CreERT2 ${ }^{287}$ ) and additionally the Gli1CreERT2 is expressed in the skin $^{288}$. Thus, in vivo activation of the CreERT2-recombinases and following deregulation of $\mathrm{Hh}$ signalling most likely would lead to general health issues aside of potential effects on the pituitary homoeostasis (e.g. medulloblastoma or BCC formation upon $\mathrm{Hh}$ signalling overactivation). To bypass this technical problem, the pituitaries from untreated 8 weeks old Aldh1/1/Smo ${ }^{f / f}$, Gli1/Ptch ${ }^{f / f}$ and Gli1/Smo ${ }^{f / f}$ mice were dissected, ex vivo cultured and recombined by a 5 days treatment with $10 \mu \mathrm{M}$ tamoxifen or solvent. Afterwards the genomic DNA of the pituitaries was isolated and 
the recombination of the Ptch $^{f}$ and $S m o^{f}$ loci were analysed by PCR (see materials and methods section 3.2.1.5 for Ptch $^{f}$ and results section 4.1.2.5 for Smof). Although the ex vivo cultivation and recombination method of pituitary glands was conducted as previously described ${ }^{\mathbf{1 8 5}}$ no recombination of the $\operatorname{Ptch}^{f}$ and $\operatorname{Smo}^{f}$ loci neither of Aldh1/1/Smo f/f nor of Gli1/Ptch ${ }^{f / f}$ or of Gli1/Smo ${ }^{f / f}$ pituitaries were detected (Figure 30). Since these results show that the ex vivo culture technique is not suitable for CreERT2activation in Aldh1/1/Smo f/f , Gli1/Ptch ${ }^{f / f}$ and Gli1/Smo ${ }^{f / f}$ pituitaries an optimized method for tamoxifen-application has to be established before using these models for deregulation of Hh signalling in somatotrophs and FSC.
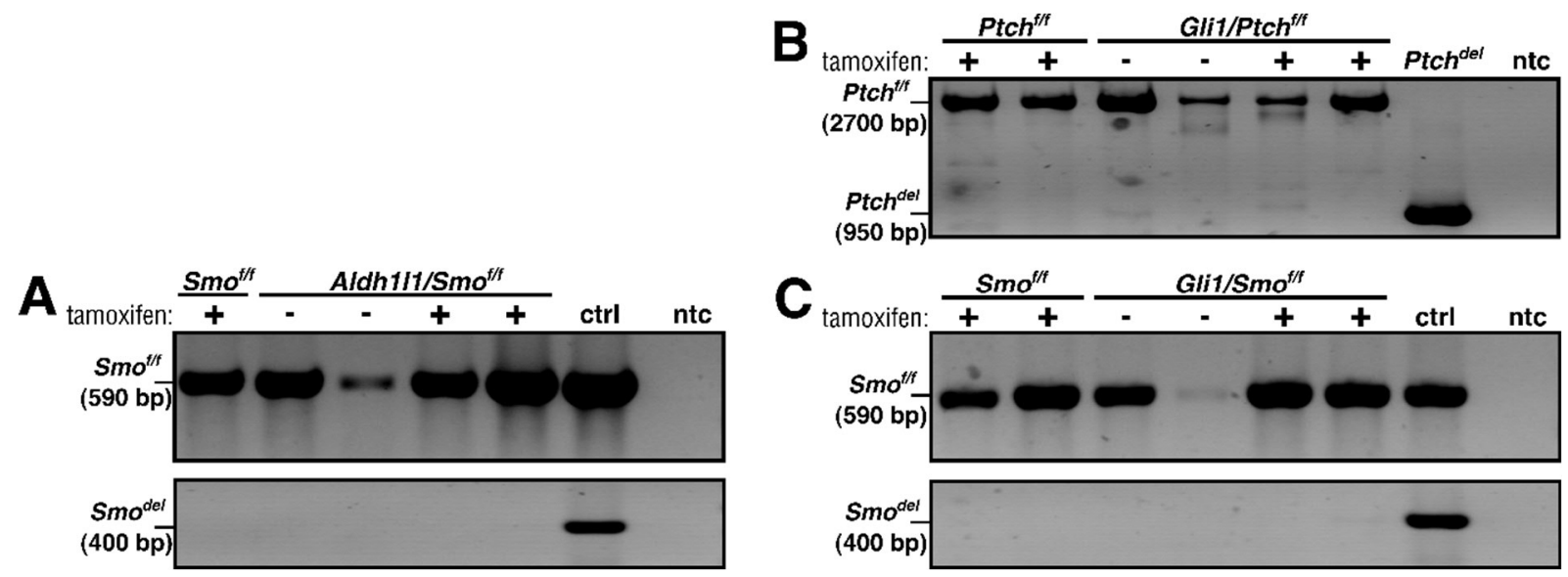

Figure 30 Genomic recombination of the Ptch $^{f}$ and Smo ${ }^{f}$ locus of Aldh1l1/Smo ${ }^{f / f}$, Gli1/Ptch ${ }^{f / f}$ and Gli1/Smo ${ }^{f / f}$ mice. Pituitary glands of tamoxifen- or solvent-treated ex vivo cultured Aldh1/1/Smo ${ }^{f / f}$ and $S_{m o}^{f / f}(\mathbf{A}), G^{\text {fi1 }} / \mathrm{Ptch}^{f / f}$, $\mathrm{Ptch}^{f / f}$ (B) Gli1/Smo ${ }^{f / f}$ and $\mathrm{Smo}^{f / f}(\mathbf{C})$ mice were collected 5 days after treatment. The genomic DNA was isolated and the samples from Gli1/Ptch ${ }^{f / f}$ and Ptch $^{f / f}$ were analysed with the DNA-oligonucleotide pair Exon7-F/NeoR via PCR (B). The amplification of the Ptch locus results in an amplicon size of 2700 bp whereas the Ptch ${ }^{\text {del }}$ amplicon has a size of $950 \mathrm{bp}$. No Ptch ${ }^{d e l}$ amplicon was achieved upon amplification on DNAs from tamoxifen- and solventtreated Gli1/Ptch f/f pituitaries. The amplification of the $S m o^{f}$ locus from genomic DNA from tamoxifen- and solventtreated $\mathrm{Aldh} 1 / 1 / \mathrm{Smo}^{f / f}$ and tamoxifen Smo ${ }^{f / f}$ pituitaries was conduceted by using the DNA-oligonucleotide pair Smo5, long forward/Smodel WT rev resulting in an band size of $590 \mathrm{bp}$. This band can be detected in all samples (A, upper panel). The amplification of the $S m o^{\text {del }}$ locus from genomic DNA from tamoxifen- and solvent-treated Aldh1/1/Smo f/f and tamoxifen Smo f/f pituitaries was achieved by using the DNA-oligonucleotide pair Smo5' long forward/Smoflox recombi rev resulting in an band size of $400 \mathrm{bp}$. The latter amplicon was only detecable upon amplificantion of the positive control (A, lower panel). The amplification of the Smo ${ }^{f}$ locus from genomic DNA from tamoxifen- and solvent-treated Gli1/Smo ${ }^{f / f}$ and tamoxifen $S m o^{f / f}$ pituitaries was mediated with the DNAoligonucleotide pair Smo5' long forward/Smodel WT rev resulting in an band size of $590 \mathrm{bp}$. This band can be detected in all samples (C, upper panel). The amplification of the Smodel locus from genomic DNA from tamoxifenand solvent-treated Gli1/Smo ${ }^{f / f}$ and tamoxifen $S m o^{f / f}$ pituitaries was conduceted by using the DNA-oligonucleotide pair Smo5' long forward/Smoflox recombi rev resulting in an band size of $400 \mathrm{bp}$. This amplicon was only detecable upon amplification of the positive control (C, lower panel). Ctrl: control; ntc: no template control. 


\subsection{The role of Hh signalling in folliculostellate cells}

\subsubsection{Identity and Hh signalling status of pituitary cell lines}

FSC of the human and the murine pituitary gland express Gli1 and/or descent from Gli1-expressing pituitary cells. However, since this knowledge is novel the role of $\mathrm{Hh}$ signalling in these cells is so far unknown. To investigate this aspect, the most elegant way would be in vivo approaches. Unfortunately, so far, no FSC-specific Cre deleter mouse strain is available and ex vivo recombination of Aldh1/1/Smo fff Gli1/Ptch ${ }^{f / f}$ and Gli1/Smo ${ }^{f / f}$ pituitaries failed. To bypass these limitations but to gain first impressions on the role of Hh signalling in FSC in vitro analyses on murine FSC cell line TtT/GF were conducted. In the pituitary gland FSC are distributed throughout the whole AL. They form a meshwork with their long processes and it is assumed that they interact with neighbouring (endocrine) cells by secreting signalling molecules that alter hormone production in the endocrine cells, especially in corticotrophs, somatotrophs and lactotrophs. To simulate the potential interaction of FSC with endocrine cells in vitro besides TtT/GF cells also the murine corticotroph cell line AtT-20 that express Pomc and Acth (Figure 17) and the rat somatotroph cell line GH3 that express Gh and Ghrhr (Figure 25) were used.

Since TtT/GF cells derive from a murine pituitary gland neoplasm ${ }^{213}$ and previously have not been used for the analysis of the Hh signalling pathway first the FSC-like phenotype and the basal $\mathrm{Hh}$ signalling activity was assessed. Therefore, their morphology and their expression of the FSC marker Sox2 were analysed via light microscopy and immunofluorescence staining. Beyond that, the expression of the FSC marker S100b, Vegfa, macrophage migration inhibitory factor (Mif) and follistatin (Fst) were analysed via qRT-PCR. The murine fibroblast cell line NIH/3T3 served as a control.

As shown in Figure 31 TtT/GF cells grew with a stellate-shaped morphology and expressed the stem cell and FSC marker Sox2. They additionally express high levels of S100b, Vegfa and Mif compared to NIH/3T3 cells (Figure 31B). Thus, it was assumed that TtT/GF cells indeed show characteristics of an FSC-derived cell line. 


\section{TtT/GF}


Figure 31 Expression analyses of FSC specific marker genes in TtT/GF and NIH/3T3 cells. The morphology of TtT/GF cells was analysed with differential interference contrast (DIC) microscopy. Arrows indicate long protrusions of the cells. PFA-fixed and permeabilized TtT/GF cells were analysed via immunofluorescence staining for the expression of Sox2 (red). Arrowheads indicate Sox $2^{+}$cells (A). RNA was isolated from TtT/GF and NIH/3T3 cells and the gene expression of S100b, Vegfa, Mif and Fst were analysed via qRT-PCR. The data were normalized to $18 \mathrm{~S}$ rRNA (18S) and are shown as fold expression in comparison to the expression of NIH/3T3 cells set to 1 (dotted line). Each dot represents a sample that was measured in technical triplicates. The data are depicted as mean \pm SD. For statistical analyses a two-tailed unpaired t-test was performed. \$ indicate significance compared to $\mathrm{NIH} / 3 \mathrm{~T} 3$ cells with $\$ p<0.05$ and $\$ \$ p<0.01$ (B). Scale bar of the DIC image represents $50 \mu \mathrm{m}$ and of the immunofluorescence image $10 \mu \mathrm{m}$.

In order to determine the basal Hh signalling activity in TtT/GF cells as well as in the endocrine cell lines AtT-20 and GH3 the expression levels of markers for active Hh signalling (Gli1, Gli2 and Ptch) were measured by qRT-PCR-based analyses. The murine fibroblast cell line NIH/3T3 served as a control. This approach revealed that all cell lines expressed Gli1, Gli2 and Ptch (Figure 32). However, the endocrine cell lines expressed significant lower levels of Gli1 in comparison to NIH/3T3 and TtT/GF cells. In contrast, Gli2 expression levels were significant higher in AtT-20 and GH3 cells compared to TtT/GF and NIH/3T3 cells whereas Ptch expression levels of AtT-20 cells were significant higher compared to all other cell lines (Figure 32A). These results suggested that all investigated cell lines are most likely capable to respond to $\mathrm{Hh}$ signalling stimulation. However, the broad distribution of Gli1 and Gli2 expression in the cell lines hint towards an impaired Hh signalling pathway in AtT-20 and GH3 cells. Next, it was analysed if the cell lines assemble primary cilia, which represents the main cellular compartment for effective Hh signalling transmission (see 1.3.1). Thus, a 
strong indicator for active $\mathrm{Hh}$ signalling is the ciliar localization of $\mathrm{Smo}^{289}$ (see introduction section). To allow a conclusion about the basal Hh signalling activity and the ability for $\mathrm{Hh}$ signalling activation due to the existence of primary cilia next TtT/GF, AtT-20 and GH3 cells were stained against Smo and the primary cilium marker acetylated tubulin. As shown in Figure 32B all 3 cell lines possess primary cilia. However, only TtT/GF cells showed a strong localization of Smo within the most of the cilia whereas in GH3 cells occasionally and in AtT-20 cells never a Smo localization in the primary cilium was observed (Figure 32B).

These data show that the murine TtT/GF cell line represents characteristics of FSC, the murine AtT-20 cell line resembles corticotroph characteristics and the rat $\mathrm{GH} 3$ cell line harbours somatotroph characteristics. Furthermore, all 3 cell lines expressed the Hh marker Gli1, Gli2 and Ptch whereas TtT/GF cells show the most abundant localization of Smo in the primary cilium. Thus, these cells were used to investigate effects of altered Hh signalling in FSC on endocrine cells. 


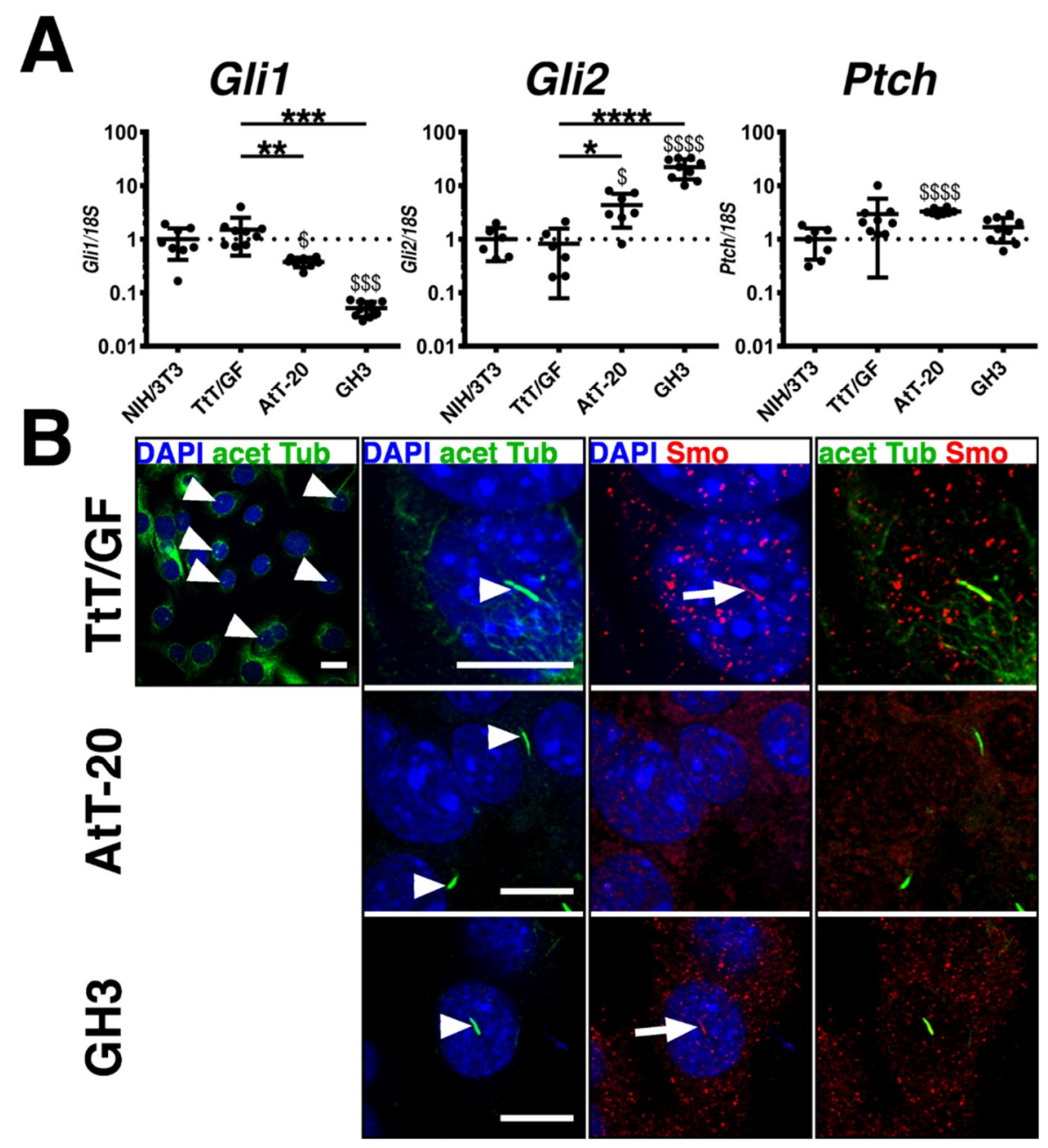

Figure $32 \mathrm{Hh}$ signalling status of TtT/GF, AtT-20 and GH3 cells. RNA from NIH/3T3, TtT/GF, AtT-20 and GH3 cells was isolated and subsequently the expression of the Hh target genes Gli1, Gli2 and Ptch was analysed via qRT-PCR. The data were normalized to $18 \mathrm{~S}$ rRNA (18S) and are shown as fold expression in comparison to the expression of NIH/3T3 cells set to 1 (dotted line). Each dot represents a sample that was measured in technical triplicates. The data are depicted as mean \pm SD. For statistical analyses a two-tailed unpaired t-test was performed. $\$$ indicate significance compared to $\mathrm{NIH} / 3 \mathrm{~T} 3$ cells with $\$ p<0.05, \$ \$ p<0.01, \$ \$ \$ p<0.001$ and $\$ \$ \$ \$ p<0.0001$. * indicate significance compared to TtT/GF cells with ${ }^{*} p<0.05,{ }^{* *} p<0.01,{ }^{* * *} p<0.001$ and ${ }^{* * * *} p<0.0001$ (A). PFAfixed and permeabilized TtT/GF, AtT-20 and GH3 cells were analysed for primary cilia with an anti-acetylated tubulin (acet Tub, green) and an anti Smo (red) antibody via immunofluorescence staining. Arrowheads indicate primary cilia and arrows Smo expression. Scale bars represent $10 \mu \mathrm{m}(\mathbf{B})$.

\subsubsection{Stimulation of Hh signalling in pituitary cell lines}

TtT/GF, AtT-20 and GH3 cells express the Hh signalling marker genes Gli1, Gli2 and Ptch and form primary cilia. However, to test an actual responsiveness of the cell lines towards Hh signalling stimulation the cells were incubated with Smoothened Agonist (SAG), which specifically binds to the Hh signalling activator and transmembrane protein Smo and thereby actives the $\mathrm{Hh}$ signalling pathway ${ }^{290}$. In case of their responsiveness towards SAG stimulation $\mathrm{Hh}$ target gene expression (e.g. Gli1, Gli2, and Ptch) should be observable 291 . 
To analyse this, TtT/GF cells were either incubated for $48 \mathrm{hrs}$ with SAG-containing standard medium (10\% HS, $2.5 \%$ FBS) or starved for $24 \mathrm{hrs}$ in serum-reduced medium (starvation medium) and afterwards treated for $48 \mathrm{hrs}$ with SAG-containing starvation medium. Incubation with DMSO served as solvent control. Afterwards the cells were harvested and the activity of the Hh signalling pathway was analysed by qRT-PCR-based measurements of Gli1, Gli2 and Ptch. This approach revealed that SAG-treatment indeed resulted in a significant increase of Gli1 expression in TtT/GF cells (1.6-fold compared to the solvent control). However, the transcription of Gli2 and Ptch were not remarkably changed compared to the DMSO-treated controls (Figure 33A). In contrast, under starving conditions SAG-incubation led to a 1.9-fold increase of Gli1 transcription and furthermore to significantly increased Gli2 expression levels (Figure 33B).

These data show that the Hh signalling pathway in TtT/GF cells can be stimulated with SAG and even further increased with prior and continuous starvation of the cells.
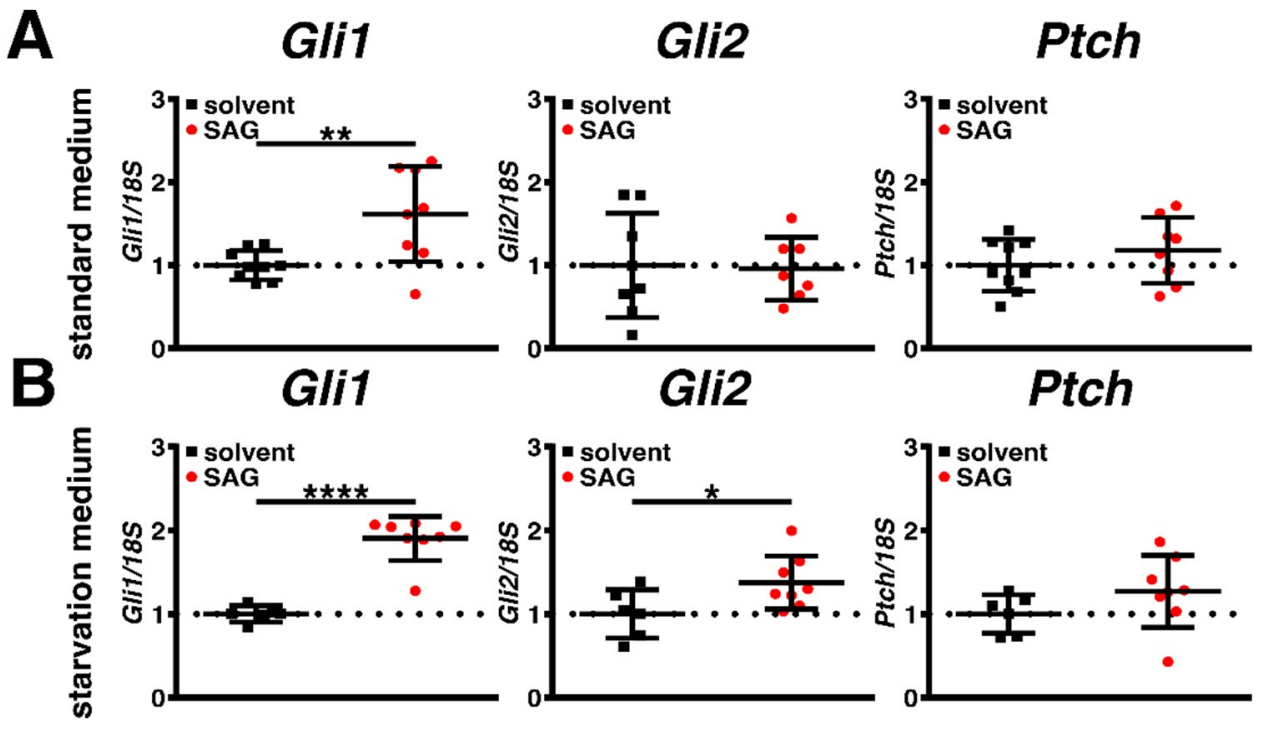

Figure $33 \mathrm{Hh}$ signalling activation in TtT/GF cells in standard and starvation medium. TtT/GF cells were cultured in standard (A) or in starvation (serum-deprived, B) medium and incubated with SAG (red) or solvent (DMSO, black). Subsequently, RNA was isolated and the expression of the Hh target genes Gli1, Gli2 and Ptch was analysed via qRT-PCR. The data were normalized to $18 \mathrm{~S}$ rRNA (18S) and are shown as fold expression in comparison to the solvent-treated TtT/GF cells set to 1 (dotted line). Each dot represents a sample that was measured in technical triplicates. The data are depicted as mean $\pm S D$. For statistical analyses a two-tailed unpaired t-test was performed. ${ }^{*}$ indicate significance compared to solvent-treated TtT/GF cells with ${ }^{*} p<0.05,{ }^{* *} p<0.01$, ${ }^{* * *} p<0.001$ and ${ }^{* * * *} p<0.0001$. 
Due to the higher responsiveness of TtT/GF cells towards SAG-stimulation upon starvation AtT-20 and GH3 cells were also starved for $24 \mathrm{hrs}$ in their respective serumreduced medium (starvation medium) and afterwards treated for $48 \mathrm{hrs}$ with SAGcontaining starvation medium. Incubation with the respective amount of DMSO served as solvent control. After harvesting of the cells, the Hh signalling activity was analysed by qRT-PCR-based measurements of Gli1, Gli2 and Ptch. Moreover, the expression of Pomc (for AtT-20 cells) and Gh (for GH3 cells) was determined since our previous data indicated a potential impact on hormone expression, at least in $\mathrm{Gh}^{+}$endocrine cells (Pyczek et al. ${ }^{185}$ and this thesis). However, despite an increased Ptch expression level no effects on the transcriptional levels of Gli1, Gli2 and Pomc were observed in AtT-20 cells treated with SAG (Figure 34A). Similarly, SAG-treatment of GH3 cells did not result in altered Gli1 or Ptch expression levels but result in decreased Gli2 and Gh transcript levels (Figure 34B).

The most reliable marker for active Hh signalling is Gli1153,154,156 since Gli1 only acts as a transcriptional activator and regulates the expression of other $\mathrm{Hh}$ target genes (e.g. Gli2 and Ptch). Thus, despite of up- or downregulation of other Hh target genes (e.g. Ptch, Gli1) it has to be assumed that a lack of increased Gli1 expression levels upon SAG-stimulation rather reflects an unresponsiveness toward $\mathrm{Hh}$ signalling stimulation that an unconventional $\mathrm{Hh}$ signalling stimulation (e.g. non-canonical). Moreover, the fact that SAG did not induce Pomc or Gh expression (but rather reduces Gh expression) demonstrate that SAG is not capable to stimulate hormone production from AtT-20 or GH3 cells. 
A


B
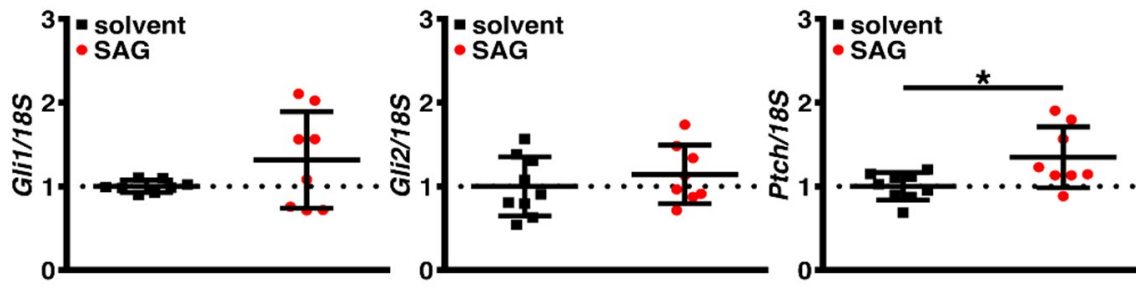

Gh
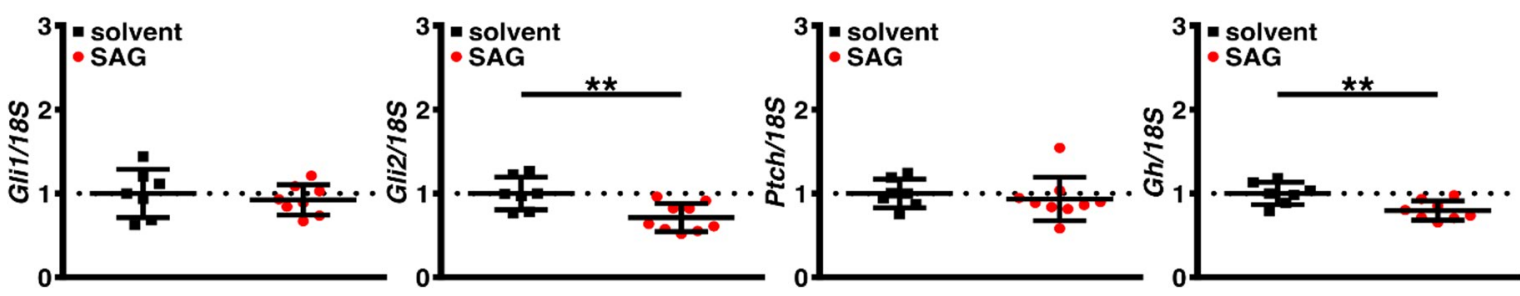

Figure $34 \mathrm{Hh}$ signalling activation in AtT-20 and GH3 cells with SAG. AtT-20 (A) or GH3 (B) cells were cultured in their respective starvation (serum-deprived) medium and stimulated with SAG (red) or solvent (DMSO, black). Subsequently, RNA was isolated and the expression of the Hh target genes Gli1, Gli2 and Ptch and the expression of Pomc (in AtT-20 cells) or Gh (for GH3 cells) was analysed via qRT-PCR. The data were normalized to 18S rRNA (18S) and are shown as fold expression in comparison to the solvent-treated AtT-20 or GH3 cells, respectively, set to 1 (dotted line). Each dot represents a sample that was measured in technical triplicates. The data are depicted as mean $\pm S D$. For statistical analyses a two-tailed unpaired t-test was performed. * indicate significance compared to solvent-treated AtT-20 or GH3 cells, respectively, with ${ }^{*} p<0.05,{ }^{* *} p<0.01,{ }^{* * *} p<0.001$ and ${ }^{* * * *} p<0.0001$.

\subsubsection{Conditioned medium of SAG-treated TtT/GF cells increases Gh secretion from $\mathrm{GH} 3$ cells}

The hormone production from AtT-20 and GH3 cells is not inducible via SAG treatment whereas TtT/GF cells response to SAG stimulation with robustly increased Gli1 and Gli2 expression levels. In light of the previously made observations that 1) ubiquitously but not corticotroph-specific activation of $\mathrm{Hh}$ signalling induces hormone production from endocrine cell (Pyczek et al. ${ }^{185}$ and this thesis), 2) subpopulations of FSC express Gli1 (this thesis) and 3) FSC most likely regulate hormone secretion of endocrine cells via paracrine factors (reviewed $\mathrm{in}^{292}$ ) these data open the possibility to study the impact of Hh signalling activated FSC on endocrine cells in a combined in vitro system. In such a system Hh signalling is stimulated in TtT/GF cells (as a model for FSC) by SAG treatment. Afterwards the effect of these $\mathrm{Hh}$ stimulated FSC on endocrine cells that are unresponsive towards SAG (e.g. AtT-20 and GH3) is assessed. Indeed, this approach would give first insights into the newly proposed hypothesis that $\mathrm{Hh}$ signalling activation in FSC cells may regulate hormone production of endocrine cells either in a 
paracrine manner or via cell-cell-interaction.

Thus, to analyse whether a paracrine mechanism may mediate FSC-endocrine cellinteraction TtT/GF cells were starved for $24 \mathrm{hrs}$ in AtT-20 or GH3 starvation medium and afterwards stimulated with SAG-containing AtT-20 or GH3 starvation medium for $48 \mathrm{hrs}$. Incubation with the respective amount of DMSO served as solvent control. Then the supernatants were harvested (conditioned medium, CM) and applied for $48 \mathrm{hrs}$ to previously starved (for $24 \mathrm{hrs}$ ) AtT-20 or GH3 cells, respectively. The activation of the Hh signalling pathway of the SAG-treated TtT/GF cells as well as of CM-treated endocrine cells was controlled by qRT-PCR-based analyses of the $\mathrm{Hh}$ target genes Gli1, Gli2 and Ptch. Furthermore, the expression levels of Pomc or Gh of CM-treated AtT-20 or GH3, respectively, as well as the Gh protein level in the medium of $\mathrm{GH} 3$ cells were measured. As shown in Figure 35A treatment of TtT/GF cells with SAG-containing AtT-20 medium led to significant increased expression of Gli1, Gli2 and Ptch in comparison to the solvent control. However, incubation of AtT-20 cells with CM from SAG-treated TtT/GF cells (CMsAG) did not change Gli1, Gli2, Ptch or Pomc expression in comparison to AtT-20 cells that were administered to CM from DMSOtreated TtT/GF cells (CMsolvent). In contrast, TtT/GF cells that were cultivated and stimulated in SAG-containing $\mathrm{GH} 3$ starvation medium showed only significant increase in Gli1 expression (Figure 36A). However, GH3 cells incubated with CMSAG showed increased Gli2 and $G h$ transcription and secrete increased levels of $G$ into the culture medium (Figure 36B).

These data demonstrate that $\mathrm{Hh}$ signalling can be still activated in TtT/GF cells even if they are cultured in AtT-20 or GH3 starvation medium although AtT-20 starvation medium seems support more efficiently $\mathrm{Hh}$ signalling activation upon SAG-treatment compared to $\mathrm{GH} 3$ starvation medium. Moreover, and in line with the proposed hypothesis $\mathrm{Hh}$ signalling activation in TtT/GF cells induces the hormone production and release from endocrine cells, at least from $\mathrm{GH} 3$ cells, most likely in a paracrine manner. 


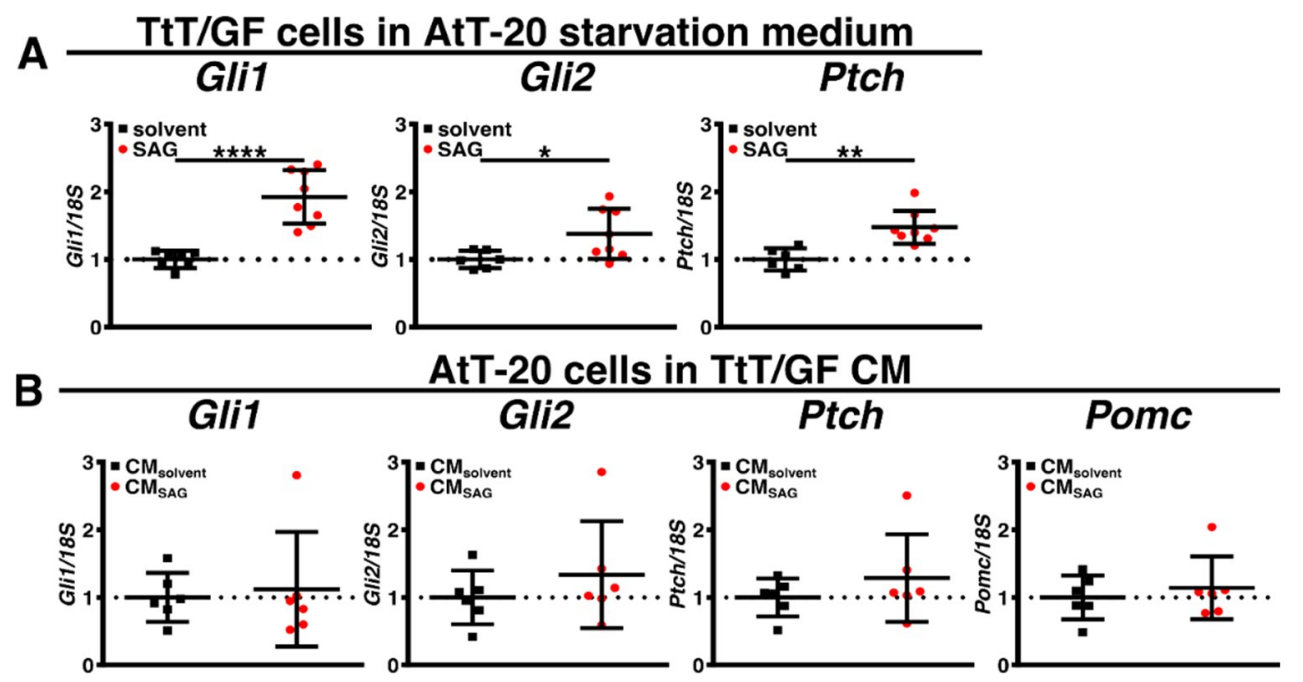

Figure $35 \mathrm{CM}$ generation from TtT/GF cells and its effect on AtT-20 cells. TtT/GF cells were cultured in AtT20 starvation medium and stimulated with SAG (red) or solvent (DMSO, black). Subsequently, RNA was isolated and the expression of the Hh target genes Gli1, Gli2 and Ptch was analysed via qRT-PCR (A). Afterwards, AtT-20 cells were incubated with the supernatant from the stimulated TtT/GF cells (conditioned medium, CM). RNA was isolated from the AtT-20 cells and the expression of the Hh target genes Gli1, Gli2 and Ptch and the expression of Pomc was analysed via qRT-PCR (B). The data were normalized to $18 S$ rRNA (18S) and are shown as fold expression in comparison to the solvent-treated TtT/GF cells or to CMsolvent-treated AtT20 cells, respectively, set to 1 (dotted line). Each dot represents a sample that was measured in technical triplicates. The data are depicted as mean \pm SD. For statistical analyses a two-tailed unpaired t-test was performed. * indicate significance compared to solvent-treated TtT/GF cells or to CMsolvent-treated AtT20 cells, respectively, with ${ }^{*} p<0.05,{ }^{* *} p<0.01,{ }^{* * *} p<0.001$ and ${ }^{* * * *} p<0.0001$.

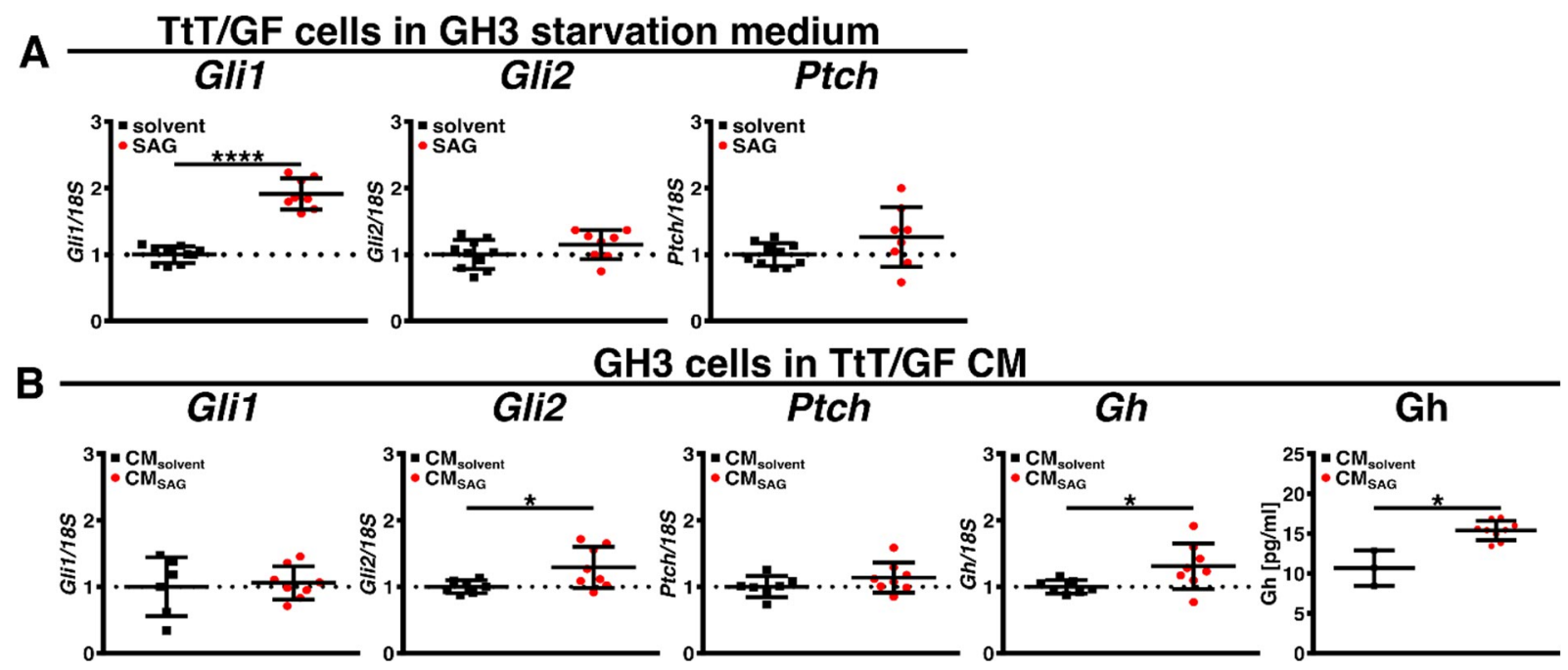

Figure 36 CM generation from SAG-treated TtT/GF cells and its effect on GH3 cells. TtT/GF cells were cultured in $\mathrm{GH} 3$ starvation medium and stimulated with SAG (red) or solvent (DMSO, black). Subsequently, RNA was isolated and the expression of the Hh target genes Gli1, Gli2 and Ptch was analysed via qRT-PCR (A). Afterwards, GH3 cells were incubated with the supernatant from the stimulated TtT/GF cells (conditioned medium, $\mathrm{CM}$ ). RNA was isolated from the GH3 cells and the expression of the Hh target genes Gli1, Gli2 and Ptch and the expression of $G h$ was analysed via qRT-PCR (B). The data were normalized to 18S rRNA (18S) and are shown as fold expression in comparison to the solvent-treated TtT/GF cells or to CMsolvent-treated AtT20 cells, respectively, set to 1 (dotted line). In addition, Gh content in the supernatant of CM-treated GH3 cells was quantified with a specific ELISA. Each dot represents a sample that was measured in technical triplicates. The data are depicted as mean $\pm S D$. For statistical analyses a two-tailed unpaired t-test was performed. * indicate significance compared to

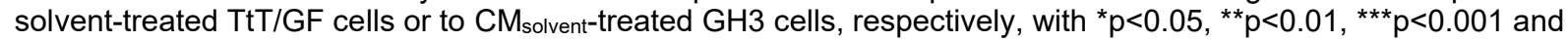
$* * * * p<0.0001$ 


\subsubsection{Transcriptome analyses of Hh signalling activated FSC cells}

Conditioned medium from $\mathrm{Hh}$ signalling activated TtT/GF cells (CMSAG) causes a significant increase in $\mathrm{Gh}$ production and release but does not alter Hh signalling activation status in $\mathrm{GH} 3$ cells. Thus, most likely Hh signalling activation of TtT/GF cells lead to the secretion of a paracrine factor that mediates $\mathrm{G}$ production and release from $\mathrm{GH} 3$ cells. To evaluate this assumption and to unravel potential candidate molecules that may be higher expressed in SAG-stimulated TtT/GF cells compared to solvent treated TtT/GF cells transcriptome analyses of these cells were conducted.

In fact and in line with the qRT-PCR-based expression analyses (see Figure 33, Figure 35 and Figure 36) SAG-treatment led to significant increased expression of $\mathrm{Hh}$ signalling target genes (e.g. Ptch, Gli1 and Hhip) but also increased the transcription of genes that belong to G-protein coupled receptor (Gpcr) signalling [e.g. pyroglutamylated RFamide peptide (Qrfp), G protein subunit alpha 15 (Gna15) and $\checkmark i p]$ and genes that are described as extracellular matrix (ECM) marker [e.g. transglutaminase 2 (Tgm2), fibronectin 1 (Fn1) and integrin beta-7 (Itgb-7)] (Figure 37A,B). Furthermore, increased expression of the angiotensin converting enzyme (Ace), insulin-like growth factor-binding protein 2 (Igfbp-2), glutamate inotropic receptor kainite type 4 (Grik4) and coxsackievirus and adenovirus receptor (Cxadr) were observed. Marker genes for FSCs (e.g. S100b, Vegfa and Mif) and for active proliferation [e.g. marker of proliferation Ki-67 (MKi67), forkhead box M1 (Foxm1) and cyclin E1 (Ccne1)] were not differential expressed (Figure 37C and D).

These results show that SAG-treatment of TtT/GF cells efficiently induces Hh signalling activity but does not alter the identity of the cells or induce proliferation in these cells. Beyond that, Hh signalling activation resulted in an increased transcription of $\mathrm{Gpcr}$ signalling markers. Most interestingly, this approach also identified the small-molecule and neuro-peptide Vip, which is known to be an inducer of Gh release from $\mathrm{GH} 3$ cells ${ }^{293,294}$, as being upregulated upon $\mathrm{Hh}$ signalling activation. 
A

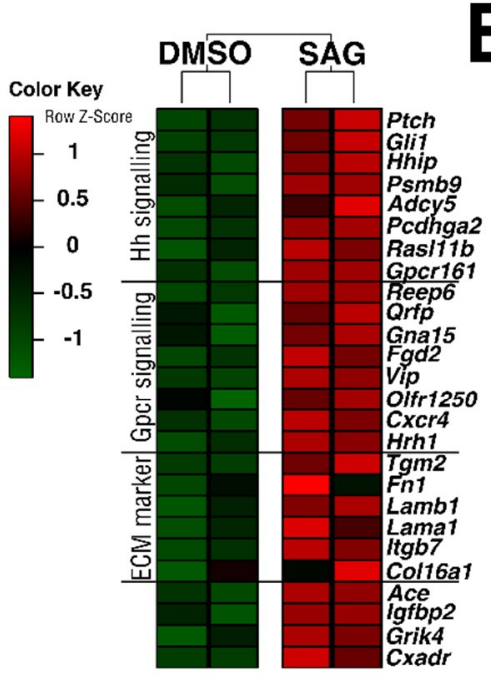

B

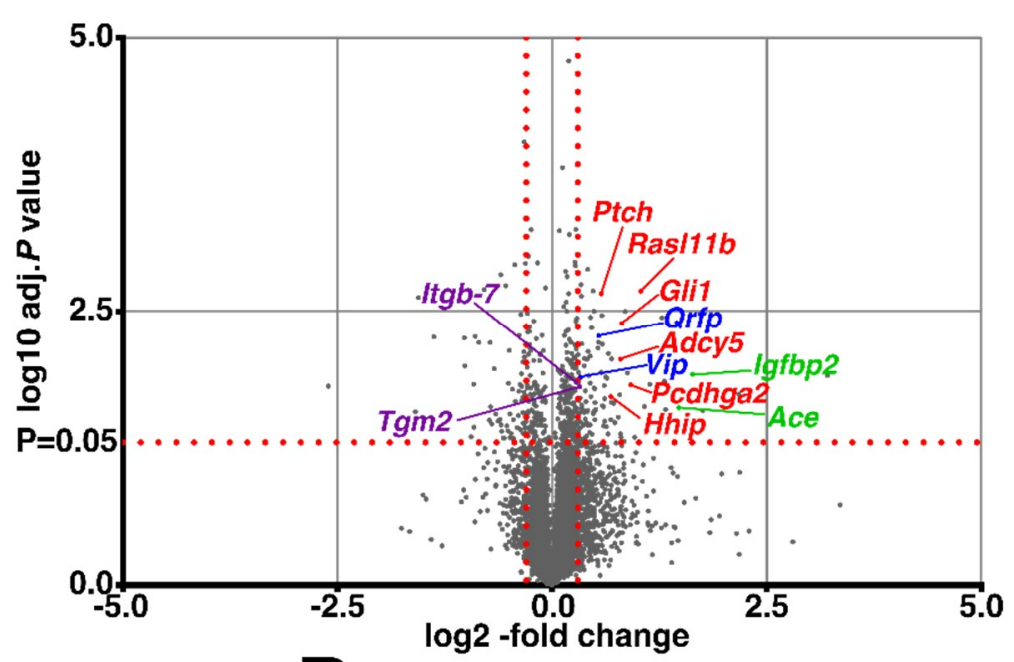

C



D

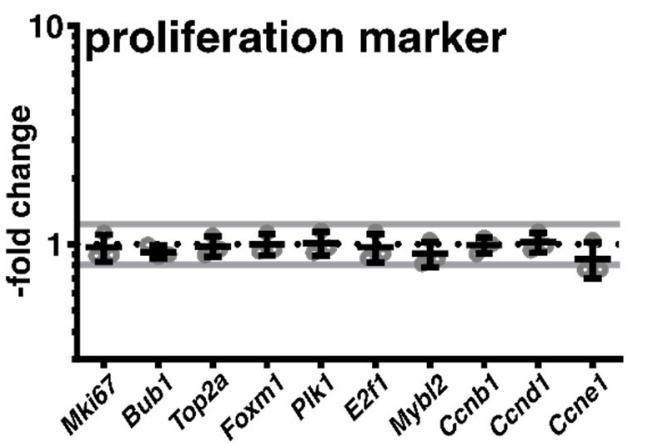

Figure 37 Transcriptome analysis of SAG- and DMSO-treated TtT/GF cells. TtT/GF cells were cultured in starvation (serum-deprived) medium and treated with SAG or DMSO. Total RNA was isolated and the transcriptome of the cells was analysed via RNASeq. Heatmap of upregulated (red) genes after SAG-treatment (A). Genes were clustered in Hh signalling, Gpcr signalling and ECM marker. Volcano plot of all gene transcripts (cut off log2 -0.3or log2 0.3-fold change, red vertical dotted lines) (B). Expression analysis genes associated with FSC profile (C) or proliferation (D). Cut off was set at 0.8 - or 1.2-fold change (grey lines). The data are shown as fold change expression in comparison to the expression of DMSO-treated TtT/GF cells set to 1 (dotted line in B and C). The data are depicted as mean \pm SD. For statistical analyses a two-tailed unpaired t-test was performed. ${ }^{*}$ indicate significance compared to DMSO-treated TtT/GF cells, respectively, with ${ }^{*} p<0.05,{ }^{* *} p<0.01,{ }^{* * *} p<0.001$ and ${ }^{* * * *} p<0.0001$ (B and C). 


\subsubsection{Vip can regulate hormone production and is secreted from SAG stimulated TtT/GF cells}

A role of $\mathrm{Hh}$ signalling in secretion of signalling molecules from $\mathrm{FSC}$ which regulate hormone production and secretion from endocrine cells was so far unknown. However, transcriptome analyses revealed that Hh signalling activation of TtT/GF cells result in an increased expression of the neuropeptide Vip that is known to be an inducer of $\mathrm{Gh}$ release from $\mathrm{GH} 3$ cells ${ }^{293,294}$. This result was also verified by qRT-PCR-based expression analyses of SAG-treated TtT/GF cells cultured in GH3 starvation medium (Figure 38). Additionally, the amount of Vip protein in the CMsAG was measured via an EIA. Thereby DMSO-treated samples served as solvent controls. This approach indeed demonstrated that the supernatant of SAG-treated TtT/GF cells consists of increased Vip protein levels compared to the controls (Figure 38C).

Beyond that, the ability of TtT/GF, AtT-20 and GH3 cells to respond to external Vip signals was investigated. For the purpose, the expression of known Vip receptors [Vip receptor 1 and 2 (Vipr1/2), or Pacap type 1 receptor (Pac1-R or Adcyap1R1)] was analysed via qRT-PCR. As controls, the expression levels of all 3 Vip receptors in $\mathrm{NIH} / 3 \mathrm{~T} 3$ cells were assessed. Figure 38D shows that all pituitary derived cell lines expressed Adcyap1R1. Thereby AtT-20 cells showed the highest Adcyap1R1 expression level. In contrast, Vipr1 transcripts were only detectable in AtT-20 cells. Most interestingly, the expression levels of Vipr2 were significantly higher expressed in TtT/GF cells and GH3 cells compared to NIH/3T3 and AtT-20 cells (Figure 38D).

These data demonstrate that Vip is produced and secreted from TtT/GF cells upon Hh signalling activation. Moreover, since Vip is a known inducer of Gh release from $\mathrm{GH} 3$ cells and $\mathrm{GH} 3$ cells express high levels of the Vip receptor Vipr2 these results suggest that Hh-dependent Vip release from TtT/GF cells mediates Gh secretion from GH3 cells via Vipr2 signalling. 


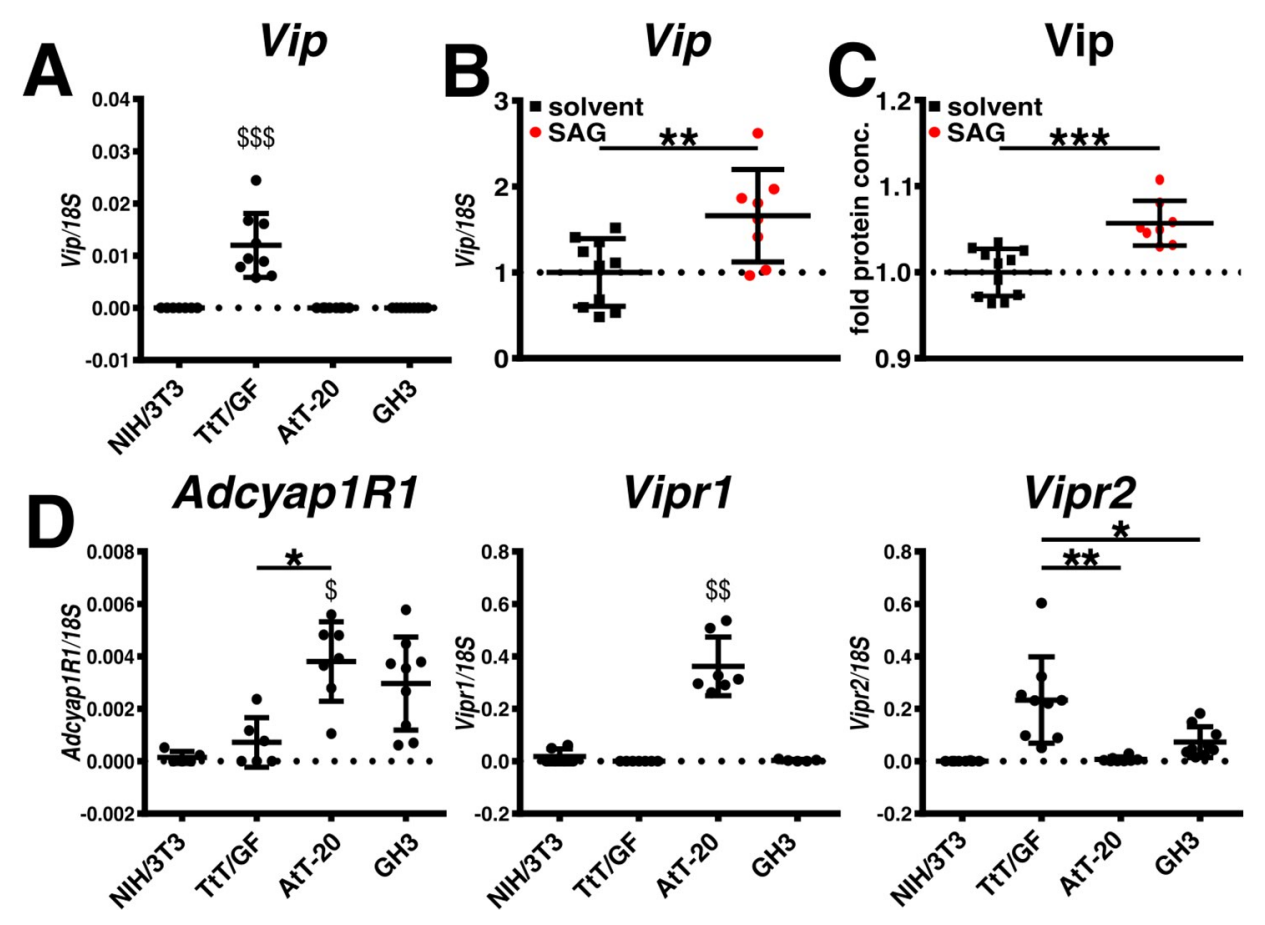

Figure 38 Vip expression and Vip signalling components in pituitary cell lines. RNA from NIH/3T3, TtT/GF, AtT-20 and GH3 cells was isolated and subsequently the expression of Vip was analysed via qRT-PCR (A). Furthermore, the expression of Vip was investigated in SAG- (red) and solvent-(black) treated TtT/GF cells (B). The amount of Vip protein in the supernatant of SAG-(red) and solvent-(black) treated TtT/GF cells was determined with a specific EIA (C). The data are shown as fold protein concentration in comparison to the solvent-treated TtT/GF cells set to 1 (dotted line in C) and are depicted as mean $\pm S D$. Each dot represents a sample that was measured in technical triplicates. The expression of the genes Adcyap1R1, Vipr1 and Vipr2 was analysed in $\mathrm{NIH} / 3 \mathrm{~T} 3, \mathrm{TtT} / \mathrm{GF}, \mathrm{AtT}-20$ and GH3 cells via qRT-PCR (D). For statistical analyses a two-tailed unpaired t-test was performed. ${ }^{*}$ indicate significance compared to solvent-treated TtT/GF cells with ${ }^{*} p<0.05,{ }^{* *} p<0.01,{ }^{* *} p<0.001$ and ${ }^{* * * *} p<0.0001$. The expression data were normalized to $18 \mathrm{~S}$ rRNA (18S) and are shown as relative expression (A and $D$ ) or as fold expression in comparison to the expression of solvent-treated TtT/GF cells set to 1 (dotted line in B). Each dot represents a sample that was measured in technical triplicates. The data are depicted as mean $\pm S D$. For statistical analyses a two-tailed unpaired t-test was performed. \$ indicate significance compared to NIH/3T3 cells with $\$ p<0.05, \$ \$ p<0.01, \$ \$ \$ p<0.001$ and $\$ \$ \$ p<0.0001$ (A and D). * indicate significance compared to TtT/GF cells or solvent-treated TtT/GF cells, respectively, with ${ }^{*} p<0.05,{ }^{* *} p<0.01,{ }^{* * *} p<0.001$ and ${ }^{* * *} p<0.0001$ (B-D). 


\section{Discussion}

The Hh signalling pathway is pivotal in the development of mammalian organs including the pituitary gland. However, its role in maintenance, physiology and pathology of the adult pituitary is ill defined. The first studies investigating the role of the Hh pathway in the pituitary demonstrated the expression of the $\mathrm{HH}$ signalling proteins GLI1 and SHH in corticotrophs and PTCH or PTCH2 in gonadotrophs, thyrotrophs, somatotrophs and a subpopulation of lactotrophs ${ }^{184}$. Vila et al. furthermore reported that Shh stimulation of a corticotroph cell line results in (1) increased Acth secretion, (2) Pomc transcription and (3) attenuation of cell growth. In addition, they showed that Shh treatment of a somatotroph cell line causes enhanced $\mathrm{Gh}$ and $\mathrm{Prl}$ secretion ${ }^{183,184}$. Similarly, also our group demonstrated that Hh signalling activation in adult pituitary explants upregulates the production of $\mathrm{Gh}, \mathrm{Prl}$ and Acth but also increases the proliferation of Sox $2^{+}$cells ${ }^{185}$. Moreover, we showed that the AL of the adult pituitary consists of Gli1-expressing cells that either are Sox2 ${ }^{+}$or Sox2 ${ }^{\text {neg185 }}$ indicating that $\mathrm{Hh}$ signalling is physiologically active in two differently differentiated pituitary cell populations: a Sox2-expressing stem cell or (committed) progenitor and a Sox $2^{\text {neg }}$ more differentiated (hormone-producing) cell population ${ }^{185}$. Since furthermore GH-, PRL- and ACTH- secreting PA show highest GL/1 and SHH expression ${ }^{185}$ it was hypothesized that $\mathrm{HH}$ signalling activation is implicated in the homeostasis and pathology of pituitary Sox $2^{+}$cells and GH-, PRL- and ACTH-expressing endocrine cells. Nevertheless, this hypothesis was based on observations by analysing pituitary explants from a mouse model for ubiquitous homozygous Ptch depletion that activates Hh signalling in every cell. Thus, these analyses did not allow to specify the phenotypecausing cell type although our ${ }^{185}$ and data of other labs ${ }^{183,184}$ hint towards a specific role of $\mathrm{Hh}$ signalling in Gh-, Prl- and Acth-expressing endocrine cells.

The main goal of this thesis was to unravel the impact of the Hh signalling in the adult pituitary gland on cellular level. For this purpose, on the one hand the effect of deregulated Hh pathway in Pomc-expressing cells using a genetically engineered mouse model was studied. On the other hand, the cell-specific activation status of the Hh pathway in the adult pituitary gland was analysed by using immunohistological and reporter mice-based approaches to finally gain insights into the Hh-mediated regulation of hormone release in the pituitary gland. 
5.1. Cell-intrinsic Hh signalling does not play a role in corticotrophs of the adult pituitary gland

Ubiquitous homozygous Ptch depletion in ex vivo cultured murine pituitary glands results in increased transcription of Pomc and Acth secretion ${ }^{185}$. Moreover, Shh treatment of the corticotroph cell line AtT-20 has been reported to increase Acth production of these cells ${ }^{184}$. Thus, initially a hypothesis was proposed in which an activation or inactivation of $\mathrm{Hh}$ signalling specifically in Pomc-expressing cells should lead to an up- or downregulated Acth secretion, respectively (Figure 39). To test this hypothesis Ptch and Smo were homozygously depleted in adult pituitaries by using the PomcCreERT2-deleter mouse strain ${ }^{260}$. The initial evaluation of the specificity of the deleter strain verified a cell-specific Cre-mediated recombination in $\mathrm{Pomc}^{+}$cells of the $\mathrm{AL}$ and the IL. However, also in absence of the CreERT2-inducer tamoxifen a recombination of the ROSA26-tdTomato reporter locus as well as of the $\mathrm{Ptch}^{f}$ and $\mathrm{Smo}^{f}$ loci was detected. These data demonstrate that although the CreERT2-recombinase is cell-specifically expressed its activity is leaky at least in the pituitary. Despite of this, in vivo depletion of Ptch or Smo in Pomc-expressing cells had no effect on pituitary development (e.g. due to the leakiness of the deleter) or on homeostasis and pathology of the adult gland (e.g. after CreERT2-induction in adult mice). None of the investigated parameters (body weight analysis, blood glucose concentration, histological analyses, transcriptional analyses) differ between the control groups and the tamoxifen-treated Pomc/Ptch fff or Pomc/Smofff groups (Figure 39). The only exception of this was a significantly decreased pituitary Pomc transcription in tamoxifen-treated Pomc/Smo ${ }^{\mathrm{f} / \mathrm{f}}$ pituitaries compared to solvent-treated animals. Interestingly, an inversed observation was not seen in pituitaries of tamoxifen-treated Pomc/Ptch ${ }^{f / f}$ mice (e.g. increased Pomc transcription) which may indicate that Pomc transcription in the adult pituitary is regulated via Smo in a Ptch independent manner. However, the expression of $\mathrm{Hh}$ signalling target genes was not altered in pituitaries of tamoxifen-treated Pomc/Smo $\mathrm{f} / \mathrm{f}$ mice arguing against this conclusion. Thus, the altered Pomc expression in pituitaries of tamoxifen-treated $\mathrm{Pomc} / \mathrm{Smo}^{\mathrm{ff} / \mathrm{f}}$ mice rather may reflect a technical artefact. This conclusion is also strengthened by the fact that tamoxifen-treated Pomc/Smo ${ }^{f / f}$ mice did not show any other conditions that argue in favour of a hormonal imbalance (e.g. altered blood glucose concentration or body weight). 
These results stand in clear contrast to the previously reported impact of active Hh signalling in the corticotroph AtT-20 cell line, since Vila et al. described that Shh treatment of these cells increases Acth release ${ }^{183,184}$. However, data gained from in vivo approaches (e.g. using genetically engineered mice) often more precisely reflect the physiological situation than in vitro approaches using stable cell lines. Thus, the in vivo data obtained in this thesis clearly argue against the initially made hypothesis that Acth production is regulated via cell-intrinsic Hh signalling in Pomcexpressing cells. Moreover, in light of the previously made observations that ubiquitous Hh signalling activation increases Pomc production in pituitary explants ${ }^{185}$ these new data rather indicate that $\mathrm{Hh}$ signalling affects a cell type, which mediates Acth expression in corticotrophs indirectly. Based on this conclusion a new hypothesis was formulated in which $\mathrm{Hh}$ signalling induces a certain cell type to stimulate Acth production from corticotrophs either by a soluble factor or via cell-cell-interaction. However, the data clearly exclude a corticotroph-intrinsic impact of $\mathrm{Hh}$ signalling and thus tumour development or increased Pomc-expression from Ptch or Smo depleted (tumour) cells is very unlikely. Thus, the attempts to re-establish a mouse line that ought to be used to increase the PA incidence from Pomc-expressing cells (Tg.PCE ${ }^{253}$ ) were not pursued further.

\section{Depletion of Ptch/Smo in Pomc $^{+}$cells of the adult pituitary}

\section{Starting hypothesis}



Pomc^ Acth^ or Pomc $\Downarrow$ Acth $\downarrow$
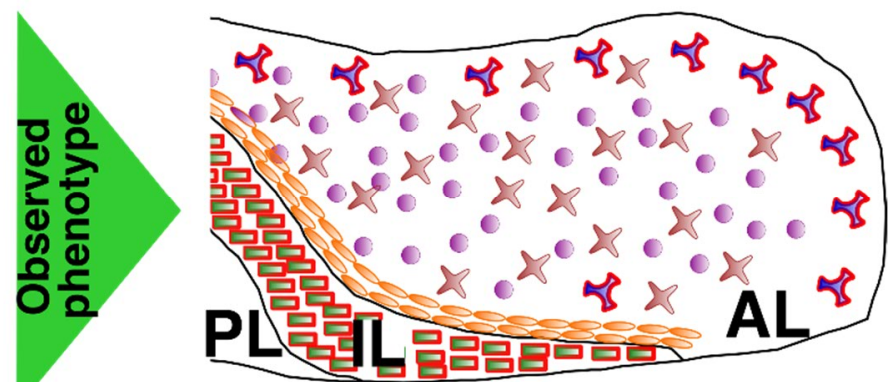

Pomc $\rightarrow$ Acth $\rightarrow$

\section{$\lceil$ Acth $\times$ PrlCGh $=\alpha M$ Sh - Sox 2}

Figure 39 Schematic representation of the expected and resulting phenotype of Pomc/Ptch ${ }^{f / f}$ or Pomc/Smo Pof $^{f / f}$ pituitaries. A conditional depletion of Ptch or Smo in Pomc-expressing cells (red-framed) was thought to either increase Pomc transcription and Acth secretion (for Ptch depletion) or decrease Pomc transcription and Acth secretion (for Smo depletion). Furthermore, a possible enhanced proliferation of Pomc ${ }^{+}$cells was estimated (left). However, the observed phenotype (right) showed that a depletion of Ptch or Smo in Pomc-expressing cells does not alter hormone production and does not change cellular proliferation in the gland. 


\subsection{Cell-intrinsic Hh signalling in somatotrophs and FSC of the adult pituitary} gland

The genetically in vivo approach clearly excludes a cell-intrinsic impact of $\mathrm{Hh}$ signalling in corticotrophs of the adult pituitary. However, two differently differentiated but so far unidentified pituitary populations (e.g. Sox $2^{+}$and Sox2 $2^{\text {neg }}$ of the AL) express Gli1 and thus show active $\mathrm{Hh}$ signalling ${ }^{185}$. Moreover, ubiquitous activation of $\mathrm{Hh}$ signalling in pituitary explants leads - besides an increased Acth, Gh and Prl expression - to increased proliferation of Sox $2^{+}$cells ${ }^{185}$. This indicates that at least in Sox $2^{+}$cells $\mathrm{Hh}$ signalling should play a role. Beyond that, also $\mathrm{Gli} 1^{+} /$Sox $2^{\text {neg }}$ cells that hypothetically represent a certain endocrine cell type (e.g. Gh- or Prl-expressing cells) seems to be cell-intrinsically regulated by $\mathrm{Hh}$ signalling. In fact, lineage tracing and RNAScope analyses revealed that a subpopulation of Gh-expressing cells and FSC of the AL but never Pomc, Acth or Prl expressing cells descent from Gli $1^{+}$cells and/or express Gli1 transcripts as the most reliable indicator for active $\mathrm{Hh}$ signalling.

On the first glance, these findings do not fully support the previously made conclusion that Hh signalling most likely regulates Acth, $G h$ and $\mathrm{Prl}$ production and/or secretion. On the other hand, these results clearly strengthened the assumption that cell-intrinsic Hh signalling does not affect the homeostasis of corticotrophs since they neither descent from Gli ${ }^{+}$cells nor stain positive for Gli1. Moreover, the new data bring somatotrophs - potentially as the previously identified $\mathrm{Gli} 1^{+} / \mathrm{So} \times 2^{\text {neg }}$ cell population and FSC as Gli1 ${ }^{+} / \mathrm{Sox}^{+}$cells into the focus of the question which pituitary cell type is implicated into the phenotype of ubiquitously $\mathrm{Hh}$ signalling activated pituitaries. In case of $\mathrm{Gli}^{+}$somatotrophs the most obvious conclusion is that $\mathrm{Hh}$ signalling regulates cellintrinsically Gh production in these cells although this has not been proven so far but is currently under investigation (see discussion section 5.2.1). However, it becomes more interestingly in case of FSC, since these non-endocrine cells are known to interact with endocrine cells including corticotrophs, somatotrophs and lactotrophs ${ }^{62,295}$. Moreover, the fact that FSC express Sox2 ${ }^{296}$ as well as $S 100 b^{63,64}$ and are able to uptake of the fluorescent dipeptide $\beta$-Ala-Lys-N(E)-AMCA ${ }^{297}$ also stain positive for the proliferation marker $\mathrm{Ki}-67$ indicate that the previously identified $\mathrm{Gli1}^{+} / \mathrm{Sox}^{+}$cells of the $\mathrm{AL}^{185}$ most likely represent FSC. The results furthermore suggest that FSC are the so far undefined Sox $2^{+}$cell type that showed increased proliferation after ubiquitously Ptch depletion ${ }^{185}$. Due to the important role of FSC in 
regulating the homeostasis of the adult gland, it also can be hypothesised that Gli1 FSC cells are responsible for the increased hormone production in Hh signalling activated pituitary explants ${ }^{185}$. Indeed, in vitro experiments using a FSC cell line hint towards the last-mentioned hypothesis at least for Gh production and release (see Figure 36). However, corticotrophs and lactotrophs never stain positive for Gli1 expression or descent from Gli1-expressing cells, which also argues in favour for an indirect regulatory mechanism for Acth and $\mathrm{Prl}$ release upon $\mathrm{Hh}$ signalling activation in FSC. In fact, FSC are demonstrated to localize in close proximity to lactotrophs ${ }^{298}$ and to produce small molecules (e.g. Anxa1) that can stimulate hormone secretion ${ }^{299}$. However, future studies are needed for evaluating this fascinating aspect.

Based on the transcriptome analyses from SAG-stimulated TtT/GF cells an impact of $\mathrm{Hh}$ signalling on the proliferative behaviour of FSC may have to be excluded since the expression of proliferation marker genes was not altered in SAG-stimulated TtT/GF cells. Nevertheless, future in vivo approaches are needed to evaluate this conclusion for the in vivo situation. Beyond that, Gli1 transcripts and reporter gene expression were only observed in mature somatotrophs and FSC but never in progenitor cells. Thus, Hh signalling rather seems to be required in the respective mature cells and most likely is not involved in differentiation processes in the adult gland.

Most remarkably, the results gained from studying murine pituitaries were also transferable to the human adenohypophysis. Combined RNAScope/ immunofluorescent stainings revealed that GL/1 transcripts are expressed in $\mathrm{GH}$ secreting cells and in $\mathrm{S}^{100^{+}} \mathrm{FSC}$ in the human AL. Thus, $\mathrm{HH}$ signalling seems to be implicated in the same pituitary cell types in mouse and human and also potentially contributes to equal functions in both species highlighting the pivotal role of this pathway in the adult gland.

\subsubsection{Genetically engineered mouse lines to analyse the impact of $\mathrm{Hh}$ signalling in vivo or ex vivo cultured organs}

The results that $\mathrm{Hh}$ signalling play a role in mature somatotrophs and FSC of the adult pituitary are remarkable and novel. However, to gain further insights into the function of a particular pathway in a certain cell type a cell-specific deregulation of the 
respective pathway (e.g. Cre/loxP system) is the gold standard. Thereby, the use of an inducible Cre-recombinase (e.g. tamoxifen-inducible CreERT2-recombinases) is advantageous because deregulation of a developmental important pathway, like the Hh pathway, during embryogenesis often impedes analyses on adult tissues. However, currently neither a somatotroph- nor a FSC-specific CreERT2-mouse line is available. Furthermore, the generation of a cell-specific deleter strain also requires the knowledge about a cell-specific promoter that in case of FSC is not given. For targeting somatotrophs, so far different mouse strains are available that expresses Crerecombinases in Gh producing cells ${ }^{282,283}$ or in cells that descent from the Pit-1281 lineage (e.g. somatotrophs, lactotrophs and thyrotrophs). However, all these strains express constitutive active Cre-recombinases that may potentially impede a study of the impact of $\mathrm{Hh}$ signalling in the pituitary of adult animals. The reason for this conclusion is that both $\mathrm{Gh}$ and Pit-1 are expressed during the organogenesis of the pituitary and during the development of the male reproductive system $39,282,283,300,301$ or trunk somite ${ }^{282}$ and eyes ${ }^{281,302,303}$, respectively. An activation or inactivation of $\mathrm{Hh}$ signalling using Gh-Cre or Pit1-Cre deleter strains most likely will not only result in hypo- or hyperplasia of the pituitary but also may lead to failed development of the respective organs which finally would impede the analysis of a deregulation of $\mathrm{Hh}$ signalling somatotrophs of the adult pituitary. Thus, an inducible somatotroph-specific Cre deleter mouse strain would be needed for in vivo analyses of a deregulated $\mathrm{Hh}$ signalling in somatotrophs.

Hence, a part of this thesis was dedicated to the generation of a mouse strain that enables a pituitary-specific expression of an inducible CreERT2-recombinase. For this purpose, the Ghrhr promoter region was cloned upstream of a CreERT2-recombinase gene. This driving promoter was chosen since at least for the rGhrhr it has been shown that its expression is tightly regulated and restricted to pituitary cells in rGhrhrCre transgenic mice ${ }^{281}$ although endogenous $G h r h r$ is also expressed in other organs like the renal medulla ${ }^{284}$, hypothalamus ${ }^{285}$, testis ${ }^{286}$. The initial analyses of an EGFP reporter under the control of the rGhrhr promoter region ${ }^{281}$ failed to be expressed in $\mathrm{Ghrhr}^{+} \mathrm{GH} 3$ cells. Thus, the rat promoter sequence was evaluated as not suitable to drive effective transcription, potentially because the promoter region of the rGhrhr_EGFP construct ends after the first ATG (at position +9, Figure 25) and thus resulting in an open reading frame upstream of the EGFP encoding sequence. However, a new attempt by using the murine and the human Ghrhr promoter 
sequences revealed that both Ghrhr promoters were able to drive EGFP-expression in GH3 cells. Thus, the shorter $(-310,-19)$ human $G h r h r$ promoter was used to generate the hGHRHRCreERT2 vector. Since the encoded CreERT2-recombinase was efficiently expressed in GH3 cells, tamoxifen-inducible and capable to recombine the $P_{t c h}^{f}$ locus this construct was used for the generation of transgenic mice. Currently 3 founder mice were born which however have to be used to establish founder mouse strains and which have to be characterized by breeding to a reporter mouse strain, like ROSA26-tdTomato. Thereby the analyses should include the evaluation of 1) a possible leakiness of the CreERT2-recombinase activity without tamoxifen-treatment during the development and in adult mice and 2) the specificity the CreERT2recombinase expression in cells of the adult pituitary or in other organs. In case of good inducibility and specific expression of the hGHRHRCreERT2-recombinase the mouse strain can be afterwards used to analyse the impact of $\mathrm{Hh}$ deregulation in somatotrophs of adult pituitaries by monitoring hGHRHRCreERT2/Ptch f/f and $h G H R H R C r e E R T 2 / S m o^{f / f}$ mice. Thereby parameters that are symptomatic for somatotropin overproduction should be documented since based on the previously generated data it is conceivable that $h G H R H R C r e E R T 2 / P_{t c h} h^{f / f}$ mice will suffer from a phenotype resembling acromegaly symptoms, like irregularly strong growth ${ }^{304}$, abnormal calcium levels ${ }^{305}$ or cardiac hypertrophy ${ }^{306}$. However, examination of $\mathrm{Gh}$ and Igf-1 blood serum levels are the most reliable and abundant parameter for acromegaly symptoms ${ }^{307}$ and therefore should also be analysed. hGHRHRCreERT2/Ptch f/f mice potentially are also predisposed for the development of PA and thus should be carefully monitored for signs of such tumours (e.g. acral enlargement, osteoarthritis or insulin resistance $\left.{ }^{308,309}\right)$. However, low PA incidences of these animals might be increasable by breeding to mouse strains with an elevated incidence for the formation of hyperplasia and adenoma formation like $\alpha$ GSU.PTTG transgenic mice that express PTTG in $\alpha \mathrm{GSU}^{+}$cells (e.g. gonadotrophs and thyrotrophs ${ }^{251}$ ). Unfortunately, $\alpha$ GSU.PTTG transgenic mice are not available anymore and have to be re-established. However, within this thesis the plasmid which has been used to generate the original $\alpha$ GSU.PTTG mouse line has been shown to be suitable to overexpress PTTG in somatotroph cells in vitro.

Parallel to the generation of $h G H R H R C r e E R T 2$ transgenic mice the Aldh1/1CreERT2 and Gli1CreERT2 deleter mouse strains were chosen to specifically activate or inactivate $\mathrm{Hh}$ signalling in somatotrophs and FSC simultaneously. As shown by lineage 
tracing experiments both deleter mouse strains express a CreERT2-recombinase in somatotrophs and FSC of the adult pituitary gland. However also adult tissues that are

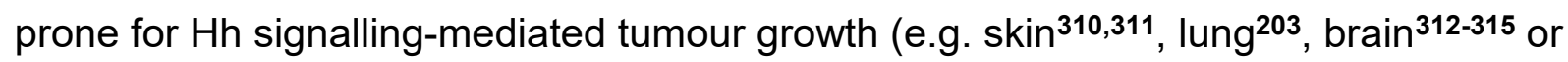
liver ${ }^{316-318}$ ) express the CreERT2-recombinases. To avoid severe health issues due to in vivo activation of the CreERT2-recombinases ex vivo tamoxifen-treatment of whole pituitary organ cultures similarly to Pyczek et al. ${ }^{185}$ were conducted. Unfortunately, ex vivo recombination of the ROSA26-tdTomato, Ptch ${ }^{f}$ and Smof loci was not accomplished. A possible reason for this may be the fact that the CreERT2recombinases of Aldh1/1CreERT2 and Gli1CreERT2 deleter mice are expressed under the control of cell-specific promoters whereas Pyczek et al. ${ }^{185}$ used a ubiquitously high expressed Rosa26CreERT2 transgene. Thus, the Rosa26CreERT2 recombinase is present more abundantly and most likely can be activated easier with tamoxifen. Moreover, the blood circulation is interrupted in ex vivo organ cultures, which may lead to a lower tamoxifen-availability in the tissue than after in vivo tamoxifen application, especially since the Aldh1/1CreERT2 and Gli1CreERT2 targeted cells are located in the central zone of the gland. Another reason could be a diminished expression of the CreERT2-driving promoters of the cultured glands similarly to the altered gene expression profile of ex vivo cultured organs ${ }^{319}$. However, since Gli1 expression can be still detected in cultured pituitaries ${ }^{185}$ most likely tamoxifen diffusion into the ex vivo cultured glands was not efficient in the approaches reported here. Since this problem can only solved by conducting single cell cultures, which on the other side impede the analysis of histological features, in vivo activation of the CreERT2-recombinases to activate or inactivate $\mathrm{Hh}$ signalling in vivo seems to be the method of choice. However, such approaches most likely will lead to Hh signalling activation/inactivation in other adult organs despite of the pituitary, which finally may result in multiple Hh-associated health issues (e.g. hyperproliferation in skin, lung, brain and/or liver). To avoid or to minimize these difficulties future studies using Aldh1/1CreERT2 and Gli1CreERT2-deleter for in vivo deregulation of $\mathrm{Hh}$ signalling should be conducted shortly after tamoxifen-application. Since the induction of a ubiquitous homozygous Ptch depletion in adult mice results in health issues at the earliest 10 days after the first tamoxifen injection ${ }^{157}$ a dissection of the pituitaries 5-10 days after tamoxifen induction might be feasible without risking adverse health issues of the mice. These analyses will show if and how Hh signalling affects hormone production in a physiological environment in FSC and $\mathrm{Gh}^{+}$cells. However, using 
Aldh1/1CreERT2 and Gli1CreERT2-deleter mice a cell-type specific (either in FSC or in $\mathrm{Gh}^{+}$cells) depletion of Ptch or Smo is not possible. Nevertheless, due to the fact that suitable mouse models for a cell-specific targeting of somatotrophs and/or FSC are currently not available in vitro model systems are the tool of choice to analyse the impact of Hh signalling in either FSC or somatotrophs separately.

\subsubsection{Hh signalling activity status and SAG-responsiveness of pituitary cell lines}

To investigate a potential impact of a signalling pathway in a respective cell type in vitro studies of tissue-specific cell lines can be analysed. Thus, and because suitable mouse models either were not suitable or are still in a generation process (see above) also in this thesis in vitro approaches using well-established pituitary cell lines were used to analyse the role of $\mathrm{Hh}$ signalling in somatotrophs and/or FSC. For this purpose, first the identity of the cell lines and second their Hh signalling status were assessed. These approaches revealed that the corticotroph AtT-20 cells, the somatotroph GH3 cells as well as the FSC-cell line TtT/GF express known markers of the respective cell types and thus verified their identity. Assessment of $\mathrm{Hh}$ signalling status showed that AtT-20 cells form only very small and deformed primary cilia without Smo localization in the cilia. Moreover, the facts that they express very high Ptch but low levels of Gli1 that were not increasable via SAG treatment indicated that they are not responsive for canonical Shh-dependent $\mathrm{Hh}$ signalling activation. These results substantiate the previous made observations that Shh-treatment is not sufficient to activate $\mathrm{Hh}$ signalling in AtT-20 cells ${ }^{185}$. However, Vila et al. previously reported that Shh-treatment can stimulate Pomc expression in AtT-20 cells ${ }^{184}$. Nevertheless, AtT-20 cells that were used for the here performed study never showed an increased expression of Pomc upon SAG- (this thesis) or Shh-treatment ${ }^{185}$ possibly due to the fact that the here utilized AtT-20 cells are unresponsive against canonical Hh signalling activation. On the other hand, Gli1 overexpression in the here used AtT-20 cells can elevate Pomc transcript level ${ }^{185}$ suggesting that Pomc expression might be a target of non-canonical Shh-independent but Gli1-dependent $\mathrm{Hh}$ signalling [similarly as in melanoma via protein kinase $B(A K T)^{320}$ or in multiple myeloma via histone deacetylases ${ }^{321}$. Nevertheless, corticotrophs in adult pituitary glands never showed Gli1 expression and in vivo deregulation of canonical $\mathrm{Hh}$ signalling in these cells did not affect Pomc- or 
Acth-production (this thesis). Thus, it has to be assumed that neither canonical nor non-canonical Hh signalling regulates Pomc expression in a cell-intrinsic manner in corticotrophs in vivo.

In contrast to AtT-20 cells, somatotroph GH3 cells form adequate cilia and frequently show ciliary Smo localization which should be considered as signs of a moderate active Hh signalling ${ }^{289}$. However, GH3 cells express very low Gli1 but very high Gli2 levels and irritatingly, SAG-treatment decreases the Gli2 mRNA levels but not did not alter Gli1 transcription levels. These results stand in contrast to the classical knowledge about Hh signalling stimulation upon SAG treatment, which normally induces Gli1 and Gli2 expression ${ }^{322-324}$. However, a downregulation of Gli2 expression as a result of $\mathrm{Hh}$ signalling activation can also be observed in a human neuroglioma cell line in which the interaction of NIMA-related expressed kinase 2A (Nek2A) with the suppressor of fused (Sufu) is responsive for this phenomenon ${ }^{325}$. Interestingly, the downregulation of Gli2 after SAG-treatment of GH3 cells was accompanied by a decreased $G h$ expression suggesting a direct link between $\mathrm{Hh}$ signalling activation status and $\mathrm{Gh}$ repression. In fact, a connection between $\mathrm{Gh}$ production and $\mathrm{Hh}$ signalling activity has been previously already made since Shh treatment can stimulate Gh release from $\mathrm{GH}^{183}$. Unfortunately, the GH3 analyses of Vila et al. did not determine Hh signalling activation status after Shh treatment ${ }^{183}$. Thus, based on the currently available data an evaluation of the actual $\mathrm{Hh}$ signalling activation status in $\mathrm{GH} 3$ cells after SAG-treatment is impossible. Time-course experiments and expression analyses of Nek2A and other $\mathrm{Hh}$ target genes are needed to determine if SAG-treatment induces or represses $\mathrm{Hh}$ signalling and Gh expression in GH3 cells. However, the fact that Gli1 expression - as the surrogate marker for active Hh signalling - did not elevate after SAG-treatment rather suggests that $\mathrm{GH} 3$ cells are unresponsive towards canonical Hh signalling activation and thus that they are an unsuitable model for studying cell-intrinsic $\mathrm{Hh}$ signalling in somatotrophs.

Contrarily to the both endocrine cell lines every single cell of the FSC-derived TtT/GF cell line form a cilium in which Smo localizes. Moreover, Gli1, Gli2 and Ptch transcription levels of TtT/GF cells were comparable to that of the Hh responsive cell line $\mathrm{NIH} / 3 \mathrm{~T}^{326}$. SAG-treatment of TtT/GF cells results in all analysed conditions in an increased transcription of the Hh target gene Gli1 whereas elevated Gli2 and Ptch expression was only observed in AtT-20 starvation medium (Figure 35 and Figure 36). 
Irrespectively, from the varying Gli2 and Ptch expression levels upon SAG treatment which might be explained by the differential composition of the respective media (e.g. in contrast to AtT-20 medium GH3 medium contains heat-inactivated FBS) these results showed that canonical $\mathrm{Hh}$ signalling is inducible in TtT/GF cells upon SAGtreatment. Moreover, these data indicate that TtT/GF cells represent a suitable in vitro model to investigate the impact of $\mathrm{Hh}$ signalling activation in FSC.

\subsubsection{Activation of $\mathrm{Hh}$ signalling in $T t T / G F$ cells induces the secretion of vasoactive intestinal polypeptide and stimulates $\mathrm{Gh}$ production from $\mathrm{GH} 3$ cells}

AtT-20, GH3 and TtT/GF cells form cilia and express the Hh signalling marker genes Gli1, Gli2 and Ptch that strongly suggested that all 3 cell lines may be responsive towards Hh signalling activation. However, in contrast to AtT-20 and $\mathrm{GH} 3$ cells only TtT/GF cells express increased levels of Gli1 and Gli2 upon SAG stimulation. This demonstrates that TtT/GF but not AtT-20 and GH3 cells are responsive towards $\mathrm{Hh}$ signalling activation. Furthermore, these data indicate that AtT-20 cells like pituitary corticotrophs do not show cell-intrinsic $\mathrm{Hh}$ signalling. On the other hand, the data revealed that $\mathrm{GH} 3$ cells do not represent a suitable in vitro model for studying a potential cell-intrinsic impact of $\mathrm{Hh}$ signalling in somatotrophs. However, the responsiveness of TtT/GF cells towards Hh signalling stimulation predispose them as a model to analyse whether $\mathrm{Hh}$ signalling is implicated in $\mathrm{FSC}$ function.

FSCs are non-endocrine cells of the $\mathrm{AL}$ that regulate hormone expression of neighbouring endocrine cells ${ }^{327,328}$. However, the exact regulatory mechanisms behind the FSC-endocrine cell interaction are not well understood although several small molecules that most likely are implicated in this process have been identified (e.g. Anxa1 ${ }^{329}$, interleukin- $6^{330-332}$ or $\mathrm{Vip}^{333}$ ). Since so far, a role of Hh signalling in FSCmediated hormone secretion is undescribed, it was hypothesized that cell-intrinsic $\mathrm{Hh}$ signalling in FSC might lead to the release of a certain signalling molecule from FSC that mediates hormone release from endocrine cells. This hypothesis was supported by the observations that an overactivation of $\mathrm{Hh}$ signalling in all pituitary cells results in increased transcription of Pomc, Gh and $\mathrm{Pr}^{185}$ whereas deregulation of $\mathrm{Hh}$ signalling in Pomc-expressing cells did not impact Acth release (this thesis). Moreover, only the function of somatotrophs and FSC seems to be regulated via cell-intrinsic $\mathrm{Hh}$ signalling 
since no other cell type express Gli1 in the normal gland. In addition, the circumstance that AtT-20 and $\mathrm{GH} 3$ cells are unresponsive towards cell-intrinsic Hh signalling activation via SAG enables the study of their hormone release independently of intrinsic $\mathrm{Hh}$ signalling activation by culture them in conditioned medium from SAGstimulated TtT/GF cells.

In fact, the medium from SAG-treated TtT/GF cells was capable to increase Gh production indicating that a small molecule secreted of the SAG-stimulated TtT/GF cells might be the mediator of Gh release. Following transcriptome and supernatant analysis furthermore revealed that the expression and secretion of the peptide hormone Vip was increased in TtT/GF cells and in its supernatant after SAG treatment, respectively. This was remarkable, since Vip is a well-known mediator for $\mathrm{Gh}^{\mathbf{2 9 3}, 294,334-}$ ${ }^{337}, \mathrm{Prl}^{336,338}$ and $\mathrm{Acth}^{339,340}$ secretion from endocrine cells both in vitro and in vivo. Moreover, SAG-stimulation of TtT/GF cells results in Vip concentrations within the medium of approximately $0.9 \mathrm{nM}$ which correlates with previously reported Vip amounts that are sufficient to facilitate $\mathrm{Gh}$ release $(1 \mathrm{nM})^{337}$. Vip physiologically signals to the responder cell via binding to the Gpcr Vipr1 or Vipr2 (type II receptors), but not via the Pacap receptor ${ }^{341}$. Since GH3 cells express Vipr2 but not Vipr1 it is most likely that the Gh release from these cells is mediated via Vip/Vipr2 signalling.

Contrarily to GH3 cells, the medium from SAG treated TtT/GF cells did not induce increased Pomc production from AtT-20 cells although Vip is known to stimulate Acth release from a substrain of AtT-20 cells ${ }^{342,343}$. However, Vip has been shown to only act via Vipr2 in AtT-20 cells ${ }^{343}$ but AtT-20 cells used in this thesis do not express this receptor. Thus, the unresponsiveness of the AtT-20 cells towards Vip-containing medium might be the result from the fact that these cells simply do not express Vipr2. However, Acth concentration was not measured in the supernatant of treated AtT-20 cells since increased Pomc transcription was not observed after 48 hrs incubation with CMsag. Due to the fact that increased Pomc transcription is often found shortly after stimulus contact (max. $3 \mathrm{hrs}^{342,343}$ ) it seems to be possible that the incubation time used here was too long compared with other studies to determine altered Pomc mRNA levels. Thus, repetition of the experiments with shorter incubation times and measurement of both Pomc mRNA and Acth protein levels should be conducted. In addition, the responsiveness of the here used AtT-20 cells towards recombinant Vip should be evaluated (e.g. by measuring Acth release or intracellular cAMP levels). 
Nevertheless, the result that Hh signalling activation in FSC increases the release of Vip which most likely acts via Vipr2 signalling to induce Gh release from somatotrophs is novel and remarkably. This is the case since these data provide new insights into the function and regulation of FSC and their interaction with endocrine cells. Moreover, additionally to the well known Hh targets Ptch ${ }^{344,345}$, Hhip ${ }^{345}$, Gli1344,345 and Gpcr161346 also an elevated expression of the Hh target genes Ras $/ 11 b^{344,347}, A d c y 5^{348}$ and Psmb9344 were identified to be upregulated in SAG-stimulated TtT/GF cells. Thus, these data also provide a new starting point to investigate the role of $\mathrm{Hh}$ signalling in FSC in more detail.

In addition to Hh target genes SAG-treatment also increased the expression of ECM marker genes in TtT/GF cells suggesting a direct link between Hh signalling and ECM. However, although $\mathrm{Hh}$ signalling is known to play a role in ECM formation in cancer $^{349,350}$ (e.g. in pancreatic cancer ${ }^{351}$ ) so far a direct $\mathrm{Hh}$ signalling-induced induction of ECM marker genes has not been described before. Nevertheless, the data provided here are obtained from transcriptional analyses and it remains elusive if SAGtreated TtT/GF cells even produce all the proteins. Thus, a proteome or a secretome analysis from SAG-treated TtT/GF cells would be advantageous. However, identification of small proteins is still challenging for this method ${ }^{352}$ and thus it is questionable if small molecules like Vip, that has a size of 28 amino acids ${ }^{353}$ will be detectable with this method.

5.3. The impact of the study in context of the pathology of the human pituitary

The most common disease of the adult pituitary gland is the development of PA. This disorder is mainly characterised by an overproduction of one or even several hormones. Thereby it leads to an imbalanced hormone status of the body and can affect other organs. In rare cases, growing of the PA disturbs the surrounding nervous tissue and causes visual disturbances and headache. Thus, investigations on the pathology of PA are of high importance.

Previously our group demonstrated that ACTH-, GH- and PRL-secreting PA show high GLI1 and SHH levels indicating an increased activity of the Hh signalling pathway in these tumours ${ }^{185}$. Thus and due to the facts, that a ubiquitous activation of the $\mathrm{Hh}$ 
signalling in murine pituitaries results in elevated Acth, Gh and Prl production and enhanced proliferation of Sox $2^{+}$cells ${ }^{185}$ the hypothesis arose that $\mathrm{Hh}$ signalling might also play a role in the pathology of the pituitary like in the formation, progression or maintenance of some PA subtypes. However, analyses of genetically engineered mouse models and immunohistological stainings on sections of human pituitary glands conducted in this thesis clearly demonstrate that the Hh signalling pathway is only active in subpopulations of FSC and somatotrophs of the adult pituitary. Moreover, the data presented here exclude an impact of cell-intrinsic Hh signalling in Pomc/Acthexpressing cells. However, these data do not rule out a role of Hh signalling in the pathology of the pituitary but rather point towards that aberrant Hh signalling may impact the function of FSC and/or somatotrophs during homeostasis and potentially also in pituitary diseases.

Indeed, FSC are found in 40-50 \% of ACTH, GH or PRL-secreting pituitary tumours ${ }^{354}$ mostly at the periphery of PA and pituitary lesions ${ }^{355-358}$. However, Hh signalling activity in tumour-associated FSC have been not studied so far. Thus, currently it can only be speculated if aberrant Hh signalling contribute to pituitary pathology. Nevertheless, the findings that FSC-like TtT/GF cells secrete Vip upon Hh signalling activation which in turn lead to increased $\mathrm{G}$ release from the somatotroph $\mathrm{GH} 3$ cell line suggests that aberrant $\mathrm{HH}$ signalling in FSC may also contribute to increased hormone secretion in PA. Indeed, $\mathrm{ACTH}^{+}, \mathrm{GH}^{+}$, and $\mathrm{PRL}^{+} \mathrm{PA}$ show increased VIP expression levels ${ }^{359}$ and VIPR are also abundantly expressed in human $\mathrm{PA}^{360}$. These findings substantiate the conclusion that FSC also control hormone secretion of PA potentially via $\mathrm{HH}$ signalling which however have to be evaluate in future studies.

Active Hh signalling is known to be involved in proliferative processes in normal adult tissues $^{361,362}$ as well as in tumours (e.g. lymphomas ${ }^{363}$ or small lung cell carcinoma ${ }^{203}$ ). Thus, and in light of the knowledge that Hh signalling is highly active in PA subtypes ${ }^{\mathbf{1 8 5}}$, it is plausible to postulate that aberrant $\mathrm{HH}$ signalling might be also involved in the proliferation of PA. This conclusion was further supported by the fact, that the ubiquitously activation of $\mathrm{Hh}$ signalling in pituitary explants results in increased proliferation of Sox $2^{+}$cells ${ }^{185}$ which potentially represent FSC due to their Sox 2 and Ki-67 expression and their active $\mathrm{Hh}$ signalling in the normal pituitary (this thesis). However, this conclusion is not fostered by in vitro experiments with TtT/GF cells since SAG-stimulation those did not increase any proliferation marker (e.g. Mki67, Foxm1, 
Ccne1). Nevertheless, TtT/GF cells represent an immortalized cell line with a high basal proliferation rate 207,215 . Thus, TtT/GF cells rather are not a suitable tool to draw any conclusions regarding the impact of $\mathrm{Hh}$ signalling activation status and the proliferative behaviour of FSC.

Besides the regulation of hormone production and proliferation, FSC seems to be also involved in basement membrane remodelling, tumour neovascularization and tumour expansion ${ }^{364,365}$ which all are also known processes in which aberrant Hh signalling can be involved (e.g. in medulloblastoma ${ }^{350}$ or angiogenesis ${ }^{366,367}$ ). Indeed, SAGtreatment of TtT/GF cells resulted in increased expression levels of genes implicated in generation or the remodelling of ECM compartments (e.g. transglutaminase $2^{368}$, fibronectin $1^{369-372}$, Laminin B1 and Alpha $1^{373}$, integrin beta- $7^{374}$ and collagen XVI ${ }^{375}$ ). Physiologically the ECM is involved in cell adhesion, migration, proliferation and survival. However, aberrant expression of genes involved in these processes play a crucial role during tumour formation and progression ${ }^{376-378}$. This is also the case for pituitary tumours. Thus, differentially expressed isoforms of fibronectin and alterations in beta1 integrin expression are observed during PA development ${ }^{379-381}$. Moreover, collagen I and IV can inhibit Acth synthesis and laminin inhibits ACTH and PRL production in $\mathrm{PA}^{379,382}$. Together these facts indicate that aberrant $\mathrm{HH}$ signalling in $\mathrm{PA}$ associated FSC may be also involved in ECM formation/remodelling of PA, which might facilitate hormone secretion beside the secretion of VIP. However, future studies are needed to test this hypothesis.

Now and then FSC have been discussed as the stem cell reservoir of the adult pituitary ${ }^{383-385}$. However, currently their role as a potential adult stem cell reservoir of the pituitary gland is secured. In fact, FSC can transdifferentiate in muscle cells ${ }^{\mathbf{3 8 6}}$ and also into endocrine cells ${ }^{387}$ under in vitro cultivation. Moreover, $\beta-A l a-L y s-N(\varepsilon)-A M C A^{+}$ cells (e.g. FSC) are capable to differentiate into $\mathrm{Gh}^{+}$cells in vivo ${ }^{388}$. This leads to the assumption that FSC contribute to PA by producing hormone secreting cells. However, the transcriptome analyses conducted in this thesis did not support the idea of a transdifferentiation of $\mathrm{Hh}$ signalling activated FSC since SAG-treatment did not change the expression profile of FSC and/or endocrine cell marker genes in TtT/GF cells. Nevertheless, in vivo transdifferentiation of FSC into endocrine cells is a long-term effect (>6 weeks) ${ }^{388}$ which may not be detectable after 48 hrs short-term treatment with SAG. Thus, more in vivo experiments are needed to determine if $\mathrm{Hh}$ signalling 
activation in FSC contribute to PA formation/maintenance by transdifferentiation to endocrine and/or tumour cells. Thereby, one of the main questions, which have to be answered in future studies, is whether PA-associated FSC show active $\mathrm{HH}$ signalling. Apart of that, also analyses on genetically engineered mouse models for FSC specific deregulation of $\mathrm{Hh}$ signalling will clarify whether $\mathrm{Hh}$ signalling in FSC plays a role in pituitary pathology. However, currently no FSC exclusive deleter mouse strain is available. One potential option would be the usage of the GLASTCreERT2 mouse deleter strain that expresses a tamoxifen-inducible CreERT2-recombinase under the control of the astrocyte-specific glutamate transporter (GLAST) promoter. Besides its expression in astroglia and radial glia of the adult brain ${ }^{389}$ GLAST is also expressed in in cells of the rat pituitary that harbour the characteristics and localization of FSC ${ }^{390}$. However, using the GLASTCreERT2 deleter strain to deregulate Hh signalling may also result in aberrant function of astrocytes by promoting the accumulation of neuronal stem cells in the brain ${ }^{391}$.

Altogether, the knowledge of the impact of $\mathrm{HH}$ signalling in $\mathrm{PA}$ is sparse albeit a role of this pathway in the pathology of the pituitary can be assumed due the currently available data. This study revealed new insights into the role of $\mathrm{HH}$ signalling in FSC and thereby bringing FSC again to the focus as pivotal players in PA formation/maintenance. Even though aberrant $\mathrm{HH}$ signalling in FSC is most likely not involved in tumour initiation, it potentially is implicated in tumour maintenance and especially hormone secretion of already established PA. Therefore, $\mathrm{HH}$ signalling could be a new therapeutic target for the treatment of PA, especially for PA with currently no medical treatment available.

\subsection{Potential role of $\mathrm{Hh}$ signalling in the adult pituitary}

In combination with the previous findings of our group ${ }^{185}$ the data gained within this thesis were used to establish a model for the role of $\mathrm{Hh}$ signalling in the adult pituitary gland (Figure 40). Within this model, 2 different cell types in the AL of the adult pituitary gland express Gli1, a subpopulation of $\mathrm{Gh}^{+}$and FSC. Whereas the cell-intrinsic role of active $\mathrm{Hh}$ signalling in somatotrophs has to be investigated in future studies, an activation of the Hh signalling in FSC leads to the secretion of paracrine factors that stimulate hormone production and/or release from neighbouring endocrine cells. The data collected within this thesis strongly agues in favour of this model especially for the 
Hh signalling induced release of Vip from FSC which in turn upregulates the expression and release of $\mathrm{Gh}$ from somatotrophs. Beyond that, Hh signalling activation enhances the proliferation of Sox $2^{+}$cells, which potentially represent FSC since they express both Sox2 as well as the proliferation marker Ki-67. Since finally, FSC are numerously found in PA Hh signalling also may play a role in tumour maintenance and/or hormone secretion.

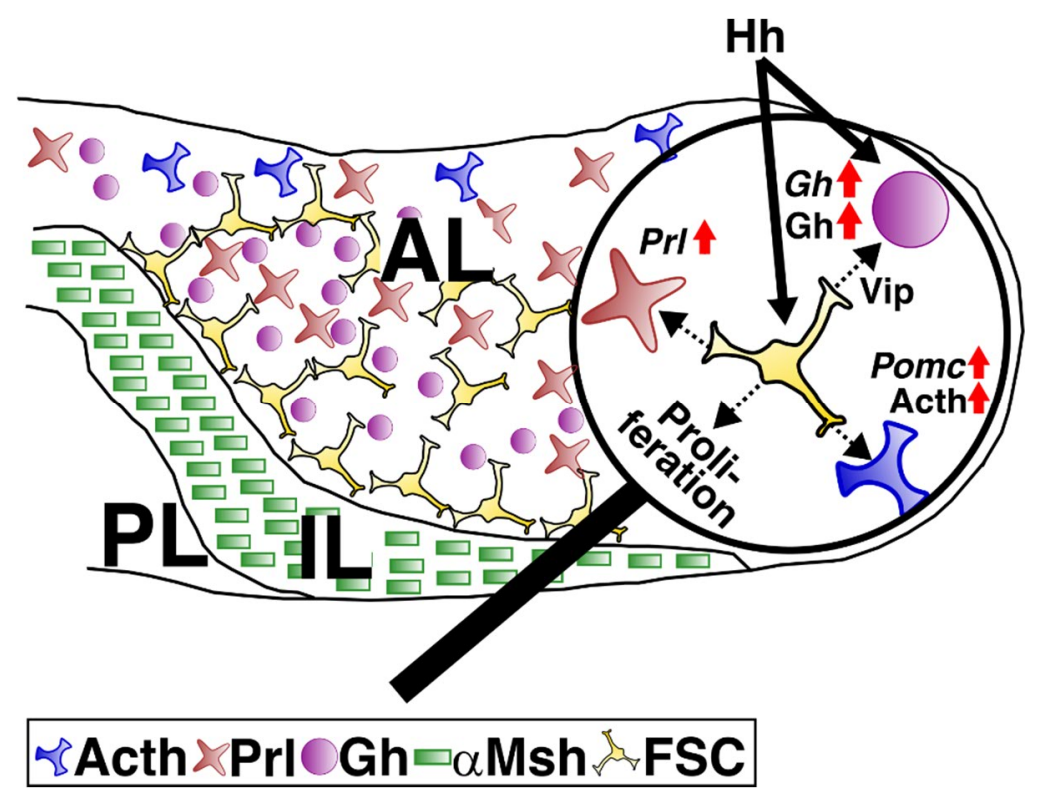

Figure 40 Proposed model for the role of $\mathrm{Hh}$ signalling in the adult pituitary gland in vivo. External $\mathrm{Hh}$ signals affect a subpopulation of FSC and $\mathrm{Gh}^{+}$cells. In FSC the stimulus leads to enhanced proliferation and secretion of paracrine factors (e.g. Vip) that stimulate Pomc, Gh and Prl transcription and Acth and Gh secretion from neighbouring cells. Beyond that, Hh signalling enhances the proliferation of $\mathrm{Sox}^{+} \mathrm{FSC}$ and cell-intrinsically stimulates $\mathrm{G}$ transcription and secretion from somatotrophs.

However, future studies using transgenic mouse models are needed to test if a) the $\mathrm{Hh}$ signalling-induced release of Vip from FSC and its stimulation of Gh production is transferable to the in vivo situation, b) whether similar mechanisms are also responsible for Acth- and/or Prl- release from corticotrophs and lactotrophs, respectively, c) Hh signalling plays also a role in proliferation of FSC and/or in somatotrophs cell-intrinsically and d) Hh signalling activated FSC contribute to the maintenance and/or hormone production of PA. In fact, the general basis for such in vivo studies has been laid by this thesis since here also a new somatotroph-specific CreERT2-deleter strain was generated and Aldh1/1CreERT2- and Gli1CreERT2deleter mice were characterized as tools for targeting somatotrophs and FSC simultaneously. 


\section{Danksagung}

Diese Arbeit wurde in der Abteilung für molekulare Entwicklungsgenetik des Instituts für Humangenetik an der Universitätsmedizin Göttingen angefertigt. Ich danke allen Kolleginnen und Kollegen für die gute Zusammenarbeit und Unterstützung.

Im Besonderen gilt mein Dank:

- PD Dr. Anja Uhmann, für die Bereitstellung dieses vielschichtigen und spannenden Themas, für die große Unterstützung sowohl in der praktischen als auch in der theoretischen Arbeit, für die Diskussionsbereitschaft und die Möglichkeit immer eine Zwischenfrage stellen zu können (dank der geringen Distanz ;)). Vielen Dank Anja!!

- Prof. Dr. Heidi Hahn, für die Chance in einem gut ausgestatten Labor zu arbeiten und für die vielen (auch manchmal unbequemen) Fragen in der Laborbesprechung.

- Prof. Dr. Sigrid Hoyer-Fender und Prof. Dr. Wolfgang Brück für die angenehme Atmosphäre, die konstruktiven Fragen und die Hilfe während der TAC Meetings.

- Prof. Dr. Hubertus Jarry für seine Bereitschaft als Zweitgutachter einzuspringen und für seine nette und freundliche Art.

- Anke Frommhold für jedes freundliche „Guten Morgen“, das einem allmorgendlich durch den Flur entgegenhallte und für die tatkräftige Unterstützung bei meinen immensen Mengen an histologischen Präparaten, ohne dich hätte ich das nie bewältigen können.

- Ina Heß für die tägliche Demonstration, dass man trotz einer halben Stelle die doppelte Arbeit leisten kann und für die hilfreichen Kniffe beim Klonieren, sonst wäre ich manchmal echt verzweifelt.

- Dr. Julia Bauer, für die vielen, vielen, vielen Gespräche über Wissenschaft aber auch über alternative Lebensformen und Hausfrauen-Themen :D ohne dich wäre mir häufig die Decke auf den Kopf gefallen und ich wäre aus dem grumpycat-Modus nicht mehr herausgekommen.

- Slavica Hristomanova Mitkovska for the kindness and the patience that you have and that thought me that work is not everything.

- Nadine Brandes für die interessanten und verblüffenden Fragen zu den verschiedensten Themen und die Hilfe bei der Heatmap Erstellung. 
Mein persönlicher Dank gilt meinen Freunden, die immer für mich da waren, wenn ich mal eine Ablenkung brauchte. Vielen Dank Stephie für die stundenlangen Gespräche trotz der Zeitverschiebung und für deine Gabe meine Gedanken zu sortieren und dass ich mich einfach bei dir aufregen kann, ohne dass es gewertet wird. Danke für unsere Freundschaft. Ich danke dem Klee-Bär für die schöne Zeit und für die Tatsache, dass wir uns nach so vielen Jahren immer noch so gut verstehen wie am Heider Bergsee. Ein großer Dank geht natürlich auch an die Uschis, die durch ihre positive Art immer alles zum Guten wenden konnten und mir den Blick über den Tellerrand gewährten.

Ganz herzlich möchte ich mich noch bei meiner Familie und insbesondere meinen Eltern bedanken, die mich immer unterstützt haben und die ich in jeder Lebenslage anrufen konnte. Ohne euch hätte ich mir das weder zugetraut noch hätte ich das hier fertigstellen können. Vielen Dank für alles!!

Zum Schluss möchte ich mich noch ganz besonders bei Bettina bedanken für die unzähligen Speisen, die du gemacht hast, damit ich nicht verhungere, für das Pendeln, das du in Kauf genommen hast, damit wir zusammenwohnen können und für die vielen aufmunternden Worte, die ich nötig hatte, damit ich nicht vollends den Verstand verliere. Ohne dich wäre das alles hier nicht möglich gewesen, vielen Dank! 


\section{References}

1. Butt, W.S. and V.N. Srinivasan, Pituitary Cancer, in StatPearls2020, (C) 2020, StatPearls Publishing LLC.: Treasure Island FL.

2. Rinehart, J.F. and M.G. Farquhar, Electron microscopic studies of the anterior pituitary gland. J Histochem Cytochem, 1953. 1(2): p. 93-113.

3. De Luca, M., W. Siegrist, S. Bondanza, M. Mathor, R. Cancedda, and A.N. Eberle, Alpha melanocyte stimulating hormone (alpha MSH) stimulates normal human melanocyte growth by binding to high-affinity receptors. J Cell Sci, 1993. 105 ( Pt 4): p. 1079-84.

4. Park, H.Y. and B.A. Gilchrest, Signaling pathways mediating melanogenesis. Cell Mol Biol (Noisy-le-grand), 1999. 45(7): p. 919-30.

5. Zhu, X., A.S. Gleiberman, and M.G. Rosenfeld, Molecular physiology of pituitary development: signaling and transcriptional networks. Physiol Rev, 2007. 87(3): p. 933-63.

6. Cuzzo, B., S.A. Padala, and S.L. Lappin, Vasopressin (Antidiuretic Hormone, $A D H$ ), in StatPearls2020, (C) 2020, StatPearls Publishing LLC.: Treasure Island FL.

7. Kamel, R.M., The onset of human parturition. Arch Gynecol Obstet, 2010. 281(6): p. 975-82.

8. Yang, H.P., L. Wang, L. Han, and S.C. Wang, Nonsocial functions of hypothalamic oxytocin. ISRN Neurosci, 2013. 2013: p. 179272.

9. Petraglia, F., A. Imperatore, and J.R. Challis, Neuroendocrine mechanisms in pregnancy and parturition. Endocr Rev, 2010. 31(6): p. 783-816.

10. Park, J.J. and Y.P. Loh, How peptide hormone vesicles are transported to the secretion site for exocytosis. Mol Endocrinol, 2008. 22(12): p. 2583-95.

11. Stevens, A. and A. White, ACTH: cellular peptide hormone synthesis and secretory pathways. Results Probl Cell Differ, 2010. 50: p. 63-84.

12. Cawley, N.X., Z. Li, and Y.P. Loh, 60 YEARS OF POMC: Biosynthesis, trafficking, and secretion of pro-opiomelanocortin-derived peptides. J Mol Endocrinol, 2016. 56(4): p. T77-97.

13. Cowley, M.A., J.L. Smart, M. Rubinstein, M.G. Cerdán, S. Diano, T.L. Horvath, R.D. Cone, and M.J. Low, Leptin activates anorexigenic POMC neurons through a neural network in the arcuate nucleus. Nature, 2001. 411(6836): p. 480-4.

14. Swanson, L.W., P.E. Sawchenko, J. Rivier, and W.W. Vale, Organization of ovine corticotropin-releasing factor immunoreactive cells and fibers in the rat brain: an immunohistochemical study. Neuroendocrinology, 1983. 36(3): p. 16586.

15. Exton, J.H., Regulation of gluconeogenesis by glucocorticoids. Monogr Endocrinol, 1979. 12: p. 535-46.

16. Braun, T.P. and D.L. Marks, The regulation of muscle mass by endogenous glucocorticoids. Front Physiol, 2015. 6: p. 12.

17. Fardet, L., I. Nazareth, and I. Petersen, Synthetic Glucocorticoids and Early Variations of Blood Pressure: A Population-Based Cohort Study. J Clin Endocrinol Metab, 2015. 100(7): p. 2777-83.

18. Magiakou, M.A., P. Smyrnaki, and G.P. Chrousos, Hypertension in Cushing's syndrome. Best Pract Res Clin Endocrinol Metab, 2006. 20(3): p. 467-82.

19. Peckett, A.J., D.C. Wright, and M.C. Riddell, The effects of glucocorticoids on adipose tissue lipid metabolism. Metabolism, 2011. 60(11): p. 1500-10.

20. Kraus-Friedmann, N., Hormonal regulation of hepatic gluconeogenesis. Physiol Rev, 1984. 64(1): p. 170-259. 
21. Cushing, H., The basophil adenomas of the pituitary body and their clinical manifestations (pituitary basophilism). 1932. Obes Res, 1994. 2(5): p. 486-508.

22. Park, S.Y., J.J. Walker, N.W. Johnson, Z. Zhao, S.L. Lightman, and F. Spiga, Constant light disrupts the circadian rhythm of steroidogenic proteins in the rat adrenal gland. Mol Cell Endocrinol, 2013. 371(1-2): p. 114-23.

23. Saleem, M., H. Martin, and P. Coates, Prolactin Biology and Laboratory Measurement: An Update on Physiology and Current Analytical Issues. Clin Biochem Rev, 2018. 39(1): p. 3-16.

24. Sorenson, R.L. and T.C. Brelje, Adaptation of islets of Langerhans to pregnancy: beta-cell growth, enhanced insulin secretion and the role of lactogenic hormones. Horm Metab Res, 1997. 29(6): p. 301-7.

25. Park, S., D.S. Kim, J.W. Daily, and S.H. Kim, Serum prolactin concentrations determine whether they improve or impair $\beta$-cell function and insulin sensitivity in diabetic rats. Diabetes Metab Res Rev, 2011. 27(6): p. 564-74.

26. Glasow, A., M. Breidert, A. Haidan, U. Anderegg, P.A. Kelly, and S.R. Bornstein, Functional aspects of the effect of prolactin (PRL) on adrenal steroidogenesis and distribution of the PRL receptor in the human adrenal gland. J Clin Endocrinol Metab, 1996. 81(8): p. 3103-11.

27. Chavez-Rueda, K., J. Hérnández, E. Zenteno, A. Leaños-Miranda, M.V. Legorreta-Haquet, and F. Blanco-Favela, Identification of prolactin as a novel immunomodulator on the expression of co-stimulatory molecules and cytokine secretions on $T$ and B human lymphocytes. Clin Immunol, 2005. 116(2): p. 18291.

28. Breves, J.P., S.B. Serizier, V. Goffin, S.D. McCormick, and R.O. Karlstrom, Prolactin regulates transcription of the ion uptake $\mathrm{Na}+/ \mathrm{Cl}$ - cotransporter (ncc) gene in zebrafish gill. Mol Cell Endocrinol, 2013. 369(1-2): p. 98-106.

29. Pathipati, P., T. Gorba, A. Scheepens, V. Goffin, Y. Sun, and M. Fraser, Growth hormone and prolactin regulate human neural stem cell regenerative activity. Neuroscience, 2011. 190: p. 409-27.

30. Freeman, M.E., B. Kanyicska, A. Lerant, and G. Nagy, Prolactin: structure, function, and regulation of secretion. Physiol Rev, 2000. 80(4): p. 1523-631.

31. Ben-Jonathan, N. and R. Hnasko, Dopamine as a prolactin (PRL) inhibitor. Endocr Rev, 2001. 22(6): p. 724-63.

32. Palm, I.F., E.M. van der Beek, H.J. Swarts, J. van der Vliet, V.M. Wiegant, R.M. Buijs, and A. Kalsbeek, Control of the estradiol-induced prolactin surge by the suprachiasmatic nucleus. Endocrinology, 2001. 142(6): p. 2296-302.

33. Bonert, V.S. and S. Melmed, Chapter 4 - Growth Hormone, in The Pituitary (Fourth Edition), S. Melmed, Editor 2017, Academic Press. p. 85-127.

34. Waters, M.J. and D.G. Blackmore, Growth hormone (GH), brain development and neural stem cells. Pediatr Endocrinol Rev, 2011. 9(2): p. 549-53.

35. Meazza, C., S. Pagani, P. Travaglino, and M. Bozzola, Effect of growth hormone $(\mathrm{GH})$ on the immune system. Pediatr Endocrinol Rev, 2004. 1 Suppl 3: p. 4905.

36. Saccà, L., A. Cittadini, and S. Fazio, Growth hormone and the heart. Endocr Rev, 1994. 15(5): p. 555-73.

37. Baudet, M.L., D. Rattray, B.T. Martin, and S. Harvey, Growth hormone promotes axon growth in the developing nervous system. Endocrinology, 2009. 150(6): p. 2758-66.

38. Brooks, A.J. and M.J. Waters, The growth hormone receptor: mechanism of activation and clinical implications. Nat Rev Endocrinol, 2010. 6(9): p. 515-25.

39. Harvey, S., Extrapituitary growth hormone. Endocrine, 2010. 38(3): p. 335-59. 
40. Lu, M., J.U. Flanagan, R.J. Langley, M.P. Hay, and J.K. Perry, Targeting growth hormone function: strategies and therapeutic applications. Signal Transduct Target Ther, 2019. 4: p. 3.

41. Heemskerk, V.H., M.A. Daemen, and W.A. Buurman, Insulin-like growth factor1 (IGF-1) and growth hormone (GH) in immunity and inflammation. Cytokine Growth Factor Rev, 1999. 10(1): p. 5-14.

42. Izadyar, F., H.T. Van Tol, B. Colenbrander, and M.M. Bevers, Stimulatory effect of growth hormone on in vitro maturation of bovine oocytes is exerted through cumulus cells and not mediated by IGF-I. Mol Reprod Dev, 1997. 47(2): p. 17580.

43. Beyea, J.A., D.M. Olson, and S. Harvey, Growth hormone (GH) action in the developing lung: changes in lung proteins after adenoviral $\mathrm{GH}$ overexpression. Dev Dyn, 2005. 234(2): p. 404-12.

44. Isaksson, O.G., C. Ohlsson, A. Nilsson, J. Isgaard, and A. Lindahl, Regulation of cartilage growth by growth hormone and insulin-like growth factor I. Pediatr Nephrol, 1991. 5(4): p. 451-3.

45. Shahid, M.A., M.A. Ashraf, and S. Sharma, Physiology, Thyroid Hormone, in StatPearls2020, (c) 2020, StatPearls Publishing LLC.: Treasure Island FL.

46. Pirahanchi, Y., F. Toro, and I. Jialal, Physiology, Thyroid Stimulating Hormone (TSH), in StatPearls2020, (c) 2020, StatPearls Publishing LLC.: Treasure Island FL.

47. Nedresky, D. and G. Singh, Physiology, Luteinizing Hormone, in StatPearls2020, (C) 2020, StatPearls Publishing LLC.: Treasure Island FL.

48. Kumar, P. and S.F. Sait, Luteinizing hormone and its dilemma in ovulation induction. J Hum Reprod Sci, 2011. 4(1): p. 2-7.

49. El Sayed, S.A., M.W. Fahmy, and J. Schwartz, Physiology, Pituitary Gland, in StatPearls2020, (c) 2020, StatPearls Publishing LLC.: Treasure Island FL.

50. Messinis, I.E., C.I. Messini, and K. Dafopoulos, Novel aspects of the endocrinology of the menstrual cycle. Reprod Biomed Online, 2014. 28(6): p. 714-22.

51. Huhtaniemi, I., A short evolutionary history of FSH-stimulated spermatogenesis. Hormones (Athens), 2015. 14(4): p. 468-78.

52. Stamatiades, G.A. and U.B. Kaiser, Gonadotropin regulation by pulsatile GnRH: Signaling and gene expression. Mol Cell Endocrinol, 2018. 463: p. 131-141.

53. Casarini, L. and P. Crépieux, Molecular Mechanisms of Action of FSH. Front Endocrinol (Lausanne), 2019. 10: p. 305.

54. Fauquier, T., K. Rizzoti, M. Dattani, R. Lovell-Badge, and I.C. Robinson, SOX2expressing progenitor cells generate all of the major cell types in the adult mouse pituitary gland. Proc Natl Acad Sci U S A, 2008. 105(8): p. 2907-12.

55. Que, J., X. Luo, R.J. Schwartz, and B.L. Hogan, Multiple roles for Sox2 in the developing and adult mouse trachea. Development, 2009. 136(11): p. 1899907.

56. Ellis, P., B.M. Fagan, S.T. Magness, S. Hutton, O. Taranova, S. Hayashi, A. McMahon, M. Rao, and L. Pevny, SOX2, a persistent marker for multipotential neural stem cells derived from embryonic stem cells, the embryo or the adult. Dev Neurosci, 2004. 26(2-4): p. 148-65.

57. Driskell, R.R., A. Giangreco, K.B. Jensen, K.W. Mulder, and F.M. Watt, Sox2positive dermal papilla cells specify hair follicle type in mammalian epidermis. Development, 2009. 136(16): p. 2815-23.

58. Brazel, C.Y., T.L. Limke, J.K. Osborne, T. Miura, J. Cai, L. Pevny, and M.S. Rao, Sox2 expression defines a heterogeneous population of neurosphere- 
forming cells in the adult murine brain. Aging Cell, 2005. 4(4): p. 197-207.

59. Yoshida, S., N. Nishimura, H. Ueharu, N. Kanno, M. Higuchi, K. Horiguchi, T. Kato, and Y. Kato, Isolation of adult pituitary stem/progenitor cell clusters located in the parenchyma of the rat anterior lobe. Stem Cell Res, 2016. 17(2): p. 318-329.

60. Roose, H., B. Cox, M. Boretto, C. Gysemans, A. Vennekens, and H. Vankelecom, Major depletion of SOX2(+) stem cells in the adult pituitary is not restored which does not affect hormonal cell homeostasis and remodelling. Sci Rep, 2017. 7(1): p. 16940.

61. Fauquier, T., A. Lacampagne, P. Travo, K. Bauer, and P. Mollard, Hidden face of the anterior pituitary. Trends Endocrinol Metab, 2002. 13(7): p. 304-9.

62. Fauquier, T., N.C. Guérineau, R.A. McKinney, K. Bauer, and P. Mollard, Folliculostellate cell network: a route for long-distance communication in the anterior pituitary. Proc Natl Acad Sci U S A, 2001. 98(15): p. 8891-6.

63. Heinzlmann, A. and K. Köves, The characteristic change in the distribution of S100 immunoreactive folliculostellate cells in rat anterior pituitary upon long-term estrogen treatment is prevented by concomitant progesterone treatment. Endocrine, 2008. 33(3): p. 342-8.

64. Nakajima, T., H. Yamaguchi, and K. Takahashi, S100 protein in folliculostellate cells of the rat pituitary anterior lobe. Brain Res, 1980. 191(2): p. 523-31.

65. Allaerts, W., P. Carmeliet, and C. Denef, New perspectives in the function of pituitary folliculo-stellate cells. Mol Cell Endocrinol, 1990. 71(2): p. 73-81.

66. Gajkowska, B., U. Wojewódzka, A. Gajewska, J. Styrna, J. Jurkiewicz, and K. Kochman, Growth hormone cell phagocytosis in adenohypophysis of mosaic mice: morphological and immunocytochemical electron microscopy study. Brain Res Bull, 2006. 70(1): p. 94-8.

67. Allaerts, W., D.M. Fluitsma, E.C. Hoefsmit, P.H. Jeucken, H. Morreau, F.T. Bosman, and H.A. Drexhage, Immunohistochemical, morphological and ultrastructural resemblance between dendritic cells and folliculo-stellate cells in normal human and rat anterior pituitaries. J Neuroendocrinol, 1996. 8(1): p. 1729.

68. Bodey, B., B. Bodey, Jr., and H.E. Kaiser, Dendritic type, accessory cells within the mammalian thymic microenvironment. Antigen presentation in the dendritic neuro-endocrine-immune cellular network. In Vivo, 1997. 11(4): p. 351-70.

69. Traverso, V., H.C. Christian, J.F. Morris, and J.C. Buckingham, Lipocortin 1 (annexin 1): a candidate paracrine agent localized in pituitary folliculo-stellate cells. Endocrinology, 1999. 140(9): p. 4311-9.

70. Bilezikjian, L.M., A.M. Leal, A.L. Blount, A.Z. Corrigan, A.V. Turnbull, and W.W. Vale, Rat anterior pituitary folliculostellate cells are targets of interleukin-1beta and a major source of intrapituitary follistatin. Endocrinology, 2003. 144(2): p. 732-40.

71. Kaiser, U.B., B.L. Lee, R.S. Carroll, G. Unabia, W.W. Chin, and G.V. Childs, Follistatin gene expression in the pituitary: localization in gonadotropes and folliculostellate cells in diestrous rats. Endocrinology, 1992. 130(5): p. 3048-56.

72. Amano, O., Y. Yoshitake, K. Nishikawa, and S. Iseki, Immunocytochemical localization of basic fibroblast growth factor in the rat pituitary gland. Arch Histol Cytol, 1993. 56(3): p. 269-76.

73. Ferrara, N. and W.J. Henzel, Pituitary follicular cells secrete a novel heparinbinding growth factor specific for vascular endothelial cells. 1989. Biochem Biophys Res Commun, 2012. 425(3): p. 540-7.

74. Jabbour, H.N., S.C. Boddy, and G.A. Lincoln, Pattern and localisation of 
expression of vascular endothelial growth factor and its receptor flt-1 in the ovine pituitary gland: expression is independent of hypothalamic control. Mol Cell Endocrinol, 1997. 134(2): p. 91-100.

75. Vidal, S., K. Kovacs, S.M. Cohen, L. Stefaneanu, R.V. Lloyd, and B.W. Scheithauer, Localization of vascular endothelial growth factor in nontumorous human pituitaries. Endocr Pathol, 1999. 10(2): p. 109-22.

76. Jin, L., I. Tsumanuma, K.H. Ruebel, J.M. Bayliss, and R.V. Lloyd, Analysis of homogeneous populations of anterior pituitary folliculostellate cells by laser capture microdissection and reverse transcription-polymerase chain reaction. Endocrinology, 2001. 142(5): p. 1703-9.

77. Jin, L., B.G. Burguera, M.E. Couce, B.W. Scheithauer, J. Lamsan, N.L. Eberhardt, E. Kulig, and R.V. Lloyd, Leptin and leptin receptor expression in normal and neoplastic human pituitary: evidence of a regulatory role for leptin on pituitary cell proliferation. J Clin Endocrinol Metab, 1999. 84(8): p. 2903-11.

78. Vertongen, P., B. Velkeniers, E. Hooghe-Peters, and P. Robberecht, Differential alternative splicing of PACAP receptor in pituitary cell subpopulations. Mol Cell Endocrinol, 1995. 113(2): p. 131-5.

79. Vigh, S., A. Arimura, P.E. Gottschall, C. Kitada, A. Somogyvári-Vigh, and G.V. Childs, Cytochemical characterization of anterior pituitary target cells for the neuropeptide, pituitary adenylate cyclase activating polypeptide (PACAP), using biotinylated ligands. Peptides, 1993. 14(1): p. 59-65.

80. Ozawa, H., T. Ito, I. Ochiai, and M. Kawata, Cellular localization and distribution of glucocorticoid receptor immunoreactivity and the expression of glucocorticoid receptor messenger RNA in rat pituitary gland. A combined double immunohistochemistry study and in situ hybridization histochemical analysis. Cell Tissue Res, 1999. 295(2): p. 207-14.

81. Vidal, S., R.V. Lloyd, L. Moya, B.W. Scheithauer, and K. Kovacs, Expression and distribution of vascular endothelial growth factor receptor Flk-1 in the rat pituitary. J Histochem Cytochem, 2002. 50(4): p. 533-40.

82. Kowarik, M., C. Onofri, T. Colaco, G.K. Stalla, and U. Renner, Platelet-derived growth factor (PDGF) and PDGF receptor expression and function in folliculostellate pituitary cells. Exp Clin Endocrinol Diabetes, 2010. 118(2): p. 113-20.

83. Findell, P.R. and R.I. Weiner, Bovine pituitary folliculo-stellate cells have betaadrenergic receptors positively coupled to adenosine 3',5'-cyclic monophosphate production. Endocrinology, 1988. 123(5): p. 2454-61.

84. Sudo, T., Y. Sakuma, and M. Kato, Bradykinin and angiotensin II-induced $[\mathrm{Ca} 2+]$ rise in cultured rat pituitary folliculo-stellate cells. J Neuroendocrinol, 2001. 13(11): p. 942-50.

85. Prummel, M.F., L.J. Brokken, G. Meduri, M. Misrahi, O. Bakker, and W.M. Wiersinga, Expression of the thyroid-stimulating hormone receptor in the folliculo-stellate cells of the human anterior pituitary. J Clin Endocrinol Metab, 2000. 85(11): p. 4347-53.

86. Denef, C., Paracrinicity: the story of 30 years of cellular pituitary crosstalk. J Neuroendocrinol, 2008. 20(1): p. 1-70.

87. Morris, J., Folliculo-stellate Cells: Paracrine Communicators in the Anterior Pituitary. The Open Neuroendocrinology Journal, 2011. 4: p. 77-89.

88. Ezzat, S., S.L. Asa, W.T. Couldwell, C.E. Barr, W.E. Dodge, M.L. Vance, and I.E. McCutcheon, The prevalence of pituitary adenomas: a systematic review. Cancer, 2004. 101(3): p. 613-9.

89. Tjörnstrand, A., K. Gunnarsson, M. Evert, E. Holmberg, O. Ragnarsson, T. 
Rosén, and H. Filipsson Nyström, The incidence rate of pituitary adenomas in western Sweden for the period 2001-2011. Eur J Endocrinol, 2014. 171(4): p. 519-26.

90. Raappana, A., J. Koivukangas, T. Ebeling, and T. Pirilä, Incidence of pituitary adenomas in Northern Finland in 1992-2007. J Clin Endocrinol Metab, 2010. 95(9): p. 4268-75.

91. Gittleman, H., Q.T. Ostrom, P.D. Farah, A. Ondracek, Y. Chen, Y. Wolinsky, C. Kruchko, J. Singer, V.R. Kshettry, E.R. Laws, A.E. Sloan, W.R. Selman, and J.S. Barnholtz-Sloan, Descriptive epidemiology of pituitary tumors in the United States, 2004-2009. J Neurosurg, 2014. 121(3): p. 527-35.

92. Yates, C.J., K.E. Lines, and R.V. Thakker, Molecular genetic advances in pituitary tumor development. Expert Rev Endocrinol Metab, 2015. 10(1): p. 3553.

93. Caimari, F. and M. Korbonits, Novel Genetic Causes of Pituitary Adenomas. Clin Cancer Res, 2016. 22(20): p. 5030-5042.

94. Aflorei, E.D. and M. Korbonits, Epidemiology and etiopathogenesis of pituitary adenomas. J Neurooncol, 2014. 117(3): p. 379-94.

95. Asa, S.L. and S. Ezzat, The pathogenesis of pituitary tumours. Nat Rev Cancer, 2002. 2(11): p. 836-49.

96. Landman, R.E., M. Horwith, R.E. Peterson, A.G. Khandji, and S.L. Wardlaw, Long-term survival with ACTH-secreting carcinoma of the pituitary: a case report and review of the literature. J Clin Endocrinol Metab, 2002. 87(7): p. 30849.

97. Pituitary Tumors Treatment $(P D Q \mathbb{R})$ : Health Professional Version, in $P D Q$ Cancer Information Summaries2002: Bethesda MD.

98. Scheithauer, B.W., T.A. Gaffey, R.V. Lloyd, T.J. Sebo, K.T. Kovacs, E. Horvath, O. Yapicier, W.F. Young, Jr., F.B. Meyer, T. Kuroki, D.L. Riehle, and E.R. Laws, Jr., Pathobiology of pituitary adenomas and carcinomas. Neurosurgery, 2006. 59(2): p. 341-53; discussion 341-53.

99. Lines, K.E., M. Stevenson, and R.V. Thakker, Animal models of pituitary neoplasia. Mol Cell Endocrinol, 2016. 421: p. 68-81.

100. Ragel, B.T. and W.T. Couldwell, Pituitary carcinoma: a review of the literature. Neurosurg Focus, 2004. 16(4): p. E7.

101. Scheithauer, B.W., K.T. Kovacs, E.R. Laws, Jr., and R.V. Randall, Pathology of invasive pituitary tumors with special reference to functional classification. J Neurosurg, 1986. 65(6): p. 733-44.

102. Kovacs, K., E. Horvath, and S. Vidal, Classification of pituitary adenomas. J Neurooncol, 2001. 54(2): p. 121-7.

103. Levy, A., Pituitary disease: presentation, diagnosis, and management. J Neurol Neurosurg Psychiatry, 2004. 75 Suppl 3(Suppl 3): p. iii47-52.

104. Pekic, S., M. Stojanovic, and V. Popovic, Contemporary issues in the evaluation and management of pituitary adenomas. Minerva Endocrinol, 2015. 40(4): p. 307-19.

105. Levy, A., Molecular and trophic mechanisms of tumorigenesis. Endocrinol Metab Clin North Am, 2008. 37(1): p. 23-50, vii.

106. Nieman, L.K., Cushing's syndrome: update on signs, symptoms and biochemical screening. Eur J Endocrinol, 2015. 173(4): p. M33-8.

107. Fleseriu, M., J.B. Delashaw, Jr., and D.M. Cook, Acromegaly: a review of current medical therapy and new drugs on the horizon. Neurosurg Focus, 2010. 29(4): p. E15.

108. Yeh, P.J. and J.W. Chen, Pituitary tumors: surgical and medical management. 
Surg Oncol, 1997. 6(2): p. 67-92.

109. Pinzone, J.J., L. Katznelson, D.C. Danila, D.K. Pauler, C.S. Miller, and A. Klibanski, Primary medical therapy of micro- and macroprolactinomas in men. $\mathrm{J}$ Clin Endocrinol Metab, 2000. 85(9): p. 3053-7.

110. Colao, A., A. Di Sarno, P. Marzullo, C. Di Somma, G. Cerbone, M.L. Landi, A. Faggiano, B. Merola, and G. Lombardi, New medical approaches in pituitary adenomas. Horm Res, 2000. 53 Suppl 3: p. 76-87.

111. Biller, B.M., A. Luciano, P.G. Crosignani, M. Molitch, D. Olive, R. Rebar, J. Sanfilippo, J. Webster, and H. Zacur, Guidelines for the diagnosis and treatment of hyperprolactinemia. J Reprod Med, 1999. 44(12 Suppl): p. 1075-84.

112. Pereira, A.M. and N.R. Biermasz, Treatment of nonfunctioning pituitary adenomas: what were the contributions of the last 10 years? A critical view. Ann Endocrinol (Paris), 2012. 73(2): p. 111-6.

113. Greenman, Y. and N. Stern, Non-functioning pituitary adenomas. Best Pract Res Clin Endocrinol Metab, 2009. 23(5): p. 625-38.

114. Reddy, R., S. Cudlip, J.V. Byrne, N. Karavitaki, and J.A. Wass, Can we ever stop imaging in surgically treated and radiotherapy-naive patients with nonfunctioning pituitary adenoma? Eur J Endocrinol, 2011. 165(5): p. 739-44.

115. Chen, Y., C.D. Wang, Z.P. Su, Y.X. Chen, L. Cai, Q.C. Zhuge, and Z.B. Wu, Natural history of postoperative nonfunctioning pituitary adenomas: a systematic review and meta-analysis. Neuroendocrinology, 2012. 96(4): p. 33342.

116. Hayhurst, C., P.N. Taylor, A.J. Lansdown, N. Palaniappan, D.A. Rees, and J.S. Davies, Current perspectives on recurrent pituitary adenoma: The role and timing of surgery vs adjuvant treatment. Clin Endocrinol (Oxf), 2020. 92(2): p. 89-97.

117. Terada, T., K. Kovacs, L. Stefaneanu, and E. Horvath, Incidence, Pathology, and Recurrence of Pituitary Adenomas: Study of 647 Unselected Surgical Cases. Endocr Pathol, 1995. 6(4): p. 301-310.

118. Rickert, C.H., B. Dockhorn-Dworniczak, G. Busch, D. Moskopp, F.K. Albert, B. Rama, and W. Paulus, Increased chromosomal imbalances in recurrent pituitary adenomas. Acta Neuropathol, 2001. 102(6): p. 615-20.

119. Rickert, C.H., B.W. Scheithauer, and W. Paulus, Chromosomal aberrations in pituitary carcinoma metastases. Acta Neuropathol, 2001. 102(2): p. 117-20.

120. Heaney, A., Management of aggressive pituitary adenomas and pituitary carcinomas. J Neurooncol, 2014. 117(3): p. 459-68.

121. Jouanneau, E., A. Wierinckx, F. Ducray, V. Favrel, F. Borson-Chazot, J. Honnorat, J. Trouillas, and G. Raverot, New targeted therapies in pituitary carcinoma resistant to temozolomide. Pituitary, 2012. 15(1): p. 37-43.

122. DeLellis, R.A., I.A.f.R.o. Cancer, W.H. Organization, and I.A.o. Pathology, Pathology and Genetics of Tumours of Endocrine Organs2004: IARC Press.

123. Batisse, M., G. Raverot, S. Maqdasy, X. Durando, N. Sturm, P.F. Montoriol, J.L. Kemeny, J. Chazal, J. Trouillas, and I. Tauveron, Aggressive silent GH pituitary tumor resistant to multiple treatments, including temozolomide. Cancer Invest, 2013. 31(3): p. 190-6.

124. Trouillas, J., P. Roy, N. Sturm, E. Dantony, C. Cortet-Rudelli, G. Viennet, J.F. Bonneville, R. Assaker, C. Auger, T. Brue, A. Cornelius, H. Dufour, E. Jouanneau, P. François, F. Galland, F. Mougel, F. Chapuis, L. Villeneuve, C.A. Maurage, D. Figarella-Branger, G. Raverot, A. Barlier, M. Bernier, F. Bonnet, F. Borson-Chazot, G. Brassier, S. Caulet-Maugendre, O. Chabre, P. Chanson, J.F. Cottier, B. Delemer, E. Delgrange, L. Di Tommaso, S. Eimer, S. Gaillard, 
M. Jan, J.J. Girard, V. Lapras, H. Loiseau, J.G. Passagia, M. Patey, A. Penfornis, J.Y. Poirier, G. Perrin, and A. Tabarin, A new prognostic clinicopathological classification of pituitary adenomas: a multicentric casecontrol study of 410 patients with 8 years post-operative follow-up. Acta Neuropathol, 2013. 126(1): p. 123-35.

125. Melmed, S., Pathogenesis of pituitary tumors. Nat Rev Endocrinol, 2011. 7(5): p. 257-66.

126. Nüsslein-Volhard, C. and E. Wieschaus, Mutations affecting segment number and polarity in Drosophila. Nature, 1980. 287(5785): p. 795-801.

127. Varjosalo, M. and J. Taipale, Hedgehog: functions and mechanisms. Genes Dev, 2008. 22(18): p. 2454-72.

128. Ingham, P.W. and A.P. McMahon, Hedgehog signaling in animal development: paradigms and principles. Genes Dev, 2001. 15(23): p. 3059-87.

129. McMahon, A.P., P.W. Ingham, and C.J. Tabin, Developmental roles and clinical significance of hedgehog signaling. Curr Top Dev Biol, 2003. 53: p. 1-114.

130. Cohen, M.M., Jr., The hedgehog signaling network. Am J Med Genet A, 2003. 123A(1): p. 5-28.

131. Porter, J.A., S.C. Ekker, W.J. Park, D.P. von Kessler, K.E. Young, C.H. Chen, Y. Ma, A.S. Woods, R.J. Cotter, E.V. Koonin, and P.A. Beachy, Hedgehog patterning activity: role of a lipophilic modification mediated by the carboxyterminal autoprocessing domain. Cell, 1996. 86(1): p. 21-34.

132. Pepinsky, R.B., C. Zeng, D. Wen, P. Rayhorn, D.P. Baker, K.P. Williams, S.A. Bixler, C.M. Ambrose, E.A. Garber, K. Miatkowski, F.R. Taylor, E.A. Wang, and A. Galdes, Identification of a palmitic acid-modified form of human Sonic hedgehog. J Biol Chem, 1998. 273(22): p. 14037-45.

133. Chamoun, Z., R.K. Mann, D. Nellen, D.P. von Kessler, M. Bellotto, P.A. Beachy, and K. Basler, Skinny hedgehog, an acyltransferase required for palmitoylation and activity of the hedgehog signal. Science, 2001. 293(5537): p. 2080-4.

134. Burke, R., D. Nellen, M. Bellotto, E. Hafen, K.A. Senti, B.J. Dickson, and K. Basler, Dispatched, a novel sterol-sensing domain protein dedicated to the release of cholesterol-modified hedgehog from signaling cells. Cell, 1999. 99(7): p. 803-15.

135. Kawakami, T., T. Kawcak, Y.J. Li, W. Zhang, Y. Hu, and P.T. Chuang, Mouse dispatched mutants fail to distribute hedgehog proteins and are defective in hedgehog signaling. Development, 2002. 129(24): p. 5753-65.

136. Tian, H., J. Jeong, B.D. Harfe, C.J. Tabin, and A.P. McMahon, Mouse Disp1 is required in sonic hedgehog-expressing cells for paracrine activity of the cholesterol-modified ligand. Development, 2005. 132(1): p. 133-42.

137. Hooper, J.E. and M.P. Scott, The Drosophila patched gene encodes a putative membrane protein required for segmental patterning. Cell, 1989. 59(4): p. 75165.

138. Marigo, V., R.A. Davey, Y. Zuo, J.M. Cunningham, and C.J. Tabin, Biochemical evidence that patched is the Hedgehog receptor. Nature, 1996. 384(6605): p. 176-9.

139. Goodrich, L.V., L. Milenković, K.M. Higgins, and M.P. Scott, Altered neural cell fates and medulloblastoma in mouse patched mutants. Science, 1997. 277(5329): p. 1109-13.

140. Wolff, C., S. Roy, and P.W. Ingham, Multiple muscle cell identities induced by distinct levels and timing of hedgehog activity in the zebrafish embryo. Curr Biol, 2003. 13(14): p. 1169-81.

141. Cohen, M.M., Jr., Hedgehog signaling update. Am J Med Genet A, 2010. 
152A(8): p. 1875-914.

142. Johnson, J.L. and M.R. Leroux, CAMP and cGMP signaling: sensory systems with prokaryotic roots adopted by eukaryotic cilia. Trends Cell Biol, 2010. 20(8): p. 435-44.

143. Hui, C.C. and S. Angers, Gli proteins in development and disease. Annu Rev Cell Dev Biol, 2011. 27: p. 513-37.

144. Hahn, H., L. Wojnowski, K. Specht, R. Kappler, J. Calzada-Wack, D. Potter, A. Zimmer, U. Müller, E. Samson, and L. Quintanilla-Martinez, Patched target Igf2 is indispensable for the formation of medulloblastoma and rhabdomyosarcoma. J Biol Chem, 2000. 275(37): p. 28341-4.

145. Pola, R., L.E. Ling, M. Silver, M.J. Corbley, M. Kearney, R. Blake Pepinsky, R. Shapiro, F.R. Taylor, D.P. Baker, T. Asahara, and J.M. Isner, The morphogen Sonic hedgehog is an indirect angiogenic agent upregulating two families of angiogenic growth factors. Nat Med, 2001. 7(6): p. 706-11.

146. Oliver, T.G., L.L. Grasfeder, A.L. Carroll, C. Kaiser, C.L. Gillingham, S.M. Lin, R. Wickramasinghe, M.P. Scott, and R.J. Wechsler-Reya, Transcriptional profiling of the Sonic hedgehog response: a critical role for $N$-myc in proliferation of neuronal precursors. Proc Natl Acad Sci U S A, 2003. 100(12): p. 7331-6.

147. Briscoe, J. and P.P. Thérond, The mechanisms of Hedgehog signalling and its roles in development and disease. Nat Rev Mol Cell Biol, 2013. 14(7): p. 41629.

148. Ingham, P.W., Hedgehog signaling. Cold Spring Harb Perspect Biol, 2012. 4(6).

149. Scales, S.J. and F.J. de Sauvage, Mechanisms of Hedgehog pathway activation in cancer and implications for therapy. Trends Pharmacol Sci, 2009. 30(6): p. 303-12.

150. Pandolfi, S. and B. Stecca, Cooperative integration between HEDGEHOG-GLI signalling and other oncogenic pathways: implications for cancer therapy. Expert Rev Mol Med, 2015. 17: p. e5.

151. Duman-Scheel, M., L. Weng, S. Xin, and W. Du, Hedgehog regulates cell growth and proliferation by inducing Cyclin D and Cyclin E. Nature, 2002. 417(6886): p. 299-304.

152. Mill, P., R. Mo, H. Fu, M. Grachtchouk, P.C. Kim, A.A. Dlugosz, and C.C. Hui, Sonic hedgehog-dependent activation of Gli2 is essential for embryonic hair follicle development. Genes Dev, 2003. 17(2): p. 282-94.

153. Hooper, J.E. and M.P. Scott, Communicating with Hedgehogs. Nat Rev Mol Cell Biol, 2005. 6(4): p. 306-17.

154. Lee, J., K.A. Platt, P. Censullo, and A. Ruiz i Altaba, Gli1 is a target of Sonic hedgehog that induces ventral neural tube development. Development, 1997. 124(13): p. 2537-52.

155. Stecca, B. and I.A.A. Ruiz, Context-dependent regulation of the GLI code in cancer by HEDGEHOG and non-HEDGEHOG signals. J Mol Cell Biol, 2010. 2(2): p. 84-95.

156. Jiang, J. and C.C. Hui, Hedgehog signaling in development and cancer. Dev Cell, 2008. 15(6): p. 801-12.

157. Uhmann, A., K. Dittmann, F. Nitzki, R. Dressel, M. Koleva, A. Frommhold, A. Zibat, C. Binder, I. Adham, M. Nitsche, T. Heller, V. Armstrong, W. SchulzSchaeffer, J. Wienands, and $\mathrm{H}$. Hahn, The Hedgehog receptor Patched controls lymphoid lineage commitment. Blood, 2007. 110(6): p. 1814-23.

158. Long, F., X.M. Zhang, S. Karp, Y. Yang, and A.P. McMahon, Genetic manipulation of hedgehog signaling in the endochondral skeleton reveals a direct role in the regulation of chondrocyte proliferation. Development, 2001. 
128(24): p. 5099-108.

159. Wetmore, C., Sonic hedgehog in normal and neoplastic proliferation: insight gained from human tumors and animal models. Curr Opin Genet Dev, 2003. 13(1): p. 34-42.

160. Harfe, B.D., P.J. Scherz, S. Nissim, H. Tian, A.P. McMahon, and C.J. Tabin, Evidence for an expansion-based temporal Shh gradient in specifying vertebrate digit identities. Cell, 2004. 118(4): p. 517-28.

161. Briscoe, J. and J. Ericson, Specification of neuronal fates in the ventral neural tube. Curr Opin Neurobiol, 2001. 11(1): p. 43-9.

162. Jessell, T.M., Neuronal specification in the spinal cord: inductive signals and transcriptional codes. Nat Rev Genet, 2000. 1(1): p. 20-9.

163. Lewis, M.T., S. Ross, P.A. Strickland, C.W. Sugnet, E. Jimenez, M.P. Scott, and C.W. Daniel, Defects in mouse mammary gland development caused by conditional haploinsufficiency of Patched-1. Development, 1999. 126(22): p. 5181-93.

164. Treier, M., S. O'Connell, A. Gleiberman, J. Price, D.P. Szeto, R. Burgess, P.T. Chuang, A.P. McMahon, and M.G. Rosenfeld, Hedgehog signaling is required for pituitary gland development. Development, 2001. 128(3): p. 377-86.

165. Treier, M. and M.G. Rosenfeld, The hypothalamic-pituitary axis: codevelopment of two organs. Curr Opin Cell Biol, 1996. 8(6): p. 833-43.

166. Sheng, H.Z. and H. Westphal, Early steps in pituitary organogenesis. Trends Genet, 1999. 15(6): p. 236-40.

167. Burrows, H.L., K.R. Douglas, A.F. Seasholtz, and S.A. Camper, Genealogy of the Anterior Pituitary Gland: Tracing a Family Tree. Trends Endocrinol Metab, 1999. 10(9): p. 343-352.

168. Dasen, J.S. and M.G. Rosenfeld, Combinatorial codes in signaling and synergy: lessons from pituitary development. Curr Opin Genet Dev, 1999. 9(5): p. 56674.

169. Takuma, N., H.Z. Sheng, Y. Furuta, J.M. Ward, K. Sharma, B.L. Hogan, S.L. Pfaff, H. Westphal, S. Kimura, and K.A. Mahon, Formation of Rathke's pouch requires dual induction from the diencephalon. Development, 1998. 125(23): p. 4835-40.

170. Treier, M., A.S. Gleiberman, S.M. O'Connell, D.P. Szeto, J.A. McMahon, A.P. McMahon, and M.G. Rosenfeld, Multistep signaling requirements for pituitary organogenesis in vivo. Genes Dev, 1998. 12(11): p. 1691-704.

171. Kelberman, D., K. Rizzoti, R. Lovell-Badge, I.C. Robinson, and M.T. Dattani, Genetic regulation of pituitary gland development in human and mouse. Endocr Rev, 2009. 30(7): p. 790-829.

172. Ericson, J., S. Norlin, T.M. Jessell, and T. Edlund, Integrated FGF and BMP signaling controls the progression of progenitor cell differentiation and the emergence of pattern in the embryonic anterior pituitary. Development, 1998. 125(6): p. 1005-15.

173. Simmons, D.M., J.W. Voss, H.A. Ingraham, J.M. Holloway, R.S. Broide, M.G. Rosenfeld, and L.W. Swanson, Pituitary cell phenotypes involve cell-specific Pit-1 mRNA translation and synergistic interactions with other classes of transcription factors. Genes Dev, 1990. 4(5): p. 695-711.

174. Japón, M.A., M. Rubinstein, and M.J. Low, In situ hybridization analysis of anterior pituitary hormone gene expression during fetal mouse development. J Histochem Cytochem, 1994. 42(8): p. 1117-25.

175. Lamolet, B., A.M. Pulichino, T. Lamonerie, Y. Gauthier, T. Brue, A. Enjalbert, and J. Drouin, A pituitary cell-restricted $T$ box factor, Tpit, activates POMC 
transcription in cooperation with Pitx homeoproteins. Cell, 2001. 104(6): p. 84959.

176. Hui, C.C., D. Slusarski, K.A. Platt, R. Holmgren, and A.L. Joyner, Expression of three mouse homologs of the Drosophila segment polarity gene cubitus interruptus, Gli, Gli-2, and Gli-3, in ectoderm- and mesoderm-derived tissues suggests multiple roles during postimplantation development. Dev Biol, 1994. 162(2): p. 402-13.

177. Pabst, O., H. Herbrand, N. Takuma, and H.H. Arnold, NKX2 gene expression in neuroectoderm but not in mesendodermally derived structures depends on sonic hedgehog in mouse embryos. Dev Genes Evol, 2000. 210(1): p. 47-50.

178. Park, H.L., C. Bai, K.A. Platt, M.P. Matise, A. Beeghly, C.C. Hui, M. Nakashima, and A.L. Joyner, Mouse Gli1 mutants are viable but have defects in SHH signaling in combination with a Gli2 mutation. Development, 2000. 127(8): p. 1593-605.

179. França, M.M., A.A. Jorge, L.R. Carvalho, E.F. Costalonga, G.A. Vasques, C.C. Leite, B.B. Mendonca, and I.J. Arnhold, Novel heterozygous nonsense GLI2 mutations in patients with hypopituitarism and ectopic posterior pituitary lobe without holoprosencephaly. J Clin Endocrinol Metab, 2010. 95(11): p. E384-91.

180. Roessler, E., Y.Z. Du, J.L. Mullor, E. Casas, W.P. Allen, G. Gillessen-Kaesbach, E.R. Roeder, J.E. Ming, A. Ruiz i Altaba, and M. Muenke, Loss-of-function mutations in the human GLI2 gene are associated with pituitary anomalies and holoprosencephaly-like features. Proc Natl Acad Sci U S A, 2003. 100(23): p. 13424-9.

181. Flemming, G.M., J. Klammt, G. Ambler, Y. Bao, W.F. Blum, C. Cowell, K. Donaghue, N. Howard, A. Kumar, J. Sanchez, H. Stobbe, and R.W. Pfäffle, Functional characterization of a heterozygous GLI2 missense mutation in patients with multiple pituitary hormone deficiency. J Clin Endocrinol Metab, 2013. 98(3): p. E567-75.

182. Teperino, R., F. Aberger, H. Esterbauer, N. Riobo, and J.A. Pospisilik, Canonical and non-canonical Hedgehog signalling and the control of metabolism. Semin Cell Dev Biol, 2014. 33: p. 81-92.

183. Vila, G., M. Theodoropoulou, J. Stalla, J.C. Tonn, M. Losa, U. Renner, G.K. Stalla, and M. Paez-Pereda, Expression and function of sonic hedgehog pathway components in pituitary adenomas: evidence for a direct role in hormone secretion and cell proliferation. J Clin Endocrinol Metab, 2005. 90(12): p. 6687-94.

184. Vila, G., M. Papazoglou, J. Stalla, M. Theodoropoulou, G.K. Stalla, F. Holsboer, and M. Paez-Pereda, Sonic hedgehog regulates $\mathrm{CRH}$ signal transduction in the adult pituitary. FASEB J, 2005. 19(2): p. 281-3.

185. Pyczek, J., R. Buslei, D. Schult, A. Hölsken, M. Buchfelder, I. Heß, H. Hahn, and A. Uhmann, Hedgehog signaling activation induces stem cell proliferation and hormone release in the adult pituitary gland. Sci Rep, 2016. 6: p. 24928.

186. Chen, J., L. Gremeaux, Q. Fu, D. Liekens, S. Van Laere, and H. Vankelecom, Pituitary progenitor cells tracked down by side population dissection. Stem Cells, 2009. 27(5): p. 1182-95.

187. Vankelecom, H., Pituitary stem/progenitor cells: embryonic players in the adult gland? Eur J Neurosci, 2010. 32(12): p. 2063-81.

188. Willems, C., Q. Fu, H. Roose, F. Mertens, B. Cox, J. Chen, and H. Vankelecom, Regeneration in the Pituitary After Cell-Ablation Injury: Time-Related Aspects and Molecular Analysis. Endocrinology, 2016. 157(2): p. 705-21.

189. Gremeaux, L., Q. Fu, J. Chen, and H. Vankelecom, Activated phenotype of the 
pituitary stem/progenitor cell compartment during the early-postnatal maturation phase of the gland. Stem Cells Dev, 2012. 21(5): p. 801-13.

190. Cox, B., H. Roose, A. Vennekens, and H. Vankelecom, Pituitary stem cell regulation: who is pulling the strings? J Endocrinol, 2017. 234(3): p. R135-R158.

191. Gorlin, R.J., Nevoid basal cell carcinoma (Gorlin) syndrome: unanswered issues. J Lab Clin Med, 1999. 134(6): p. 551-2.

192. Gorlin, R.J. and R.W. Goltz, Multiple nevoid basal-cell epithelioma, jaw cysts and bifid rib. A syndrome. N Engl J Med, 1960. 262: p. 908-12.

193. Hahn, H., L. Wojnowski, A.M. Zimmer, J. Hall, G. Miller, and A. Zimmer, Rhabdomyosarcomas and radiation hypersensitivity in a mouse model of Gorlin syndrome. Nat Med, 1998. 4(5): p. 619-22.

194. Lo Muzio, L., Nevoid basal cell carcinoma syndrome (Gorlin syndrome). Orphanet J Rare Dis, 2008. 3: p. 32.

195. Xie, J., C.M. Bartels, S.W. Barton, and D. Gu, Targeting hedgehog signaling in cancer: research and clinical developments. Onco Targets Ther, 2013. 6: p. 1425-35.

196. Oro, A.E., K.M. Higgins, Z. Hu, J.M. Bonifas, E.H. Epstein, Jr., and M.P. Scott, Basal cell carcinomas in mice overexpressing sonic hedgehog. Science, 1997. 276(5313): p. 817-21.

197. Xie, J., M. Murone, S.M. Luoh, A. Ryan, Q. Gu, C. Zhang, J.M. Bonifas, C.W. Lam, M. Hynes, A. Goddard, A. Rosenthal, E.H. Epstein, Jr., and F.J. de Sauvage, Activating Smoothened mutations in sporadic basal-cell carcinoma. Nature, 1998. 391(6662): p. 90-2.

198. Lam, C.W., J. Xie, K.F. To, H.K. Ng, K.C. Lee, N.W. Yuen, P.L. Lim, L.Y. Chan, S.F. Tong, and F. McCormick, $A$ frequent activated smoothened mutation in sporadic basal cell carcinomas. Oncogene, 1999. 18(3): p. 833-6.

199. Reifenberger, J., M. Wolter, C.B. Knobbe, B. Köhler, A. Schönicke, C. Scharwächter, K. Kumar, B. Blaschke, T. Ruzicka, and G. Reifenberger, Somatic mutations in the PTCH, SMOH, SUFUH and TP53 genes in sporadic basal cell carcinomas. Br J Dermatol, 2005. 152(1): p. 43-51.

200. Reifenberger, J., M. Wolter, R.G. Weber, M. Megahed, T. Ruzicka, P. Lichter, and G. Reifenberger, Missense mutations in SMOH in sporadic basal cell carcinomas of the skin and primitive neuroectodermal tumors of the central nervous system. Cancer Res, 1998. 58(9): p. 1798-803.

201. Berman, D.M., S.S. Karhadkar, A. Maitra, R. Montes De Oca, M.R. Gerstenblith, K. Briggs, A.R. Parker, Y. Shimada, J.R. Eshleman, D.N. Watkins, and P.A. Beachy, Widespread requirement for Hedgehog ligand stimulation in growth of digestive tract tumours. Nature, 2003. 425(6960): p. 846-51.

202. Thayer, S.P., M.P. di Magliano, P.W. Heiser, C.M. Nielsen, D.J. Roberts, G.Y. Lauwers, Y.P. Qi, S. Gysin, C. Fernández-del Castillo, V. Yajnik, B. Antoniu, M. McMahon, A.L. Warshaw, and M. Hebrok, Hedgehog is an early and late mediator of pancreatic cancer tumorigenesis. Nature, 2003. 425(6960): p. 8516.

203. Watkins, D.N., D.M. Berman, S.G. Burkholder, B. Wang, P.A. Beachy, and S.B. Baylin, Hedgehog signalling within airway epithelial progenitors and in small-cell lung cancer. Nature, 2003. 422(6929): p. 313-7.

204. Ramaglia, L., F. Morgese, M. Pighetti, and R. Saviano, Odontogenic keratocyst and uterus bicornis in nevoid basal cell carcinoma syndrome: case report and literature review. Oral Surg Oral Med Oral Pathol Oral Radiol Endod, 2006. 102(2): p. 217-9.

205. Evans, D.G., E.J. Ladusans, S. Rimmer, L.D. Burnell, N. Thakker, and P.A. 
Farndon, Complications of the naevoid basal cell carcinoma syndrome: results of a population based study. J Med Genet, 1993. 30(6): p. 460-4.

206. Kimonis, V.E., A.M. Goldstein, B. Pastakia, M.L. Yang, R. Kase, J.J. DiGiovanna, A.E. Bale, and S.J. Bale, Clinical manifestations in 105 persons with nevoid basal cell carcinoma syndrome. Am J Med Genet, 1997. 69(3): p. 299-308.

207. Zhu, Z., W. Cui, D. Zhu, N. Gao, and Y. Zhu, Common tools for pituitary adenomas research: cell lines and primary cells. Pituitary, 2020. 23(2): p. 182188.

208. Tashjian, A.H., Jr., Y. Yasumura, L. Levine, G.H. Sato, and M.L. Parker, Establishment of clonal strains of rat pituitary tumor cells that secrete growth hormone. Endocrinology, 1968. 82(2): p. 342-52.

209. Haug, E., O. Naess, and K.M. Gautvik, Receptors for 17beta-estradiol in prolactin-secreting rat pituitary cells. Mol Cell Endocrinol, 1978. 12(1): p. 81-95.

210. Koenig, R.J., R.L. Warne, G.A. Brent, J.W. Harney, P.R. Larsen, and D.D. Moore, Isolation of a cDNA clone encoding a biologically active thyroid hormone receptor. Proc Natl Acad Sci U S A, 1988. 85(14): p. 5031-5.

211. Patel, Y.C., K.K. Murthy, E.E. Escher, D. Banville, J. Spiess, and C.B. Srikant, Mechanism of action of somatostatin: an overview of receptor function and studies of the molecular characterization and purification of somatostatin receptor proteins. Metabolism, 1990. 39(9 Suppl 2): p. 63-9.

212. Yasamura, Y., A.H. Tashjian, Jr., and G.H. Sato, Establishment of four functional, clonal strains of animal cells in culture. Science, 1966. 154(3753): p. 1186-9.

213. Inoue, K., H. Matsumoto, C. Koyama, K. Shibata, Y. Nakazato, and A. Ito, Establishment of a folliculo-stellate-like cell line from a murine thyrotropic pituitary tumor. Endocrinology, 1992. 131(6): p. 3110-6.

214. Wang, J., B. Voellger, J. Benzel, U. Schlomann, C. Nimsky, J.W. Bartsch, and B. Carl, Metalloproteinases ADAM12 and MMP-14 are associated with cavernous sinus invasion in pituitary adenomas. Int J Cancer, 2016. 139(6): p. 1327-39.

215. Voellger, B., N. Waldt, R. Rupa, E. Kirches, O. Melhem, H.J. Ochel, C. Mawrin, and $\mathrm{R}$. Firsching, Combined effects of resveratrol and radiation in $\mathrm{GH} 3$ and TtT/GF pituitary adenoma cells. J Neurooncol, 2018. 139(3): p. 573-582.

216. Koike, K., Z.X. Zhang, Y. Sakamoto, Y. Kanda, K. Murakami, A. Miyake, and M. Inoue, The pituitary folliculo-stellate cell line TtT/GF augments basal and TRHinduced prolactin secretion by GH3 cell. Life Sci, 1997. 61(25): p. 2491-7.

217. Brokken, L.J., M. Leendertse, O. Bakker, W.M. Wiersinga, and M.F. Prummel, Expression of adenohypophyseal-hormone receptors in a murine folliculostellate cell line. Horm Metab Res, 2004. 36(8): p. 538-41.

218. Tsukada, T., S. Yoshida, K. Kito, K. Fujiwara, H. Yako, K. Horiguchi, Y. Isowa, T. Yashiro, T. Kato, and Y. Kato, TGF $\beta$ signaling reinforces pericyte properties of the non-endocrine mouse pituitary cell line TtT/GF. Cell Tissue Res, 2018. 371(2): p. 339-350.

219. Chapman, L., A. Nishimura, J.C. Buckingham, J.F. Morris, and H.C. Christian, Externalization of annexin I from a folliculo-stellate-like cell line. Endocrinology, 2002. 143(11): p. 4330-8.

220. Melmed, S., D. Odenheimer, H.E. Carlson, and J.M. Hershman, Establishment of functional human pituitary tumor cell cultures. In Vitro, 1982. 18(1): p. 35-42.

221. Ishikawa, H., Isolation of different types of anterior pituitary cells in rats. Endocrinol Jpn, 1969. 16(5): p. 517-29. 
222. Allen, R.G., E. Herbert, M. Hinman, H. Shibuya, and C.B. Pert, Coordinate control of corticotropin, beta-lipotropin, and beta-endorphin release in mouse pituitary cell cultures. Proc Natl Acad Sci U S A, 1978. 75(10): p. 4972-6.

223. Martinez-Barbera, J.P. and C.L. Andoniadou, Concise Review: Paracrine Role of Stem Cells in Pituitary Tumors: A Focus on Adamantinomatous Craniopharyngioma. Stem Cells, 2016. 34(2): p. 268-76.

224. Donangelo, I., S.G. Ren, T. Eigler, C. Svendsen, and S. Melmed, Sca ${ }^{+}$murine pituitary adenoma cells show tumor-growth advantage. Endocr Relat Cancer, 2014. 21(2): p. 203-16.

225. Xu, Q., X. Yuan, P. Tunici, G. Liu, X. Fan, M. Xu, J. Hu, J.Y. Hwang, D.L. Farkas, K.L. Black, and J.S. Yu, Isolation of tumour stem-like cells from benign tumours. Br J Cancer, 2009. 101(2): p. 303-11.

226. Chen, L., H. Ye, X. Wang, X. Tang, Y. Mao, Y. Zhao, Z. Wu, X.O. Mao, L. Xie, $\mathrm{K}$. Jin, and Y. Yao, Evidence of brain tumor stem progenitor-like cells with low proliferative capacity in human benign pituitary adenoma. Cancer Lett, 2014. 349(1): p. 61-6.

227. Sonnenschein, C., U.I. Richardson, and A.H. Tashjian, Jr., Chromosomal analysis, organ-specific function and appearance of six clonal strains of rat pituitary tumor cells. Exp Cell Res, 1970. 61(1): p. 121-8.

228. Jin, L., E. Kulig, X. Qian, B.W. Scheithauer, N.L. Eberhardt, and R.V. Lloyd, A human pituitary adenoma cell line proliferates and maintains some differentiated functions following expression of SV40 large T-antigen. Endocr Pathol, 1998. 9(2): p. 169-184.

229. Crabtree, J.S., P.C. Scacheri, J.M. Ward, L. Garrett-Beal, M.R. Emmert-Buck, K.A. Edgemon, D. Lorang, S.K. Libutti, S.C. Chandrasekharappa, S.J. Marx, A.M. Spiegel, and F.S. Collins, A mouse model of multiple endocrine neoplasia, type 1, develops multiple endocrine tumors. Proc Natl Acad Sci U S A, 2001. 98(3): p. 1118-23.

230. Bertolino, P., W.M. Tong, D. Galendo, Z.Q. Wang, and C.X. Zhang, Heterozygous Men1 mutant mice develop a range of endocrine tumors mimicking multiple endocrine neoplasia type 1. Mol Endocrinol, 2003. 17(9): p. 1880-92.

231. Biondi, C., M. Gartside, I. Tonks, C. Paterson, N.K. Hayward, and G.F. Kay, Targeting and conditional inactivation of the murine Men1 locus using the Cre recombinase: loxP system. Genesis, 2002. 32(2): p. 150-1.

232. Biondi, C.A., M.G. Gartside, P. Waring, K.A. Loffler, M.S. Stark, M.A. Magnuson, G.F. Kay, and N.K. Hayward, Conditional inactivation of the MEN1 gene leads to pancreatic and pituitary tumorigenesis but does not affect normal development of these tissues. Mol Cell Biol, 2004. 24(8): p. 3125-31.

233. Loffler, K.A., C.A. Biondi, M. Gartside, P. Waring, M. Stark, M.M. SerewkoAuret, H.K. Muller, N.K. Hayward, and G.F. Kay, Broad tumor spectrum in a mouse model of multiple endocrine neoplasia type 1. Int J Cancer, 2007. 120(2): p. 259-67.

234. Loffler, K.A., C.A. Biondi, M.G. Gartside, M.M. Serewko-Auret, R. Duncan, I.D. Tonks, A.W. Mould, P. Waring, H.K. Muller, G.F. Kay, and N.K. Hayward, Lack of augmentation of tumor spectrum or severity in dual heterozygous Men1 and Rb1 knockout mice. Oncogene, 2007. 26(27): p. 4009-17.

235. Harding, B., M.C. Lemos, A.A. Reed, G.V. Walls, J. Jeyabalan, M.R. Bowl, H. Tateossian, N. Sullivan, T. Hough, W.D. Fraser, O. Ansorge, M.T. Cheeseman, and R.V. Thakker, Multiple endocrine neoplasia type 1 knockout mice develop parathyroid, pancreatic, pituitary and adrenal tumours with hypercalcaemia, 
hypophosphataemia and hypercorticosteronaemia. Endocr Relat Cancer, 2009. 16(4): p. 1313-27.

236. Kiyokawa, H., R.D. Kineman, K.O. Manova-Todorova, V.C. Soares, E.S. Hoffman, M. Ono, D. Khanam, A.C. Hayday, L.A. Frohman, and A. Koff, Enhanced growth of mice lacking the cyclin-dependent kinase inhibitor function of p27(Kip1). Cell, 1996. 85(5): p. 721-32.

237. Nakayama, K., N. Ishida, M. Shirane, A. Inomata, T. Inoue, N. Shishido, I. Horii, and D.Y. Loh, Mice lacking p27(Kip1) display increased body size, multiple organ hyperplasia, retinal dysplasia, and pituitary tumors. Cell, 1996. 85(5): p. 707-20.

238. Fero, M.L., M. Rivkin, M. Tasch, P. Porter, C.E. Carow, E. Firpo, K. Polyak, L.H. Tsai, V. Broudy, R.M. Perlmutter, K. Kaushansky, and J.M. Roberts, $A$ syndrome of multiorgan hyperplasia with features of gigantism, tumorigenesis, and female sterility in p27(Kip1)-deficient mice. Cell, 1996. 85(5): p. 733-44.

239. Brandi, M.L., R.F. Gagel, A. Angeli, J.P. Bilezikian, P. Beck-Peccoz, C. Bordi, B. Conte-Devolx, A. Falchetti, R.G. Gheri, A. Libroia, C.J. Lips, G. Lombardi, M. Mannelli, F. Pacini, B.A. Ponder, F. Raue, B. Skogseid, G. Tamburrano, R.V. Thakker, N.W. Thompson, P. Tomassetti, F. Tonelli, S.A. Wells, Jr., and S.J. Marx, Guidelines for diagnosis and therapy of MEN type 1 and type 2. J Clin Endocrinol Metab, 2001. 86(12): p. 5658-71.

240. Brandi, M.L., S.J. Marx, G.D. Aurbach, and L.A. Fitzpatrick, Familial multiple endocrine neoplasia type I: a new look at pathophysiology. Endocr Rev, 1987. 8(4): p. 391-405.

241. Skogseid, B., K. Oberg, B. Eriksson, C. Juhlin, D. Granberg, G. Akerström, and J. Rastad, Surgery for asymptomatic pancreatic lesion in multiple endocrine neoplasia type I. World J Surg, 1996. 20(7): p. 872-6; discussion 877.

242. Trump, D., B. Farren, C. Wooding, J.T. Pang, G.M. Besser, K.D. Buchanan, C.R. Edwards, D.A. Heath, C.E. Jackson, S. Jansen, K. Lips, J.P. Monson, D. O'Halloran, J. Sampson, S.M. Shalet, M.H. Wheeler, A. Zink, and R.V. Thakker, Clinical studies of multiple endocrine neoplasia type 1 (MEN1). QJM, 1996. 89(9): p. 653-69.

243. Marx, S., A.M. Spiegel, M.C. Skarulis, J.L. Doppman, F.S. Collins, and L.A. Liotta, Multiple endocrine neoplasia type 1: clinical and genetic topics. Ann Intern Med, 1998. 129(6): p. 484-94.

244. Lemos, M.C., B. Harding, A.A. Reed, J. Jeyabalan, G.V. Walls, M.R. Bowl, J. Sharpe, S. Wedden, J.E. Moss, A. Ross, D. Davidson, and R.V. Thakker, Genetic background influences embryonic lethality and the occurrence of neural tube defects in Men1 null mice: relevance to genetic modifiers. J Endocrinol, 2009. 203(1): p. 133-42.

245. Fisher, E.M., E. Lana-Elola, S.D. Watson, G. Vassiliou, and V.L. Tybulewicz, New approaches for modelling sporadic genetic disease in the mouse. Dis Model Mech, 2009. 2(9-10): p. 446-53.

246. Jacks, T., A. Fazeli, E.M. Schmitt, R.T. Bronson, M.A. Goodell, and R.A. Weinberg, Effects of an Rb mutation in the mouse. Nature, 1992. 359(6393): p. 295-300.

247. Vooijs, M., J. Jonkers, S. Lyons, and A. Berns, Noninvasive imaging of spontaneous retinoblastoma pathway-dependent tumors in mice. Cancer Res, 2002. 62(6): p. 1862-7.

248. Vooijs, M., M. van der Valk, H. te Riele, and A. Berns, Flp-mediated tissuespecific inactivation of the retinoblastoma tumor suppressor gene in the mouse. Oncogene, 1998. 17(1): p. 1-12. 
249. Bai, F., H.L. Chan, M.D. Smith, H. Kiyokawa, and X.H. Pei, p19Ink4d is a tumor suppressor and controls pituitary anterior lobe cell proliferation. Mol Cell Biol, 2014. 34(12): p. 2121-34.

250. Sáez, C., M.A. Japón, F. Ramos-Morales, F. Romero, D.I. Segura, M. Tortolero, and J.A. Pintor-Toro, hpttg is over-expressed in pituitary adenomas and other primary epithelial neoplasias. Oncogene, 1999. 18(39): p. 5473-6.

251. Abbud, R.A., I. Takumi, E.M. Barker, S.G. Ren, D.Y. Chen, K. Wawrowsky, and S. Melmed, Early multipotential pituitary focal hyperplasia in the alpha-subunit of glycoprotein hormone-driven pituitary tumor-transforming gene transgenic mice. Mol Endocrinol, 2005. 19(5): p. 1383-91.

252. Donangelo, I., S. Gutman, E. Horvath, K. Kovacs, K. Wawrowsky, M. Mount, and S. Melmed, Pituitary tumor transforming gene overexpression facilitates pituitary tumor development. Endocrinology, 2006. 147(10): p. 4781-91.

253. Roussel-Gervais, A., S. Bilodeau, S. Vallette, F. Berthelet, A. Lacroix, D. Figarella-Branger, T. Brue, and J. Drouin, Cooperation between cyclin $E$ and p27(Kip1) in pituitary tumorigenesis. Mol Endocrinol, 2010. 24(9): p. 1835-45.

254. Gu, H., Y.R. Zou, and K. Rajewsky, Independent control of immunoglobulin switch recombination at individual switch regions evidenced through Cre-loxPmediated gene targeting. Cell, 1993. 73(6): p. 1155-64.

255. Muzumdar, M.D., B. Tasic, K. Miyamichi, L. Li, and L. Luo, A global doublefluorescent Cre reporter mouse. Genesis, 2007. 45(9): p. 593-605.

256. Winchenbach, J., T. Düking, S.A. Berghoff, S.K. Stumpf, S. Hülsmann, K.A. Nave, and G. Saher, Inducible targeting of CNS astrocytes in Aldh1/1-CreERT2 BAC transgenic mice. F1000Res, 2016. 5: p. 2934.

257. Singh, S., M. Singh, I. Mak, and M. Ghert, Expressional Analysis of GFPTagged Cells in an In Vivo Mouse Model of Giant Cell Tumor of Bone. Open Orthop J, 2013. 7: p. 109-13.

258. Kimmel, R.A., D.H. Turnbull, V. Blanquet, W. Wurst, C.A. Loomis, and A.L. Joyner, Two lineage boundaries coordinate vertebrate apical ectodermal ridge formation. Genes Dev, 2000. 14(11): p. 1377-89.

259. Uhmann, A., U. Ferch, R. Bauer, S. Tauber, Z. Arziman, C. Chen, B. Hemmerlein, L. Wojnowski, and H. Hahn, A model for PTCH1/Ptch1-associated tumors comprising mutational inactivation and gene silencing. Int J Oncol, 2005. 27(6): p. 1567-75.

260. Berglund, E.D., C. Liu, J.W. Sohn, T. Liu, M.H. Kim, C.E. Lee, C.R. Vianna, K.W. Williams, Y. Xu, and J.K. Elmquist, Serotonin 2C receptors in proopiomelanocortin neurons regulate energy and glucose homeostasis. J Clin Invest, 2013. 123(12): p. 5061-70.

261. Madisen, L., T.A. Zwingman, S.M. Sunkin, S.W. Oh, H.A. Zariwala, H. Gu, L.L. Ng, R.D. Palmiter, M.J. Hawrylycz, A.R. Jones, E.S. Lein, and H. Zeng, A robust and high-throughput Cre reporting and characterization system for the whole mouse brain. Nat Neurosci, 2010. 13(1): p. 133-40.

262. Arnold, K., A. Sarkar, M.A. Yram, J.M. Polo, R. Bronson, S. Sengupta, M. Seandel, N. Geijsen, and K. Hochedlinger, Sox2(+) adult stem and progenitor cells are important for tissue regeneration and survival of mice. Cell Stem Cell, 2011. 9(4): p. 317-29.

263. Iguchi, G., Y. Okimura, T. Takahashi, I. Mizuno, M. Fumoto, Y. Takahashi, H. Kaji, H. Abe, and K. Chihara, Cloning and characterization of the 5'-flanking region of the human growth hormone-releasing hormone receptor gene. J Biol Chem, 1999. 274(17): p. 12108-14.

264. Uhmann, A., H. Niemann, B. Lammering, C. Henkel, I. Hess, F. Nitzki, A. 
Fritsch, N. Prüfer, A. Rosenberger, C. Dullin, A. Schraepler, J. Reifenberger, S. Schweyer, T. Pietsch, F. Strutz, W. Schulz-Schaeffer, and H. Hahn, Antitumoral effects of calcitriol in basal cell carcinomas involve inhibition of hedgehog signaling and induction of vitamin $D$ receptor signaling and differentiation. Mol Cancer Ther, 2011. 10(11): p. 2179-88.

265. Ahn, S. and A.L. Joyner, Dynamic changes in the response of cells to positive hedgehog signaling during mouse limb patterning. Cell, 2004. 118(4): p. 50516.

266. Vives, V., G. Alonso, A.C. Solal, D. Joubert, and C. Legraverend, Visualization of S100B-positive neurons and glia in the central nervous system of EGFP transgenic mice. J Comp Neurol, 2003. 457(4): p. 404-19.

267. Schindelin, J., I. Arganda-Carreras, E. Frise, V. Kaynig, M. Longair, T. Pietzsch, S. Preibisch, C. Rueden, S. Saalfeld, B. Schmid, J.Y. Tinevez, D.J. White, V. Hartenstein, K. Eliceiri, P. Tomancak, and A. Cardona, Fiji: an open-source platform for biological-image analysis. Nat Methods, 2012. 9(7): p. 676-82.

268. Dobin, A., C.A. Davis, F. Schlesinger, J. Drenkow, C. Zaleski, S. Jha, P. Batut, M. Chaisson, and T.R. Gingeras, STAR: ultrafast universal RNA-seq aligner. Bioinformatics, 2013. 29(1): p. 15-21.

269. Li, B. and C.N. Dewey, RSEM: accurate transcript quantification from RNA-Seq data with or without a reference genome. BMC Bioinformatics, 2011. 12: p. 323.

270. Law, C.W., Y. Chen, W. Shi, and G.K. Smyth, voom: Precision weights unlock linear model analysis tools for RNA-seq read counts. Genome Biol, 2014. 15(2): p. R29.

271. Yu, G., L.G. Wang, Y. Han, and Q.Y. He, clusterProfiler: an $R$ package for comparing biological themes among gene clusters. OMICS, 2012. 16(5): p. 2847.

272. Ewels, P., M. Magnusson, S. Lundin, and M. Käller, MultiQC: summarize analysis results for multiple tools and samples in a single report. Bioinformatics, 2016. 32(19): p. 3047-8.

273. Bonnefont, X., J. Fiekers, A. Creff, and P. Mollard, Rhythmic bursts of calcium transients in acute anterior pituitary slices. Endocrinology, 2000. 141(3): p. 86875.

274. Lugo, D.I., J.L. Roberts, and J.E. Pintar, Analysis of proopiomelanocortin gene expression during prenatal development of the rat pituitary gland. Mol Endocrinol, 1989. 3(8): p. 1313-24.

275. Wijgerde, M., M. Ooms, J.W. Hoogerbrugge, and J.A. Grootegoed, Hedgehog signaling in mouse ovary: Indian hedgehog and desert hedgehog from granulosa cells induce target gene expression in developing theca cells. Endocrinology, 2005. 146(8): p. 3558-66.

276. Clark, A.M., K.K. Garland, and L.D. Russell, Desert hedgehog (Dhh) gene is required in the mouse testis for formation of adult-type Leydig cells and normal development of peritubular cells and seminiferous tubules. Biol Reprod, 2000. 63(6): p. 1825-38.

277. Yao, H.H., W. Whoriskey, and B. Capel, Desert Hedgehog/Patched 1 signaling specifies fetal Leydig cell fate in testis organogenesis. Genes Dev, 2002. 16(11): p. 1433-40.

278. Bitgood, M.J., L. Shen, and A.P. McMahon, Sertoli cell signaling by Desert hedgehog regulates the male germline. Curr Biol, 1996. 6(3): p. 298-304.

279. Corrales, J.D., G.L. Rocco, S. Blaess, Q. Guo, and A.L. Joyner, Spatial pattern of sonic hedgehog signaling through Gli genes during cerebellum development. Development, 2004. 131(22): p. 5581-90. 
280. Brownell, I., E. Guevara, C.B. Bai, C.A. Loomis, and A.L. Joyner, Nerve-derived sonic hedgehog defines a niche for hair follicle stem cells capable of becoming epidermal stem cells. Cell Stem Cell, 2011. 8(5): p. 552-65.

281. Yin, Z., L. Williams-Simons, L. Rawahneh, S. Asa, and L.S. Kirschner, Development of a pituitary-specific cre line targeted to the Pit-1 lineage. Genesis, 2008. 46(1): p. 37-42.

282. Nasonkin, I.O., M.A. Potok, and S.A. Camper, Cre-mediated recombination in pituitary somatotropes. Genesis, 2009. 47(1): p. 55-60.

283. Luque, R.M., G. Amargo, S. Ishii, C. Lobe, R. Franks, H. Kiyokawa, and R.D. Kineman, Reporter expression, induced by a growth hormone promoter-driven Cre recombinase (rGHp-Cre) transgene, questions the developmental relationship between somatotropes and lactotropes in the adult mouse pituitary gland. Endocrinology, 2007. 148(5): p. 1946-53.

284. Mayo, K.E., T.L. Miller, V. DeAlmeida, J. Zheng, and P.A. Godfrey, The growthhormone-releasing hormone receptor: signal transduction, gene expression, and physiological function in growth regulation. Ann N Y Acad Sci, 1996. 805: p. 184-203.

285. Takahashi, T., Y. Okimura, K. Yoshimura, Y. Shigeyoshi, H. Kaji, H. Abe, and $\mathrm{K}$. Chihara, Regional distribution of growth hormone-releasing hormone $(G H R H)$ receptor $m R N A$ in the rat brain. Endocrinology, 1995. 136(10): p. 47214.

286. Gaylinn, B.D., Molecular and cell biology of the growth hormone-releasing hormone receptor. Growth Horm IGF Res, 1999. 9 Suppl A: p. 37-44.

287. Sanchez, M.A., G.M. Sullivan, and R.C. Armstrong, Genetic detection of Sonic hedgehog (Shh) expression and cellular response in the progression of acute through chronic demyelination and remyelination. Neurobiol Dis, 2018. 115: p. 145-156.

288. Sun, X., A. Are, K. Annusver, U. Sivan, T. Jacob, T. Dalessandri, S. Joost, A. Füllgrabe, M. Gerling, and M. Kasper, Coordinated hedgehog signaling induces new hair follicles in adult skin. Elife, 2020. 9.

289. Corbit, K.C., P. Aanstad, V. Singla, A.R. Norman, D.Y. Stainier, and J.F. Reiter, Vertebrate Smoothened functions at the primary cilium. Nature, 2005. 437(7061): p. 1018-21.

290. Rohatgi, R., L. Milenkovic, R.B. Corcoran, and M.P. Scott, Hedgehog signal transduction by Smoothened: pharmacologic evidence for a 2-step activation process. Proc Natl Acad Sci U S A, 2009. 106(9): p. 3196-201.

291. Bragina, O., S. Sergejeva, M. Serg, T. Zarkovsky, A. Maloverjan, P. Kogerman, and A. Zarkovsky, Smoothened agonist augments proliferation and survival of neural cells. Neurosci Lett, 2010. 482(2): p. 81-5.

292. Allaerts, W. and H. Vankelecom, History and perspectives of pituitary folliculostellate cell research. Eur J Endocrinol, 2005. 153(1): p. 1-12.

293. Chihara, K., J. Iwasaki, N. Minamitani, H. Kaji, S. Matsukura, N. Tamaki, S. Matsumoto, and T. Fujita, Effect of vasoactive intestinal polypeptide on growth hormone secretion in perifused acromegalic pituitary adenoma tissues. J Clin Endocrinol Metab, 1982. 54(4): p. 773-9.

294. Matsushita, N., Y. Kato, H. Katakami, A. Shimatsu, N. Yanaihara, and H. Imura, Stimulation of growth hormone release by vasoactive intestinal polypeptide from human pituitary adenomas in vitro. J Clin Endocrinol Metab, 1981. 53(6): p. 1297-300.

295. Morand, I., P. Fonlupt, A. Guerrier, J. Trouillas, A. Calle, C. Remy, B. Rousset, and Y. Munari-Silem, Cell-to-cell communication in the anterior pituitary: 
evidence for gap junction-mediated exchanges between endocrine cells and folliculostellate cells. Endocrinology, 1996. 137(8): p. 3356-67.

296. Andoniadou, C.L., D. Matsushima, S.N. Mousavy Gharavy, M. Signore, A.I. Mackintosh, M. Schaeffer, C. Gaston-Massuet, P. Mollard, T.S. Jacques, P. Le Tissier, M.T. Dattani, L.H. Pevny, and J.P. Martinez-Barbera, Sox2(+) stem/progenitor cells in the adult mouse pituitary support organ homeostasis and have tumor-inducing potential. Cell Stem Cell, 2013. 13(4): p. 433-45.

297. Otto, C., S. tom Dieck, and K. Bauer, Dipeptide uptake by adenohypophysial folliculostellate cells. Am J Physiol, 1996. 271(1 Pt 1): p. C210-7.

298. Acosta, M., V. Filippa, and F. Mohamed, Folliculostellate cells in pituitary pars distalis of male viscacha: immunohistochemical, morphometric and ultrastructural study. Eur J Histochem, 2010. 54(1): p. e1.

299. Taylor, A.D., J.G. Philip, C.D. John, P.O. Cover, J.F. Morris, R.J. Flower, and J.C. Buckingham, Annexin 1 (lipocortin 1) mediates the glucocorticoid inhibition of cyclic adenosine 3',5'-monophosphate-stimulated prolactin secretion. Endocrinology, 2000. 141(6): p. 2209-19.

300. Berger, P., G. Untergasser, M. Hermann, A. Hittmair, S. Madersbacher, and S. Dirnhofer, The testis-specific expression pattern of the growth hormone/placental lactogen (GH/PL) gene cluster changes with malignancy. Hum Pathol, 1999. 30(10): p. 1201-6.

301. Untergasser, G., W. Kranewitter, F. Walser, S. Madersbacher, S. Dirnhofer, and $\mathrm{P}$. Berger, [The testis as eutopic production site of human growth hormone, placental lactogen and prolactin: possible autocrine/paracrine effects on testicular function]. Wien Klin Wochenschr, 1996. 108(17): p. 541-6.

302. Harvey, S., M. Kakebeeke, A.E. Murphy, and E.J. Sanders, Growth hormone in the nervous system: autocrine or paracrine roles in retinal function? Can $\mathrm{J}$ Physiol Pharmacol, 2003. 81(4): p. 371-84.

303. Harvey, S., M. Kakebeeke, and E.J. Sanders, Growth hormone localization in the neural retina and retinal pigmented epithelium of embryonic chicks. J Mol Neurosci, 2004. 22(1-2): p. 139-45.

304. Melmed, S., Acromegaly pathogenesis and treatment. J Clin Invest, 2009. 119(11): p. 3189-202.

305. Pivonello, R., R.S. Auriemma, L.F. Grasso, C. Pivonello, C. Simeoli, R. Patalano, M. Galdiero, and A. Colao, Complications of acromegaly: cardiovascular, respiratory and metabolic comorbidities. Pituitary, 2017. 20(1): p. 46-62.

306. Lombardi, G., C. Di Somma, L.F. Grasso, M.C. Savanelli, A. Colao, and R. Pivonello, The cardiovascular system in growth hormone excess and growth hormone deficiency. J Endocrinol Invest, 2012. 35(11): p. 1021-9.

307. Melmed, S., A. Colao, A. Barkan, M. Molitch, A.B. Grossman, D. Kleinberg, D. Clemmons, P. Chanson, E. Laws, J. Schlechte, M.L. Vance, K. Ho, and A. Giustina, Guidelines for acromegaly management: an update. J Clin Endocrinol Metab, 2009. 94(5): p. 1509-17.

308. Rajasoorya, C., I.M. Holdaway, P. Wrightson, D.J. Scott, and H.K. Ibbertson, Determinants of clinical outcome and survival in acromegaly. Clin Endocrinol (Oxf), 1994. 41(1): p. 95-102.

309. Mehta, G.U. and R.R. Lonser, Management of hormone-secreting pituitary adenomas. Neuro Oncol, 2017. 19(6): p. 762-773.

310. Nilsson, M., A.B. Undèn, D. Krause, U. Malmqwist, K. Raza, P.G. Zaphiropoulos, and R. Toftgård, Induction of basal cell carcinomas and trichoepitheliomas in mice overexpressing GLI-1. Proc Natl Acad Sci U S A, 
2000. 97(7): p. 3438-43.

311. Grachtchouk, M., R. Mo, S. Yu, X. Zhang, H. Sasaki, C.C. Hui, and A.A. Dlugosz, Basal cell carcinomas in mice overexpressing Gli2 in skin. Nat Genet, 2000. 24(3): p. 216-7.

312. Clement, V., P. Sanchez, N. de Tribolet, I. Radovanovic, and A. Ruiz i Altaba, HEDGEHOG-GLI1 signaling regulates human glioma growth, cancer stem cell self-renewal, and tumorigenicity. Curr Biol, 2007. 17(2): p. 165-72.

313. Ehtesham, M., A. Sarangi, J.G. Valadez, S. Chanthaphaychith, M.W. Becher, T.W. Abel, R.C. Thompson, and M.K. Cooper, Ligand-dependent activation of the hedgehog pathway in glioma progenitor cells. Oncogene, 2007. 26(39): p. 5752-61.

314. Schüller, U., V.M. Heine, J. Mao, A.T. Kho, A.K. Dillon, Y.G. Han, E. Huillard, T. Sun, A.H. Ligon, Y. Qian, Q. Ma, A. Alvarez-Buylla, A.P. McMahon, D.H. Rowitch, and K.L. Ligon, Acquisition of granule neuron precursor identity is a critical determinant of progenitor cell competence to form Shh-induced medulloblastoma. Cancer Cell, 2008. 14(2): p. 123-34.

315. Yang, Z.J., T. Ellis, S.L. Markant, T.A. Read, J.D. Kessler, M. Bourboulas, U. Schüller, R. Machold, G. Fishell, D.H. Rowitch, B.J. Wainwright, and R.J. Wechsler-Reya, Medulloblastoma can be initiated by deletion of Patched in lineage-restricted progenitors or stem cells. Cancer Cell, 2008. 14(2): p. 13545.

316. Lu, J.T., W.D. Zhao, W. He, and W. Wei, Hedgehog signaling pathway mediates invasion and metastasis of hepatocellular carcinoma via ERK pathway. Acta Pharmacol Sin, 2012. 33(5): p. 691-700.

317. Zheng, X., N.B. Vittar, X. Gai, M.G. Fernandez-Barrena, C.D. Moser, C. Hu, L.L. Almada, A.L. McCleary-Wheeler, S.F. Elsawa, A.M. Vrabel, A.M. Shire, A. Comba, S.S. Thorgeirsson, Y. Kim, Q. Liu, M.E. Fernandez-Zapico, and L.R. Roberts, The transcription factor GLI1 mediates TGF 1 driven EMT in hepatocellular carcinoma via a SNAI1-dependent mechanism. PLoS One, 2012. 7(11): p. e49581.

318. Zheng, X., Y. Yao, Q. Xu, K. Tu, and Q. Liu, Evaluation of glioma-associated oncogene 1 expression and its correlation with the expression of sonic hedgehog, E-cadherin and S100a4 in human hepatocellular carcinoma. Mol Med Rep, 2010. 3(6): p. 965-70.

319. Liu, M.G., H. Li, X. Xu, C.J. Barnstable, and S.S. Zhang, Comparison of gene expression during in vivo and in vitro postnatal retina development. J Ocul Biol Dis Infor, 2008. 1(2-4): p. 59-72.

320. Stecca, B., C. Mas, V. Clement, M. Zbinden, R. Correa, V. Piguet, F. Beermann, and I.A.A. Ruiz, Melanomas require HEDGEHOG-GLI signaling regulated by interactions between GLI1 and the RAS-MEKJAKT pathways. Proc Natl Acad Sci U S A, 2007. 104(14): p. 5895-900.

321. Geng, Y., J. Liu, Y. Xie, H. Jiang, K. Zuo, T. Li, and Z. Liu, Trichostatin A promotes GLI1 degradation and P21 expression in multiple myeloma cells. Cancer Manag Res, 2018. 10: p. 2905-2914.

322. Kim, J., M. Kato, and P.A. Beachy, Gli2 trafficking links Hedgehog-dependent activation of Smoothened in the primary cilium to transcriptional activation in the nucleus. Proc Natl Acad Sci U S A, 2009. 106(51): p. 21666-71.

323. Santos, N. and J.F. Reiter, A central region of Gli2 regulates its localization to the primary cilium and transcriptional activity. J Cell Sci, 2014. 127( $\mathrm{Pt} \mathrm{7):} \mathrm{p.}$ 1500-10.

324. Liu, J., H. Zeng, and A. Liu, The loss of Hh responsiveness by a non-ciliary Gli2 
variant. Development, 2015. 142(9): p. 1651-60.

325. Zhou, F., D. Huang, Y. Li, G. Hu, H. Rao, Q. Lu, S. Luo, and Y. Wang, Nek2A/SuFu feedback loop regulates Gli-mediated Hedgehog signaling pathway. Int J Oncol, 2017. 50(2): p. 373-380.

326. Taipale, J., J.K. Chen, M.K. Cooper, B. Wang, R.K. Mann, L. Milenkovic, M.P. Scott, and P.A. Beachy, Effects of oncogenic mutations in Smoothened and Patched can be reversed by cyclopamine. Nature, 2000. 406(6799): p. 1005-9.

327. Kawakami, S., Y. Fujii, Y. Okada, and S.J. Winters, Paracrine regulation of FSH by follistatin in folliculostellate cell-enriched primate pituitary cell cultures. Endocrinology, 2002. 143(6): p. 2250-8.

328. Inoue, K., E.F. Couch, K. Takano, and S. Ogawa, The structure and function of folliculo-stellate cells in the anterior pituitary gland. Arch Histol Cytol, 1999. 62(3): p. 205-18.

329. Theogaraj, E., C.D. John, H.C. Christian, J.F. Morris, S.F. Smith, and J.C. Buckingham, Perinatal glucocorticoid treatment produces molecular, functional, and morphological changes in the anterior pituitary gland of the adult male rat. Endocrinology, 2005. 146(11): p. 4804-13.

330. Gloddek, J., P. Lohrer, J. Stalla, E. Arzt, G.K. Stalla, and U. Renner, The intrapituitary stimulatory effect of lipopolysaccharide on ACTH secretion is mediated by paracrine-acting IL-6. Exp Clin Endocrinol Diabetes, 2001. 109(8): p. 410-5.

331. Lohrer, P., J. Gloddek, A.C. Nagashima, Z. Korali, U. Hopfner, M.P. Pereda, E. Arzt, G.K. Stalla, and U. Renner, Lipopolysaccharide directly stimulates the intrapituitary interleukin-6 production by folliculostellate cells via specific receptors and the p38alpha mitogen-activated protein kinase/nuclear factorkappaB pathway. Endocrinology, 2000. 141(12): p. 4457-65.

332. Correa-de-Santana, E., B. Fröhlich, M. Labeur, M. Páez-Pereda, M. Theodoropoulou, J.L. Monteserin, U. Renner, and G.K. Stalla, NOD2 receptors in adenopituitary folliculostellate cells: expression and function. J Endocrinol, 2009. 203(1): p. 111-22.

333. Leung, D.W., G. Cachianes, W.J. Kuang, D.V. Goeddel, and N. Ferrara, Vascular endothelial growth factor is a secreted angiogenic mitogen. Science, 1989. 246(4935): p. 1306-9.

334. Bluet-Pajot, M.T., F. Mounier, J.F. Leonard, C. Kordon, and D. Durand, Vasoactive intestinal peptide induces a transient release of growth hormone in the rat. Peptides, 1987. 8(1): p. 35-8.

335. Denef, C., C. Schramme, and M. Baes, Stimulation of growth hormone release by vasoactive intestinal peptide and peptide PHI in rat anterior pituitary reaggregates. Permissive action of a glucocorticoid and inhibition by thyrotropin-releasing hormone. Neuroendocrinology, 1985. 40(1): p. 88-91.

336. Fazekas, I., E. Bácsy, I. Varga, F. Slowik, K. Bálint, E. Pásztor, S. Czirják, and E. Gláz, Effect of vasoactive intestinal polypeptide (VIP) on growth hormone $(G H)$ and prolactin (PRL) release and cell morphology in human pituitary adenoma cell cultures. Folia Histochem Cytobiol, 2000. 38(3): p. 119-27.

337. Murakami, Y., K. Koshimura, K. Yamauchi, M. Nishiki, J. Tanaka, H. Furuya, T. Miyake, and Y. Kato, Pituitary adenylate cyclase activating polypeptide (PACAP) stimulates growth hormone release from GH3 cells through type II PACAP receptor. Regul Pept, 1995. 56(1): p. 35-40.

338. Abe, H., D. Engler, M.E. Molitch, J. Bollinger-Gruber, and S. Reichlin, Vasoactive intestinal peptide is a physiological mediator of prolactin release in the rat. Endocrinology, 1985. 116(4): p. 1383-90. 
339. Alexander, L.D. and L.D. Sander, Vasoactive intestinal peptide stimulates ACTH and corticosterone release after injection into the PVN. Regul Pept, 1994. 51(3): p. 221-7.

340. Mazzocchi, G., P. Rebuffat, L. Gottardo, and G.G. Nussdorfer, Vasoactive intestinal peptide stimulates rat adrenal glucocorticoid secretion, through an ACTH receptor-dependent activation of the adenylate cyclase signaling pathway. Horm Metab Res, 1998. 30(5): p. 241-3.

341. Hirabayashi, T., T. Nakamachi, and S. Shioda, Discovery of PACAP and its receptors in the brain. J Headache Pain, 2018. 19(1): p. 28.

342. Reisine, T., S. Heisler, V.Y. Hook, and J. Axelrod, Multireceptor-induced release of adrenocorticotropin from anterior pituitary tumor cells. Biochem Biophys Res Commun, 1982. 108(3): p. 1251-7.

343. Aoki, Y., Y. Iwasaki, M. Katahira, Y. Oiso, and H. Saito, Regulation of the rat proopiomelanocortin gene expression in AtT-20 cells. II: Effects of the pituitary adenylate cyclase-activating polypeptide and vasoactive intestinal polypeptide. Endocrinology, 1997. 138(5): p. 1930-4.

344. Lu, Y., J. Li, J. Cheng, and D.B. Lubahn, Genes targeted by the Hedgehogsignaling pathway can be regulated by Estrogen related receptor $\beta$. BMC Mol Biol, 2015. 16: p. 19.

345. Liu, H., D. Gu, and J. Xie, Clinical implications of hedgehog signaling pathway inhibitors. Chin J Cancer, 2011. 30(1): p. 13-26.

346. Ramsbottom, S.A. and M.E. Pownall, Regulation of Hedgehog Signalling Inside and Outside the Cell. J Dev Biol, 2016. 4(3): p. 23.

347. Dhanyamraju, P.K., P.S. Holz, F. Finkernagel, V. Fendrich, and M. Lauth, Histone deacetylase 6 represents a novel drug target in the oncogenic Hedgehog signaling pathway. Mol Cancer Ther, 2015. 14(3): p. 727-39.

348. Moore, B.S., A.N. Stepanchick, P.H. Tewson, C.M. Hartle, J. Zhang, A.M. Quinn, T.E. Hughes, and T. Mirshahi, Cilia have high cAMP levels that are inhibited by Sonic Hedgehog-regulated calcium dynamics. Proc Natl Acad Sci U S A, 2016. 113(46): p. 13069-13074.

349. Yauch, R.L., S.E. Gould, S.J. Scales, T. Tang, H. Tian, C.P. Ahn, D. Marshall, L. Fu, T. Januario, D. Kallop, M. Nannini-Pepe, K. Kotkow, J.C. Marsters, L.L. Rubin, and F.J. de Sauvage, A paracrine requirement for hedgehog signalling in cancer. Nature, 2008. 455(7211): p. 406-10.

350. Cheng, Y., J. Franco-Barraza, Y. Wang, C. Zheng, L. Zhang, Y. Qu, Y. Long, E. Cukierman, and Z.J. Yang, Sustained hedgehog signaling in medulloblastoma tumoroids is attributed to stromal astrocytes and astrocyte-derived extracellular matrix. Lab Invest, 2020.

351. Tian, C., K.R. Clauser, D. Öhlund, S. Rickelt, Y. Huang, M. Gupta, D.R. Mani, S.A. Carr, D.A. Tuveson, and R.O. Hynes, Proteomic analyses of ECM during pancreatic ductal adenocarcinoma progression reveal different contributions by tumor and stromal cells. Proc Natl Acad Sci U S A, 2019. 116(39): p. 1960919618.

352. Moo-Young, M., Comprehensive biotechnology2019: Elsevier.

353. Umetsu, Y., T. Tenno, N. Goda, M. Shirakawa, T. Ikegami, and H. Hiroaki, Structural difference of vasoactive intestinal peptide in two distinct membranemimicking environments. Biochim Biophys Acta, 2011. 1814(5): p. 724-30.

354. McNicol, A.M., Folliculostellate cells in pituitary adenomas: Studies of hormonal profile and tumor vascularity. Endocr Pathol, 1991. 2(4): p. 193-199.

355. Cimpean, A.M., A.R. Ceausu, A. Corlan, E. Melnic, A.A. Jitariu, and M. Raica, The "game" of glial fibrillary acidic and S100 proteins in pituitary adenomas: two 
players or several? Endokrynol Pol, 2017. 68(4): p. 380-389.

356. Voit, D., W. Saeger, and D.K. Lüdecke, Folliculo-stellate cells in pituitary adenomas of patients with acromegaly. Pathol Res Pract, 1999. 195(3): p. 1437.

357. Horvath, E. and K. Kovacs, Folliculo-stellate cells of the human pituitary: a type of adult stem cell? Ultrastruct Pathol, 2002. 26(4): p. 219-28.

358. Nishioka, H., J.F. Llena, and A. Hirano, Immunohistochemical study of folliculostellate cells in pituitary lesions. Endocr Pathol, 1991. 2(3): p. 155-160.

359. Hsu, D.W., P.N. Riskind, and E.T. Hedley-Whyte, Vasoactive intestinal peptide in the human pituitary gland and adenomas. An immunocytochemical study. Am J Pathol, 1989. 135(2): p. 329-38.

360. Oka, H., L. Jin, J.C. Reubi, X. Qian, B.W. Scheithauer, K. Fujii, T. Kameya, and R.V. Lloyd, Pituitary adenylate-cyclase-activating polypeptide (PACAP) binding sites and PACAP/vasoactive intestinal polypeptide receptor expression in human pituitary adenomas. Am J Pathol, 1998. 153(6): p. 1787-96.

361. Karhadkar, S.S., G.S. Bova, N. Abdallah, S. Dhara, D. Gardner, A. Maitra, J.T. Isaacs, D.M. Berman, and P.A. Beachy, Hedgehog signalling in prostate regeneration, neoplasia and metastasis. Nature, 2004. 431(7009): p. 707-12.

362. Fendrich, V., F. Esni, M.V. Garay, G. Feldmann, N. Habbe, J.N. Jensen, Y. Dor, D. Stoffers, J. Jensen, S.D. Leach, and A. Maitra, Hedgehog signaling is required for effective regeneration of exocrine pancreas. Gastroenterology, 2008. 135(2): p. 621-31.

363. Singh, R.R., J.H. Cho-Vega, Y. Davuluri, S. Ma, F. Kasbidi, C. Milito, P.A. Lennon, E. Drakos, L.J. Medeiros, R. Luthra, and F. Vega, Sonic hedgehog signaling pathway is activated in ALK-positive anaplastic large cell lymphoma. Cancer Res, 2009. 69(6): p. 2550-8.

364. Farnoud, M.R., M. Kujas, P. Derome, J. Racadot, F. Peillon, and J.Y. Li, Interactions between normal and tumoral tissues at the boundary of human anterior pituitary adenomas. An immunohistochemical study. Virchows Arch, 1994. 424(1): p. 75-82.

365. Ilie, M.D., A. Vasiljevic, G. Raverot, and P. Bertolino, The Microenvironment of Pituitary Tumors-Biological and Therapeutic Implications. Cancers (Basel), 2019. 11(10).

366. Chen, W., T. Tang, J. Eastham-Anderson, D. Dunlap, B. Alicke, M. Nannini, S. Gould, R. Yauch, Z. Modrusan, K.J. DuPree, W.C. Darbonne, G. Plowman, F.J. de Sauvage, and C.A. Callahan, Canonical hedgehog signaling augments tumor angiogenesis by induction of VEGF-A in stromal perivascular cells. Proc Natl Acad Sci U S A, 2011. 108(23): p. 9589-94.

367. Agrawal, V., D.Y. Kim, and Y.G. Kwon, Hhip regulates tumor-stroma-mediated upregulation of tumor angiogenesis. Exp Mol Med, 2017. 49(1): p. e289.

368. Cardoso, I., J. Stamnaes, J.T. Andersen, G. Melino, R. Iversen, and L.M. Sollid, Transglutaminase 2 interactions with extracellular matrix proteins as probed with celiac disease autoantibodies. FEBS J, 2015. 282(11): p. 2063-75.

369. Carsons, S.E., Fibronectin in health and disease1989: CRC Press.

370. Hynes, R., Fibronectins. New York: Springer-Verlag. 1990.

371. Yamada, K. and R. Clark, The molecular and cellular biology of wound repair. 1996.

372. Timpl, R. and J.C. Brown, Supramolecular assembly of basement membranes. Bioessays, 1996. 18(2): p. 123-32.

373. Hohenester, E. and P.D. Yurchenco, Laminins in basement membrane assembly. Cell Adh Migr, 2013. 7(1): p. 56-63. 
374. Brezinschek, R.I., H.P. Brezinschek, A.I. Lazarovits, P.E. Lipsky, and N. Oppenheimer-Marks, Expression of the beta 7 integrin by human endothelial cells. Am J Pathol, 1996. 149(5): p. 1651-60.

375. Grässel, S., C. Unsöld, H. Schäcke, L. Bruckner-Tuderman, and P. Bruckner, Collagen XVI is expressed by human dermal fibroblasts and keratinocytes and is associated with the microfibrillar apparatus in the upper papillary dermis. Matrix Biol, 1999. 18(3): p. 309-17.

376. Varner, J.A. and D.A. Cheresh, Integrins and cancer. Curr Opin Cell Biol, 1996. 8(5): p. 724-30.

377. Giancotti, F.G. and E. Ruoslahti, Integrin signaling. Science, 1999. 285(5430): p. 1028-32.

378. Sethi, T., R.C. Rintoul, S.M. Moore, A.C. MacKinnon, D. Salter, C. Choo, E.R. Chilvers, I. Dransfield, S.C. Donnelly, R. Strieter, and C. Haslett, Extracellular matrix proteins protect small cell lung cancer cells against apoptosis: a mechanism for small cell lung cancer growth and drug resistance in vivo. Nat Med, 1999. 5(6): p. 662-8.

379. Farnoud, M.R., N. Veirana, P. Derome, F. Peillon, and J.Y. Li, Adenomatous transformation of the human anterior pituitary is associated with alterations in integrin expression. Int J Cancer, 1996. 67(1): p. 45-53.

380. Farnoud, M.R., F. Farhadian, J.L. Samuel, P. Derome, F. Peillon, and J.Y. Li, Fibronectin isoforms are differentially expressed in normal and adenomatous human anterior pituitaries. Int J Cancer, 1995. 61(1): p. 27-34.

381. Paez-Pereda, M., F. Kuchenbauer, E. Arzt, and G.K. Stalla, Regulation of pituitary hormones and cell proliferation by components of the extracellular matrix. Braz J Med Biol Res, 2005. 38(10): p. 1487-94.

382. Kuchenbauer, F., U. Hopfner, J. Stalla, E. Arzt, G.K. Stalla, and M. PáezPereda, Extracellular matrix components regulate ACTH production and proliferation in corticotroph tumor cells. Mol Cell Endocrinol, 2001. 175(1-2): p. 141-8.

383. Vankelecom, H., Stem cells in the postnatal pituitary? Neuroendocrinology, 2007. 85(2): p. 110-30.

384. Vankelecom, H., Non-hormonal cell types in the pituitary candidating for stem cell. Semin Cell Dev Biol, 2007. 18(4): p. 559-70.

385. Devnath, S. and K. Inoue, An insight to pituitary folliculo-stellate cells. J Neuroendocrinol, 2008. 20(6): p. 687-91.

386. Osuna, M., Y. Sonobe, E. Itakura, S. Devnath, T. Kato, Y. Kato, and K. Inoue, Differentiation capacity of native pituitary folliculostellate cells and brain astrocytes. J Endocrinol, 2012. 213(3): p. 231-7.

387. Higuchi, M., N. Kanno, S. Yoshida, H. Ueharu, M. Chen, H. Yako, S. Shibuya, M. Sekita, M. Tsuda, H. Mitsuishi, N. Nishimura, T. Kato, and Y. Kato, GFPexpressing S100ß-positive cells of the rat anterior pituitary differentiate into hormone-producing cells. Cell Tissue Res, 2014. 357(3): p. 767-79.

388. Lepore, D.A., G.P. Thomas, K.R. Knight, A.J. Hussey, T. Callahan, J. Wagner, W.A. Morrison, and P.Q. Thomas, Survival and differentiation of pituitary colonyforming cells in vivo. Stem Cells, 2007. 25(7): p. 1730-6.

389. Mori, T., K. Tanaka, A. Buffo, W. Wurst, R. Kühn, and M. Götz, Inducible gene deletion in astroglia and radial glia--a valuable tool for functional and lineage analysis. Glia, 2006. 54(1): p. 21-34.

390. Berger, U.V. and M.A. Hediger, Distribution of the glutamate transporters GLAST and GLT-1 in rat circumventricular organs, meninges, and dorsal root ganglia. J Comp Neurol, 2000. 421(3): p. 385-99. 
391. Daynac, M., L. Tirou, H. Faure, M.A. Mouthon, L.R. Gauthier, H. Hahn, F.D. Boussin, and M. Ruat, Hedgehog Controls Quiescence and Activation of Neural Stem Cells in the Adult Ventricular-Subventricular Zone. Stem Cell Reports, 2016. 7(4): p. 735-748. 


\section{List of Abbreviations}

\begin{tabular}{|c|c|}
\hline${ }^{\circ} \mathrm{C}$ & Degree Celsius \\
\hline$\alpha G S U$ & Glycoprotein Hormones, Alpha Polypeptide \\
\hline$\beta$-Ala-Lys-N(ع)-AMCA & $\beta$-Ala-Lys-Ne-amino-4-methylcoumarin-3-acetic acid \\
\hline$\mu \mathrm{M}$ & Micromolar \\
\hline$A b$ & Antibody \\
\hline Acth & Adrenocorticotropic Hormone \\
\hline$A E C$ & 3-Amino-9-ethylcarbazole \\
\hline $\mathrm{AL}$ & Anterior Lobe \\
\hline Aldh1I1 & Aldehyde Dehydrogenase 1 Family, Member L1 \\
\hline $\mathrm{ARH}$ & Arcuate Nucleus of the Hypothalamus \\
\hline ATCC & American Type Culture Collection \\
\hline BCC & Basal Cell Carcinoma \\
\hline BLAST & Basic Local Alignment Search Tool \\
\hline & Base pair \\
\hline BrdU & Bromodeoxyuridine \\
\hline BSA & Bovine Serum Albumin \\
\hline cAMP & Cyclic Adenosine Monophosphate \\
\hline cDNA & Complementary Deoxyribonucleic Acid \\
\hline $\mathrm{CM}$ & Conditioned Medium \\
\hline CMV & Cytomegalovirus \\
\hline Cre & Cyclization Recombination \\
\hline $\mathrm{CRH} / \mathrm{CRF}$ & $\begin{array}{l}\text { Corticotropin-Releasing Hormone / Corticotropin-Releasing } \\
\text { factor }\end{array}$ \\
\hline CT & Cycle Threshold \\
\hline Cy3 & Cyanine Dye 3 \\
\hline DAPI & 4',6-diamidino-2-phenylindole \\
\hline $\mathrm{ddH}_{2} \mathrm{O}$ & Double-Distilled $\mathrm{H}_{2} \mathrm{O}$ \\
\hline del & Deleted \\
\hline Dhh & Desert Hedgehog \\
\hline Disp & Dispatched \\
\hline DMEM & Dulbecco's Modified Eagle Medium \\
\hline DMF & Dimethylformamide \\
\hline DMSO & Dimethylsulfoxide \\
\hline DNA & Deoxyribonucleic Acid \\
\hline dNTP & Deoxyribonucleotide Triphosphates \\
\hline DTT & Dithiothreitol \\
\hline e.g. & Exempli Gratia \\
\hline ECL & Enhanced Chemiluminescence \\
\hline $\mathrm{ECM}$ & Extracellular Matrix \\
\hline EDTA & Ethylenediamine Tetraacetic Acid \\
\hline EGFP & Enhanced Green Fluorescent Protein \\
\hline ELISA & Enzyme-Linked Immunosorbent Assay \\
\hline EtBr & Ethidium Bromide \\
\hline $\mathrm{EtOH}$ & Ethanol \\
\hline FBS & Fetal Bovine Serum \\
\hline
\end{tabular}




\begin{tabular}{|c|c|}
\hline $\mathrm{F}$ & floxed \\
\hline FSC & Folliculostellate Cells \\
\hline $\mathrm{FSH}$ & Follicle-stimulating Hormone \\
\hline gDNA & Genomic Deoxyribonucleic Acid \\
\hline $\mathrm{Gh}$ & Growth Hormone \\
\hline Ghrh & Growth Hormone Releasing Hormone \\
\hline Ghrhr & Growth Hormone Releasing Hormone \\
\hline Gli & Glioma-Associated Oncogene \\
\hline GliA & Glioma-Associated Oncogene Activator Form \\
\hline GliR & Glioma-Associated Oncogene Repressor Form \\
\hline GOI & Gene of Interest \\
\hline Gpcr & G-Protein Coupled Receptor \\
\hline $\mathrm{h}$ & Human \\
\hline$H \& E$ & Haematoxylin and Eosin \\
\hline HBSS & Hank's Balanced Salt Solution \\
\hline HEPES & 4-(2-hydroxyethyl)-1-piperazineethanesulfonic acid \\
\hline $\mathrm{Hh}$ & Hedgehog \\
\hline Hhip & Hedgehog Interacting Protein \\
\hline $\mathrm{hr}(\mathrm{s})$ & Hour(s) \\
\hline HRP & Horseradish Peroxidase \\
\hline HS & Horse Serum \\
\hline HSC-70 & Heat Shock Cognate $71 \mathrm{kDa}$ Protein \\
\hline i.e. & Id Est \\
\hline i.p. & Intraperitoneal \\
\hline ICC & Immunocytochemistry \\
\hline IF & Immunofluorescence \\
\hline $\mathrm{IHC}$ & Immunohistochemistry \\
\hline Ihh & Indian Hedgehog \\
\hline II & Interleukin \\
\hline $\mathrm{IL}$ & Intermediate Lobe \\
\hline $\mathrm{kb}$ & Kilo Bases \\
\hline $\mathrm{kDa}$ & Kilo Dalton \\
\hline LB & Lysogeny Broth \\
\hline Lh & Luteinzing Hormone \\
\hline $\log$ & Logarithm to Base 10 \\
\hline LoxP & Locus of Crossing-Over of Bacteriophage P1 \\
\hline $\mathrm{m}$ & Murine \\
\hline $\mathrm{MeOH}$ & Methanol \\
\hline $\min (\mathrm{s})$ & Minute(s) \\
\hline MolTaq & Thermus aquaticus-Polymerase \\
\hline mRNA & Messenger Ribonucleic Acid \\
\hline$M Z$ & Marginal Zone \\
\hline $\mathrm{NCBI}$ & National Center for Biotechnology Information \\
\hline $\mathrm{nM}$ & Nanomolar \\
\hline PA & Pituitary Adenoma \\
\hline PBS & Phosphate Buffered Saline \\
\hline PBS-T & Phosphate Buffered Saline with Tween-20 \\
\hline PCR & Polymerase Chain Reaction \\
\hline
\end{tabular}




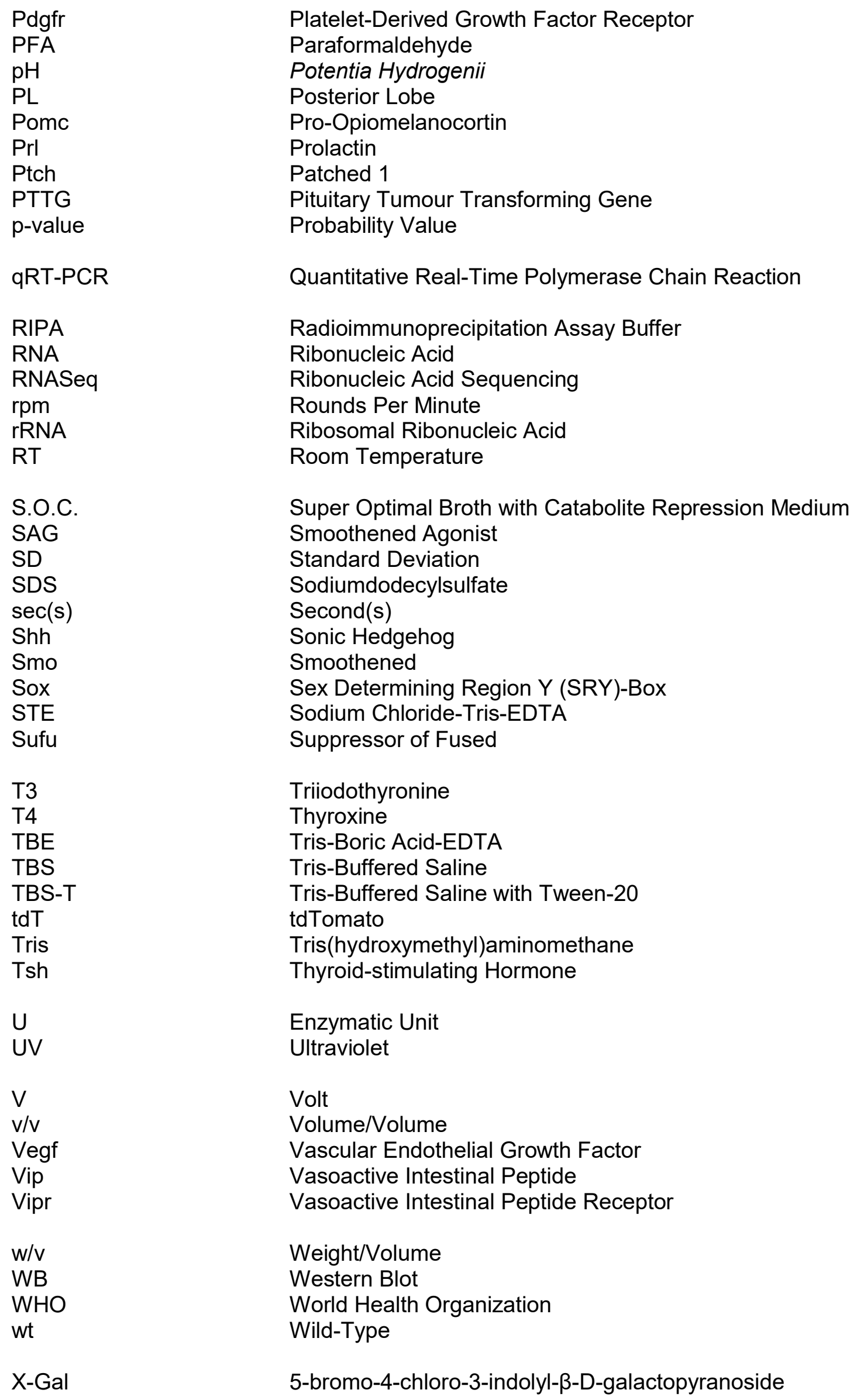

